\title{
CÂNCER DE BOCA: MORTALIDADE ENTRE OS RESIDENTES NO ESTADO DE SÃO PAULO NO PERÍODO DE MARÇO DE 1979 A FEVEREIRO DE 1982
}

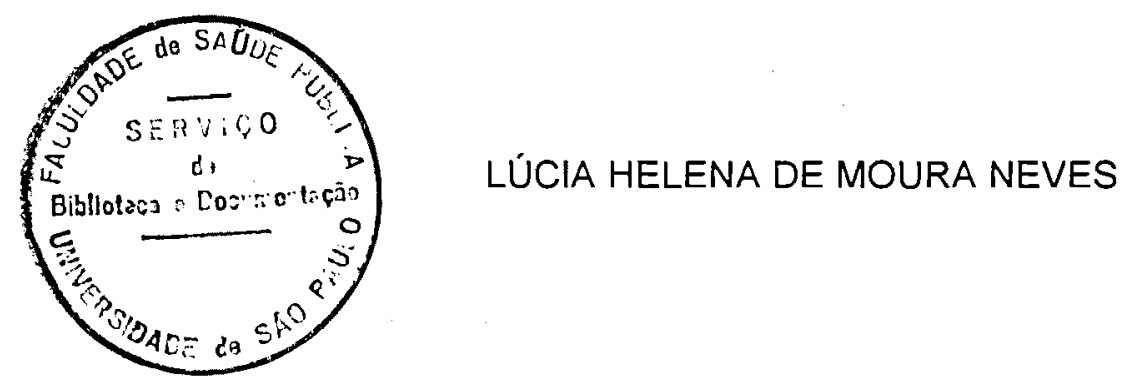

Tese apresentada à Faculdade de Saúde Pública da Universidade de São Paulo, Departamento de Epidemiologia, para obtenção do título de Doutor em Saúde Pública.

Orientador: José Maria Pacheco de Souza 
A meus pais

e àqueles com quem divido minha vida:

Melina, Leonardo, Camila e Edgar. 


\section{AGRADECIMENTOS}

Ao meu orientador de tese, José Maria Pacheco de Souza, pela disponibilidade constante, pelo inestimável apoio e pela segurança transmitida.

À Professora Sabina Léa Davidson Gotlieb, pelas sugestões oferecidas desde a fase de planejamento deste trabalho, e, especialmente, pelo exemplo de dedicação.

À Professora Leonor de Castro Monteiro Loffredo, pelo grande incentivo em minhas atividades acadêmicas e pela valiosa amizade de tantos anos.

Ao Professor Luiz Roberto de Toledo Ramalho, Diretor da Faculdade de Odontologia de Araraquara - UNESP, pela ajuda na obtenção, junto à Fundação SEADE, dos dados populacionais informatizados.

Ao Professor Alcyr Azzoni, pelas indicações para levantamento do material referente à criação das Regiões Administrativas do Estado de São Paulo.

À Professora Maria Helena de Moura Neves, pela revisão cuidadosa do texto.

Ao auditor de sistemas, Edgar Roberto Pacheco D'Andrea, pelo apoio e incentivo em todos os momentos, e pela colaboração, especialmente na preparação de programas computacionais, sem a qual não teria sido possivel o desenvolvimento desta tese.

A meus pais, que, na retaguarda, me forneceram as condições de trabalho.

A meus filhos, por terem compreendido minhas ausências e por terem sabido repartir a mãe com esta pesquisa. 
Ao analista de sistemas do Departamento de Epidemiologia da Faculdade de Saúde Pública - USP, Fernão Dias de Lima, pelo auxilio na seleção dos registros dos óbitos armazenados em CD-ROM.

Às bibliotecárias da Faculdade de Saúde Pública - USP, pela revisão das referências bibliográficas.

Ao Escritório Regional do Interior - ERIN de Araraquara, pelo fornecimento do material referente à Divisão Administrativa do Estado.

À Fundação SEADE, pelo fornecimento dos dados populacionais informatizados do Censo de 1980.

À Coordenação de Aperfeiçoamento de Pessoal de Nível Superior - CAPES, pelo auxílio concedido dentro do Programa Institucional de Capacitação de Docente (PICD). 


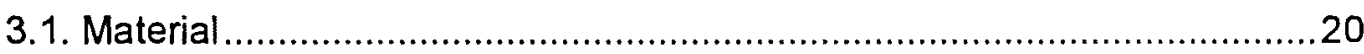

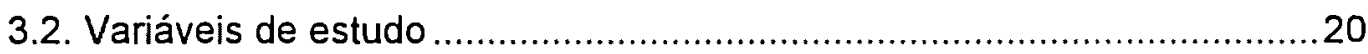

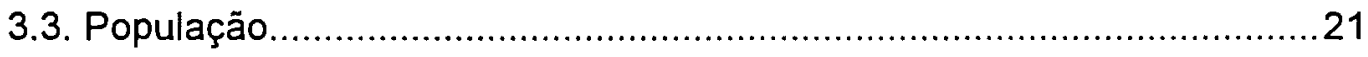

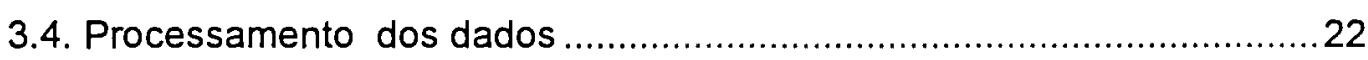

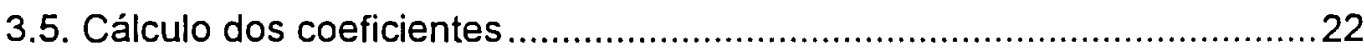

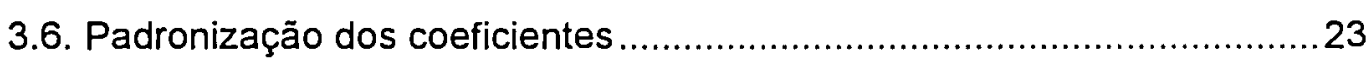

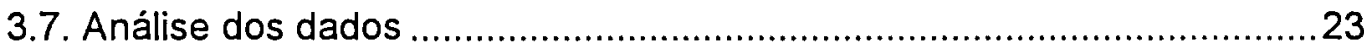

4. Resultados e discussão.................................................... 24

4.1. Resultados gerais para o Estado de São Paulo .....................................24

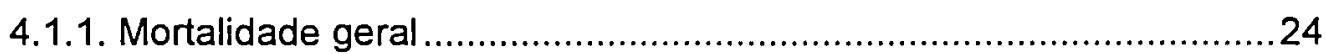

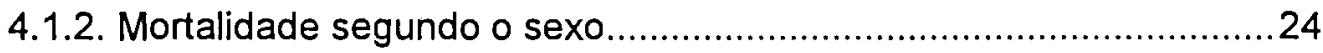

4.1.3. Mortalidade segundo a idade .....................................................26

4.1.4. Mortalidade segundo a localização do tumor .................................28

4.1.4.1. Mortalidade segundo a localização

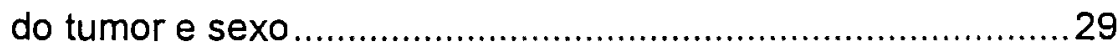

4.1.4.2. Mortalidade segundo a localização

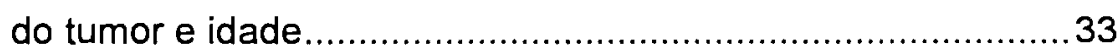

4.2. Resultados obtidos segundo as Regiões Administrativas ......................38

4.2.1. Coeficientes gerais de mortalidade ........................................... 38

4.2.2. Coeficientes de mortalidade especificos por sexo........................... 41

4.2.3. Coeficientes de mortalidade especificos por idade ........................44 42

4.2.4. Coeficientes de mortalidade especificos

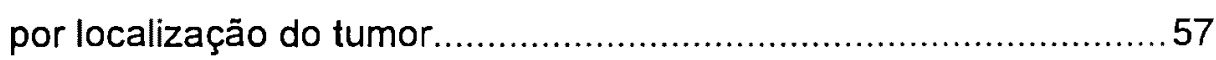

4.2.4.1. Coeficientes de mortalidade específicos

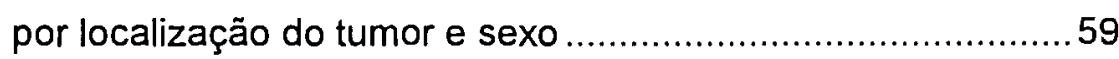

4.2.4.2. Coeficientes de mortalidade específicos por localização do tumor e idade .......................................67

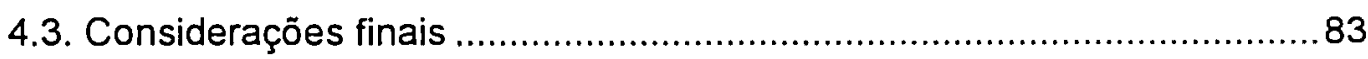


5. Conclusões 85

Referências Bibliográficas 89

\section{Anexos}

1. Regiões Administrativas do Estado de São Paulo

2. População do Estado de São Paulo (censo de 1980)

3. Distribuição dos óbitos por câncer de boca dos residentes no Estado de São Paulo

4. Populações-padrão 


\section{Tabelas}

página

Tabela 1 - Número de óbitos e coeficientes de mortalidade por câncer de boca (por 100.000), segundo grupo etário e sexo. Estado de São Paulo,1979 -1982. .26

Tabela 2 - Distribuição dos óbitos por câncer de boca ( $n^{\circ}$ e \%), segundo a localização do tumor. Estado de São Paulo, $1979-1982$

Tabela 3 - Distribuição dos óbitos por câncer de boca ( $n^{\circ}$ e \%), segundo localização do tumor e sexo. Estado de São Paulo, 1979 - 1982 30

Tabela 4 - Coeficientes de mortalidade por câncer de boca (por 100.000), brutos e padronizados, segundo as Regiōes Administrativas de residência. Estado de São Paulo, 1979 -1982

Tabela 5 - Coeficientes de mortalidade por câncer de boca (por 100.000), padronizados por idade, segundo sexo

e Região de residência, e razão entre os sexos.

Estado de São Paulo, 1979 -1982

Tabela 6 - Coeficientes de mortalidade por câncer de boca (por 100.000), segundo idade e Região de residência.

Estado de São Paulo, 1979 -1982 


\section{Figuras}

página

Figura 1 - Mortalidade por câncer de boca, segundo sexo

e localização do tumor. Estado de São Paulo,

$1979-1982$

Figura 2 - Mortalidade por câncer de boca, segundo

localização do tumor e idade. Estado de São

Paulo, 1979 -1982

Figura 3 - Mortalidade por câncer de boca, segundo

localização do tumor e idade - sexo masculino.

Estado de São Paulo, 1979 -1982

Figura 4 - Mortalidade por câncer de boca, segundo

localização do tumor e idade - sexo feminino.

Estado de São Paulo, 1979 -1982

Figura 5 - Mortalidade por câncer de boca, segundo as

Regiões Administrativas do Estado de São

Paulo, 1979 -1982

Figura 6 - Mortalidade por câncer de boca, segundo sexo

e idade. Município de São Paulo, $1979-1982$

Figura 7 - Mortalidade por câncer de boca, segundo sexo

e idade. Região da Grande São Paulo, 1979 -

1982

Figura 8 - Mortalidade por câncer de boca, segundo sexo

e idade. Região do Litoral, 1979 -1982

Figura 9 - Mortalidade por câncer de boca, segundo sexo e idade. Região do Vale do Paraiba, $1979-1982$

Figura 10 - Mortalidade por câncer de boca, segundo sexo

e idade. Região de Sorocaba, $1979-1982$ .48 
Figura 11 - Mortalidade por câncer de boca, segundo sexo e idade. Região de Campinas, 1979 -1982

Figura 12 - Mortalidade por câncer de boca, segundo sexo e idade. Região de Ribeirão Preto, 1979 1982

Figura 13 - Mortalidade por câncer de boca, segundo sexo e idade. Região de Bauru, 1979 -1982 51

Figura 14 - Mortalidade por câncer de boca, segundo sexo e idade. Região de São José do Rio Preto, $1979-1982$

Figura 15 - Mortalidade por câncer de boca, segundo sexo e idade. Região de Araçatuba, 1979 -1982 53

Figura 16 - Mortalidade por câncer de boca, segundo sexo e idade. Região de Presidente Prudente, $1979-1982$ 54

Figura 17 - Mortalidade por câncer de boca, segundo sexo e idade. Região de Marília, 1979 -1982 .55

Figura 18 - Mortalidade por câncer de boca, segundo localização do tumor e Região do Estado de São Paulo, 1979 -1982. 58

Figura 19 - Mortalidade por câncer de lábio, segundo sexo e Região de residência. Estado de São Paulo, $1979-1982$

Figura 20 - Mortalidade por câncer de língua, segundo sexo e Região de residência. Estado de São Paulo, 1979 -1982

Figura 21 - Mortalidade por câncer de glândulas salivares, segundo sexo e Região de residência. Estado de São Paulo, 1979 -1982. 
Figura 22 - Mortalidade por câncer de gengiva, segundo sexo e Região de residência. Estado de São Paulo, $1979-1982$

Figura 23 - Mortalidade por câncer de assoalho da boca segundo sexo e Região de residência. Estado de São Paulo, 1979 -1982. 64

Figura 24 - Mortalidade por câncer de palato, segundo sexo e Região de residência. Estado de São Paulo, 1979-1982

Figura 25 - Mortalidade por câncer de boca, segundo localização do tumor e idade. Município de São Paulo, $1979-1982$ 68

Figura 26 - Mortalidade por câncer de boca, segundo localização do tumor e idade. Região da Grande São Paulo, 1979 -1982. 69

Figura 27 - Mortalidade por câncer de boca, segundo localização do tumor e idade. Região do Litoral, $1979-1982$ .70

Figura 28 - Mortalidade por câncer de boca, segundo localização do tumor e idade. Região do Vale do Paraiba, 1979 -1982 .71

Figura 29 - Mortalidade por câncer de boca, segundo localização do tumor e idade. Região de Sorocaba, $1979-1982$ .72

Figura 30 - Mortalidade por câncer de boca, segundo localização do tumor e idade. Região de Campinas, $1979-1982$ .73

Figura 31 - Mortalidade por câncer de boca, segundo localização do tumor e idade. Região de Ribeirão Preto, 1979 -1982 
Figura 32 - Mortalidade por câncer de boca, segundo localização do tumor e idade. Região de Bauru, $1979-1982$.

Figura 33 - Mortalidade por câncer de boca, segundo localização do tumor e dade. Região de São José do Rio Preto, 1979 - 1982

Figura 34 - Mortalidade por câncer de boca, segundo localização do tumor e idade. Região de Araçatuba, $1979-1982$

Figura 35 - Mortalidade por câncer de boca, segundo localização do tumor e idade. Região de Presidente Prudente, 1979 -1982. .78

Figura 36 - Mortalidade por câncer de boca, segundo localização do tumor e idade. Região de Marilia, $1979-1982$. 


\section{RESUMO}

O trabalho descreve a mortalidade por câncer de boca no Estado de São Paulo, no período de 1 de março de 1979 a 28 de fevereiro de 1982, segundo as variáveis sexo, idade, localização do tumor e Região Administrativa de residência. Constituíram material de estudo as declarações registradas dos óbitos de residentes no Estado de São Paulo que ocorreram nesse período e que apresentaram câncer de boca como causa básica de morte, segundo registros armazenados em meio magnético, com tecnologia de CD-ROM, do Ministério da Saúde. A fonte dos dados populacionais necessários para o cálculo dos coeficientes de mortalidade foi o censo de 1980.

O Estado de São Paulo como um todo apresentou, no período estudado, um total de 1.158 óbitos, correspondendo a 2,1\% da mortalidade por câncer em geral e originando um coeficiente de mortalidade por câncer de boca igual a 1,54 por 100.000 habitantes, com uma razão homens/mulheres de 4,92: 1 (2,56 por 100.000 homens e 0,52 por 100.000 mulheres). Acima dos 30 anos, a mortalidade foi mais elevada no sexo masculino, em todos os grupos etários. Para ambos os sexos, o câncer de língua constituiu a principal causa de mortalidade $(50,4 \%$ dos óbitos masculinos e $36,2 \%$ dos femininos), seguido, para o sexo masculino, pelo câncer de assoalho $(9,9 \%)$, de palato $(7,2 \%)$ e de glândulas salivares $(6,2 \%)$ e, para o sexo feminino, pelo câncer de palato $(14,9 \%)$, de glândulas salivares $(13,8 \%)$ e de gengiva $(5,6 \%)$. Para cada uma das localizações do tumor obtiveram-se coeficientes maiores no sexo masculino do que no feminino. A maior razão homens/mulheres foi encontrada para a localização assoalho da boca $(12,50: 1)$, seguindo-se a lingua $(6,79: 1)$, o lábio $(3,33: 1)$, a gengiva $(3,00: 1)$, as glândulas salivares $(2,29: 1)$ e 0 palato $(2,25: 1)$.

No estudo por Regiões Administrativas, os coeficientes gerais de mortalidade por câncer de boca, padronizados por idade, tendo como padrão a população total do Estado de São Paulo (censo de 1980), configuraram uma 
distribuição geográfica com alterações gradativas, compondo-se blocos geograficamente contíguos de resultados semelhantes. As duas Regiões que apresentaram os maiores coeficientes de mortalidade - Litoral (2,16 por 100.000 habitantes) e Vale do Paraiba (1,83 por 100.000 habitantes) - ocupam o Sul e o Sudeste do Estado. As três Regiōes de menores coeficientes - Araçatuba $(0,55$ por 100.000 habitantes), Presidente Prudente $(0,95$ por 100.000 habitantes) e Marilia $(1,11$ por 100.000 habitantes) - se concentram no Oeste do Estado. Na comparação da mortalidade entre os sexos, obteve-se razão homens/mulheres de aproximadamente $5: 1$, na maioria das Regiões, observando-se valores discrepantes para Presidente Prudente $(18,10: 1)$, São José do Rio Preto $(13,87: 1)$ e Araçatuba $(1,89: 1)$. Para a maioria das Regiões, a mortalidade é maior quanto mais avançado é o grupo etário, localizando-se o pico no grupo de 70 anos e mais. A idade em que se inicia a ocorrência de óbitos por câncer de boca varia entre as Regiões, mas, para a maior parte delas, os valores dos coeficientes só têm valor expressivo após os 40 anos. Em todas as Regiões, a língua apresenta os maiores valores de coeficientes de mortalidade, e, em quase todas as Regiões, o lábio e a gengiva apresentam os menores valores. Nas posições intermediárias se alternam, nas diferentes Regiões, as localizações assoalho, palato e glândulas salivares. Para cada uma das Regiões Administrativas foram feitas, ainda, análises conjuntas das variáveis sexo, idade e localização do tumor. 


\section{SUMMARY}

The study describes the mortality from oral cancer in the State of Sao Paulo, Brazil, from March 1, 1979 through February 28, 1982, according to variables which include sex, age, tumor site and Administrative Region. Research material comprised the death certificates of Sao Paulo State residents which presented oral cancer as the main cause of death, according to information obtained from Ministry of Health CD-ROM files. The census carried out in 1980 was used as the source of population data required to calculate the death rate.

During the period under study, Sao Paulo State as a whole presented a total of 1,158 deceases ( $2.1 \%$ of mortality due to cancer of all sites), amounting to a mortality rate for oral cancer equivalent to 1.54 per 100,000 , with a male/female ratio of $4.92: 1$ (2.56 per 100,000 men and 0.52 per 100,000 women). Over the age of 30 , the mortality rate was higher among males in all such age groups. For both sexes, the cancer of the tongue was the main cause of death $(50.4 \%$ of male and $36.2 \%$ of female deaths), followed, for males, by the cancer of the floor of the mouth $(9.9 \%)$, of the palate $(7.2 \%)$ and of the salivary glands $(6.2 \%)$, and, for females, by the cancer of the palate $(14.9 \%)$, of the salivary glands $(13.8 \%)$ and of the gum $(5.6 \%)$. Higher rates were observed in relation to males rather than females for all tumor sites. The highest male/female ratio was observed for the floor of the mouth $(12.50: 1)$, followed by the tongue $(6.79: 1)$, the lip $(3.33: 1)$, the gum $(3.00: 1)$, the salivary glands $(2.29: 1)$ and the palate $(2.25: 1)$.

In the study by Administrative Regions, the mortality rates for oral cancer, age-adjusted using the population of Sao Paulo State (1980 Census) as standard, formed a geographical distribution with gradual modifications, comprising geographically proximate blocks with similar results. The two Regions which presented the highest mortality rates - Litoral (2.16 per 100,000) and Vale do Paraíba (1.83 per $100,000)$ - are situated in the South and Southwest State areas. The three Regions which obtained the lowest rates - Araçatuba $(0.55$ per 100,000), Presidente Prudente 
(0.95 per 100,000) and Marilia (1.11 per 100,000) - are located in the State's Western area. When the mortality rate comparison was made between the sexes, a man/woman ratio of approximately 5:1 was observed in the majority of the Regions, with discrepancies in Presidente Prudente (18.10:1), Sao José do Rio Preto (13.87:1) and Araçatuba $(1.89: 1)$. In most Regions the mortality rate rises in proportion to the increase in age, reaching its peak in the 70's and older group. The age at which deaths from oral cancer begin to occur varies from Region to Region, however, the rates only become significant above the age of 40 . The cancer of the tongue shows the highest mortality rates in all Regions; the cancer of the lip and the cancer of the salivary glands show the lowest rates in almost all Regions. The intermediary positions are held on a varying basis by the lip and gum in the several Regions. In addition, joint analyses of variables comprising sex, age and tumor site were made in each of the Administrative Regions. 


\section{INTRODUÇÃO}

O câncer de boca constitui um grave problema de saúde pública em várias regiões do mundo $50,68,99$. É uma das poucas formas de doença maligna cuja incidência está crescendo em muitos países, tanto desenvolvidos como em desenvolvimento 9,17 , registrando-se, nas últimas décadas, um grande aumento em paises do Ocidente ${ }^{51,132}$, especialmente entre os jovens ${ }^{50,54,58}$.

Várias publicações $9,13,50,122$ indicam que o câncer bucal se tornará um problema de saúde pública cada vez maior em muitos paises ocidentais. Entre vinte e quatro países da América e da Europa estudados em uma pesquisa, apenas a Finlândia não apresentou aumento na mortalidade por câncer de boca, no periodo de 1955 a $1985^{9}$. Há evidência, ainda, de que a idade de pacientes que apresentam esse tipo de neoplasia é cada vez menor ${ }^{9}$. O número de novos casos vem crescendo, nos Estados Unidos 122 registrando-se cerca de 30.000 novos casos anuais ${ }^{114.131}$, dos quais pelo menos 9.000 resultam em morte ${ }^{31}$.

A ocorrência do câncer de boca é bastante diferenciada geograficamente. É no Sul e Sudeste da Ásia que estão as mais altas incidências do mundo 106,136, especialmente na índia, no Paquistão e em Cingapura ${ }^{92}$. O Brasil aparece em pesquisas como um dos países mais afetados pelo problema ${ }^{34,54}$. Hamada 49 indica o Brasil na segunda posição, logo após a Índia. Segundo publicação da Organização Mundial de Saúde ${ }^{89}$, São Paulo se coloca abaixo apenas do BaixoReno, França, e seguido de Terra-Nova, Canadá, e da Índia. Nos grupos populacionais do Norte e do Leste da Europa, bem como do Japão e da China, estão as mais baixas taxas de incidência do mundo ${ }^{\text {. }}$.

Boyle et alii ${ }^{9}$ afirmam que o número de casos de câncer bucal tem importância no total dos casos de câncer no mundo, e, segundo a Organização Mundial de Saúde ${ }^{136}$, esse tipo de câncer é um dos dez tipos mais comuns. Silverman e Gorsky ${ }^{114}$ afirmam que cresce a cada ano o número de casos dessa 
neoplasia em relação aos demais tipos de câncer diagnosticados nos Estados Unidos. $\mathrm{Na}$ Índia, o câncer bucal é o câncer mais freqüente entre os homens e o terceiro entre as mulheres ${ }^{109}$, representando, segundo algumas pesquisas, $40 \%$ ou mais ${ }^{36,50}$, e, segundo outras $50,106,15 \%$ a $20 \%$ de todos os tumores malignos. No Senegal encontraram-se, entre todos os casos de câncer estudados, $5,49 \%$ de casos de câncer de boca ${ }^{30}$. No mundo ocidental, essa neoplasia é mais rara, mas as taxas são comparativamente altas nos grupos socioeconomicamente baixos e em muitas áreas metropolitanas ${ }^{132}$. Na maioria dos paises ocidentais, esse tipo responde por 2 a $4 \%$ de todos os casos de câncer 3,58,76,77,99. Para os Estados Unidos 17,33,113,114,131 e também para Israel ${ }^{37}$ as pesquisas indicam proporção semelhante. No Brasil, o Registro Nacional de Patologia Tumoral 82 aponta, para o sexo masculino, no período de 1981 a 1985, uma proporção de 6,7\% de diagnósticos histopatológicos para o câncer de boca, - que representa a terceira posição, abaixo apenas do câncer de pele $(28,5 \%)$ e de estômago $(10,7 \%)$; para o sexo feminino, o câncer de boca ocupa a oitava posição, representando $1,8 \%$ dos diagnósticos histopatológicos de todos os tipos de câncer. No Estado da Paraiba, que é a segunda região de maior prevalência de câncer de boca no Brasil, esse câncer também vem logo abaixo dos cânceres de pele e de estômago, que são os de mais altas taxas no Estado ${ }^{105}$.

A mortalidade por câncer de boca é considerada alta 50,114. Para os Estados Unidos, Gerson ${ }^{38}$ encontrou $1 \%$ dos óbitos por câncer devidos a esse tipo de patologia,mas outra pesquisa feita anteriormente ${ }^{113}$, aponta uma proporção de $2,5 \%$. Na Inglaterra e País de Gales a proporção encontrada, para os periodos de 1962 a 1967 e 1980 a 1984, foi de 1\% 51. No Município de São Paulo, segundo dados do Departamento de Estatística do Estado de São Paulo, citados em Samara ${ }^{104}$ a mortalidade proporcional por câncer de boca foi de aproximadamente $2 \%$ em 1970 . No Municipio de Araraquara, Estado de São Paulo, no período de 1979 a 1991, essa causa representou $0,87 \%$ da mortalidade por câncer em geral ${ }^{91}$.

As estatísticas baseadas nos dados de mortalidade, nos paises em desenvolvimento ou subdesenvolvidos, enfrentam o problema de sub-registro de dados. Ao relatar pesquisa feita na Índia, Sankaranarayanan ${ }^{106}$ afirma que há poucos 
estudos baseados na mortalidade por câncer bucal nesse país por causa das deficiências dos sistemas de registro de óbitos. No Brasil, o diagnóstico das Regiões Administrativas publicado pelo Governo do Estado de São Paulo 110, em 1971, revelava a suspeita de existência de sub-registro de óbitos na maior parte das Regiões paulistas. Entretanto, segundo Laurenti ${ }^{61}$, mesmo com as falhas apontadas nas estatísticas oficiais de mortalidade, elas trazem valiosa contribuição à epidemiologia do câncer. Laurenti 62 afirma que essas estatísticas têm importante uso na descrição completa da mortalidade, constituindo-se um gerador de hipóteses. Especialmente no caso das doenças de alta letalidade, é de grande importância a disponibilidade dos dados de mortalidade, que, de certo modo, traduzem os de incidência ${ }^{78}$.

O câncer de boca é altamente letal $53,54,68$, com taxa de sobrevida de cinco anos menor do que $50 \%$ 10,54,106,109,113,114,131, taxa considerada baixa em relação às dos principais tipos de câncer ${ }^{13}$. Na cidade de São Paulo, taxas de sobrevida de um ano foram estimadas em $76,8 \%$ para homens e $91,2 \%$ para mulheres ${ }^{104}$. Hardt e Schlenk ${ }^{50}$ observam que a qualidade de vida pós-operatória pôde ser sensivelmente melhorada em razão de técnicas terapêuticas modernas, mas não foi ainda possivel prolongar significativamente o período de sobrevida.

Quanto à classificação dos cânceres, diz Lilienfeld ${ }^{66}$ que, na falta de um conhecimento preciso sobre a etiologia da doença, os epidemiologistas classificam os tumores segundo sua localização anatômica, segundo o tipo histológico e, menos freqüentemente, segundo o estádio da doença.

Do ponto de vista histológico, distinguem-se quatro tipos de carcinoma bucal: espinocecular, "in situ", basocelular e adenocarcinoma ${ }^{92}$. O tipo histológico mais comum é o carcinoma espinocelular, ou de células escamosas, ou epidermóide 17,25,58,92,99,123. Segundo várias pesquisas, essa forma de carcinoma é responsável por cerca de $90 \%$ dos casos diagnosticados $31,77,113,114,122,131$, sendo que, para a Índia, chega-se indicar a uma proporção de quase $99 \%{ }^{106}$. Considerada a localização do tumor na boca, verifica-se que, para o câncer das glândulas salivares, a proporção de carcinomas de células escamosas é mais baixa. O Registro Nacional de Patologia Tumoral 82 indica, para o Estado de São Paulo, no período de 1981 a 1985, uma 
proporção de mais de $95 \%$ no caso das localizações lábio, língua e assoalho da boca, de mais de $85 \%$ no caso das localizações gengiva e outras partes da boca, mas de apenas $23,5 \%$ no caso das glândulas salivares, apesar de, nesta localização, esse tipo de carcinoma ser, também, o mais freqüente.

A classificação pelo estádio da doença pode ser baseada em achados clínicos apenas, ou em achados clínicos aliados a observações feitas durante cirurgia e a resultados de exames histopatológicos de tecidos removidos ${ }^{66}$. Na classificação segundo o estádio usa-se o método formulado pelo American Joint Committee of Cancer (AJJC). Trata-se de um sistema (TNM) que tem base nos três eventos considerados significativos na história de um câncer: o tamanho do tumor primário (T), o alastramento para nódulos linfáticos da região $(N)$ e a metástase à distância $(M)$; na conjunção desses três eventos se caracterizam quatro estádios do câncer, designados como I (o menos avançado) a IV (o mais avançado) ${ }^{66,70}$.

A classificação pela localização anatômica do tumor mais conhecida é a Classificação Internacional de Doenças (CID), utilizada em todos os países do mundo e atualmente com sua 10a revisão já aprovada e com implantação prevista para 1995 65. Essa classificação é considerada de grande valor para se estabelecer a comparabilidade dos materiais de diferentes periodos de tempo ou de diferentes lugares, necessária à investigação epidemiológica, embora, como aponta Lilienfeld ${ }^{66}$, haja problemas ligados às diferenças de critérios de classificação dos especialistas e, também, a diagnósticos indefinidos.

As investigações revelam que, tanto na incidência como na mortalidade, há grande variação na localização principal do tumor na boca segundo a região geográfica em estudo, o que revela dependência dos hábitos e das condições de vida nas diversas regiões, isto é, revela diversidade de atuação dos fatores de risco.

Pesquisa feita na Irlanda ${ }^{79}$ aponta os óbitos por neoplasmas da língua como os mais comuns entre os cânceres bucais; também no Municipio de São Paulo 104 e no Municipio de Araraquara, Estado de São Paulo 91 , as maiores proporções de óbitos por câncer de boca foram devidas à localização língua (40,5\% e $56,3 \%$, respectivamente). Quanto à incidência, a língua foi a localização mais 
freqüente em pesquisas feitas na Califórnia, EUA ${ }^{131}$, em Cuba ${ }^{103}$ e na Colômbia ${ }^{40}$. O assoalho da boca é indicado na primeira posição em pesquisas para o Município de Araraquara, Estado de São Paulo ${ }^{90}$, Indiana, USA ${ }^{122}$ e Itália ${ }^{22}$. No Município de São Paulo 104, em João Pessoa, Estado da Paraíba 101,105, bem como em Israel ${ }^{37}$, o maior número de casos encontrados foi de lábio. Diferentemente desses resultados encontrados nos paises do Ocidente, na Índia ${ }^{15,109}$ e na Nova Guiné ${ }^{127}$ o local mais atingido é a mucosa bucal, o que deve explicar-se pelo contacto dessa parte da boca com substâncias carcinógenas, devido aos hábitos de vida dessas regiões.

Independentemente da consideração do efeito dos fatores de risco, as pesquisas feitas em todo o mundo têm relacionado a incidência do câncer bucal à variável idade, definindo essa neoplasia como uma doença da faixa etária mais avançada 4,20,22,30,70,76,99,114,126,131,133. Mais de $90 \%$ dos tumores ocorrem em pessoas de mais de 40 anos de idade $70,76,77,114,116,122,131$ e mais de $80 \%$ ocorrem a partir da sexta década 99,114,116,131. Acredita-se que a alta freqüência da neoplasia a partir da quinta década pode ser parcialmente explicada pelo maior tempo de exposição aos fatores co-carcinogênicos ${ }^{114,116}$, associada à perda imunológica provocada pela idade ${ }^{114}$, indicando-se, para a ocorrência da doença em crianças e em jovens, uma relação potencial com distúrbio genético ou imunodeficiência ${ }^{116}$.

Tem-se considerado que as taxas de incidência do câncer de boca também dependem da variável sexo, embora, em última análise, atuem os hábitos de vida dos diferentes sexos. Assim, as pesquisas em geral indicam que os homens são muito mais atingidos que as mulheres $9,40,59,99,103,113,114,115,131,133$, especialmente nos países industrializados ${ }^{50}$, o que possivelmente se liga ao maior consumo de tabaco e de álcool no sexo masculino ${ }^{50,92}$. Na Índia, por outro lado, onde o hábito de fumar e de mascar tabaco é bastante difundido entre as mulheres, a razão entre o sexo masculino e o feminino, na incidência do câncer bucal, é de, aproximadamente, ${ }^{49,50}$. Sabe-se ainda que alterações na razão entre os dois sexos através do tempo têm ocorrido, com aumento da incidência entre as mulheres 16,51,122,131, em decorrência de alterações de hábito, como, por exemplo, do aumento de fumantes, e de consumidores de álcóol no sexo feminino $17,50,58,70,99,114$. Reychler ${ }^{99}$ fala 
numa tendência para os dois sexos se igualarem, lembrando, porém, que já se considerou a existência de uma proteção hormonal para as mulheres ${ }^{60}$.

Os fatores de risco para o câncer de boca são de várias ordens. Eles podem ser classificados em extrínsecos, ou exógenos, e intrínsecos, ou endógenos ${ }^{128}$. Os fatores exógenos podem ser biológicos (como agentes virais ou agentes infecciosos), químicos (como tabaco e álcool) e físicos (como irritação mecânica, irritação térmica e radiação); entre os fatores endógenos estão os fatores genéticos, os fatores endócrinos e a auto-imunidade.

Os fatores de risco podem determinar, inicialmente, uma lesão potencialmente cancerosa ${ }^{92}$, como a leucoplasia, a fibrose da submucosa ou a eritroplasia ${ }^{106}$. A leucoplasia, ou "placa branca", é a lesão mais freqüentemente associada com o aparecimento de câncer bucal 4,92,113,131,138, mas também para a fibrose da submucosa foi indicado, na Índia, grande risco de transformação maligna, em dependência de componentes genéticos, imunológicos, virais, nutricionais e de auto-imunidade ${ }^{97}$. Estudo epidemiológico de câncer de boca na İndia, entretanto, aponta que $75 \%$ dos casos se relacionam com uma leucoplasia pré-existente ${ }^{106}$.

A insuficiência do conhecimento da ação dos fatores de risco para os carcinomas buco-maxilo-faciais tem sido acentuada por vários autores 18,99,106; alguns dos fatores têm sido inequivocamente ligados à doença, enquanto que, para outros, não se têm obtido evidências indiscutíveis.

Apesar desse conhecimento insuficiente, sabe-se que os fatores químicos são os mais freqüentemente responsáveis por esses tumores ${ }^{99}$. Segundo Reychler ${ }^{99}$, trata-se de um papel difícil de ser evidenciado no ser humano, mas os agentes carcinogênicos químicos bucais agem segundo um procedimento de etapas múltiplas: fases de iniciação, de promoção e de progressão; parece que a saliva desempenha um papel protetor no nível bucal e que a ausência de glândulas anexas pode explicar uma resistência maior que a da pele à ação química carcinogênica.

Os fatores quimicos envolvem, além do fumo e do álcool, a dieta 18,45,64,77,80,99 , e certos oligo-elementos, como os cromatos de níquel, o arsênico, o cádmio e o zinco ${ }^{99,115}$. No sentido inverso, vem sendo estudado em vários países o 
efeito protetor de certos alimentos, como frutas e vegetais $34,45,64,99,106,109$ e das vitaminas $A, B, C$ e $E^{46,50,57,99,109}$. Hardt e Schlenk 50 afirmam que uma alimentação deficiente provoca atrofia das mucosas bucais e pode torná-las mais sensiveis a um fator carcinogênico local. Quanto às vitaminas, uma redução significativa do risco só ficou evidenciada para o uso da vitamina $E^{45}$.

São muitas as investigações epidemiológicas que têm colocado o consumo de tabaco e de álcool como os dois mais importantes fatores de risco para 0 câncer de boca 6,7,13,17,18,22,29,31,33,34,37,64,70,72,73,77,80,106,109,126,130,131,137,139. Alterações nas taxas de incidência desse câncer em diversos países têm podido ser atribuídas a mudanças de hábito relativas ao consumo de tabaco e de bebidas alcoólicas, bem como à dieta ${ }^{88}$. Na Índia a mudança de hábitos no modo de consumo de tabaco, cada vez mais fumado e menos mascado, responde por uma diminuição dos casos de câncer de boca, paralela a um aumento dos casos de câncer de pulmão ${ }^{108}$. No Norte da Tailândia, o câncer bucal ocupou o terceiro lugar entre todas as localizações de câncer entre 1975 e 1984, caindo para o sétimo lugar em 1987, com a diminuição do hábito de mascar tabaco e de fumar ${ }^{98}$.

O consumo do tabaco é apontado como o principal fator de risco do câncer de boca no mundo 9,50. Em pesquisa feita nos Estados Unidos verificou-se que $68 \%$ dos pacientes com esse tipo de câncer eram fumantes na época do diagnóstico ${ }^{114}$. Mecklenburg et alii 77 indicam que o risco de desenvolver câncer bucal é, em média, quatro vezes maior nos fumantes do que nos não-fumantes.

O consumo de tabaco, como fator de risco para o câncer de boca, independe da forma de uso ${ }^{99}$. Aponta-se, entretanto, que há aumento de risco para os usuários de tabaco mascado e aspirado 24,77 . O hábito de mascar tabaco freqüentemente misturado com bétel, é disseminado em regiões de alta incidência de câncer bucal, como no Sul e Sudeste da Ásia, no Norte da África e no Oriente Próximo $2,9,48,50$.

Sankaranarayanan 106 explica o modo de uso do bétel (Piper betle), cujas folhas verdes, untadas de pasta de cal hidratada, são enroladas com folhas secas ou hastes de tabaco e pedaços de noz de areca (Areca catechu), sendo 
acrescentados, ainda, certos condimentos. As peças são mastigadas, e conservam-se comprimidas junto à mucosa bucal por periodos de tempo que vão de cinco a sessenta minutos, ou, ainda toda noite, durante o sono. Esse hábito é parte integrante da herança cultural e religiosa hindu. O efeito das diferentes substâncias usadas na mistura tem sido bastante estudado, mas a conclusão dos inúmeros trabalhos indica que o componente mais carcinogênico é o tabaco, observando-se o aparecimento da lesão no local em que a mistura é habitualmente conservada $32,43,74,106$. Na Índia várias pesquisas têm apontado uma associação significativa entre esse hábito de mascar tabaco e o câncer de boca ${ }^{14,15,92,107,108}$, com associação direta do risco à quantidade de substância mascada e à intensidade do uso ${ }^{42,106}$. Também na Nova Guiné esse hábito é ligado ao aparecimento de lesões neoplásicas na boca ${ }^{127}$. Hardt e Schlenk 50 afirmam que o hábito de mascar tabaco se vem expandindo cada vez mais nos paises ocidentais e que esse hábito deverá favorecer 0 aparecimento de carcinomas bucais e de outras lesões potencialmente malignas.

Pesquisas nos Estados Unidos relacionam o risco de desenvolver o câncer de boca ao hábito de aspirar e de mascar tabaco 26,74,77; esse hábito, pretensamente correlacionado com uma melhor atuação atlética, foi adotado por jogadores de beisebol, e foi imitado por adolescentes ${ }^{21}$. Glover et alii ${ }^{39}$ indicam que o uso de tabaco aspirado e mascado é um sério problema nas universidades e colégios americanos. Em pesquisa com mais de mil jogadores profissionais de beisebol, durante o treinamento de 1988, nos Estados Unidos, Graddy et alii ${ }^{43}$ encontraram lesões leucoplásicas de mucosa bucal ligadas ao hábito de aspirar ou mascar tabaco. A propósito desses hábitos, tem-se defendido a necessidade de uma ação educativa junto aos jovens, nesse país ${ }^{26}$.

Outro hábito que representa grande risco é o de fumar invertido, isto é, com a ponta acesa dentro da boca, hábito disseminado em regiões da Índia, da América do Sul e do Caribe ${ }^{121}$, e que afeta, especialmente, o palato e a língua 40,121. González ${ }^{40}$, estudando o carcinoma escamocelular da cavidade oral ocorrente na região costeira colombiana, apontou diferenças, no aspecto epidemiológico, entre as lesões encontradas e as que aparecem nas outras regiões da Colômbia, atribuindo a 
diferença a esse hábito, comum entre as populações de baixa condição socioeconômica, especialmente as lavadeiras e os pescadores.

O risco que o hábito de fumar representa aumenta com a intensidade e o tempo de exposição ao agente 18,27,34,77,80,99,139. Tem-se verificado, também, uma variação do risco em função dos diferentes modos de processamento do tabaco. Fumantes de cigarros enrolados à mão mostraram maior risco de desenvolver câncer de boca, em comparação com fumantes de cigarros industrializados ${ }^{27}$. Os bidis indianos, cigarros preparados com 0,2 a 0,3 g de tabaco enrolado em folhas secas de um determinado vegetal (Diospyros melanoseylon), liberam, segundo estudos químicos realizados, uma vez e meia mais hidrocarboneto do que os cigarros populares americanos sem filtro ${ }^{106}$. Verificou-se, também, maior risco com o uso de charuto do que de cigarro ou de cachimbo ${ }^{80}$ e com o uso de cachimbo do que de cigarro ${ }^{139}$. Em pesquisa realizada no Brasil, encontrou-se também maior risco relativo com o uso de cachimbo $(R R=13,9)$ do que com o de cigarro $(R R=$ $5,5)$, sendo maior o risco com cigarro manualmente enrolado $(R R=14,4)$ do que com cigarro industrializado $(R R=9,3)^{34}$.

Embora já se tenha apontado que o tabaco e o álcool são fatores de risco independentes para o câncer de boca ${ }^{125,139}$, as pesquisas em geral têm mostrado que esses dois fatores atuam sinergicamente $9,13,50,77,92$, havendo um efeito não simplesmente aditivo, mas multiplicativo da sua combinação 7,37,72,73,99. Mecklenburg et alii 77 afirmam que 3/4 de todos os casos de câncer de boca e de faringe nos Estados Unidos ocorrem em pessoas que fumam e bebem. É certo, porém, que o abuso do álcool potencializa outros carcinógenos, em particular o tabaco ${ }^{50}$, de modo que as pessoas que misturam os dois hábitos formam uma população de alto risco ${ }^{106}$.

Não se tem conseguido evidência de que o álcool sozinho possa provocar um carcinoma ${ }^{7}$. A ação carcinogênica do álcool é considerada uma questão ainda controversa 92,106, e não se tem encontrado evidência de um mecanismo específico que possa associar o consumo do álcool a certos cânceres ${ }^{18}$. Entretanto, embora em estudos experimentais o etanol não tenha sido apontado como carcinogênico, ele pode promover carcinogênese por uma variedade de mecanismos, 
incluindo a indução de enzimas envolvidas no metabolismo, as deficiências associadas com o consumo muito grande de bebida, a irritação da mucosa pelo contato direto e a contaminação de bebidas alcoólicas com impurezas carcinogênicas ${ }^{18}$. Tem-se considerado que ainda é necessário verificar o papel do álcool na etiopatogenia do câncer de boca, embora estudos sugiram uma possivel associação com os cânceres dos dois terços anteriores da língua e do assoalho da boca ${ }^{106}$. Estudos realizados em certas regiões da França têm ligado o aumento do consumo de álcool à progressão do número de casos de câncer de boca ${ }^{50}$. Em pesquisa relativa a países do Mediterrâneo, o álcool é colocado em segundo lugar, depois do tabaco, como fator de risco para esse tipo de câncer ${ }^{130}$.

Esse risco se relaciona diretamente com a intensidade do uso 18,80,88,99,120, e, segundo algumas pesquisas, também com o tipo de bebida 5.55 . Tem-se afirmado que a cerveja e os álcoois secos oferecem maior risco que o vinho ${ }^{5,99}$. Entretanto, em pesquisa feita no Brasil ${ }^{34}$, encontrou-se risco mais evidente no uso do vinho (câncer da língua) e da cachaça (câncer das outras localizações).

Ainda com relação a agentes químicos, cabe observar que, investigada a ação do bochecho como fator de risco do câncer bucal, não se encontrou nenhuma associação com o aumento de risco em termos de frequência, duração do uso, diluição e práticas ${ }^{56}$. O risco se restringiu à utilização de líquido com elevado grau de álcool 135. Quanto à ação do flúor, não foi possivel estabelecer nenhum papel na etiologia do câncer de boca, especialmente pela confusão com outras variáveis, como o tabaco e o álcool 1 .

Sobre agentes virais, bem como sobre agentes infecciosos (como os causadores de sífilis, candidíase, etc.), na etiologia do câncer de boca, nada pôde, ainda, ser provado ${ }^{99}$. Entretanto, tem-se apontado que os vírus podem participar da gênese de tumores malignos ${ }^{50}$. Estudos sugerem alguma associação de certos tipos de vírus 17,109, especificamente do vírus do herpes ${ }^{7,23,69,113,118}$ e do vírus do papiloma 23,69,118 com o câncer bucal. Tem-se apontado, porém, que deve ser considerado o papel dos co-fatores ${ }^{118}$ e que é necessário fixarem-se critérios antes que esses agentes potencialmente oncogênicos sejam, com segurança, implicados na 
carcinogênese humana ${ }^{23}$.

Quanto a fatores genéticos, não tem sido indicada uma associação direta com o câncer bucal ${ }^{99}$. Entretanto em pesquisa realizada na Noruega para o período de 1963 a $1972^{10}$, encontrou-se uma prognose significativamente pior para os pacientes com fator Rh negativo ( $8 \%$ de sobrevida de cinco anos) do que para os pacientes com fator $\mathrm{Rh}$ positivo ( $30 \%$ de sobrevida de cinco anos).

Entre os fatores traumáticos, apontam-se as próteses mal feitas e os bordos cortantes dos dentes muito cariados ${ }^{92}$. Entretanto, Reychler ${ }^{99}$ afirma que não se tem podido associar o câncer bucal a irritações de origem mecânica, antigamente evocadas como agente etiológico. O uso de dentadura em si não tem efeito no aparecimento desse câncer ${ }^{138}$. Esse uso é freqüente em pacientes com câncer de gengiva ${ }^{135}$, mas Silverman e Galante ${ }^{113}$ apontam a irritação pela dentadura apenas como co-fator carcinogênico em indivíduos com predisposição. Altini et alii ${ }^{2}$ consideram que o papel das dentaduras e das arestas de dentes, bem como o da falta de higiene bucal, foi superestimado no passado. Por outro lado, a falta de dez ou mais dentes já foi correlacionada significativamente com o câncer de boca ${ }^{56,138}$. Também têm sido apontadas como irritativas da cavidade oral as correntes eletrogalvânicas entre próteses de materiais diversos ${ }^{92}$.

Outros fatores que têm sido investigados são os fatores ocupacionais ${ }^{93}$, que, segundo Maier et alii ${ }^{71}$, estão evidentemente associados com o câncer de cabeça e pescoço. Segundo os autores, os estudos dos últimos trinta anos indicam um crescente risco para trabalhadores expostos a agentes inalados orgânicos ou inorgânicos, embora sejam necessários estudos mais pormenorizados, clinicamente orientados, para se conseguir uma melhor compreensão do papel dos fatores ocupacionais nesse tipo de câncer. Para o câncer de boca, esses autores destacam, na Alemanha, o aumento de risco ligado à exposição longa ao pó de cimento. Corino e Sargian 22 não encontraram relação particular entre uma determinada ocupação profissional e esse tipo de câncer, mas verificaram que a maioria dos doentes eram da indústria ou da agricultura; em todos os casos, notaram associação com falta de higiene. Merletti et alii ${ }^{81}$ observaram em Turim, Itália, casos de câncer da cavidade oral 
ou orofaríngea relacionados com dezenas de ocupações, observando crescimento de risco para os prestadores de serviços e os trabalhadores em produção, e redução de risco para profissionais de vendas; entre os prestadores de serviços, as maiores taxas se referiram aos cozinheiros, garçons e servidores de bar; entre os trabalhadores em produção, as maiores taxas se referiram aos trabalhadores quimicos, alfaiates e costureiros, montadores e ajustadores de máquinas, e ajustadores e reparadores de chaminés. Todas as ocupações demonstraram crescimento de risco associado ao hábito de fumar, enquanto somente no caso dos que trabalhavam com chaminés se observou crescimento similar relacionado com o consumo de álcool. Embora reconheçam que não se tenha podido controlar o efeito reciproco das exposições ocupacionais e a interação entre o modo de vida e os fatores ocupacionais, os autores consideram que o estudo confirmou como de risco um grupo de ocupações e atividades que já tinham sido apontadas: têxtil, elétrica, de construção, de operação de máquinas, gráfica e de funilaria. Para o câncer de lábio, Nocchetti et alii ${ }^{92}$ encontraram associação com ocupações como as de agricultor e pescador, que exigem longos periodos de exposição ao sol. Várias pesquisas têm ligado a ação dos raios ultravioleta à incidência do câncer de lábios 2,31,99,126.

Finalmente, têm de ser considerados, no estudo da etiologia do câncer bucal, o grupo étnico e a condição sócio-econômico-cultural do paciente. Em certas regiões dos Estados Unidos observa-se maior incidência nos negros (risco relativo variando de 1,1 a 2,1 , conforme a região estudada) ${ }^{9}$. Para o câncer dos lábios, entretanto, Sampaio et alii ${ }^{105}$ observam que os indivíduos de pele mais escura são os menos afetados, e que isso pode ser explicado pelo efeito protetor da melanina; já nas atividades externas, a protrusão do lábio inferior expõe os negros às radiações actínicas que podem atuar sinergicamente com produtos químicos utilizados no meio rural, colaborando no aparecimento de lesões, que se associam, ainda, à ação deletéria do hábito de fumar. Entretanto, lembram os autores, as diferenças de distribuição da neoplasia entre os grupos étnicos também podem ser entendidas, por vezes, como resultante das condições sócio-econômicas e culturais, devendo-se reavaliar os riscos de exposição a certos hábitos ou fatores atuantes nessas 
comunidades. Greenberg ${ }^{44}$ encontrou, nos Estados Unidos, relação entre o câncer orofaríngeo e as condições sociais e educacionais, concluindo que a instabilidade social e/ou econômica está relacionada a um risco maior desse tipo de câncer.

As grandes diferenças encontradas nas taxas de incidência de câncer bucal e de mortalidade por essa neoplasia no mundo sugerem diferenças, entre as regiões, que podem refletir combinações de fatores individuais e ambientais ${ }^{113}$. Encontra-se, por exemplo, grande variação nas taxas de mortalidade conforme a região dos Estados Unidos, com extremos de 6,3 por 100.000 no Distrito de Colúmbia e 1,4 por 100.000 em Dakota do Sul e em Utah ${ }^{13}$. Ocorre que, na verdade, exposto contínua e simultaneamente a um amplo espectro de forças biológicas, químicas e físicas, o homem reage diferentemente a cada uma dessas forças, sendo a reação de cada indivíduo condicionada pela idade, pelo sexo, pela hereditariedade e por um grande número de outros agentes ${ }^{113}$, ligados a aspectos geográficos, raciais, ocupacionais, sócio-econômicos, alimentares, de higiene e de clima ${ }^{40}$. Nocchetti et alii ${ }^{2}$ afirmam que o carcinoma da cavidade oral pode ser considerado um exemplo de como o ambiente, as modificações que nele provocam os homens e os hábitos pessoais e sociais podem determinar o aparecimento de uma patologia. Como afirma Fraumeni ${ }^{35}$ em relação ao câncer em geral, variações nos padrões internacionais de prevalência e mortalidade, juntamente com mudanças na incidência entre populações migrantes, sugerem que muitos tumores humanos têm uma etiologia ligada ao ambiente e, a partir daí, que a prevenção é teoricamente possivel. Também com relação ao câncer das várias localizações, se aponta a possivel variação regional da contribuição etiológica relativa dos fatores de risco 8,87 e, a partir daí, se depreende que as medidas de prevenção ou controle podem apresentar diferentes graus de eficiência dependendo da região ou da comunidade estudada ${ }^{87}$.

Para o câncer de boca, em especial, considera-se grande a possibilidade de prevenção 9,96 . Verifica-se, entretanto, que o diagnóstico e 0 tratamento dessa neoplasia ocorrem, em geral, tardiamente $3,19,20,50,109,114,131$, embora seja altamente importante, no prognóstico da doença, a detecção precoce ${ }^{76,126,134}$, que reduz substancialmente a mortalidade ${ }^{13}$ e eleva o período de sobrevida ${ }^{51,113,122}$. 
Estudo realizado em Copenhague ${ }^{67}$ mostrou que a taxa de sobrevivência não foi influenciada pelo sexo, pela idade, ou pela localização do tumor, mas que há uma diferença significante relacionada com o estádio da doença. Krutchkoff ${ }^{58}$ encontrou uma taxa de sobrevida de cinco anos de $20 \%$ para tumores diagnosticados em estágio avançado, enquanto, para os tumores pequenos e limitados ao local de origem, ela foi de $67 \%$. Fedele ${ }^{33}$ afirma que as taxas de sobrevida de cinco anos são mais de quatro vezes maiores nos indivíduos com lesões localizadas do que nos que têm metástase. Vários outros estudos também explicam pelo estádio da doença no momento do diagnóstico essa baixa taxa de sobrevida 67,109,113,119,131.

A prevenção abrange mais de um aspecto: a detecção precoce, que pode reduzir a morbidade e a mortalidade, o reconhecimento e tratamento das lesões pré-malignas, que podem evitar sua transformação em malignas ${ }^{131}$, além do monitoramento do modo de vida, com modificação dos hábitos que constituam exposição aos fatores de risco. A deteç̧ão precoce das lesões orais durante o exame dentário de rotina é fator significativo no diagnóstico da neoplasia ${ }^{75}$. Esse reconhecimento precoce é considerado uma meta atingivel, para a maioria dos pacientes, com consultas dentárias regulares ${ }^{96}$, face ao fato de que a grande maioria dos cânceres bucais são carcinomas epidermóides, que constituem um tipo epitelial de superfície, facilmente detectável em estágio inicial ${ }^{131}$. Sabe-se, ainda, que inflamações crônicas, facilmente observáveis no exame odontológico, podem estar ligadas à patogênese do câncer de boca ${ }^{29,138}$.

O dentista tem, pois, um grande papel no diagnóstico precoce da doença e no aconselhamento de pacientes ${ }^{11,58,68,129}$. Historicamente, aos profissionais de saúde dentária tem sido atribuida a responsabilidade primária de detecção precoce da lesão, através do exame bucal de seus pacientes ${ }^{13}$. O dentista é, além do médico, o especialista mais consultado pelos individuos afetados por neoplasia maligna da boca, e sobre ele recai grande parte da responsabilidade na prevenção e no diagnóstico precoce; por isso é importante que ele tenha perfeito conhecimento dos vários aspectos dessa que é a doença mais grave da cavidade oral 50,112,122. Pesquisa realizada por Rindum e Pindborg 100 sugerem, porém, que é necessária mais 
informação entre os médicos e os dentistas, com relação ao diagnóstico precoce das doenças malignas intra-orais. Estudo feito nos Estados Unidos conclui que os profissionais de saúde, especialmente os dentistas, devem assumir um papel mais ativo na educação e monitoramento de pacientes que mascam tabaco ${ }^{24}$. A redução da mortalidade causada pelos cânceres bucal e faríngeo pode resultar de esforços que incluam maior envolvimento e treinamento de todos os profissionais de saúde no que diz respeito a métodos de exame e acompanhamento para pacientes de alto risco ${ }^{13}$.

É evidente a necessidade, em Odontologia, de programas sobre etiologia, patogênese, diagnose e conduta na área das neoplasias intra-orais ${ }^{36}$. Uma comissão da Comunidade Européia preparou um documento em que faz recomendações relativas ao currículo dos cursos de Odontologia, destinadas a preparar o profissional para atuar na prevenção e na deteç̧ão precoce de tumores malignos orais ${ }^{129}$. Ocorre que, apesar da facilidade aparente de detecção precoce, infelizmente o diagnóstico de tumores malignos da cavidade oral em estágio inicial é ainda um problema que preocupa a Organização Mundial de Saúde ${ }^{99}$. E, segundo Boyle et alii ${ }^{9}$, essa é uma neoplasia que, comparada a outras, tem atraído pouca atenção dos epidemiologistas.

Para fundamentar uma atuação eficiente, são necessárias pesquisas epidemiológicas do câncer de boca que apresentem dados comparáveis nos diversos centros de investigação, com vistas a açōes preventivas e a definições clínicas. Um dos primeiros cuidados tem de ser a determinação precisa da localização investigada, já que a designação "câncer oral" é genérica, no sentido de que abarca todos os tipos de neoplasias malignas que ocorrem na cavidade oral ${ }^{122}$. A distribuição por sublocalizações para os termos câncer oral, câncer de boca e câncer da cavidade oral é descrita e entendida com muita variação nos trabalhos científicos publicados, o que não ocorre com a maior parte dos estudos sobre o câncer de outras localizações, como pulmão, estômago ou fígado, que têm um significado inequívoco em qualquer parte do mundo ${ }^{106}$. Segundo o autor, muitos trabalhos deixam de especificar quais as sublocalizações que estão incluidas na localização geral boca, o que desserve os objetivos principais da epidemiologia descritiva e impede uma comparação significativa 
dos dados de incidência e de mortalidade pela doença.

Para tentar evitar esses problemas, o presente trabalho circunscreve seu objeto de estudo, o câncer de boca, segundo uma classificação internacional ${ }^{94} \mathrm{e}$ propõe-se estudar a mortalidade por essa neoplasia no Estado de São Paulo, considerado nas suas diferentes Regiōes Administrativas.

A divisão do Estado em Regiões Administrativas obedece à determinação de decretos governamentais. A divisão constitui um processo de descentralização espacial da administração direta do Estado, com vistas a uma atuação regionalizada. A criação das Regiões Administrativas objetivou, pois, a constituição de uma estrutura regional integrada, com a definição de áreas que dependessem de uma decisão central e coordenada; considerou-se que a divisão regional, de um lado, contribui para o tratamento do aspecto territorial do desenvolvimento regional e, de outro, permite a melhoria das práticas administrativas ${ }^{111}$

A primeira medida oficial de regionalização do sistema de planejamento estadual foi o Decreto $n^{\circ} 48.152$, de 03 de julho de 1967, que criou dez Regiões Administrativas para 0 Estado de São Paulo. Criaram-se áreas geográficas circunscritas, Regiões polarizadas abrigando um espaço heterogêneo, sob a liderança de uma cidade definida com centro de irradiação e captação das atividades econômicas, sociais, políticas, administrativas e culturais. O Municipio foi adotado como unidade de referência, e destacaram-se níveis sub-regionais.

O Decreto $n^{\circ} 52.576$, de 12 de dezembro de 1970, alterou a divisão regional primeiramente estabelecida, definindo onze Regiões Administrativas, mas mantendo as diretrizes que haviam norteado a divisão regional anterior, especialmente o critério de polarização.

A base de divisão em Regiões Administrativas, apesar de primariamente ser geográfica, incorpora características de topografia, de vegetação, de atividades produtivas e de condições sócio-econômicas que se refletem em ações integradas de saúde. A partir daí, considerou-se, neste trabalho, a conveniência de o exame dos dados do comportamento do câncer bucal registrarem as especificações 
regionais, especialmente tendo em conta que, como aponta a literatura acima revisada:

a) A incidência do câncer bucal é diferenciada geograficamente.

b) A incidência do câncer bucal tem sido relacionada com grupos de diferentes condições sócio-econômicas e com áreas de determinados graus de desenvolvimento.

c) A incidência do câncer bucal tem sido ligada a hábitos e a condições de vida.

d) Do ponto de vista da localização do tumor, há grandes variações, tanto na incidência como na mortalidade, segundo a região geográfica em estudo, revelando dependência de hábitos e de condições de vida.

Considerou-se, por outro lado, que, apesar da importância dos estudos por Municípios, o exame por Regiões permite uma maior estabilidade estatística, pela possibilidade de maior base de dados.

Considerou-se, neste trabalho, afinal que, para dar suporte a novas investigações sobre o comportamento do câncer de boca e a ações efetivas nesse campo, é importante que se disponha de dados regionais específicos, já que essa doença pode ser prevenida, pela observação da ação de seus fatores de risco, muitas vezes ambientais, e pode ser tratada, em dependência de uma detecção precoce, propiciada por boas condições de atendimento na área de saúde.

Cabe observar, finalmente, que o trabalho circunscreve seu objeto de estudo aos óbitos dos residentes no local, considerando com Pastorelo e Gotlieb ${ }^{95}$, que as estatisticas de mortalidade baseadas no local do evento determinam conclusões distorcidas sobre a situação de mortalidade em uma determinada área, em decorrência dos fenômenos de invasão e evasão de óbitos. Apontam os autores que a preparação de estatísticas de mortalidade segundo o local de residência, por outro lado, permitindo o conhecimento do real risco de morte, pelas diferentes causas de óbito, pode levar ao desencadeamento de um raciocínio epidemiológico que, à luz de informações posteriores, tente elucidar o mecanismo responsável pelas diferenças observadas. 
É com base nesses pressupostos e pretendendo apresentar dados que possam contribuir para ações de saúde no seu campo, que este trabalho se propõe estudar, em relação a um período determinado, a mortalidade por câncer de boca dos residentes no Estado de São Paulo, considerado não apenas como um todo, mas também nas suas Regiões Administrativas. 


\section{OBJETIVO}

Descrever a mortalidade por câncer de boca dos residentes no Estado de São Paulo, no período de 1 de março de 1979 a 28 de fevereiro de 1982, segundo as variáveis sexo, idade, localização do tumor e Região Administrativa de residência. 


\section{MATERIAL E MÉTODOS}

\subsection{Material}

Constituiram material de estudo as declarações registradas dos óbitos de residentes no Estado de São Paulo, ocorridos no período de 1 de março de 1979 a 28 de fevereiro de 1982, e que apresentaram câncer de boca como causa básica de morte, segundo registros armazenados em meio magnético, com tecnologia de CDROM do Ministério da Saúde ${ }^{86}$.

\subsection{Variáveis de estudo}

Os casos de óbito foram analisados segundo as variáveis:

1) Sexo.

2) Idade, apresentada nos grupos decenais: zero a nove anos completos, dez a dezenove anos completos, vinte a vinte e nove anos completos, trinta a trinta e nove anos completos, quarenta a quarenta e nove anos completos, cinquenta a cinquenta e nove anos completos, sessenta a sessenta e nove anos completos, setenta anos e mais.

3) Localização do tumor, segundo a codificação por categorias de 3 dígitos constante do Manual de Classificação Estatística Internacional de Doenças, Lesões e Causas de Óbito (CID- $9^{a}$ revisão, 1975) ${ }^{94}$, que é a seguinte:

- 140 Neoplasma maligno do lábio

- 141 Neoplasma maligno da lingua

- 142 Neoplasma maligno das glândulas salivares maiores

- 143 Neoplasma maligno da gengiva

- 144 Neoplasma maligno do assoalho da boca

- 145 Neoplasma maligno de outras partes e de partes não especificadas da boca Para a última dessas categorias (145) foram consideradas as subcategorias, que apresentam codificação com 4 dígitos, de acordo com a CID- $9^{\text {a }}$ revisão ${ }^{94}$ : 
- 145.0 Mucosa da bochecha

- 145.1 Vestíbulo da boca

- 145.2 Palato duro

- 145.3 Palato mole

- 145.4 Úvula

- 145.5 Palato, não especificado

- 145.6 Área retromolar

- 145.9 Boca, não especificada

4) Regiões Administrativas, segundo a divisão criada pelos Decretos $n^{\circ} 48.162$, de 03/07/1967 e no 52.576, de 12/12/1970 (mapas no anexo 1).

Segundo esse agrupamento, foram as seguintes as Regiões consideradas:

01. Grande São Paulo, subdividida, neste estudo em:

01a. Municipio de São Paulo

01b. Demais Municípios da Grande São Paulo (36 Municipios)

02. Litoral (sede : Santos), com 23 Municipios

03. Vale do Paraíba (sede: São José dos Campos), com 32 Municípios

04. Sorocaba (sede: Sorocaba), com 59 Municípios

05. Campinas (sede: Campinas), com 83 Municípios

06. Ribeirão Preto (sede: Ribeirão Preto), com 80 Municípios

07. Bauru (sede: Bauru) com 38 Municipios

08. São José do Rio Preto (sede: São José do Rio Preto), com 85 Municipios

09. Araçatuba (sede: Araçatuba), com 37 Municípios

10. Presidente Prudente (sede: Presidente Prudente), com 50 Municípios

11. Marilia (sede: Marilia), com 47 Municipios.

\subsection{População}

Os dados populacionais utilizados para o cálculo dos coeficientes de mortalidade foram os do censo de 1980. Esses dados foram obtidos a partir de arquivos magnéticos gravados em disquete, contendo imagens de relatórios, 
fornecidos pela Fundação Sistema Estadual de Análise de Dados (SEADE).

\subsection{Processamento dos dados}

Criaram-se programas computacionais específicos para que os dados populacionais pudessem ser tratados e processados, e para que as populações dos Municipios fossem agrupadas por Regiões Administrativas. As tabelas 1 e 2 do anexo 2 trazem, para o sexo masculino e para o sexo feminino, respectivamente, esses dados populacionais segundo os grupos etários, os Municipios e as Regiões Administrativas de residência.

As informações referentes às variáveis de interesse constantes das declarações de óbitos foram selecionadas dos registros contidos no CD-ROM, e gravadas em disquetes. Bancos de dados foram criados para serem processados pelo programa EPI INFO ${ }^{28}$. A distribuição desses óbitos segundo sexo, idade, localização do tumor e Região Administrativa de residência, encontra-se nas tabelas 1 a 24 do anexo 3 .

\subsection{Cálculo dos coeficientes}

Tendo em vista a data de 01/09/1980 do censo populacional, fixou-se para estudo o periodo de 01/03/1979 a 28/02/1982, não sendo necessárias estimativas populacionais.

Os coeficientes de mortalidade por câncer de boca foram calculados mediante a fórmula básica:

Coeficiente de mortalidade $=\frac{n^{0} \text { de óbitos por câncer de boca, no periodo estudado }}{3 \times \text { população censitária }} \times 100.000$

Os cálculos dos coeficientes de mortalidade por câncer de boca específicos por sexo, por idade, por localização do tumor e por Região foram baseados nessa fórmula, com as modificações necessárias. 


\subsection{Padronização dos coeficientes}

Para controlar as possiveis diferenças nas estruturas etárias das populações das diversas Regiões, os coeficientes gerais e especificos de mortalidade das Regiões foram padronizados ${ }^{102}$, tomando-se como padrão a população total do Estado de São Paulo, obtida pelo censo de 1980 (tabela 1 do anexo 4).

Para possiveis comparações com resultados de outros trabalhos, esses coeficientes também foram padronizados tomando-se como padrão a população mundial ${ }^{133}$ (tabela 1 do anexo 4), encontrando-se o resultado dessa padronização na tabela 2 do anexo 4.

\subsection{Análise dos dados}

Os dados foram analisados utilizando-se tabelas, gráficos de linhas, gráficos de barras e cartograma. 


\section{RESULTADOS E DISCUSSÃO}

\subsection{Resultados gerais para o Estado de São Paulo}

\subsubsection{Mortalidade geral}

No período de março de 1979 a fevereiro de 1982 foram observados, no Estado de São Paulo, 1.158 casos de óbitos por câncer de boca. Esse número representa $2,1 \%$ do total de 54.500 óbitos por câncer em geral ocorridos nos anos de 1979, 1980 e 1981 83,84,85, período que apresenta a mesma duração do período estudado nesta pesquisa, apenas com diferença de dois meses no limite inicial, que é compensada no limite final.

O coeficiente de mortalidade encontrado foi de 1,54 por 100.000 habitantes.

\subsubsection{Mortalidade segundo 0 sexo}

Para o sexo masculino, com 962 óbitos nesse período de 3 anos, obteve-se um coeficiente de mortalidade de 2,56 por 100.000 homens. Para o sexo feminino, com 196 óbitos no mesmo período, obteve-se coeficiente de 0,52 por 100.000 mulheres. A razão entre os sexos masculino e feminino, relativamente à mortalidade, foi $4,92: 1$.

As pesquisas disponiveis na literatura também registram coeficientes de mortalidade maiores para os homens que para as mulheres ${ }^{12,79}$. Estudo no Municipio de São Paulo, referente a $1970{ }^{41}$, obteve resultados semelhantes aos que aqui se apresentam: 2,6 por 100.000 homens e 0,3 por 100.000 mulheres. Outro estudo feito no Municipio de São Paulo, referente ao periodo de 1969 a 1971104, aponta coeficientes de mortalidade de 3,2 por 100.000 homens e de 0,4 por 100.000 mulheres. Para o Município de Araraquara, pesquisa relativa ao periodo de 1979 a 199191 encontrou um coeficiente de mortalidade de 1,7 por 100.000 homens, não tendo havido nenhum caso de óbito por câncer de boca no sexo feminino. Em Israel foi encontrado coeficiente de mortalidade no sexo masculino semelhante ao obtido nesta 
pesquisa (2,3 por 100.000 homens), mas no sexo feminino, ele foi maior ( 1,5 por 100.000 mulheres) ${ }^{37}$. Nos Estados Unidos, em ambos os sexos indicam-se coeficientes mais elevados que os que aqui se obtiveram: 5,8 por 100.000 homens e 2,0 por 100.000 mulheres ${ }^{37}$. Pesquisa realizada na Inglaterra e no País de Gales, apenas para o sexo masculino, encontrou coeficiente de 2,8 por 100.000 homens $^{9}$.

Os dados encontrados no presente estudo podem ser comparados com os referidos em trabalhos sobre incidência de câncer bucal. Os valores dos coeficientes de incidência são mais altos que os de mortalidade. Na pesquisa feita no Município de São Paulo para o periodo de 1969 a 1971, já referida 104, os coeficientes de incidência encontrados foram de 10,7 por 100.000 homens e de 2,19 por 100.000 mulheres. Em Connecticut, Estados Unidos, em 1985, encontrou-se uma incidência de 10,9 por 100.000 homens e de 4,9 por 100.000 mulheres ${ }^{17}$.

$\mathrm{Na}$ incidência, como na mortalidade, o sexo masculino é o mais atingido. Segundo Reychler ${ }^{99}$, os homens são de 1,3 a 10 vezes mais atingidos que as mulheres. Doherty ${ }^{31}$ aponta que, nos Estados Unidos, 70 a $80 \%$ dos casos de câncer de boca ocorrem em homens. Em Cuba, Ruiz Mendez et alii 103 verificaram, em biópsias, que $80 \%$ dos casos eram do sexo masculino. No Senegal, em 181 casos estudados, $60,22 \%$ eram de homens e $39,78 \%$ eram de mulheres ${ }^{30}$. Na Índia, entretanto, os estudos têm apontado uma razão homens/mulheres igual a 149,50 .

Hamada ${ }^{49}$ propõe que se dividam os países do mundo em dois grupos, quanto à razão entre os sexos para o câncer de boca: um grupo com razão relativamente alta (os exemplos são o Brasil e o Canadá, que apresentam razão homens/mulheres de $3: 1$ ) e outro grupo com razão entre os sexos próxima a 1 (os exemplos são a Índia e as Filipinas, com razão igual a 1 e a 0,8, respectivamente). Essa diferença reflete uma relação entre o sexo e os principais fatores de risco para o câncer de boca, que são, para o primeiro grupo de países, o hábito de fumar, associado ou não ao hábito de beber, e, para o segundo grupo, o hábito de mascar tabaco.

Também reflete a relação entre o sexo e os fatores de risco a diminuição que se vem verificando na razão homens/mulheres quanto à incidência do 
câncer bucal. Segundo Magee ${ }^{70}$, nos Estados Unidos a razão entre o sexo masculino e o feminino, que em 1950 era 6:1, passou, em 1980, para 2,4:1. Segundo Silverman e Gorsky ${ }^{114}$, a razão homens/ mulheres que, na Califórnia, EUA, em 1950, era $6: 1$, passou para $2: 1$, em 1990, explicando-se essa mudança, provavelmente, pelo aumento do uso do tabaco e do consumo de álcool entre as mulheres. Chen ${ }^{16}$ encontrou, em Connecticut, EUA, entre a década de 30 e a de 80 , uma diminuição da razão entre homens e mulheres na incidência do câncer de boca (de 10,4:1 para $2,7: 1)$.

\subsubsection{Mortalidade segundo a idade}

A distribuição dos óbitos segundo a idade pode ser observada por meio dos coeficientes de mortalidade por câncer de boca constantes da tabela 1. Verifica-se que, tanto para a população masculina como para a feminina, os coeficientes aumentam com o avanço da idade.

Os coeficientes do sexo masculino encontrados foram bem maiores que os do sexo feminino, em quase todos os grupos etários, exceto nos grupos de idades mais baixas, como o de 20 a 29 anos, em que os coeficientes dos dois sexos foram iguais, e o de 10 a 19 anos, em que não houve nenhum óbito no sexo masculino.

TABELA 1. Número de óbitos e coeficientes de mortalidade por câncer de boca (por 100.000), segundo grupo etário e sexo. Estado de São Paulo, 1979-1982.

\begin{tabular}{|c|c|c|c|c|c|c|}
\hline \multirow{3}{*}{$\begin{array}{l}\text { GRUPO } \\
\text { ETARIO }\end{array}$} & \multicolumn{4}{|c|}{ SEXO } & \multirow{2}{*}{\multicolumn{2}{|c|}{ TOTAL }} \\
\hline & \multicolumn{2}{|c|}{ MASCULINO } & \multicolumn{2}{|c|}{ FEMININO } & & \\
\hline & $n^{0}$ & coef. & $n^{\circ}$ & coef. & $n^{0}$ & coef. \\
\hline $10+20$ & - & - & 2 & 0,03 & 2 & 0,01 \\
\hline $20 \vdash 30$ & 5 & 0,07 & 5 & 0,07 & 10 & 0,07 \\
\hline $30+40$ & 39 & 0,77 & 3 & 0,06 & 42 & 0,42 \\
\hline $40+50$ & 191 & 5,25 & 13 & 0,36 & 204 & 2,81 \\
\hline $50 \vdash 60$ & 311 & 12,22 & 41 & 1,56 & 352 & 6,82 \\
\hline $60+70$ & 229 & 16,26 & 56 & 3,58 & 285 & 9,58 \\
\hline $70 e+$ & 187 & 23,98 & 76 & 7,71 & 263 & 14,89 \\
\hline TOTAL & 962 & 2,56 & 196 & 0,52 & 1158 & 1,54 \\
\hline
\end{tabular}


No estudo realizado por Samara ${ }^{104}$ para o Município de São Paulo, referente ao periodo de 1969 a 1971, os coeficientes de mortalidade também aumentam com $o$ avanço da idade, em ambos os sexos, ocorrendo, entretanto, um decréscimo no grupo de 80 anos e mais, no sexo masculino, e no grupo de 75 a 79 anos, no sexo feminino; os maiores valores de coeficientes se encontram, para o sexo masculino, no grupo de 75 a 79 anos (42,89 por 100.000 homens) e, para o sexo feminino, no grupo de 80 anos e mais (10,51 por 100.000 mulheres).

Algumas pesquisas levam em conta o número de óbitos, sem considerar a estrutura populacional, apresentando a proporção dos óbitos por grupo etário. $\mathrm{Na}$ Irlanda, para o período de 1979 a 1986 79, encontrou-se um maior número de mortes ligado ao avanço dos grupos etários, com $66 \%$ dos óbitos ocorrendo acima dos 64 anos. No Município de Araraquara, Estado de São Paulo ${ }^{91}$, verificou-se, entre 1979 e 1991, maior proporção $(37,50 \%)$ no grupo etário acima dos 70 anos, diminuindo a proporção nos grupos etários mais baixos, não se registrando nenhum óbito abaixo dos 30 anos.

Esses dados sobre mortalidade podem ser comparados com os dados sobre a incidência do câncer de boca. Relatando pesquisa feita na Áustria, para o período de 1960 a 1987, Swoboda et alii 124 encontraram uma evolução da mortalidade específica por idade similar à da incidência.

O câncer de boca é muito raramente encontrado abaixo dos 40 anos, e, excepcionalmente, abaixo dos 15 anos $^{99}$. Em pesquisa realizada na Califórnia, EUA, para o periodo de 1973 a 1985 , encontraram-se $44 \%$ de todos os novos casos de câncer bucal em pessoas de 65 anos ou mais, constituindo esse grupo apenas $13 \%$ da população total ${ }^{114}$. Krutchkoff ${ }^{58}$ encontrou, também nos Estados Unidos (Connecticut), para o período de 1975 a 1986, o pico de incidência no grupo de 60 a 69 anos (32\%), sendo de 26 anos a idade do paciente mais jovem, e de 102 anos a do mais velho. Ainda para os Estados Unidos (Indiana), Summerlin ${ }^{122}$ encontrou, para o periodo de 1985 a 1990, um total de $95 \%$ dos casos ocorrendo a partir da quinta década. $\mathrm{Na}$ França, $73 \%$ dos casos são diagnosticados antes dos 65 anos, $45 \%$ antes dos 55 anos e somente $20 \%$ dos casos antes dos 50 anos ${ }^{99}$. Em Cuba, estudo de prevalência 
do câncer bucal registrou maior número de casos no grupo de 55 a 64 anos (28\%), seguindo-se o grupo de 65 anos ou mais (25\%) e vindo em terceiro lugar o grupo de 45 a 54 anos (22\%) ${ }^{117}$.

Sankaranarayanan et alii ${ }^{106}$ afirmam que o pico de incidência de câncer bucal na Índia é pelo menos uma década mais baixo do que o descrito na literatura ocidental. Nesse pais a idade média encontrada foi de cerca de 52 anos ${ }^{15}$, enquanto, nos países ocidentais, tem-se verificado idade média de cerca de 62 anos 25,99,114,122

\subsubsection{Mortalidade segundo a localização do tumor}

A tabela 2 apresenta a distribuição dos óbitos segundo a localização do tumor. A língua aparece como a localização mais frequente $(48,0 \%)$, seguida pelo assoalho $(9,0 \%)$, pelo palato (consideradas as três subcategorias) $(8,4 \%)$ e pelas glândulas salivares (7,5\%). A alta proporção de casos classificados como 145.9 "neoplasma maligno da boca, não especificada" (15,9\%), pode refletir dificuldade de diagnóstico, ou desconhecimento do correto preenchimento das declarações. Segundo Laurenti e Jorge ${ }^{63}$, o erro no preenchimento é devido, principalmente, a falta de programas de esclarecimento dos médicos, bem como a deficiências do ensino do assunto nas escolas médicas, decorrentes do desconhecimento da importância dessas informações para a saúde pública. 
TABELA 2. Distribuição dos óbitos por câncer de boca $\left(n^{\circ}\right.$ e \%), segundo localização do tumor. Estado de São Paulo, 1979-1982.

\begin{tabular}{llrr}
\hline & LOCALIZAÇÃO * $^{*}$ & $\mathrm{n}^{\circ}$ & $\%$ \\
\hline 140 & Lábio & 47 & 4,1 \\
141 & Lingua & 556 & 48,0 \\
142 & Glândulas salivares & 87 & 7,5 \\
143 & Gengiva & 43 & 3,7 \\
144 & Assoalho & 104 & 9,0 \\
145.0 & Mucosa da bochecha & 11 & 0,9 \\
145.1 & Vestíbulo da boca & 1 & 0,1 \\
145.2 & Palato duro & 11 & 0,9 \\
145.3 & Palato mole & 20 & 1,7 \\
145.4 & Úvula & 3 & 0,3 \\
145.5 & Palato, não especificado & 67 & 5,8 \\
145.6 & Área retromolar & 24 & 2,1 \\
145.9 & Boca, não especificada & 184 & 15,9 \\
\hline TOTAL & & 1158 & 100 \\
\hline
\end{tabular}

${ }^{*} \mathrm{CID}$ (9a revisåo)

\subsubsection{Mortalidade segundo a localização do tumor e o sexo}

Analisando-se separadamente os dois sexos, verifica-se que a língua foi a localização mais freqüente $(50,4 \%$ dos óbitos masculinos e $36,2 \%$ dos óbitos femininos). Para o sexo masculino, segue-se o assoalho $(9,9 \%)$, o palato $(7,2 \%)$ e as glândulas salivares $(6,2 \%)$; para o sexo feminino, segue-se o palato $(14,9 \%)$, as glândulas salivares $(13,8 \%)$ e a gengiva $(5,6 \%)$. Em ambos os sexos, a classificação "boca, não especificada" representa uma grande proporção dos óbitos (15,5\% no sexo masculino e $17,9 \%$ no sexo feminino).

Esses resultados podem ser observados na tabela 3, que mostra, ainda, que a proporção com que cada localização participa na mortalidade por câncer de boca difere bastante entre um sexo e outro. Assim, o lábio, as glândulas salivares maiores, a gengiva, o palato em suas diferentes sublocalizações, bem como a "boca, não especificada", estão mais representados na mortalidade das mulheres do que na dos homens; por outro lado, a língua, o assoalho da boca e a área retromolar, estão 
mais representados na mortalidade dos homens do que na das mulheres; a mucosa da bochecha, o vestíbulo da boca e a úvula são as localizações que têm, praticamente, a mesma participação na mortalidade, nos dois sexos.

TABELA 3. Distribuição de óbitos por câncer de boca (ne \%), segundo localização do tumor e sexo. Estado de São Paulo, 1979-1982

\begin{tabular}{llrrrr}
\hline & & \multicolumn{4}{c}{ SEXO } \\
\cline { 3 - 6 } & LOCALIZAÇÃO * & \multicolumn{2}{c}{$\mathrm{n}^{\circ}$} & $\%$ & \multicolumn{2}{c}{ FEMININO } & $\mathrm{n}^{\circ}$ \\
\hline 140 & Lábio & 37 & 3,9 & 10 & 5,1 \\
141 & Lingua & 485 & 50,4 & 71 & 36,2 \\
142 & Glândulas salivares & 60 & 6,2 & 27 & 13,8 \\
143 & Gengiva & 32 & 3,3 & 11 & 5,6 \\
144 & Assoalho & 95 & 9,9 & 9 & 4,6 \\
145.0 & Mucosa da bochecha & 9 & 0,9 & 2 & 1,0 \\
145.1 & Vestibulo da boca & 1 & 0,1 & - & - \\
145.2 & Palato duro & 3 & 0,3 & 8 & 4,1 \\
145.3 & Palato mole & 15 & 1,6 & 5 & 2,6 \\
145.4 & Úvula & 3 & 0,3 & - & - \\
145.5 & Palato, não especificado & 51 & 5,3 & 16 & 8,2 \\
145.6 & Área retromolar & 22 & 2,3 & 2 & 1,0 \\
145.9 & Boca, não especificada & 149 & 15,5 & 35 & 17,9 \\
\hline TOTAL & & 962 & 100 & 196 & 100 \\
\hline
\end{tabular}

${ }^{\star} \operatorname{CID}\left(9^{\mathrm{a}}\right.$ revisåa)

No Municipio de São Paulo, para o período de 1969 a 1971104, os maiores valores de mortalidade foram encontrados, para o sexo masculino, nos tumores de língua, de outras partes e partes não especificadas da boca, e do assoalho, e, para o sexo feminino, nos tumores de língua, de outras partes e partes não especificadas da boca, e de gengiva, devendo-se observar que esse estudo não considerou a localização glândulas salivares. O trabalho refere dados da American Cancer Society que apontam, nos Estados Unidos, em 1967, a morte por câncer de língua como responsável por $49,0 \%$ dos óbitos por câncer de boca, nos homens, e por $47,2 \%$, nas mulheres. 
No estudo da incidência do câncer de boca também se encontra variação por sexo na localização do tumor ${ }^{99}$. Krutchkoff ${ }^{58}$ encontrou, nos Estados Unidos, uma razão maior homens/mulheres para o câncer da área retromolar e do assoalho da boca, sugerindo sua ligação com o uso do charuto e do cachimbo; na população masculina, o assoalho da boca representou $36,5 \%$ dos casos de câncer bucal e a língua representou $28,4 \%$; na população feminina, a língua representou $32,6 \%$ dos casos e o assoalho da boca representou $25,7 \%$; a terceira e a quarta localizações, nos dois sexos, foram a área gengival e a área retromolar, respectivamente. Estudo feito em Liverpool 119 indica o assoalho da boca como a localização mais comum nos homens.

No Brasil, levantamento de dados histopatológicos referente ao Estado de São Paulo, para o periodo de 1981 a $1985^{82}$ registra: no sexo masculino, a língua na primeira posição $(30,6 \%)$, seguida do lábio $(27,1 \%)$ e do assoalho da boca $(10,4 \%)$; no sexo feminino, o lábio na primeira posição $(24,8 \%)$, seguido da língua $(23,6 \%)$ e das glândulas salivares $(13,8 \%)$.

Para comparação das forças de mortalidade de cada uma das localizações entre um sexo e outro, foram calculados os coeficientes de mortalidade especificos para as principais localizações e para cada sexo (figura 1).

Observa-se que, para todas as localizações, o coeficiente masculino é maior que o feminino. Os coeficientes masculinos e femininos, por localização, foram, respectivamente: 0,10 por 100.000 homens e 0,03 por 100.000 mulheres, para lábio; 1,29 por 100.000 homens e 0,19 por 100.000 mulheres, para língua; 0,16 por 100.000 homens e 0,07 por 100.000 mulheres, para glândulas salivares; 0,09 por 100.000 homens e 0,03 por 100.000 mulheres, para gengiva; 0,25 por 100.000 homens e 0,02 por 100.000 mulheres, para assoalho da boca; e 0,18 por 100.000 homens e 0,08 por 100.000 mulheres, para palato. 
FIG.1 - MORTALIDADE POR CÂNCER DE BOCA, SEGUNDO SEXO E LOCALIZACAẢO DO TUMOR. ESTADO DE SẢO PAULO, 1979 - 1982.

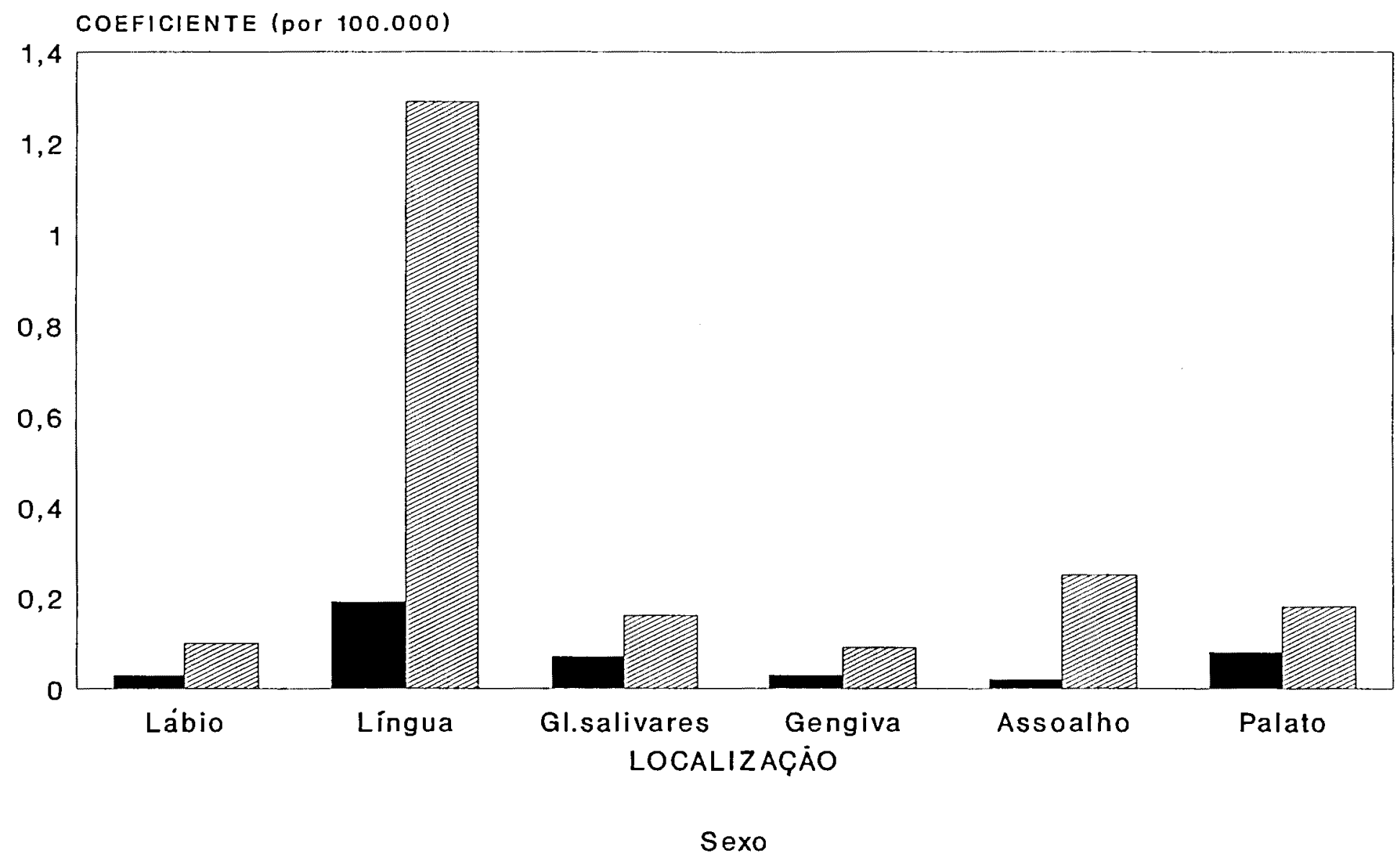

Feminino Masculino 
Para o Município de São Paulo, no periodo de 1969 a $1971^{104}$, os maiores coeficientes foram obtidos, no sexo masculino, para o câncer de língua $(1,33$ por 100.000 homens), o de outras partes e partes não especificadas da boca $(0,78$ por 100.000 homens) e o do assoalho da boca (0,61 por 100.000 homens), e, no sexo feminino, para o câncer de língua (0,13 por 100.000 mulheres), o de outras partes e partes não especificadas da boca $(0,11$ por 100.000 mulheres) e o de gengiva $(0,07$ por 100.000 mulheres). Deve-se lembrar que nesse trabalho não foram considerados os óbitos por câncer de glândulas salivares.

A maior razão entre os sexos masculino e feminino foi obtida para a localização assoalho da boca $(12,50: 1)$ e a menor foi obtida para a localização palato $(2,25$ : 1). No Município de São Paulo, no periodo de 1969 a 1971 104, a maior razão homens/mulheres também foi para a localização assoalho da boca $(20,30: 1)$; a menor razão obtida, que foi para a gengiva, coincide com a obtida neste trabalho para a mesma localização: $2,90: 1$.

Quanto à incidência, esse mesmo estudo feito para o Município de São Paulo ${ }^{104}$ aponta como localizações de maiores valores de coeficientes, tanto no sexo masculino como no feminino, o lábio (3,46 por 100.00 homens e 0,81 por 100.000 mulheres) e a lingua ( 3,00 por 100.000 homens e 0,51 por 100.000 mulheres).

\subsubsection{Mortalidade segundo a localização do tumor e a idade}

Verifica-se que, para a população total e para a população masculina, a mortalidade por câncer de língua é superior à mortalidade por câncer das demais localizações, em todos os grupos etários em que ocorre, sendo que essa superioridade vai se acentuando nos grupos etários mais avançados.

Para a população total (figura 2), a partir do grupo etário de 30 a 39 anos até o grupo de 50 a 59 anos, a segunda e a terceira posição são ocupadas, respectivamente, pelo assoalho e pelo palato. A partir do grupo de 60 a 69 anos, o palato se coloca em segundo lugar e o terceiro lugar passa a ser ocupado pelas glândulas salivares. 
FIG.2 - MORTALIDADE POR CÂNCER DE BOCA, SEGUNDO LOCALIZAÇĀO DO TUMOR E IDADE . ESTADO DE SẢO PAULO, 1979-1982 .

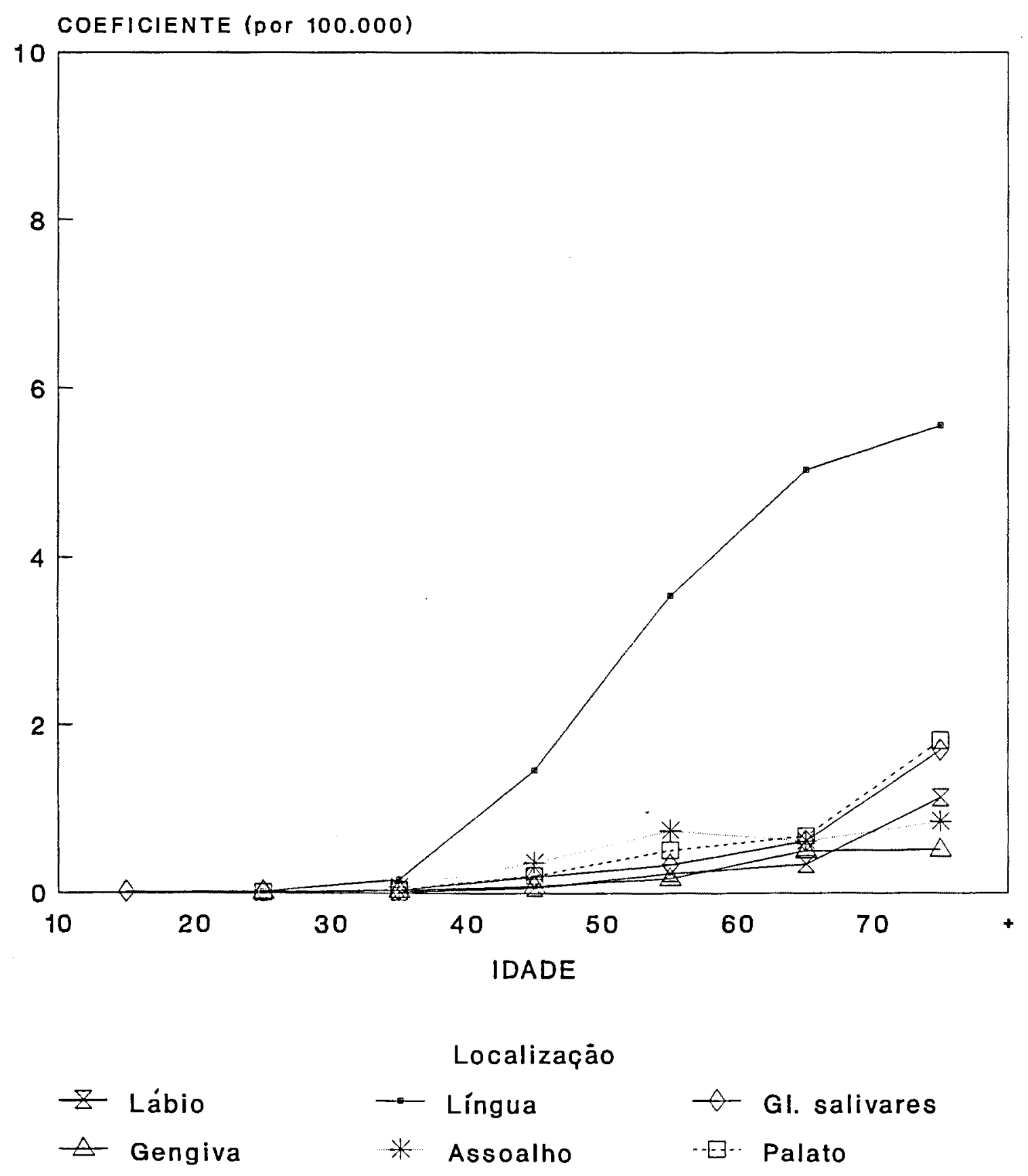


Para a população masculina (figura 3), o assoalho e o palato ocupam a segunda e a terceira posição, respectivamente, dos 30 aos 70 anos. No grupo de 70 anos e mais a segunda posição passa a ser ocupada pelas glândulas salivares e a terceira pelo palato. Para o grupo de 20 a 29 anos, que representa apenas $0,5 \%$ de todos os óbitos por câncer de boca do sexo masculino, ocorreram apenas óbitos por câncer das localizações glândulas salivares (dois casos), língua e gengiva (um caso de cada uma).

Em relação à população feminina (figura 4) verifica-se que, a partir do grupo de 40 a 49 anos, a língua apresenta os maiores valores de coeficientes de mortalidade. Nos grupos etários abaixo dos 40 anos não ocorrem óbitos por câncer de lábio, de gengiva e de assoalho, e só a partir do grupo de 50 a 59 anos ocorrem óbitos por câncer de gengiva. Abaixo desse grupo etário, todas as localizações apresentam valores muito baixos de coeficientes. No grupo de 50 a 59 anos, nas duas posições imediatamente abaixo da língua situam-se, pela ordem, as glândulas salivares e o assoalho. A partir do grupo de 60 a 69 anos, o palato ocupa a segunda posição, e as glândulas salivares a terceira. No grupo de 10 a 19 anos, só no sexo feminino se verificam óbitos (dois casos), sendo as glândulas salivares a única localização responsável pela mortalidade por câncer de boca. A ocorrência de mortalidade por câncer de glândulas salivares já nesse grupo etário requer estudos ligados à etiologia dessa neoplasia. Observe-se que, segundo Horn-Ross ${ }^{52}$, as causas do câncer de glândulas salivares são relativamente desconhecidas, havendo poucas pesquisas sobre o assunto, e tendo sido estabelecidos como fatores de risco apenas a exposição a radiação (que responde por $10 \%$ a $30 \%$ dos casos) e a história de um câncer precedente. 
FIG.3 - MORTALIDADE POR CÂNCER DE BOCA , SEGUNDO LOCALIZAÇĀO DO TUMOR E IDADE SEXO MASCULINO. EST.SÄO PAULO,1979-1982.

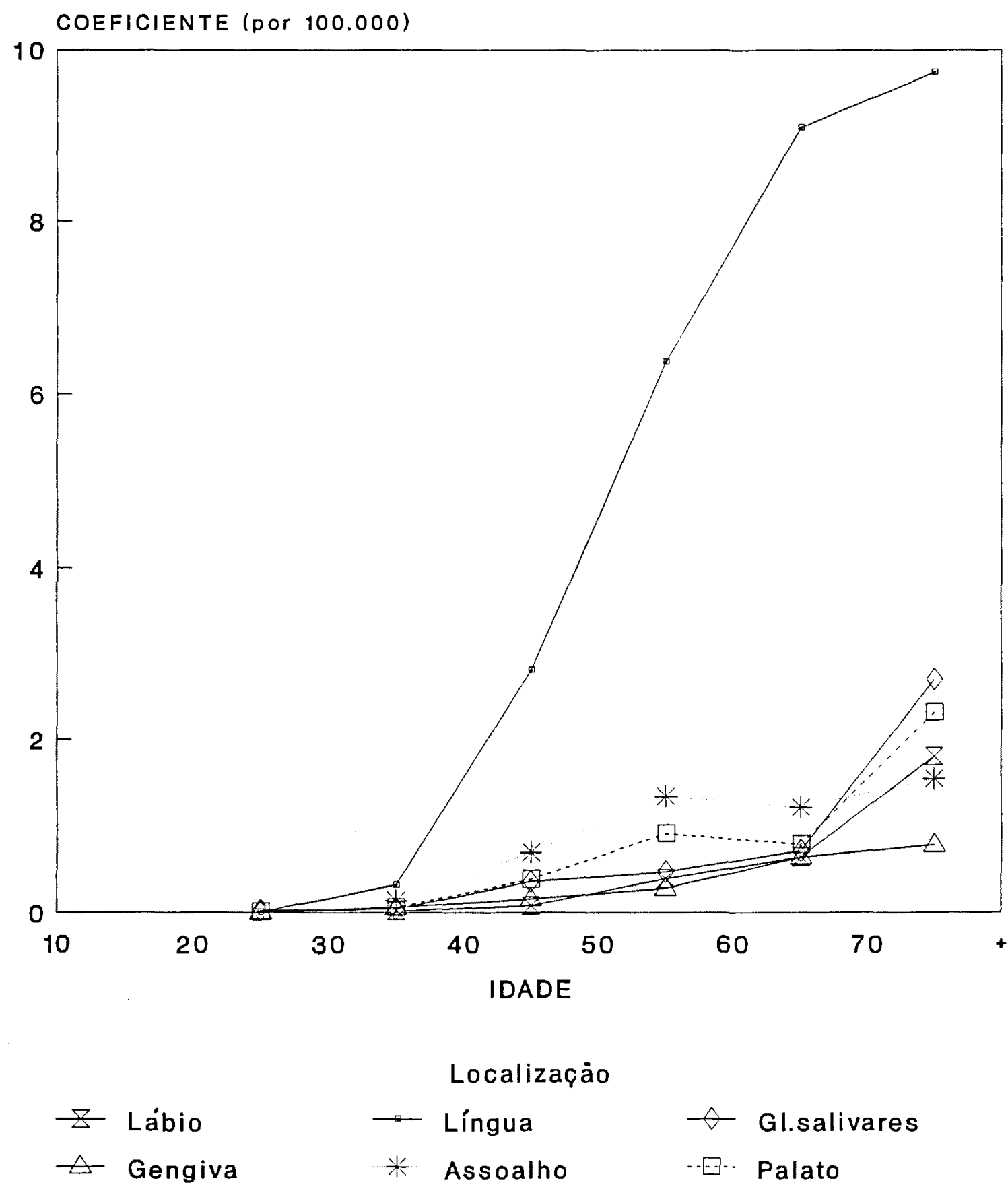


FIG.4 - MORTALIDADE POR CÂNCER DE BOCA, SEGUNDO LOCALIZAÇẢO DO TUMOR E IDADE SEXO FEMININO. EST.SẢO PAULO, 1979-1982.

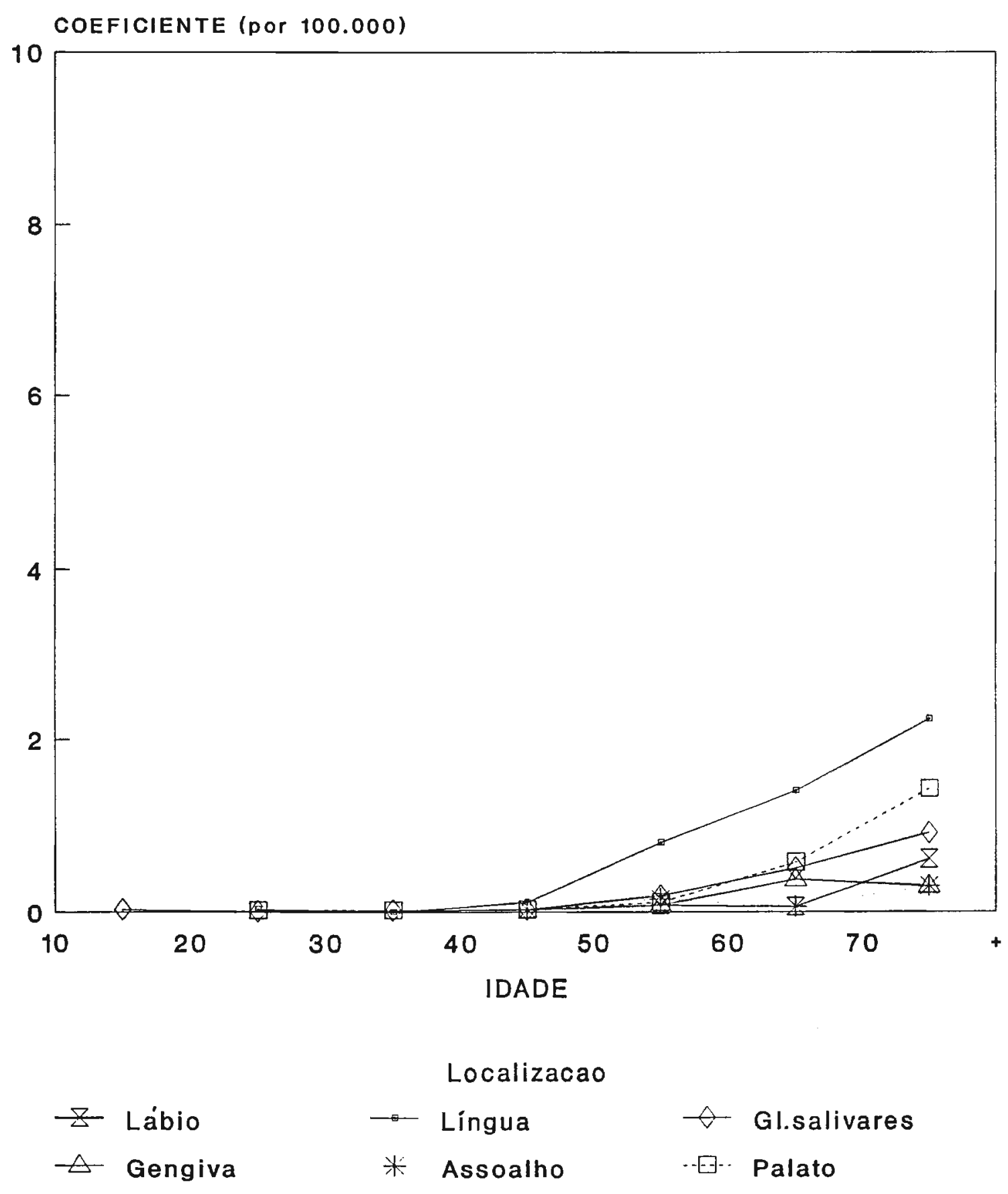


Quanto à incidência, pesquisa feita nos Estados Unidos, referente ao periodo de 1975 a $1986{ }^{58}$, encontrou a idade média mais baixa para o carcinoma gengival (58,5 anos) e a mais alta para o carcinoma da mucosa bucal (69,7 anos). Outra pesquisa realizada nos Estados Unidos, referente ao periodo de 1973-1990, aponta a idade média de incidência de 60 anos para a língua, 62 para 0 assoalho da boca, e 65 para os lábios ${ }^{131}$. Pesquisa feita no Brasil ${ }^{101}$ aponta o grupo de 61 a 70 anos como o mais atingido pelas lesões de língua, assoalho da boca, rebordo gengival, palato mole e palato duro; para a região retromolar o grupo etário mais atingido foi o de 51 a 60 anos e, para os lábios, foi o de 71 a 80 anos. Stell ${ }^{119}$ afirma que há uma ligação entre a idade e a localização do tumor; em sua pesquisa, realizada em Liverpool, os tumores da parte superior da boca foram mais freqüentes em pacientes com idade superior a 70 anos, enquanto que todos os outros tumores foram mais comuns entre as idades de 60 e 70 anos.

\subsection{Resultados obtidos segundo as Regiões Administrativas}

\subsubsection{Coeficientes gerais de mortalidade}

Os coeficientes gerais de mortalidade por câncer de boca, brutos e padronizados, tomando-se como padrão a população do Estado de São Paulo, para cada uma da Regiões, encontram-se na tabela 4.

TABELA 4. Coeficientes de mortalidade por câncer de boca (por 100.000), brutos e padronizados, segundo as Regiões Administrativas de residência. Estado de São Paulo, 1979 a 1982.

\begin{tabular}{llcc}
\hline & REGIÃO & COEF. BRUTO & COEF. PADRON. \\
\hline $01 a$ & Municipio de São Paulo & 1,71 & 1,66 \\
$01 \mathrm{~b}$ & Grande São Paulo & 1,16 & 1,50 \\
02 & Litoral & 2,28 & 2,16 \\
03 & Vale do Paraíba & 1,65 & 1,83 \\
04 & Sorocaba & 1,24 & 1,22 \\
05 & Campinas & 1,53 & 1,45 \\
06 & Ribeirão Preto & 1,60 & 1,46 \\
07 & Bauru & 1,85 & 1,60 \\
08 & São José do Rio Preto & 1,93 & 1,73 \\
09 & Araçatuba & 0,57 & 0,55 \\
10 & Presidente Prudente & 1,01 & 0,95 \\
11 & Marília & 1,24 & 1,11 \\
\hline
\end{tabular}


Para facilitar a comparação entre as Regiões, apresenta-se a figura 5, que mostra a distribuição dos coeficientes padronizados.

Esse agrupamento dos coeficientes por intervalos de classe permite verificar que as diversas Regiões Administrativas, em termos de localização geográfica dentro do Estado, se agrupam em blocos maiores, para os quais se pode indicar comportamento semelhante, com uma aparente gradação geográfica. Assim, a primeira e a segunda classes de maiores coeficientes de mortalidade por câncer de boca se referem ao Litoral e ao Vale do Paraíba, respectivamente, que se localizam no Sul e no Sudeste do Estado. Por outro lado, Araçatuba, que se situa na classe de menores coeficientes, e Presidente Prudente e Marilia, que se situam na segunda classe de menores coeficientes, formam um bloco, no Oeste do Estado.

$\mathrm{Na}$ terceira classe de maiores coeficientes se agrupam seis Regiões: pela ordem, São José do Rio Preto, Município de São Paulo, Bauru, Grande São Paulo, Ribeirão Preto e Campinas. Essas Regiões formam um bloco que se estende de Noroeste a Oeste. Ao sul desse bloco, no Sudoeste do Estado, se localiza a Região de Sorocaba, que está na quarta classe de maiores coeficientes.

Em 1972 Guedes ${ }^{47}$ apresentou uma hierarquização das Regiões Administrativas do Estado de São Paulo baseada nos indicadores de saúde, saneamento, educação, economia e situação demográfica. Comparando-se os resultados aqui obtidos com essa hierarquização, verifica-se que a Região que apresenta os maiores coeficientes de mortalidade por câncer de boca (Litoral) é exatamente a que tem as melhores notas na hierarquização de Guedes ${ }^{47}$, além de ser a segunda classificada, no mesmo trabalho, quando se avaliam apenas os indicadores econômicos, o que contraria a literatura revisada. Do mesmo modo, as quatro Regiões que apresentam as mais baixas taxas de mortalidade por câncer de boca (Araçatuba, Marilia, Presidente Prudente e Sorocaba) aparecem em Guedes ${ }^{47}$ entre as de mais baixa renda do Estado, além de se colocarem nas últimas posições na hierarquização geral. Guedes ${ }^{47}$ se refere, explicitamente, às Regiões do Oeste do Estado, e também a Sorocaba, como Regiões que se encontram em situação de inferioridade, com notas baixas para quase todos os indicadores. 


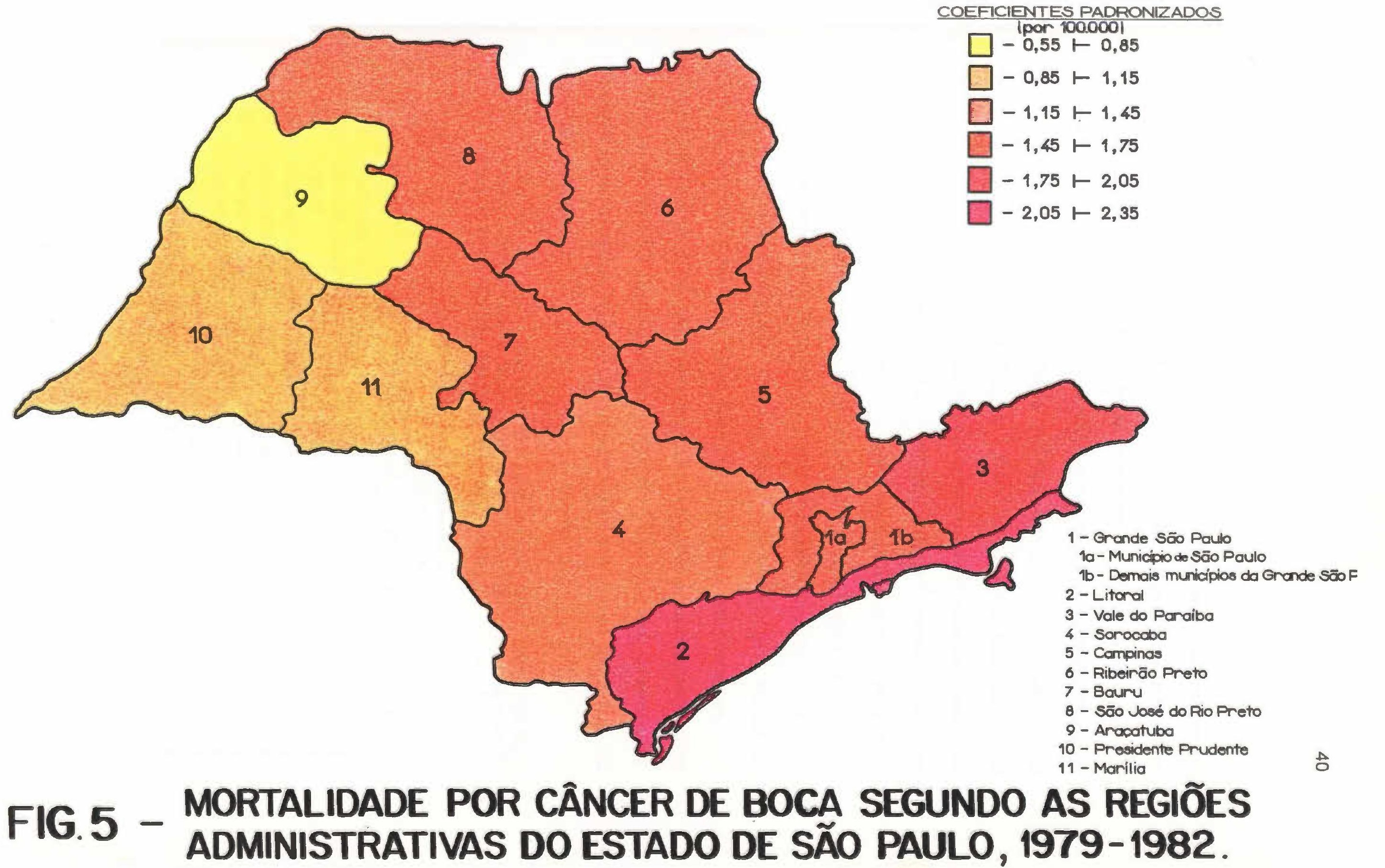




\subsubsection{Coeficientes de mortalidade específicos por sexo.}

A tabela 5 traz, para cada Região, os coeficientes de mortalidade, padronizados por idade, específicos para cada sexo e a razão masculino/feminino. Para o sexo masculino, o menor coeficiente foi encontrado na Região de Araçatuba $(0,72$ por 100.000 homens) e, para o sexo feminino, na Região de Presidente Prudente $(0,10$ por 100.000 mulheres). Os maiores coeficientes para o sexo masculino foram observados nas Regiões do Litoral (3,40 por 100.000 homens) e de São José do Rio Preto $(3,19$ por 100.000 homens) e, para o sexo feminino, nas Regiões do Litoral $(0,98$ por 100.000 mulheres) e de Bauru (0,60 por 100.000 mulheres). A maioria das Regiões apresentou, em média, uma razão entre os sexos masculino e feminino de 4,96:1 enquanto que valores discrepantes foram encontrados para a Região de Araçatuba $(1,89: 1)$, de São José do Rio Preto $(13,87: 1)$ e de Presidente Prudente $(18,10: 1)$.

A mais baixa razão entre os sexos, apresentada pela Região de Araçatuba, é determinada pela baixa taxa de mortalidade observada no sexo masculino nessa Região. As altas razões entre os sexos, apresentadas pelas Regiões de São José do Rio Preto e de Presidente Prudente, são determinadas, respectivamente, pela alta taxa de mortalidade masculina e pela baixa taxa de mortalidade feminina.

TABELA 5. Coeficientes de mortalidade por câncer de boca (por 100.000), padronizados por idade, segundo sexo e Região de residência, e razão entre os sexos. Estado de São Paulo, $1979-1982$.

\begin{tabular}{llccr}
\hline & & \multicolumn{2}{c}{ SEXO } \\
\cline { 3 - 4 } & REGIÃo & MASCULINO & FEMININO & M/F \\
\hline 01a & Município de São Paulo & 3,04 & 0,50 & $6,08: 1$ \\
01b & Grande São Paulo & 2,57 & 0,48 & $5,35: 1$ \\
02 & Litoral & 3,40 & 0,98 & $3,47: 1$ \\
03 & Vale do Paraíba & 3,17 & 0,54 & $5,87: 1$ \\
04 & Sorocaba & 2,08 & 0,34 & $6,12: 1$ \\
05 & Campinas & 2,44 & 0,49 & $4,98: 1$ \\
06 & Ribeirão Preto & 2,48 & 0,49 & $5,06: 1$ \\
07 & Bauru & 2,60 & 0,60 & $4,33: 1$ \\
08 & São Josė do Rio Preto & 3,19 & 0,23 & $13,87: 1$ \\
09 & Araçatuba & 0,72 & 0,38 & $1,89: 1$ \\
10 & Presidente Prudente & 1,81 & 0,10 & $18,10: 1$ \\
11 & Marilia & 1,70 & 0,50 & $3,40: 1$ \\
\hline
\end{tabular}




\subsubsection{Coeficientes de mortalidade especificos por idade}

$\mathrm{Na}$ tabela 6, encontram-se os coeficientes de mortalidade por grupo etário, para cada uma das Regiões Administrativas.

Os maiores valores de coeficientes sāo encontrados, em geral, no grupo etário de 70 anos e mais, constituindo exceção a Região da Grande São Paulo, na qual é o grupo etário de 60 a 69 anos que apresenta o maior coeficiente de mortalidade .

Para a maioria das Regiōes, a mortalidade cresce com o avanço da idade. Entretanto, na Região da Grande São Paulo, a mortalidade decresce no grupo de 70 anos e mais, enquanto que, na Região de Presidente Prudente, o coeficiente diminui no grupo de 60 a 69 anos e, na Região de Marilia, no grupo de 50 a 59 anos, voltando novamente a crescer, nestas duas últimas Regiões, nos grupos etários subseqüentes.

O grupo etário em que se inicia a ocorrência de óbitos por câncer de boca varia entre as Regiões em estudo. Apenas as Regiões da Grande São Paulo e de Ribeirão Preto já registram casos de óbito no grupo de 10 a 19 anos. No grupo de 20 a 29 anos aparecem os primeiros casos de óbito nas Regiões do Município de São Paulo, Litoral, Sorocaba e Campinas, e, no grupo de 30 a 39 anos, nas Regiões do Vale do Paraíba, Bauru, São José do Rio Preto e Marília. Nas Regiões de Araçatuba e Presidente Prudente, a mortalidade só é observada a partir dos 40 anos. Embora a maioria das Regiões já apresente mortalidade antes dessa idade, é importante ressaltar que os coeficientes encontrados nesses grupos etários mais jovens têm valor bastante baixo. 
TABELA 6. Coeficientes de mortalidade por câncer de boca (por 100.000), segundo idade e Regiāo de residência. Estado de São Paulo, 1979-1982.

\begin{tabular}{|c|c|c|c|c|c|c|c|c|c|c|c|c|}
\hline \multirow{3}{*}{$\begin{array}{l}\text { GRUPO } \\
\text { ETÁRIO }\end{array}$} & \multicolumn{12}{|c|}{ REGIÃO DE RESIDÊNCIA } \\
\hline & & & & & & & & & & & & \\
\hline & $01 a$ & $01 \mathrm{~b}$ & 02 & 03 & 04 & 05 & 06 & 07 & 08 & 09 & 10 & 11 \\
\hline $10+20$ & - & 0,04 & - & - & - & - & 0,08 & - & - & - & - & - \\
\hline $20+30$ & 0,04 & 0,04 & 0,04 & - & 0,13 & 0,11 & 0,29 & - & - & - & - & - \\
\hline $30+40$ & 0,33 & 0,29 & 0,82 & 0,23 & 0,94 & 0,64 & 0,59 & 0,43 & 0,26 & - & * & 0,40 \\
\hline $40+50$ & 3,20 & 2,56 & 5,18 & 2,42 & 1,93 & 2,24 & 2,62 & 2,01 & 4,18 & 0,65 & 0,49 & 2.94 \\
\hline $50+60$ & 8,68 & 5,53 & 7,14 & 8,34 & 6,17 & 5,80 & 4,13 & 7,87 & 7,31 & 2,83 & 6,42 & 1,33 \\
\hline $60+70$ & 9,36 & 13,25 & 5,89 & 12,90 & 6,24 & 7,47 & 9,18 & 12,49 & 8,87 & 4,53 & 2,48 & 7,31 \\
\hline $70 \mathrm{e}+$ & 13,98 & 12,22 & 16,83 & 20,54 & 8,80 & 18,38 & 17,16 & 13,20 & 18,53 & 4,82 & 15,40 & 16,33 \\
\hline
\end{tabular}

Quanto aos coeficientes de mortalidade por câncer de boca em função da idade e do sexo, em cada uma das Regiões Administrativas, obtiveram-se os resultados que se apresentam nas figuras 6 a 17 . 
FIG.6 - MORTALIDADE POR CÂNCER DE BOCA, SEGUNDO SEXO E IDADE . MUNICIPIO DE SĀO PAULO, 1979-1982.

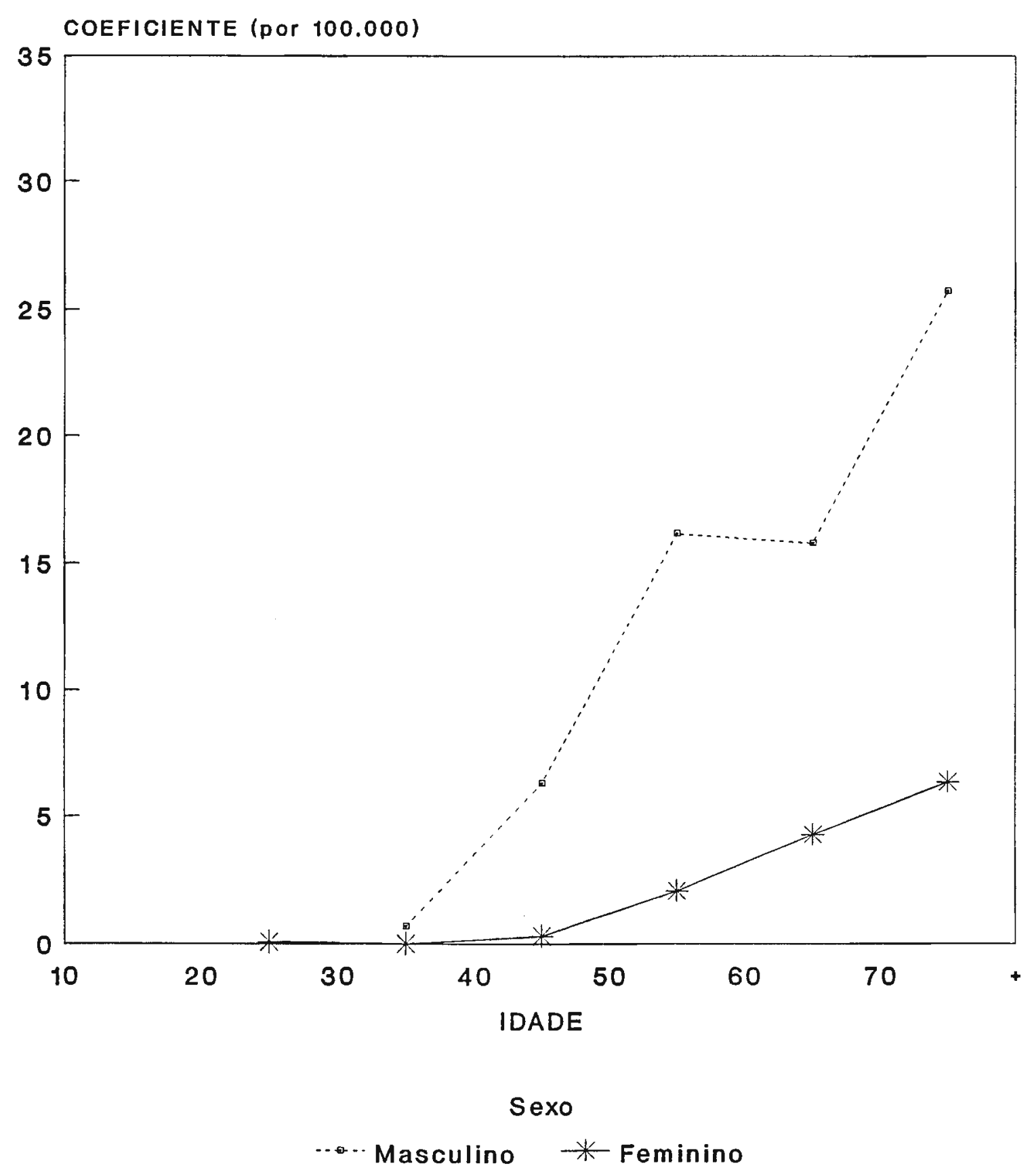


FIG.7 - MORTALIDADE POR CÂNCER DE BOCA SEGUNDO SEXO E IDADE . REGIÄO DA GRANDE SẢO PAULO, 1979-1982 .

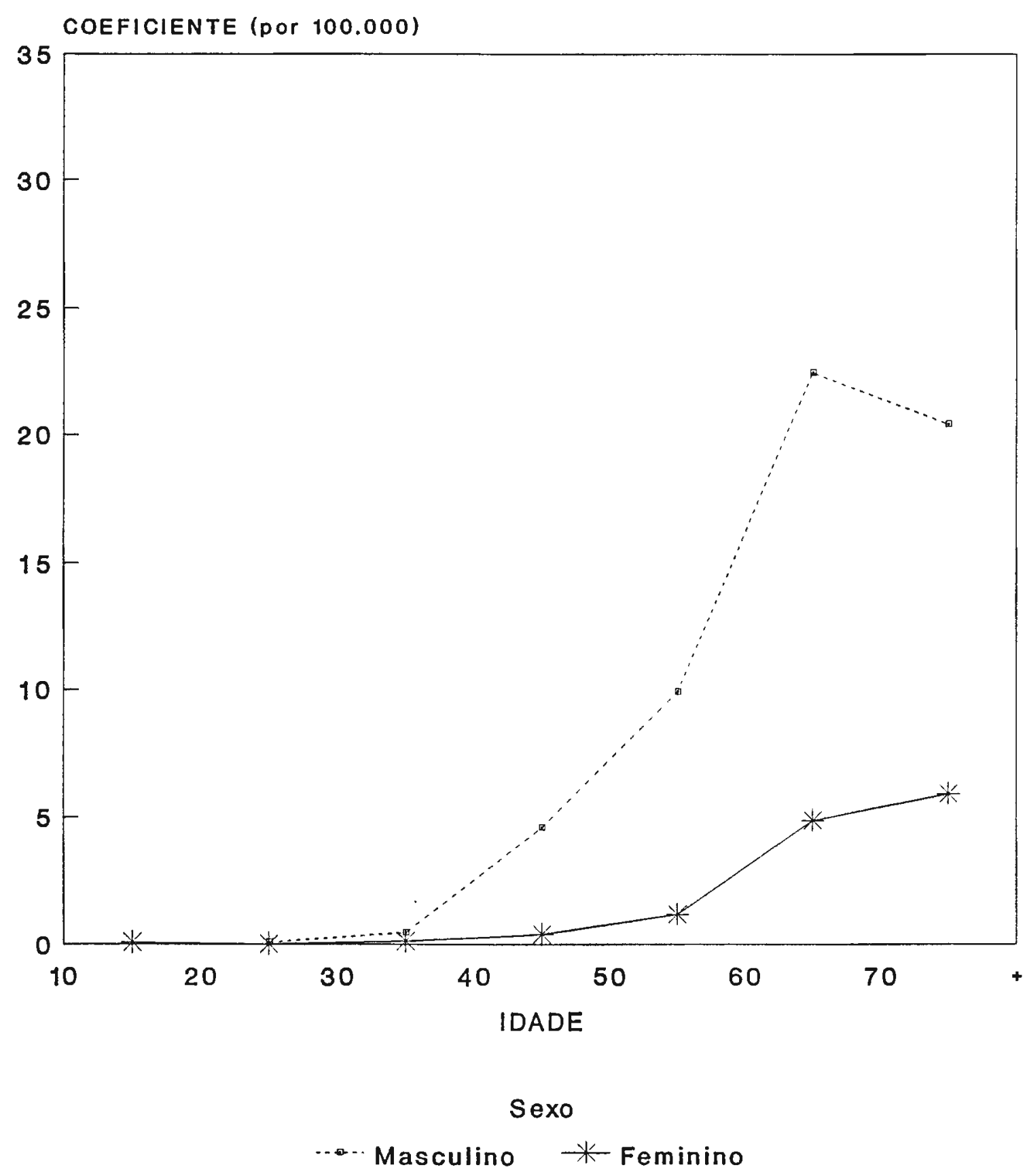


FIG.8 - MORTALIDADE POR CÂNCER DE BOCA, SEGUNDO SEXO E IDADE. REGIÄO DO LITORAL, $1979-1982$.

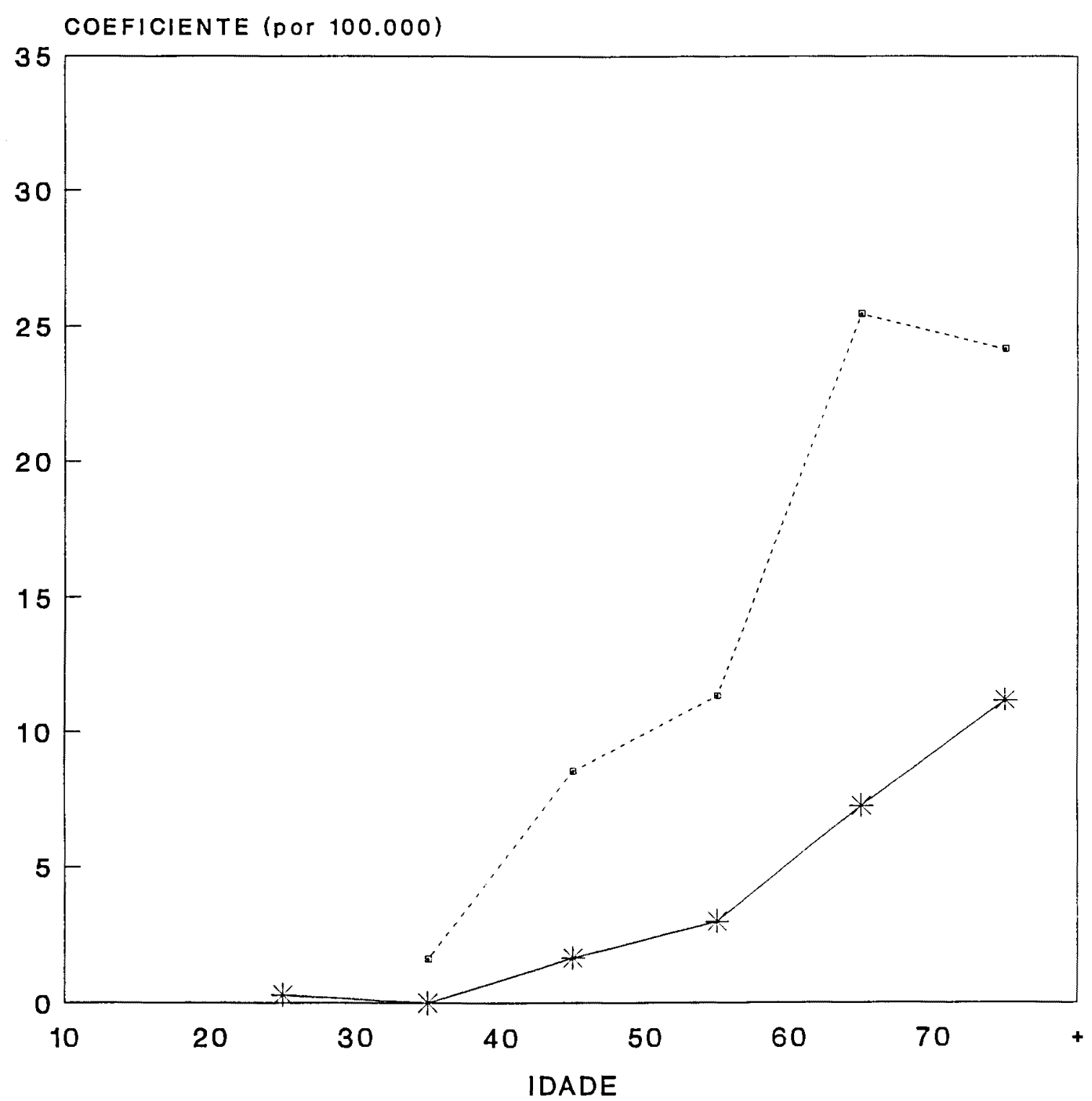

Sexo

.... Masculino $\quad$ feminino 
FIG.9 - MORTALIDADE POR CÂNCER DE BOCA, SEGUNDO SEXO E IDADE . REGIẢO DO VALE DO PARAIBA, 1979-1982.

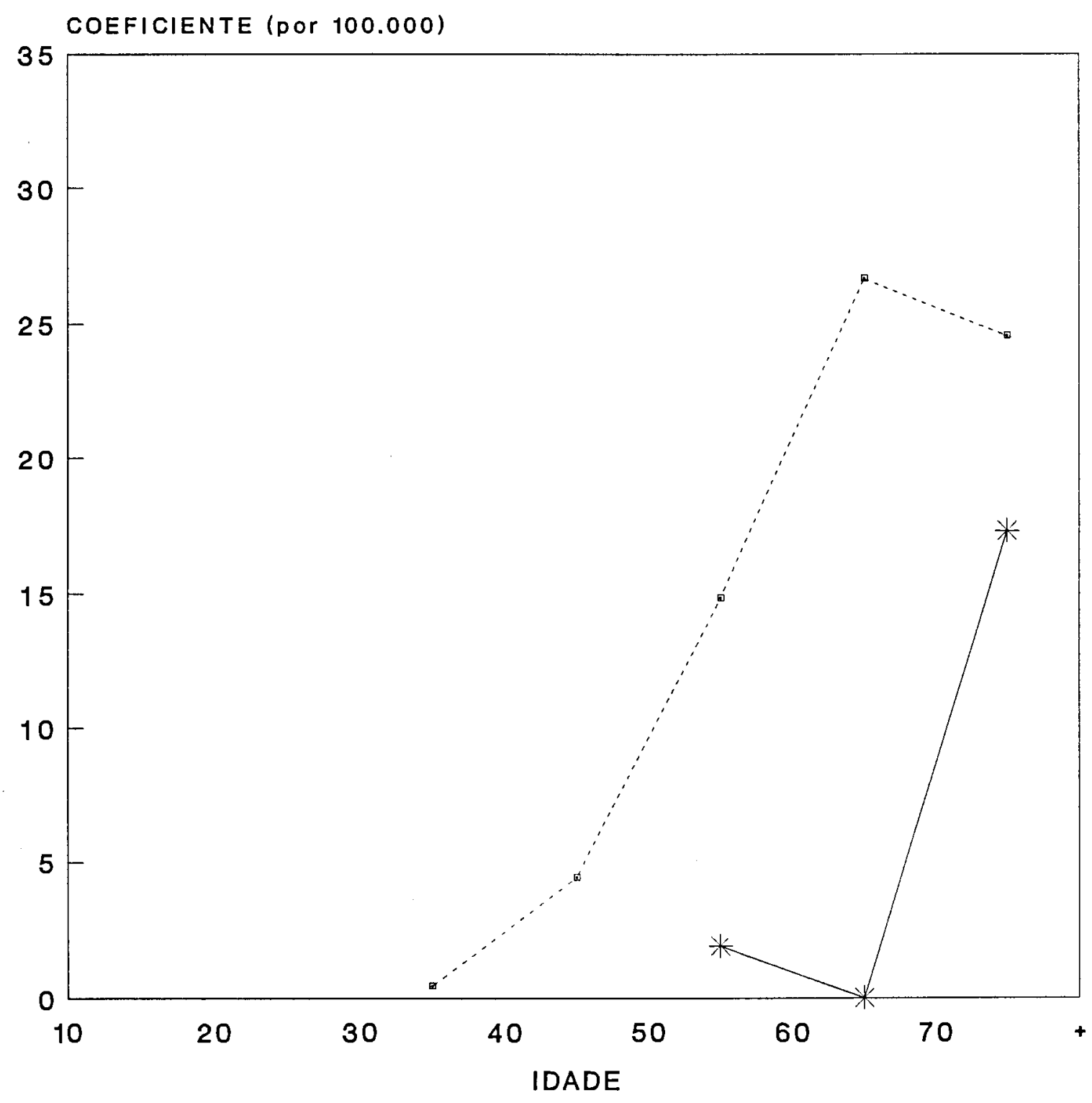

Sexo

.... Masculino * Feminino 
FIG.10 - MORTALIDADE POR CÂNCER DE BOCA, SEGUNDO SEXO E IDADE. REGIẢO DE SOROCABA 1979 - 1982 .

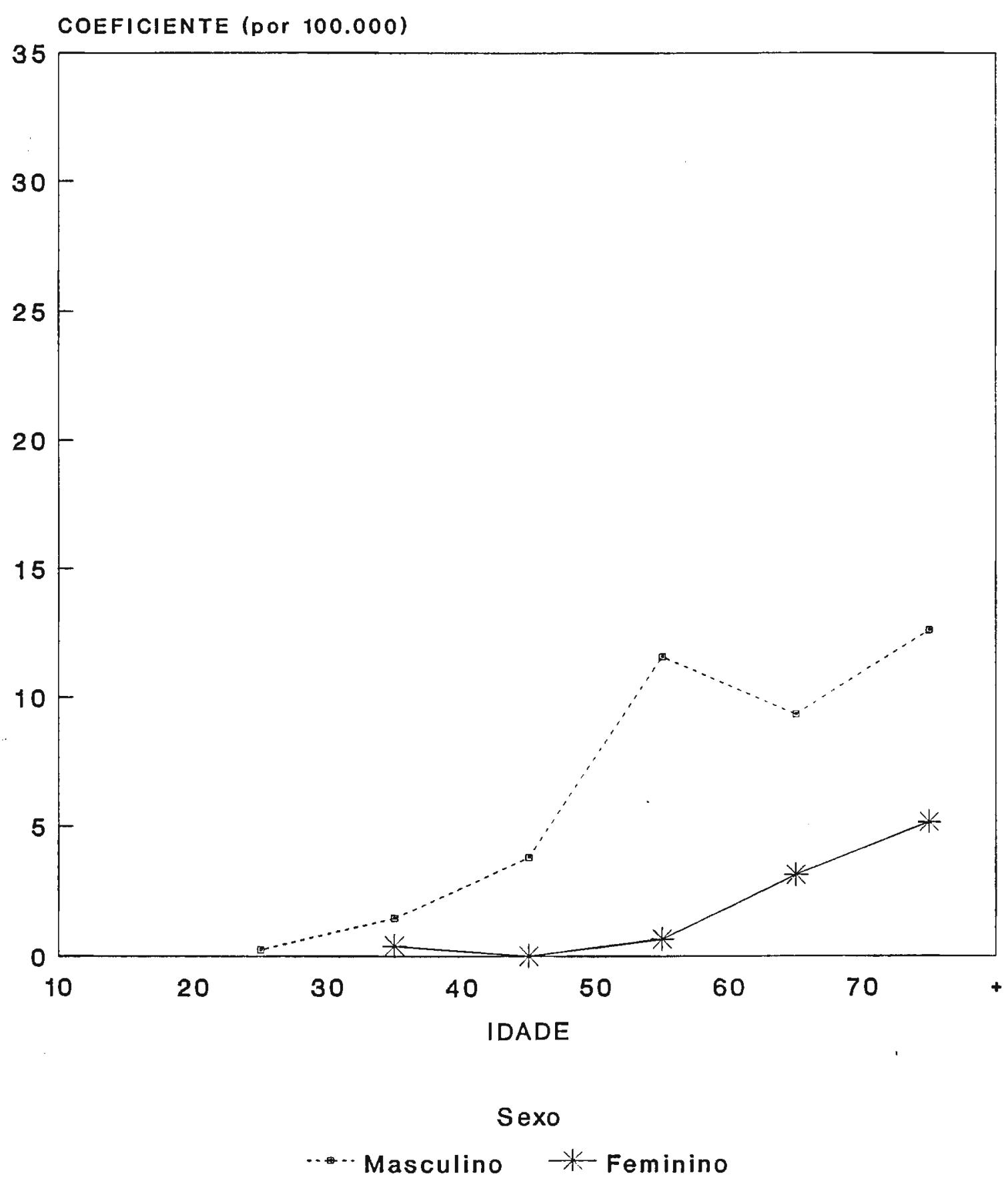


FIG.11 - MORTALIDADE POR CÂNCER DE BOCA, SEGUNDO SEXO E IDADE. REGIẢO DE CAMPINAS $1979-1982$.

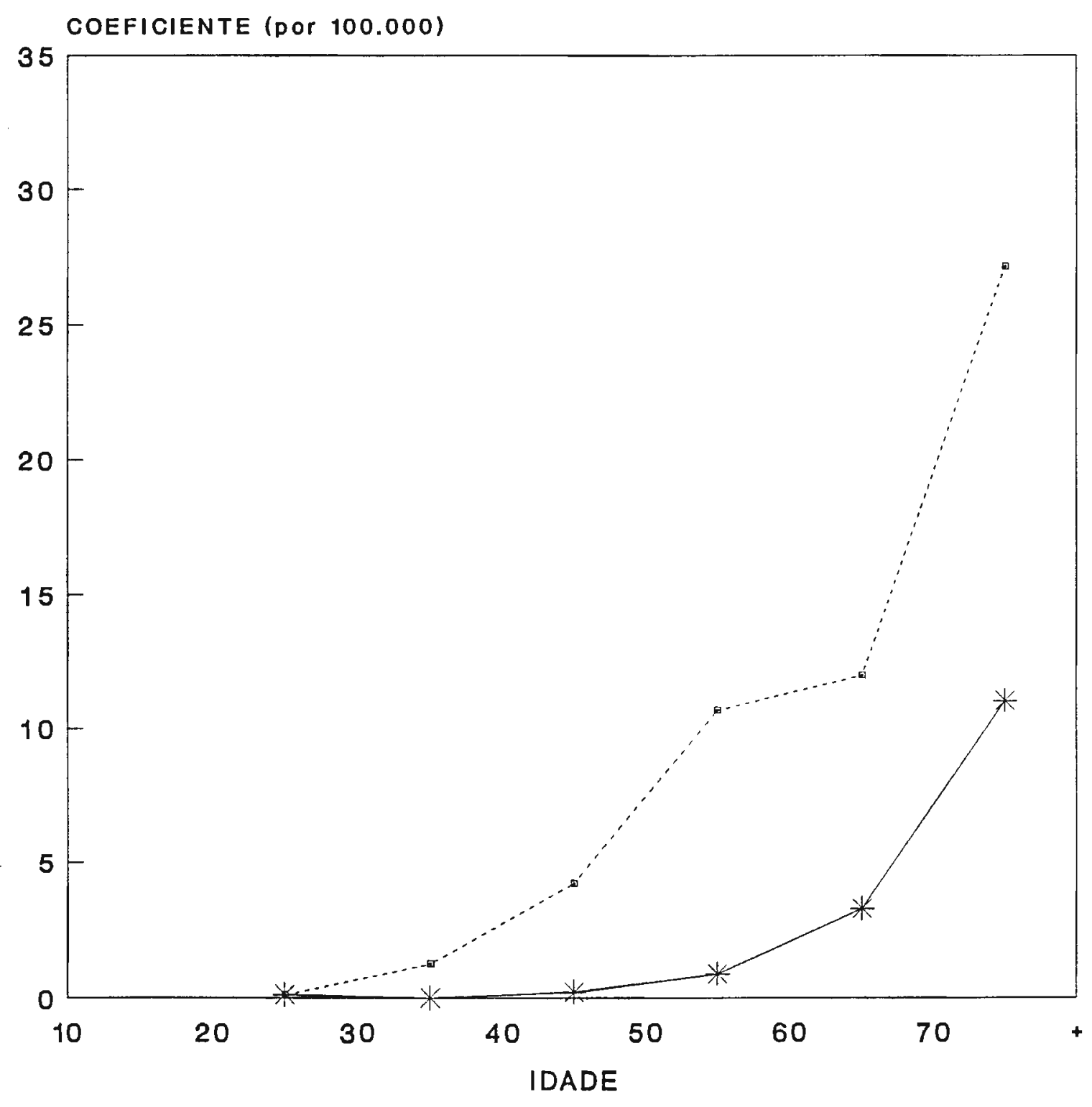

Sexo

Masculino * Feminino 
FIG.12 - MORTALIDADE POR CÂNCER DE BOCA, SEGUNDO SEXO E IDADE. REGIẢO DE RIBEIRẢO PRETO, 1979-1982.

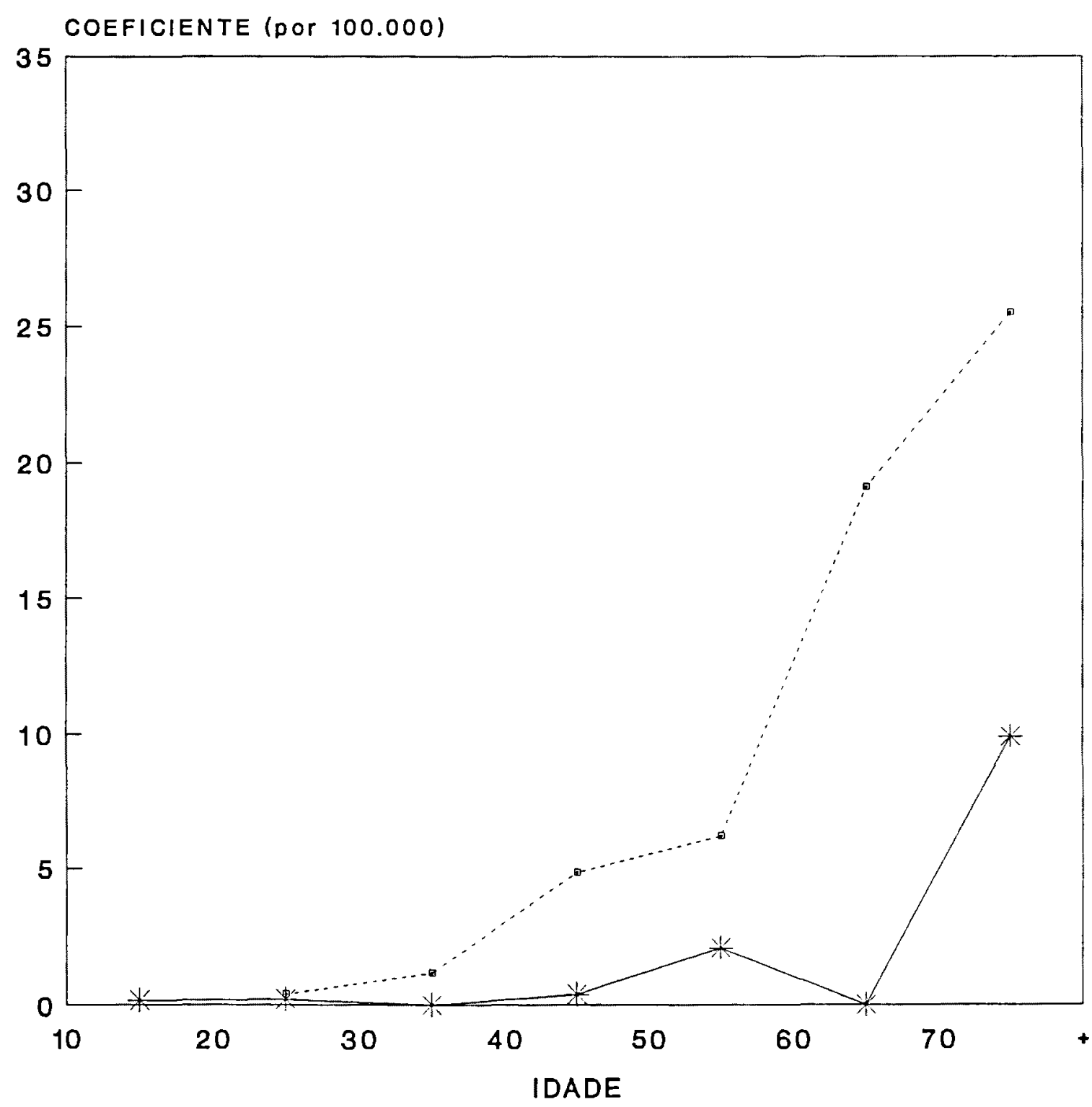

Sexo

-... Masculino $\quad$ - Feminino 
FIG.13 - MORTALIDADE POR CÂNCER DE BOCA, SEGUNDO SEXO E IDADE . REGIẢO DE BAURU, $1979-1982$.

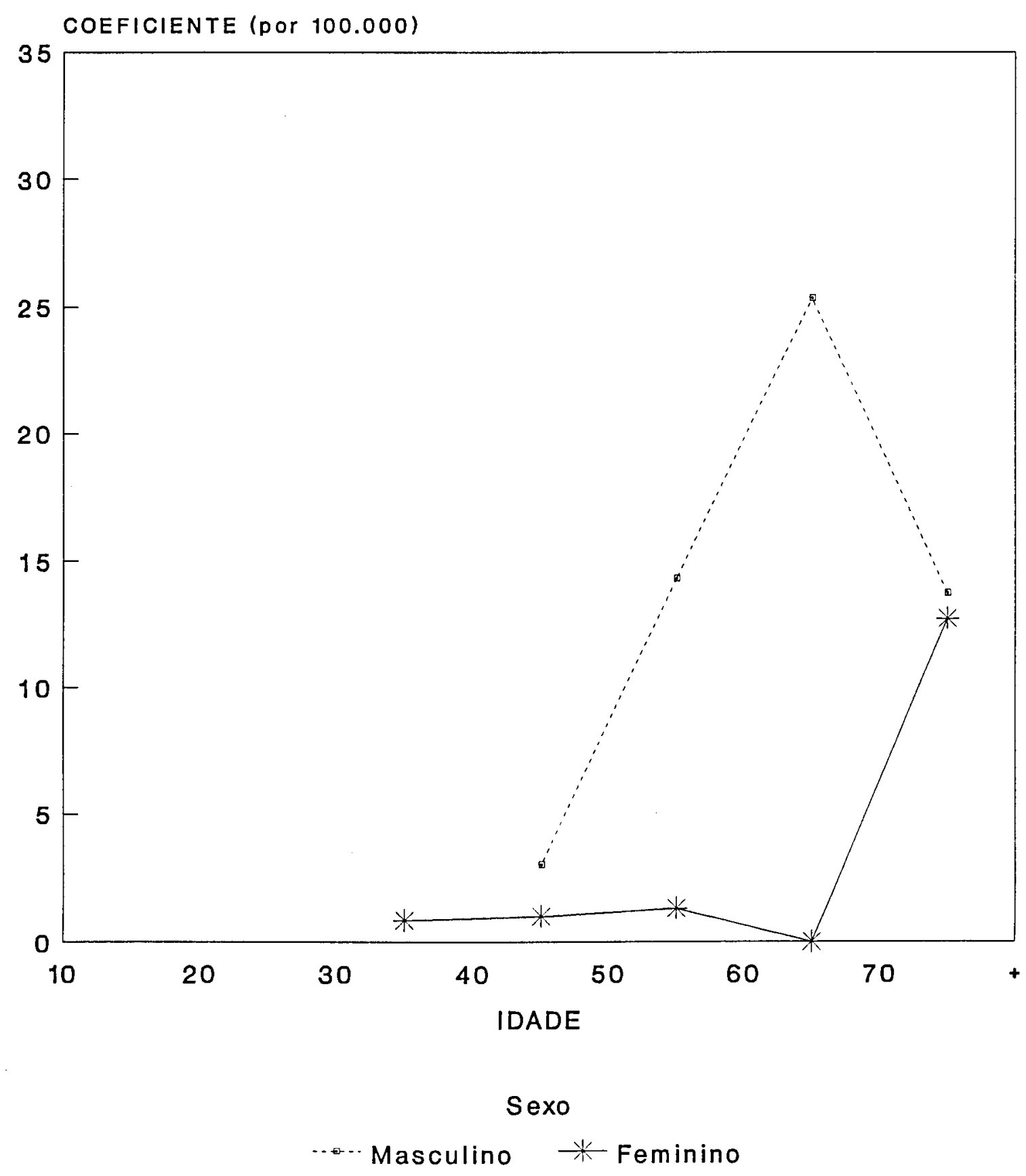


FIG.14 - MORTALIDADE POR CÂNCER DE BOCA, SEGUNDO SEXO E IDADE. REGIĀO DE SẢO JOSÉ DO RIO PRETO, 1979-1982.

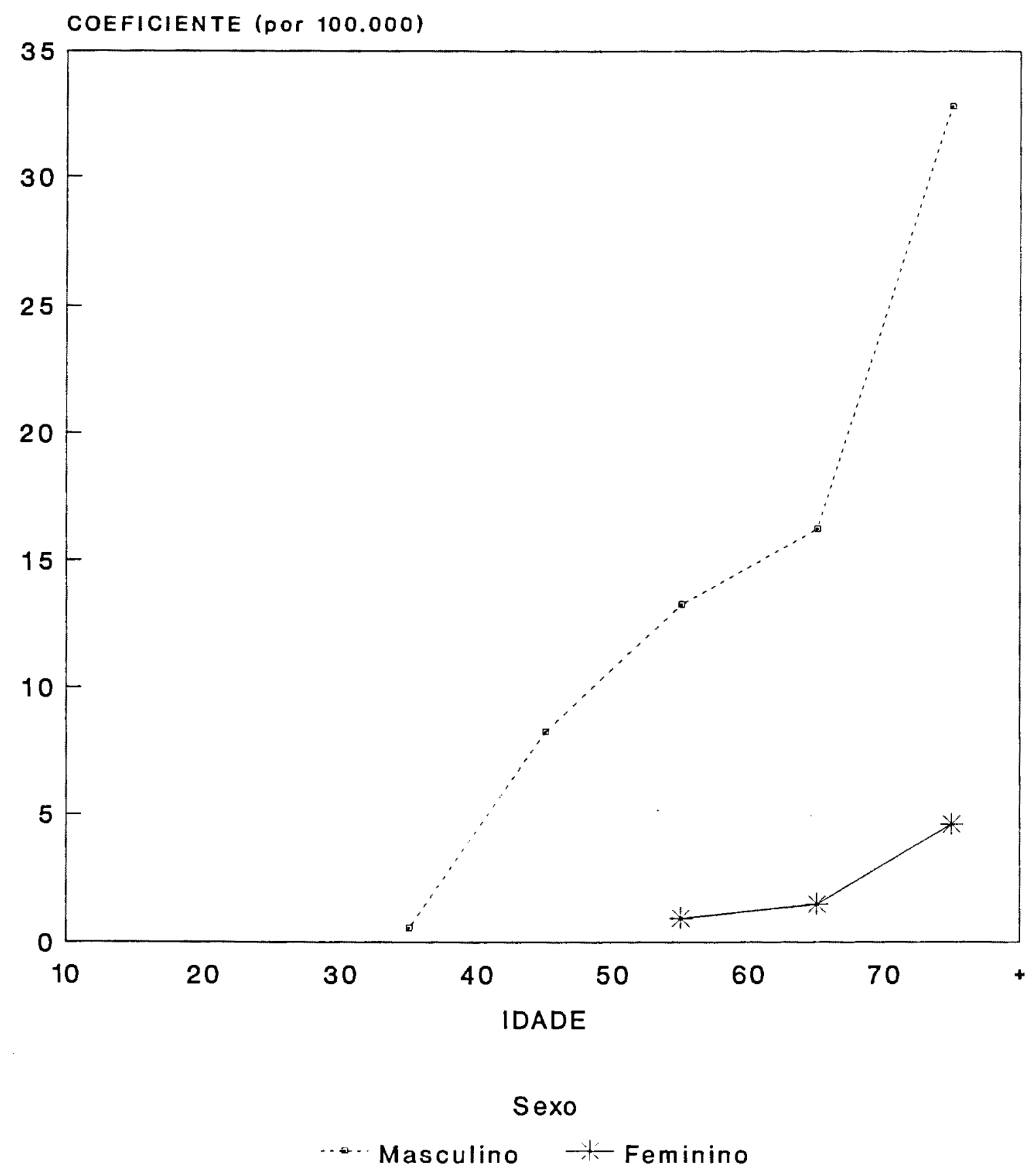


FIG.15 - MORTALIDADE POR CÂNCER DE BOCA, SEGUNDO SEXO E IDADE.REGIĀO DE ARAÇATUBA $1979-1982$.

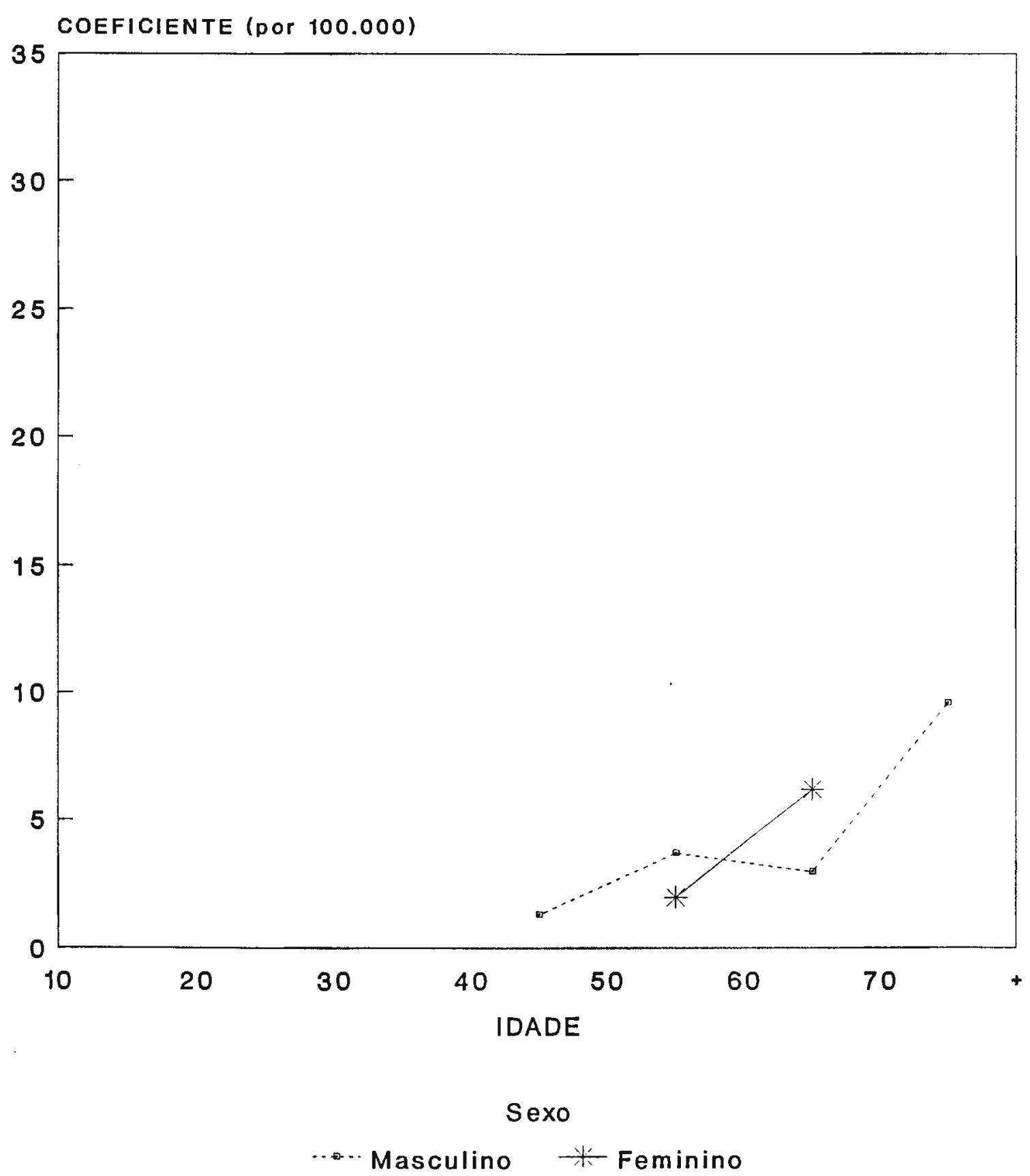


FIG.16 - MORTALIDADE POR CÂNCER DE BOCA, SEGUNDO SEXO E IDADE . REGIĀO DE PRESIDENTE PRUDENTE, 1979-1982 .

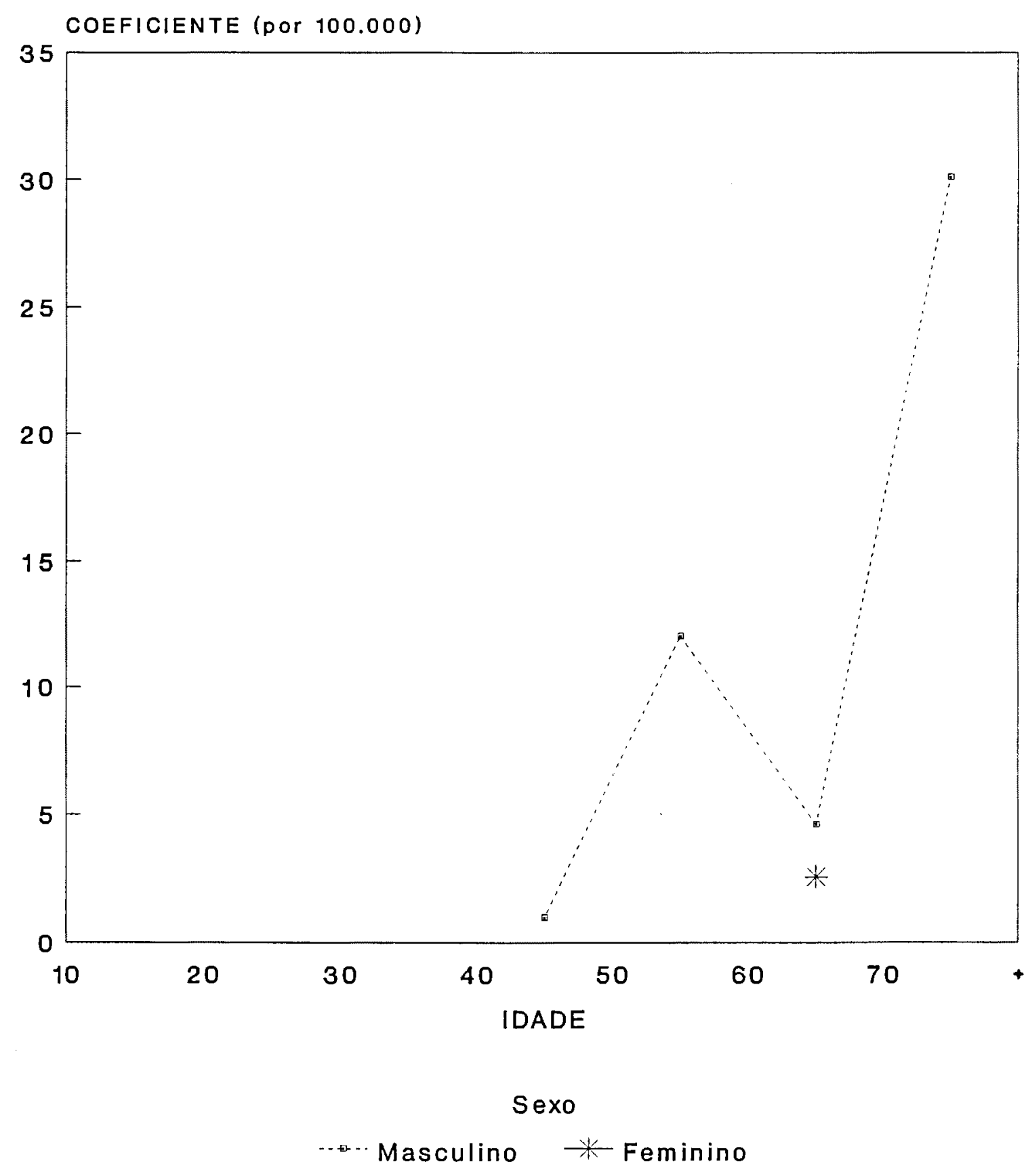


FIG.17 - MORTALIDADE POR CÂNCER DE BOCA, SEGUNDO SEXO E IDADE. REGIĀO DE MARÍLIA, $1979-1982$.

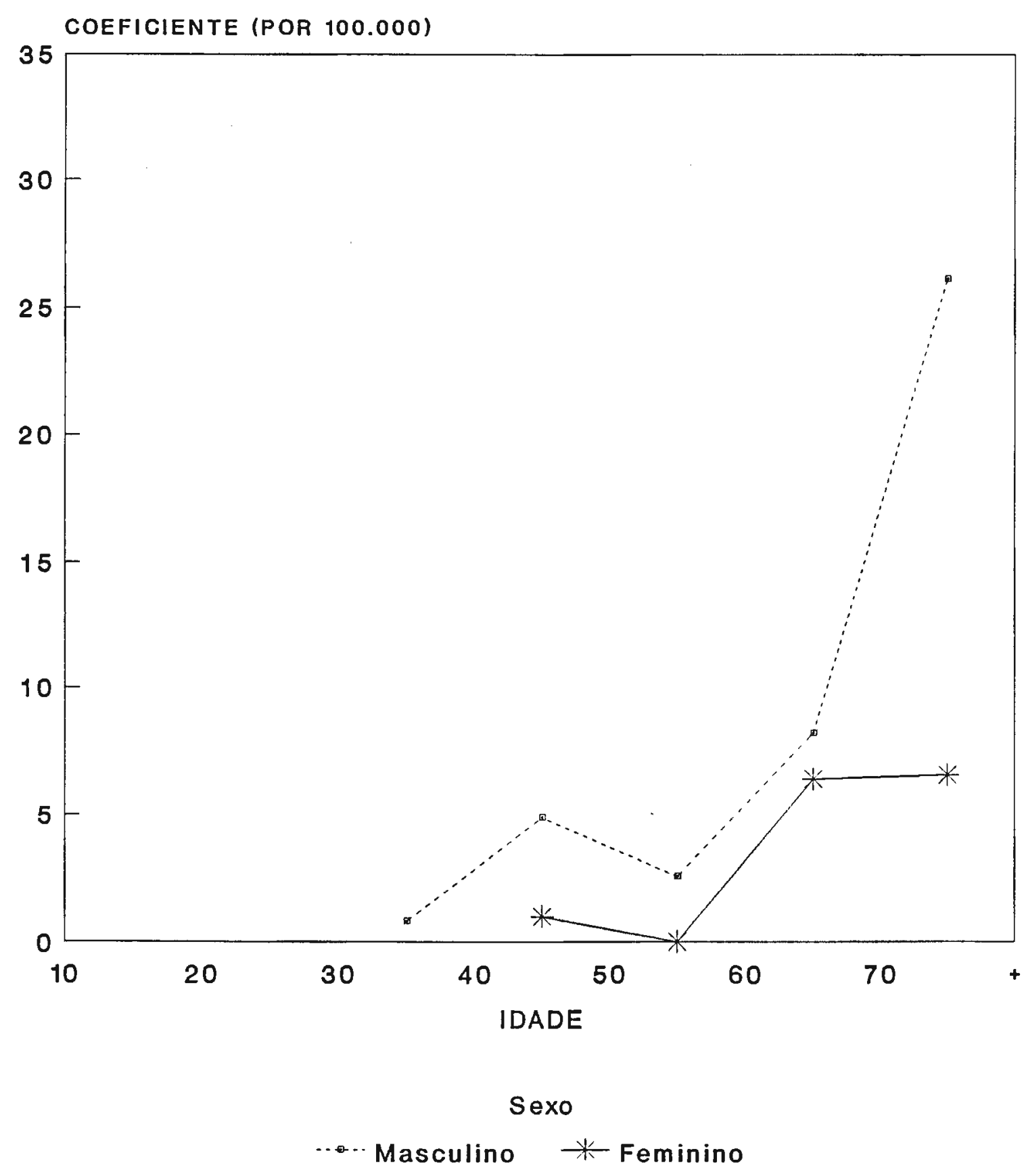


Para todas a idades, em todas as Regiões, os coeficientes do sexo masculino foram superiores aos do sexo feminino, exceto na Região de Araçatuba, para o grupo de 60 a 69 anos.

No sexo masculino não se registram óbitos no grupo de 10 a 19 anos; em quatro Regiões (Grande São Paulo, Sorocaba, Campinas e Ribeirão Preto) registram-se, com baixos coeficientes, óbitos no grupo de 20 a 29 anos. No sexo feminino, duas Regiões registram óbitos no grupo de 10 a 19 anos (Grande São Paulo e Ribeirão Preto) e três Regiões registram óbitos a partir do grupo de 20 a 29 anos (Município de São Paulo, Litoral e Campinas), sempre com baixos coeficientes. As Regiões da Grande São Paulo, Ribeirão Preto e Campinas são, pois, as Regiões em que, nos dois sexos, ocorrem óbitos antes dos 30 anos, enquanto na Região do Municipio de São Paulo e do Litoral apenas no sexo feminino isso ocorre e, na Região de Sorocaba, apenas no sexo masculino.

No sexo masculino, apenas em três Regiões (Bauru, Araçatuba e Presidente Prudente) não se verifica ocorrência de óbitos por câncer de boca em idade inferior a 40 anos, enquanto que, no sexo feminino, uma Região (Presidente Prudente) só tem registros após os 60 anos, três Regiões (Vale do Paraíba, São José do Rio Preto e Araçatuba), após os 50 anos, e uma Região (Marilia) após os 40 anos. Entretanto, em cinco Regiões (Município de São Paulo, Grande São Paulo, Litoral, Ribeirão Preto e Bauru) há, no sexo feminino, registro de mortalidade em grupos etários mais jovens do que no sexo masculino.

No sexo masculino todas as Regiões registram óbitos no grupo etário de 70 anos e mais; no sexo feminino, duas Regiões (Araçatuba e Presidente Prudente) só apresentam óbitos até o grupo de 60 a 69 anos.

A curva de mortalidade é, em geral, regularmente ascendente, nos dois sexos. O sexo masculino registra, porém, em quatro Regiões (Grande São Paulo, Litoral, Vale do Paraíba e Bauru), decréscimo após os 70 anos. Em cinco Regiões (Município de São Paulo, Campinas, São José do Rio Preto, Presidente Prudente e Marilia), pelo contrário, nesse último grupo há aumento acentuado dos coeficientes, no sexo masculino. Esse aumento acentuado nesse grupo ocorre, para o sexo feminino, 
apenas em três Regiões (Vale do Paraiba, Ribeirão Preto e Bauru).

Em todas as Regiões, tanto para o sexo masculino como para o feminino, o pico de mortalidade foi observado após os 60 anos, sendo que, para o sexo masculino o pico está no grupo de 70 anos e mais em oito Regiões (Municipio de São Paulo, Sorocaba, Campinas, Ribeirão Preto, São José do Rio Preto, Araçatuba, Presidente Prudente e Marilia) e, para o sexo feminino, em dez Regiões (Município de São Paulo, Grande São Paulo, Litoral, Vale do Paraíba, Sorocaba, Campinas, Ribeirão Preto, Bauru, São José do Rio Preto e Marilia).

\subsubsection{Coeficientes de mortalidade específicos por localização do tumor}

Para cada uma das Regiões Administrativas foram calculados os coeficientes de mortalidade relativos a cada uma das localizações do tumor. Esses coeficientes, padronizados por idade, podem ser observados na figura 18.

Verifica-se que, para todas as Regiões, os maiores coeficientes são os de câncer de lingua, com valores destacadamente superiores aos encontrados para as demais localizações. A Região de São José do Rio Preto apresenta o maior valor de coeficiente de mortalidade por câncer dessa localização (0,96 po 100.000 habitantes) e a Região de Araçatuba o menor (0,19 por 100.000 habitantes).

Os coeficientes relativos aos cânceres de lábio e de gengiva são os que ocupam, na maior parte das Regiões, as duas últimas posições. Observe-se que não ocorreu nenhum óbito por câncer de lábio nas Regiões de Araçatuba, Presidente Prudente e Marilia, e nenhum óbito por câncer de gengiva nas Regiões de São José do Rio Preto e Presidente Prudente. Além disso, o lábio ocupa a última posição nas Regiões do Litoral e Ribeirão Preto, a gengiva ocupa a última posição nas Regiões da Grande São Paulo, Sorocaba e Campinas, e o lábio juntamente com a gengiva ocupam a última posição na Região do Municipio de São Paulo. 
FIG.18 - MORTALIDADE POR CÂNCER DE BOCA, SEGUNDO LOCALIZACCẢO DO TUMOR E REGIẢO DO ESTADO DE SÃO PAULO, 1979-1982 .

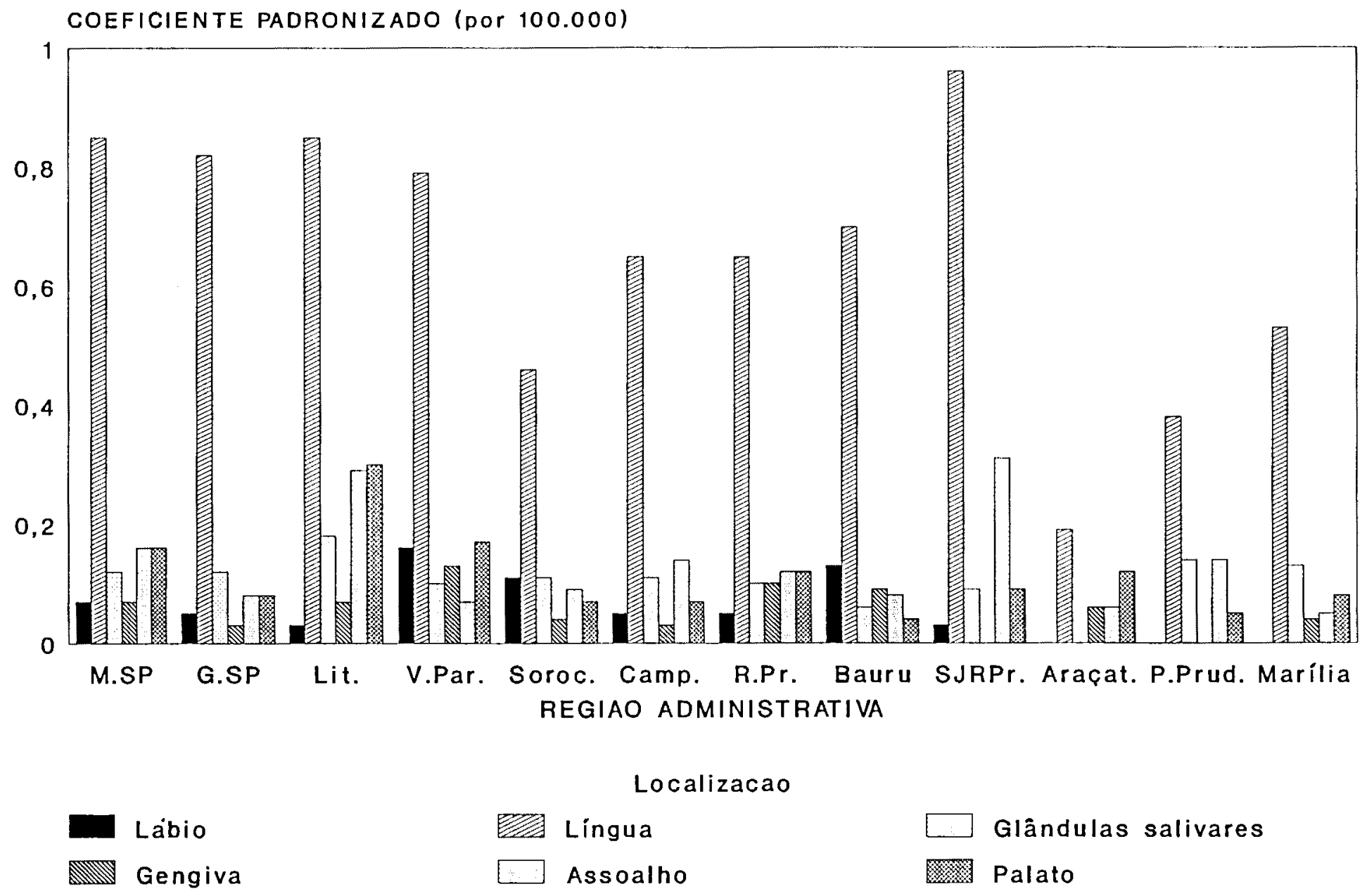


Na segunda posição estão: o assoalho, em cinco Regiões (Municipio de São Paulo, Campinas, Ribeirão Preto, São José do Rio Preto e Presidente Prudente); o palato, em cinco Regiões (Municipio de São Paulo, Litoral, Vale do Paraiba, Ribeirão Preto e Araçatuba); as glândulas salivares em quatro Regiões (Grande São Paulo, Sorocaba, Presidente Prudente e Marilia). Essas mesmas localizações ocupam, em geral, as demais posições intermediárias nas diversas Regiões, exceto no Vale do Paraíba (em que o assoalho está em último lugar), em Bauru (em que é o palato que ocupa a última posição) e em Araçatuba (em que as glândulas salivares ocupam o último lugar juntamente com o lábio, ambas as localizações, com nenhum óbito registrado).

4.2.4.1. Coeficientes de mortalidade específicos por localização do tumor e sexo

As figuras 19 a 24 trazem os coeficientes de mortalidade para cada uma das localizações do tumor, obtidos para cada sexo, em cada uma das Regiões Administrativas, e padronizados por idade. 
FIG.19- MORTALIDADE POR CÂNCER DE LÁBIO, SEGUNDO SEXO E REGIẢO DE RESIDÊNCIA.

ESTADO DE SÃO PAULO, 1979 - 1982 .

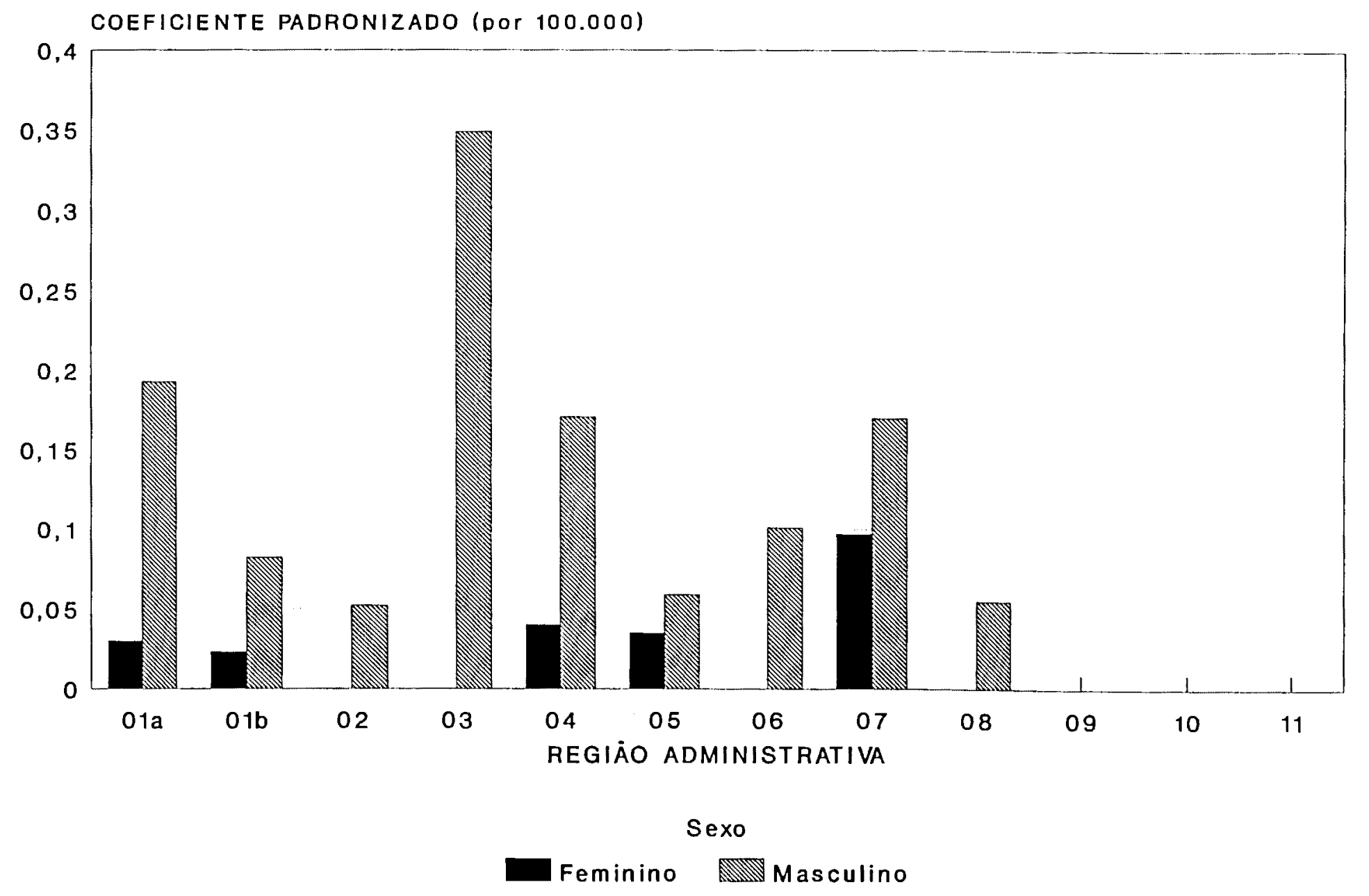


FIG.20-MORTALIDADE POR CÂNCER DE LINGUA, SEGUNDO SEXO E REGIẢO DE RESIDÊNCIA.

ESTADO DE SĀO PAULO, 1979 - 1982.

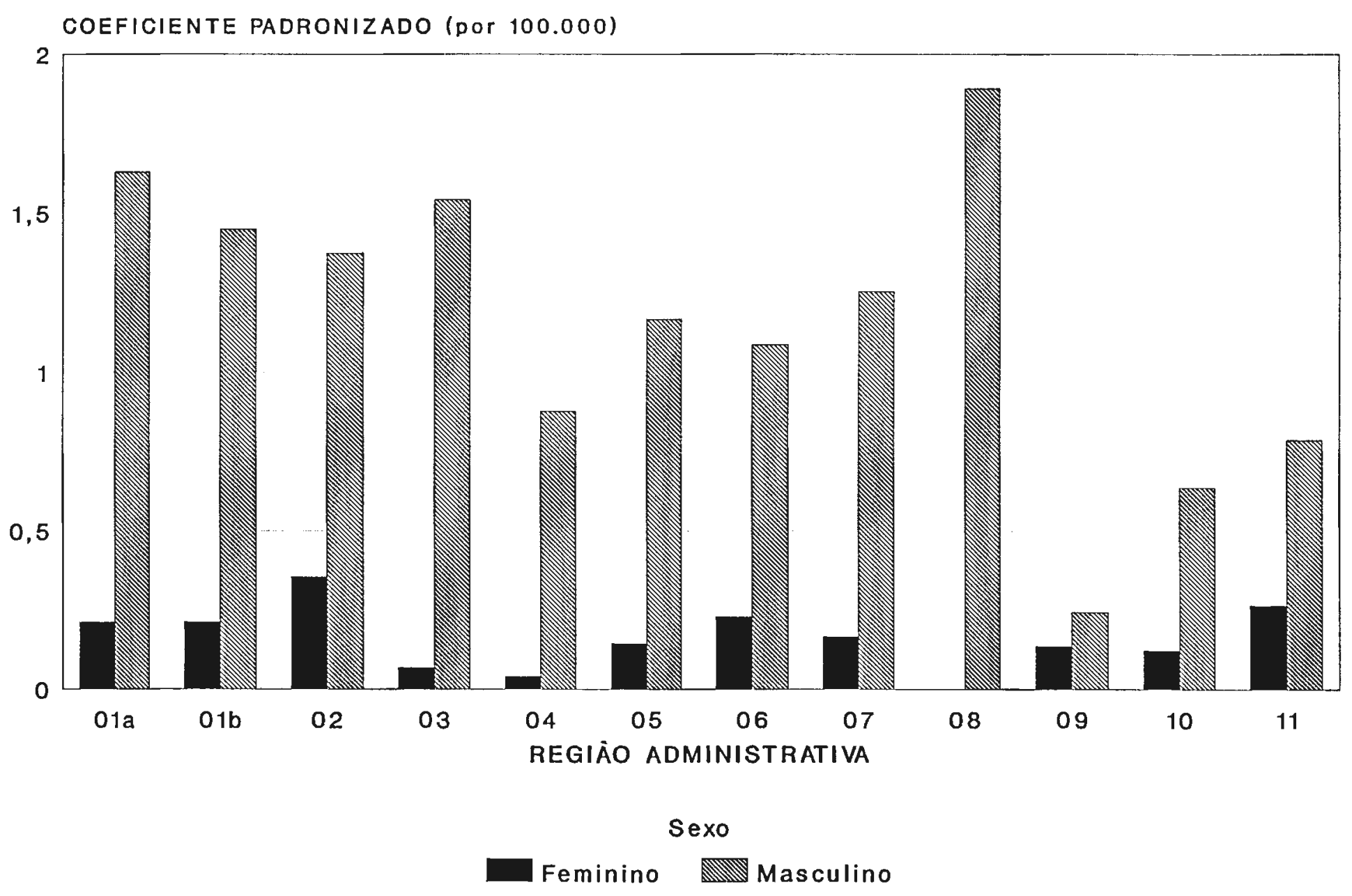


FIG.21- MORTALIDADE POR CÂNCER DE GL.SALIVARES, SEGUNDO SEXO E REGIẢO DE RESI -

DÊNCIA'. ESTADO DE SẢO PAULO, 1979-1982.

COEFICIENTE PADRONIZADO (POR 100.000)

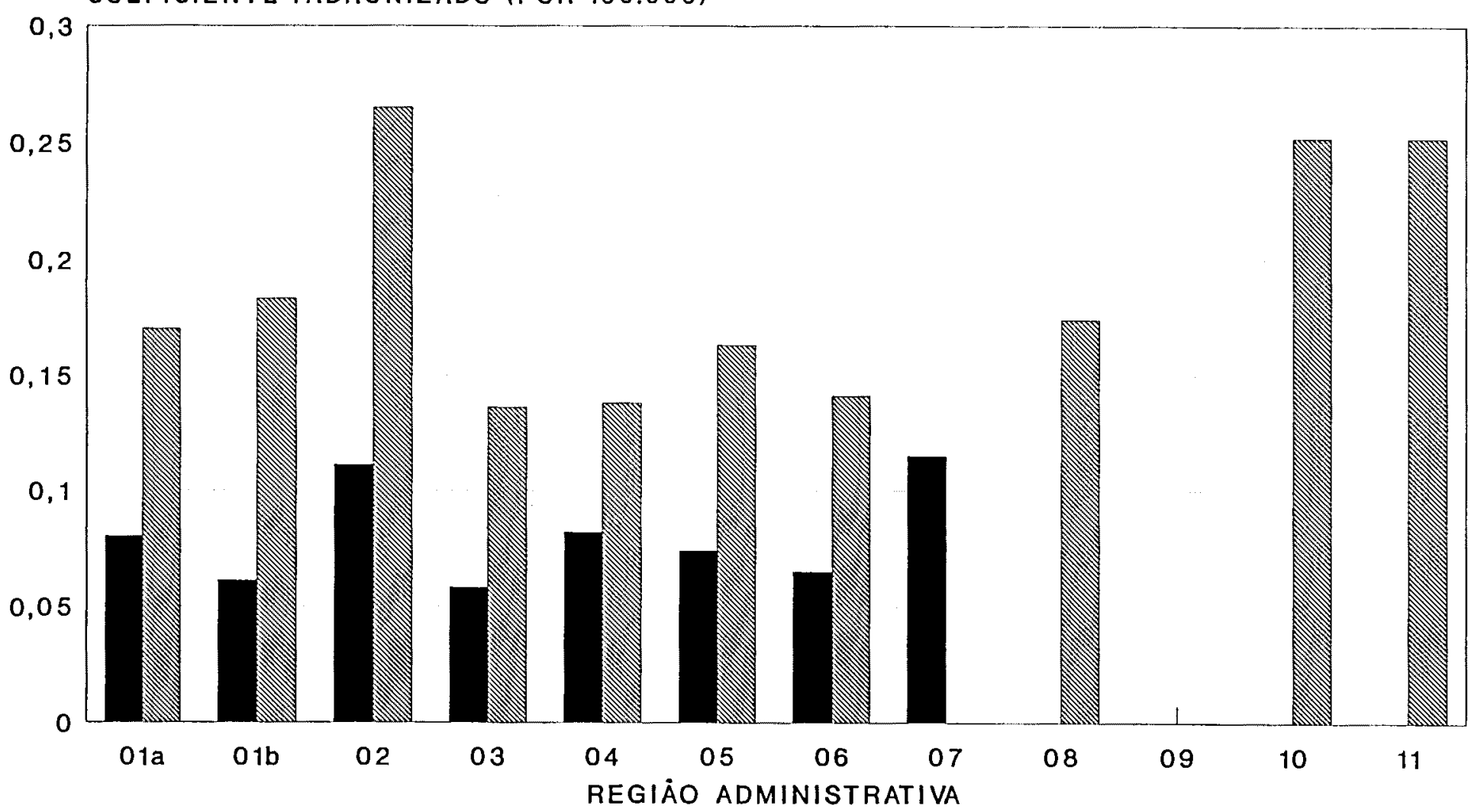

Sexo

Feminino Masculino 
FIG.22- MORTALIDADE POR CÂNCER DE GENGIVA, SEGUNDO SEXO E REGIĀO DE RESIDÉNCIA. ESTADO DE SẢO PAULO, 1979-1982.

COEFICIENTE PADRONIZADO (por 100.000 )

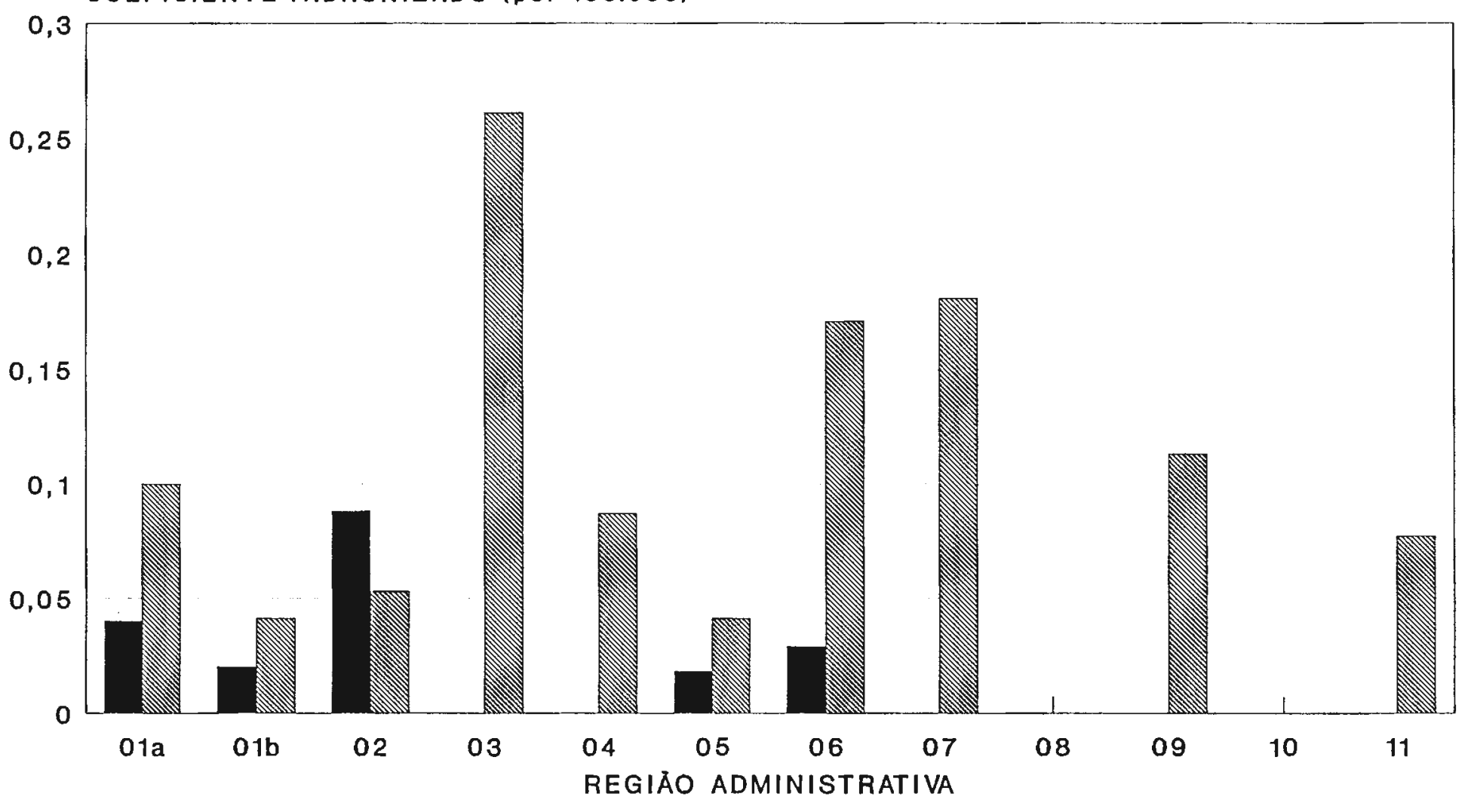

Sexo

Feminino Masculino 
FIG.23- MORTALIDADE POR CÂNCER DE ASSOA-

LHO, SEGUNDO SEXO E REGIẢO DE RESIDÊNCIA ESTADO DE SẢO PAULO, 1979-1982.

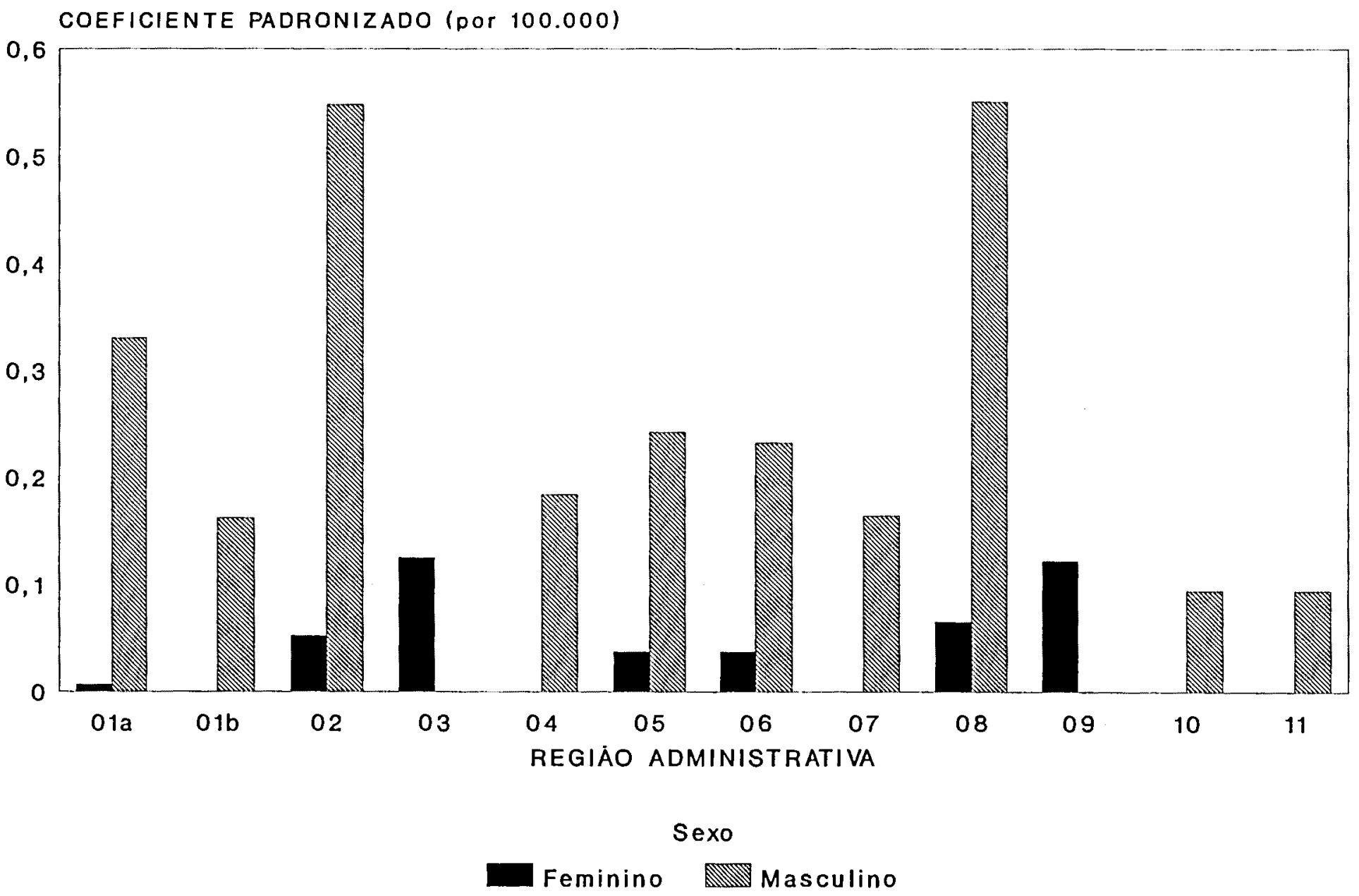


FIG.24-MORTALIDADE POR CÂNCER DE PALATO, SEGUNDO SEXO E REGIÄO DE RESIDÉNCIA.

ESTADO DE SẢO PAULO, 1979-1982.

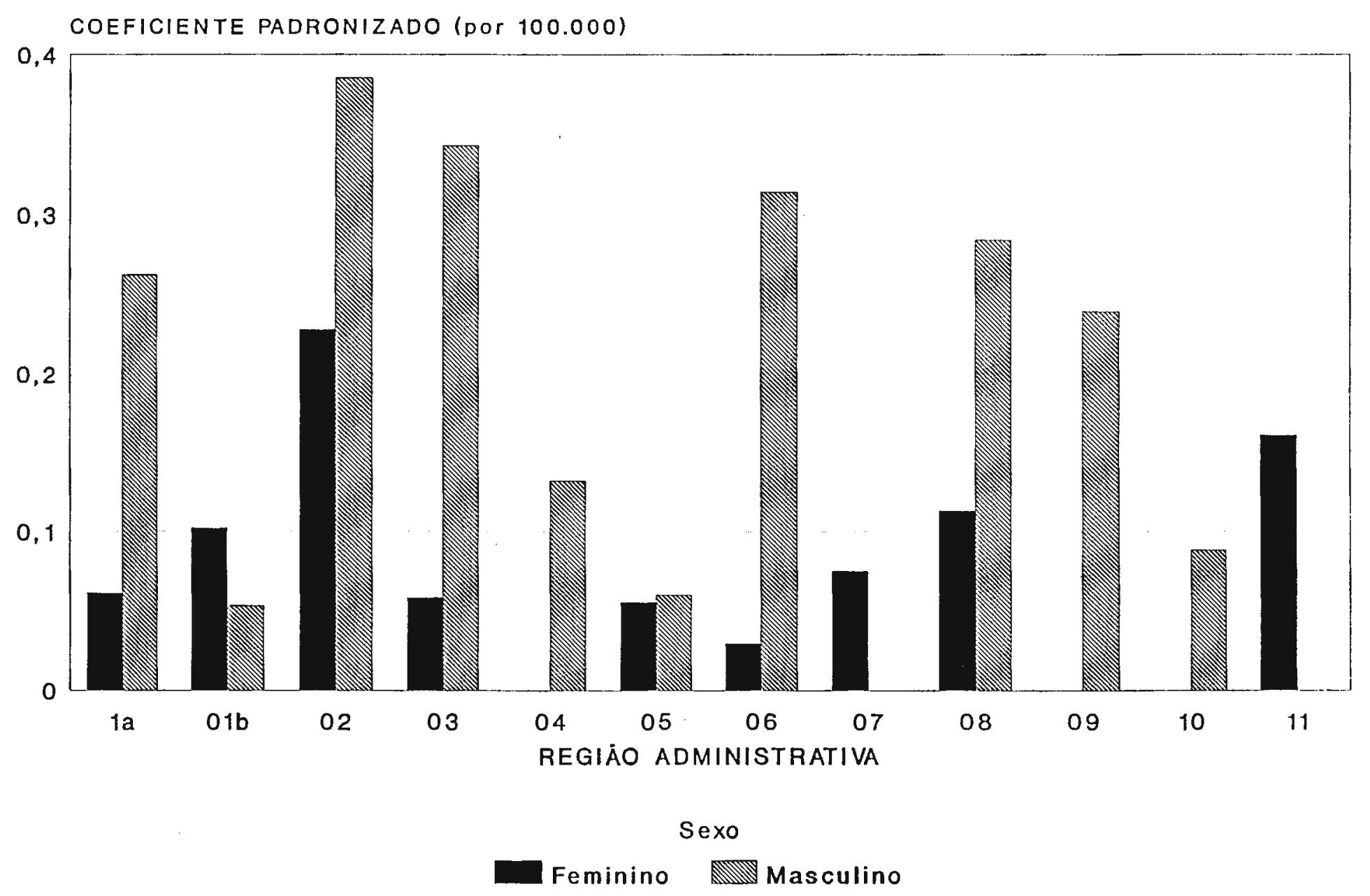


Verifica-se que, considerada a localização do tumor, os coeficientes obtidos para o sexo masculino são maiores que os obtidos para o sexo feminino, na maioria das Regiões. Esse comportamento apenas não é observado: em duas Regiões em que os coeficientes de mortalidade por câncer de palato (Grande São Paulo) e de gengiva (Litoral) são maiores para as mulheres do que para os homens; em quatro Regiões em que não se registrou nenhum óbito, entre os homens, por câncer de algumas das localizações: glândulas salivares e palato, na Região de Bauru; assoalho da boca, nas Regiões do Vale do Paraíba e Araçatuba; palato, na Região de Marília.

Além das Regiões em que não houve nenhum óbito por câncer de uma determinada localização em qualquer dos sexos, observa-se que, em algumas Regiões, e para diversas localizações, o coeficiente de mortalidade no sexo feminino foi zero. Isso ocorre com: o câncer de lábio, nas Regiões do Litoral, Vale do Paraíba, Ribeirão Preto e São José do Rio Preto; o câncer de glândulas salivares, nas Regiões de São José do Rio Preto, Presidente Prudente e Marilia; o câncer de gengiva, nas Regiões do Vale do Paraíba, Sorocaba, Bauru, Araçatuba e Marilia; o câncer do assoalho da boca, nas Regiões da Grande São Paulo, Sorocaba, Bauru, Presidente Prudente e Marilia; o câncer de palato, nas Regiões de Sorocaba, Araçatuba e Presidente Prudente; o câncer de língua na Região de São José do Rio Preto. Observe-se, para este último caso, que a mortalidade por câncer de língua é justamente a que apresenta os maiores coeficientes, para o sexo masculino, em todas as Regiões, e é também a que tem os maiores coeficientes, para o sexo feminino, no geral das Regiões; além disso, é exatamente nessa Região de São José do Rio Preto que está o maior coeficiente de mortalidade por câncer de língua, no Estado de São Paulo (figura 18).

Para as localizações lábio e gengiva, verifica-se que justamente a Região que apresenta os maiores coeficientes de mortalidade no sexo masculino, o Vale do Paraíba, é uma daquelas em que não ocorrem óbitos no sexo feminino.

Inversamente, o câncer de lábio é a localização que apresenta o menor valor de coeficiente, no sexo masculino, na Região do Litoral, na qual, ainda, não ocorre nenhum óbito por essa localização, no sexo feminino. Esse resultado merece 
ser estudado em confronto com a literatura sobre o câncer de lábio, a qual indica relação entre a incidência de câncer dessa localização e a exposição ao sol 2,31,99. Tem de ser lembrado, porém, que a literatura também indica melhor prognóstico para o câncer de lábio ${ }^{50}$ do que para os outros cânceres de boca, o que significa diferença entre os valores de incidência e de mortalidade. A partir desse prognóstico a taxa de sobrevida de 5 anos é de $80 \%$ para o câncer de lábio e de $30 \%$ a $40 \%$, conforme o país, para o carcinoma das outras localizações da boca ${ }^{50}$. Em seu estudo de mortalidade e incidencia para o Município de São Paulo, periodo de 1969 a 1971 , Samara ${ }^{104}$ encontrou, para o lábio, incidência de $34,1 \%$, para os homens, e de $37,1 \%$, para as mulheres, e mortalidade de apenas $8,6 \%$ tanto para homens como para mulheres, enquanto, em todas as outras localizações, a mortalidade teve proporções maiores do que a incidência, no mesmo período.

4.2.4.2. Coeficientes de mortalidade específicos por localização do tumor e idade

Nas figuras de 25 a 36 estão os coeficientes de mortalidade específicos por localização do tumor e idade, referentes às quatro localizações que apresentaram os maiores valores de mortalidade proporcional no Estado como um todo (sendo consideradas as subcategorias da categoria 145$)$ : lingua $(48,0 \%)$; assoalho $(9,0 \%)$; palato $(8,4 \%)$ e glândulas salivares $(7,5 \%)$ (tabela 2$)$. 
FIG.25-MORTALIDADE POR CÂNCER DE BOCA, SEGUNDO LOCALIZAÇẢO DO TUMOR E IDADE . MUNICIPIO DE SẢO PAULO, 1979-1982 .

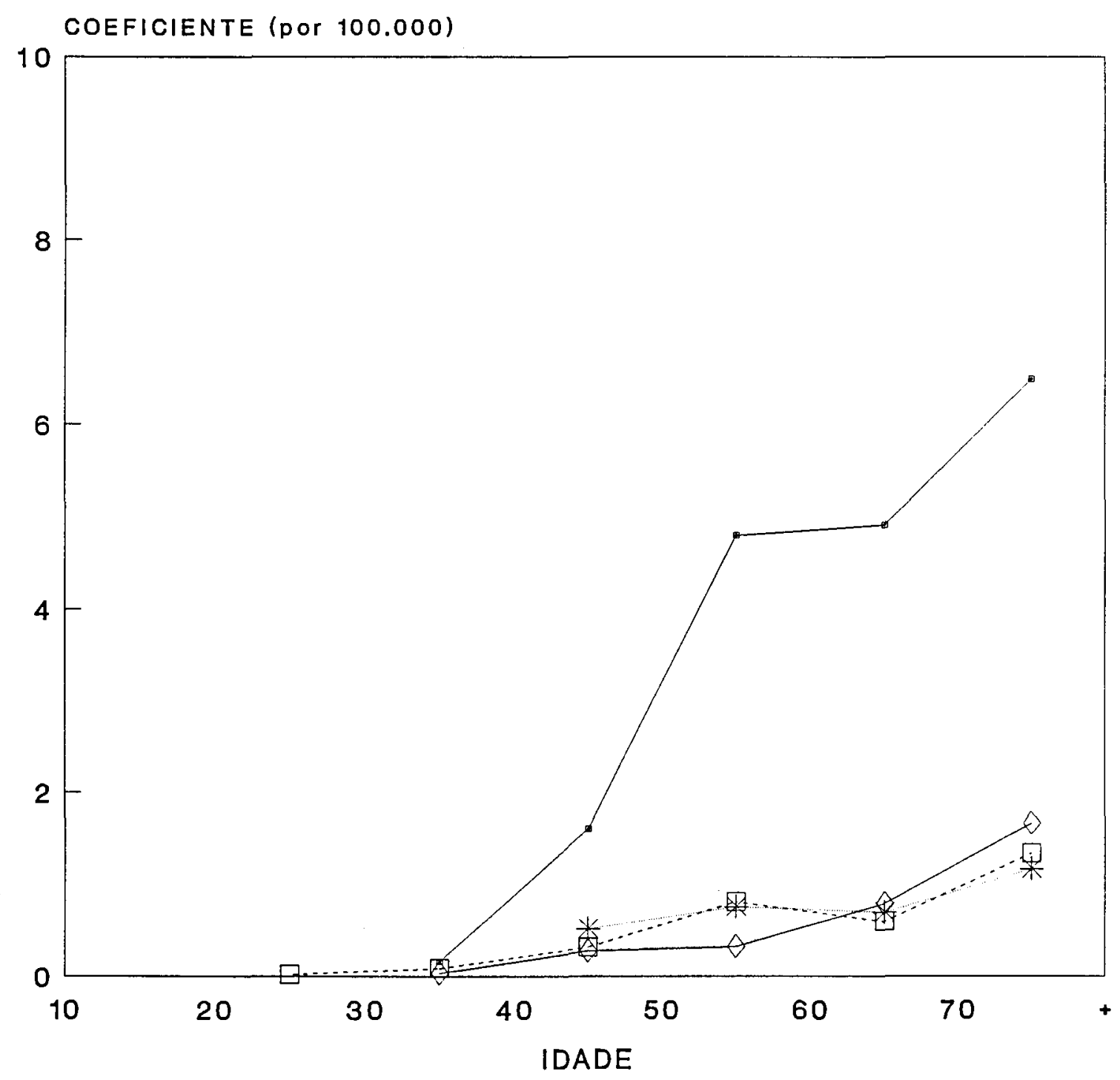

Localizacāo

$\rightarrow$ Lingua

*... Assoalho $\vartheta$ Glândulas salivares

- $\exists$ - Palato 
FIG.26-MORTALIDADE POR CÂNCER DE BOCA, SEGUNDO LOCALIZACÃO DO TUMOR E IDADE . REG. DA GRANDE SẢO PAULO, 1979-1982 .

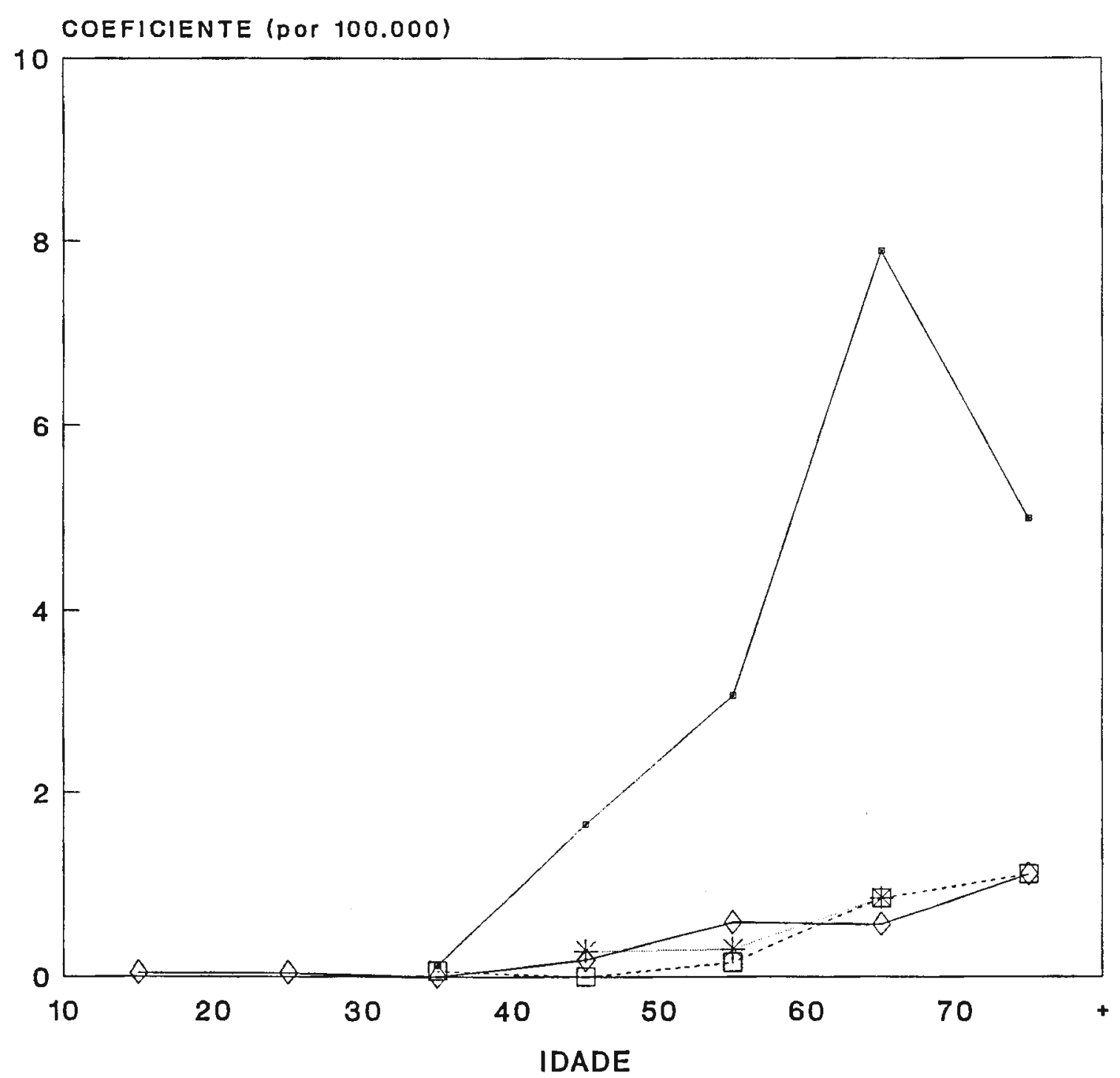

Localizaçáo
$\rightarrow$ Língua
$\hat{\nabla}$ Glândulas salivares
* Assoalho
- $\cdot$.'Palato 
FIG.27-MORTALIDADE POR CÂNCER DE BOCA, SEGUNDO LOCALIZAÇẢO DO TUMOR E IDADE . REG. DO LITORAL, 1979-1982 .

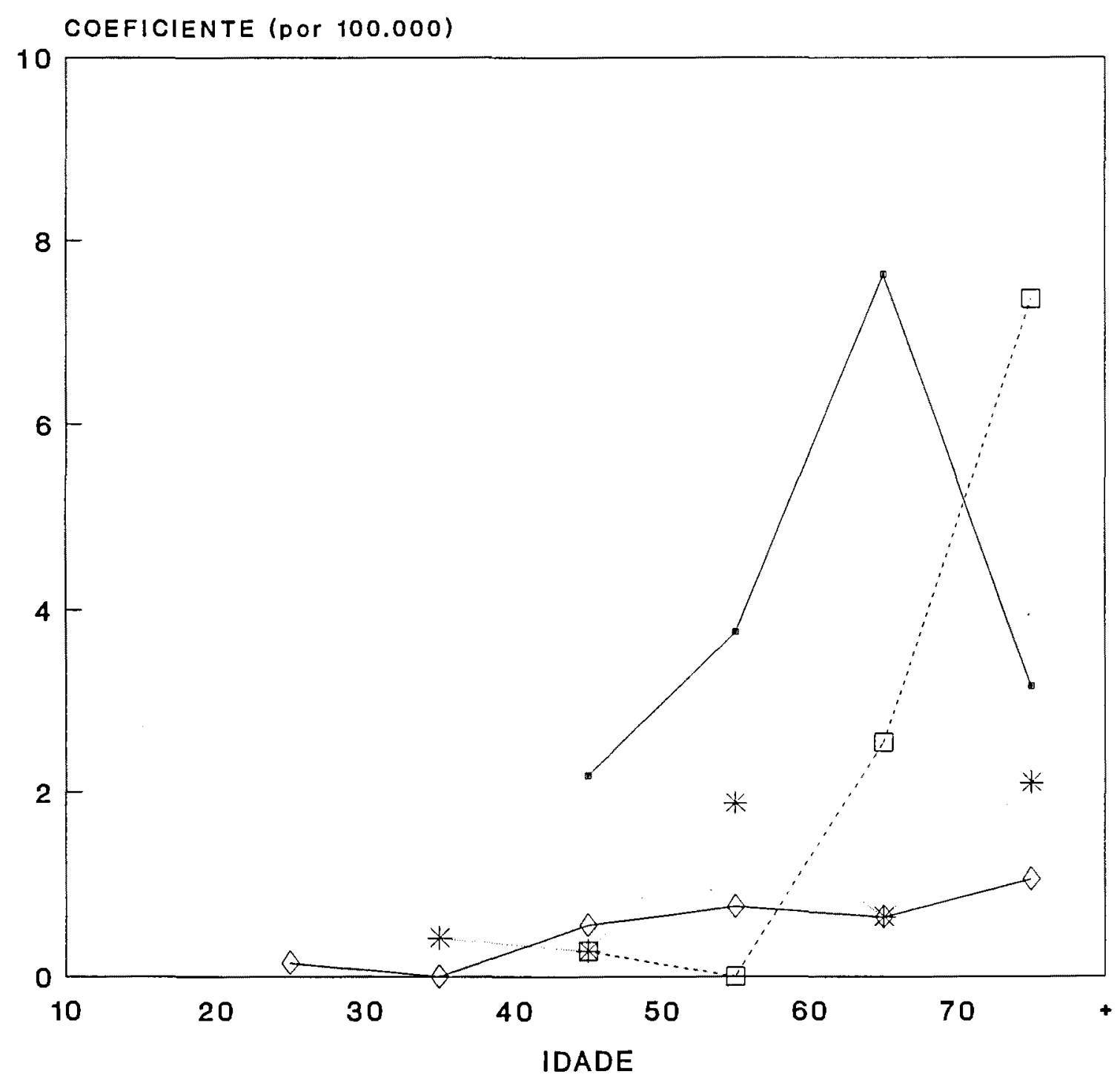

Localizaçào

$\rightarrow$ Língua

* Assoalho $\smile$ Glândulas salivares

曰- Palato 
FIG.28-MORTALIDADE POR CÂNCER DE BOCA, SEGUNDO LOCALIZAÇẢO DO TUMOR E IDADE . REG. DO VALE DO PARAIBAA, 1979-1982 .

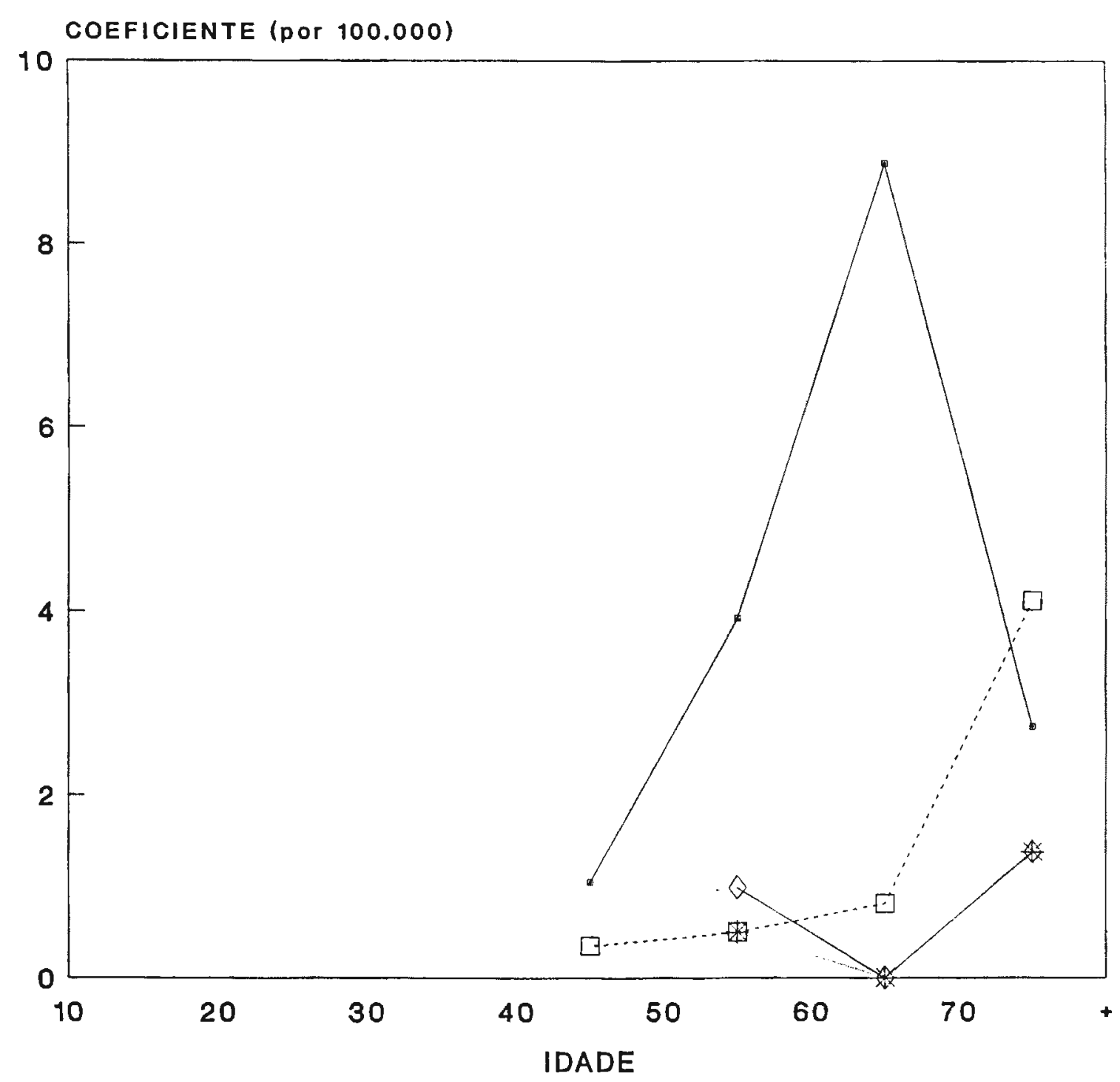

Localizaçào

- Lingua

*... Assoalho $\leftarrow$ Glândulas salivares

- $\boxminus$. Palato 
FIG.29-MORTALIDADE POR CÂNCER DE BOCA, SEGUNDO LOCALIZAÇẢO DO TUMOR E IDADE .

REG. DE SOROCABA, 1979-1982 .

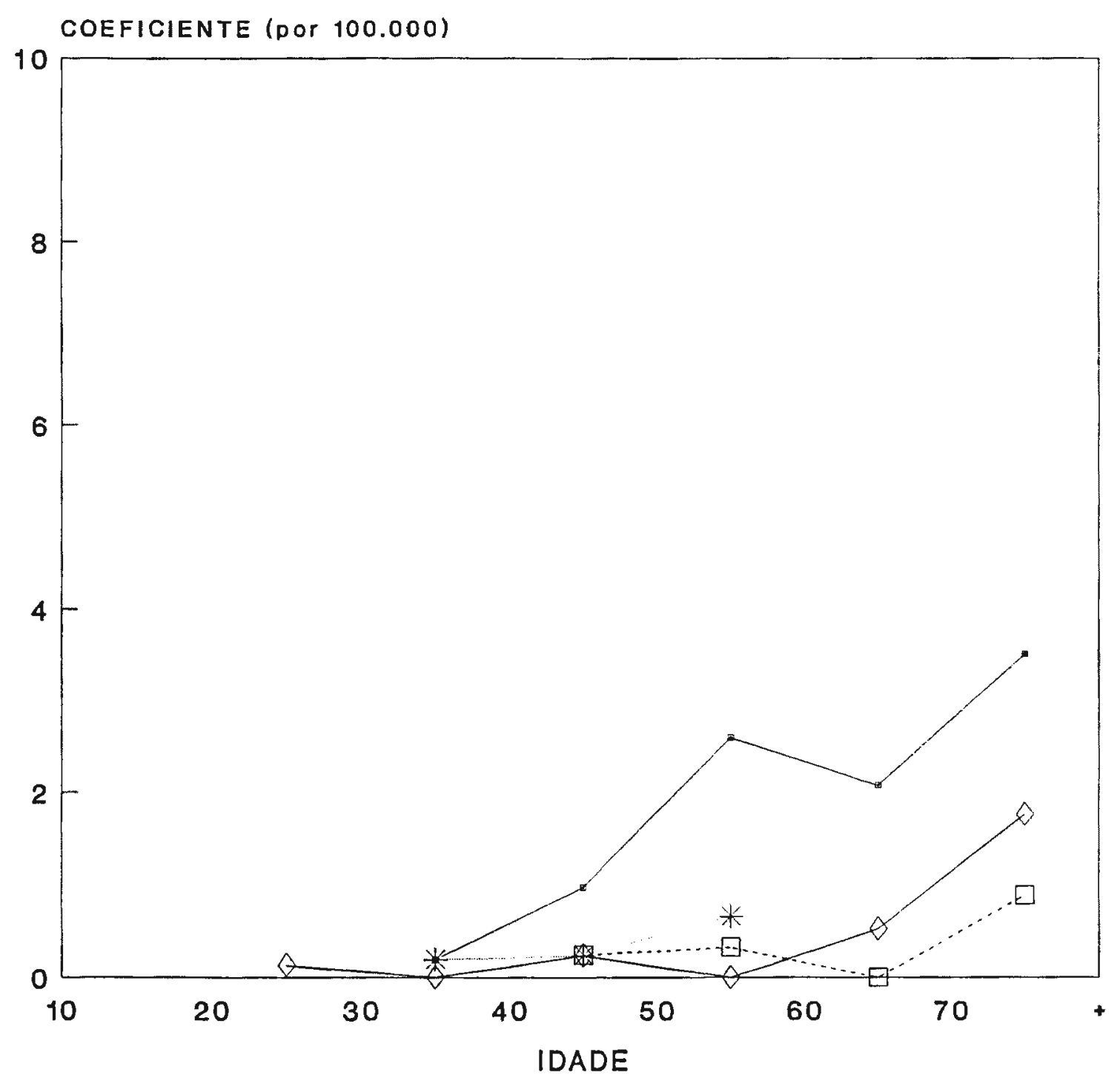

Localizacào

$\rightarrow$ Lingua

* Assoalho $\hat{\forall}$ Glândulas salivares

- $\rightarrow$ Palato 
FIG.30-MORTALIDADE POR CÂNCER DE BOCA, SEGUNDO LOCALIZACẢO DO TUMOR E IDADE .

REG. DE CAMPINAS, 1979-1982 .

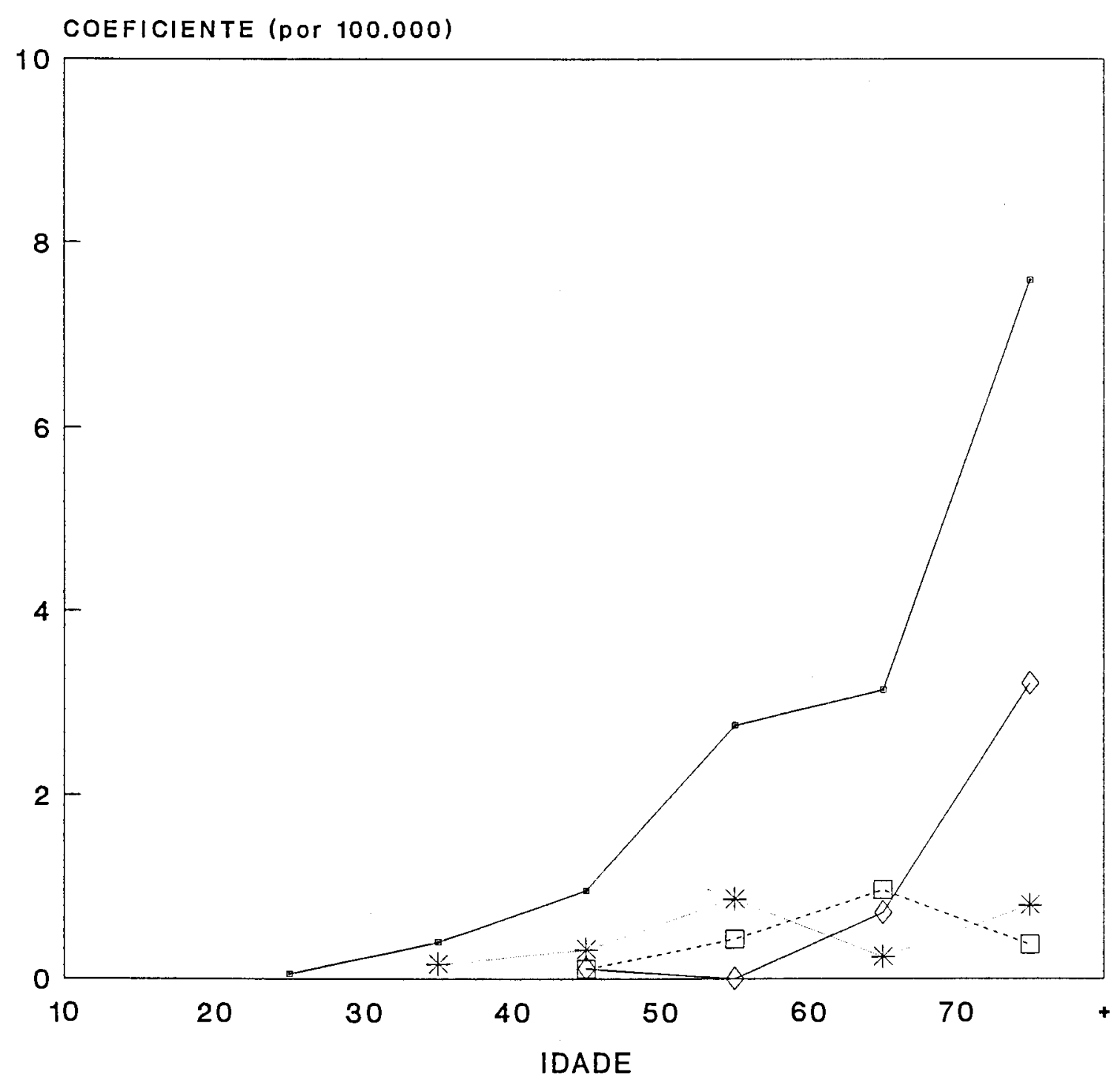

Localizaçào

- Língua

* Assoalho $\diamond$ Glândulas salivares

$-\boxminus$ - Palato 
FIG.31-MORTALIDADE POR CÂNCER DE BOCA, SEGUNDO LOCALIZACẢO DO TUMOR E IDADE . REG. DE RIBEIRȦO PRETO, 1979-1982 .

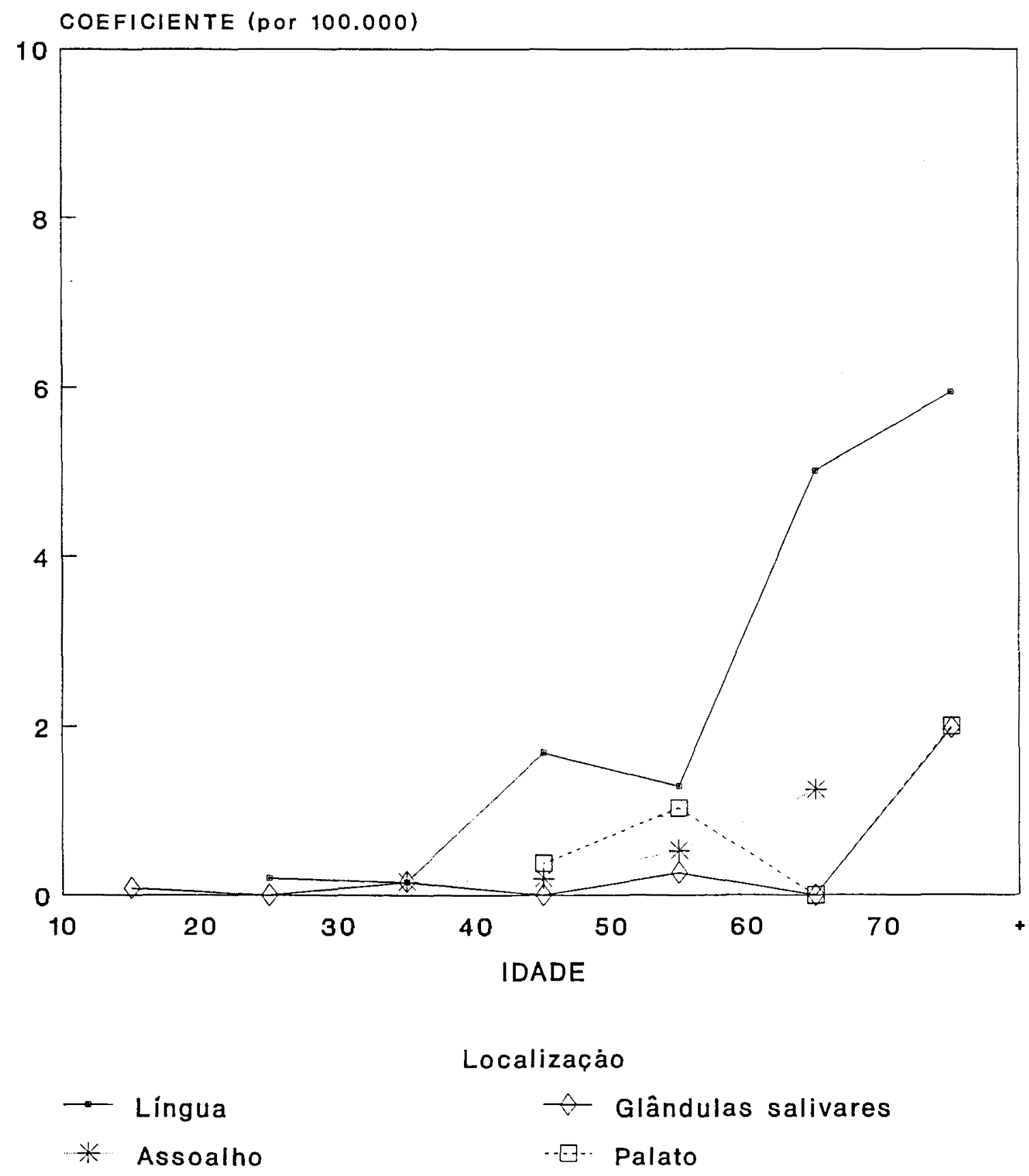


FIG.32-MORTALIDADE POR CÂNCER DE BOCA, SEGUNDO LOCALIZACẢO DO TUMOR E IDADE . REG. DE BAURU, 1979-1982 .

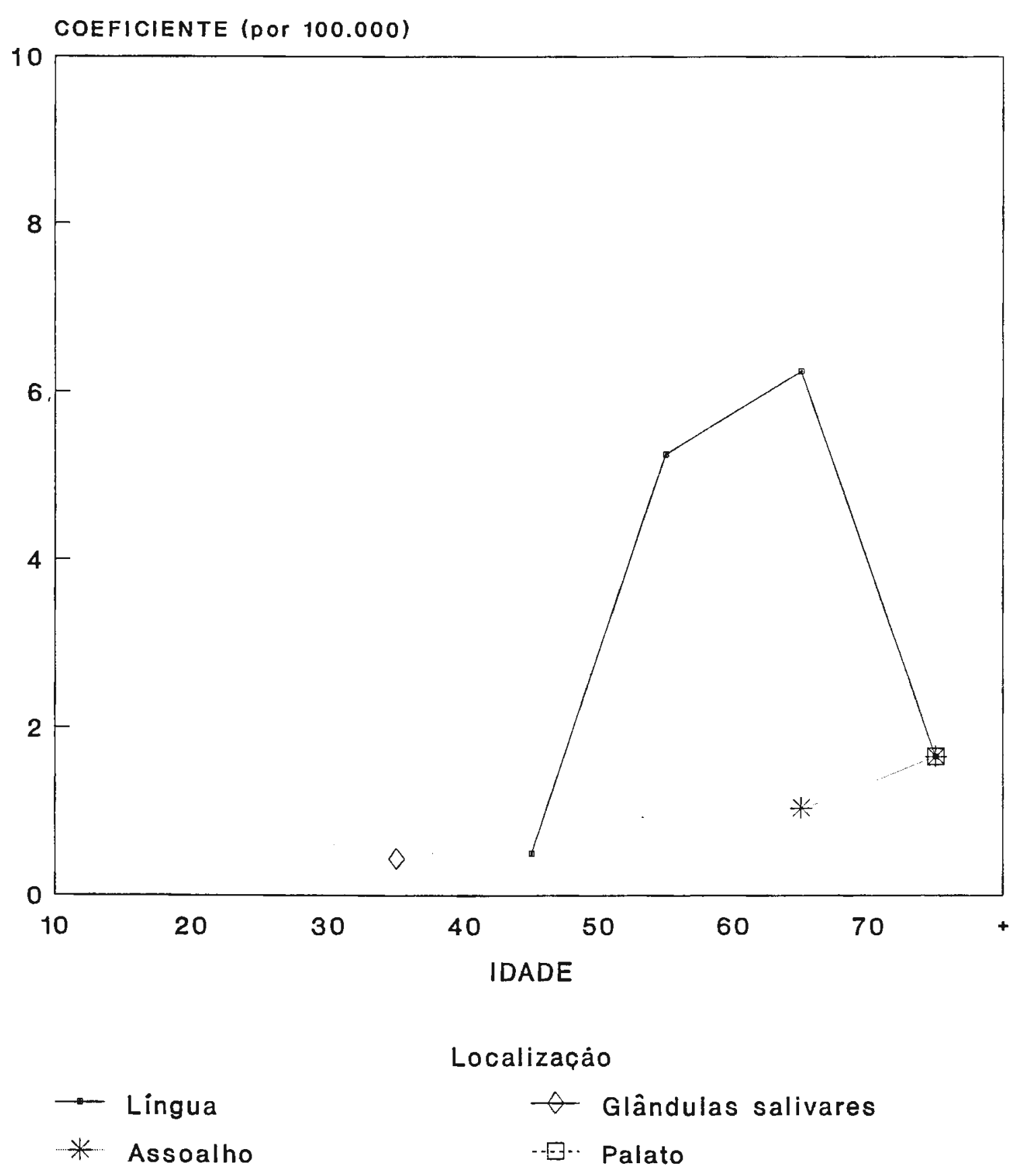


FIG.33-MORTALIDADE POR CÂNCER DE BOCA, SEGUNDO LOCALIZACAAO DO TUMOR E IDADE . REG. DE S.J.DO RIO PRETO, 1979-1982 .

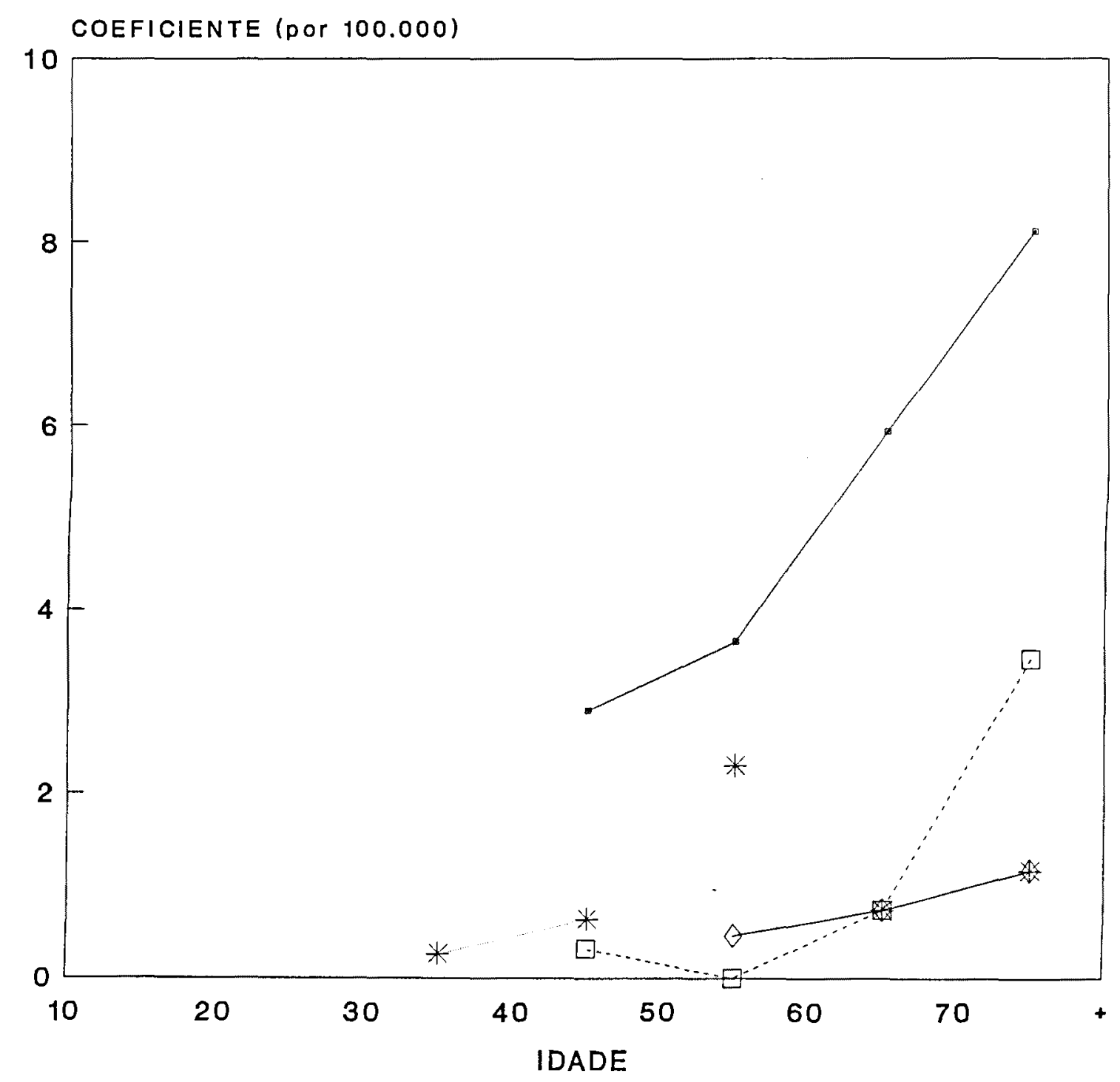

Localizaçào
$\longrightarrow$ Língua
$\diamond$ Glândulas salivares
* Assoalho
- $\boxminus$ Palato 
FIG.34-MORTALIDADE POR CÂNCER DE BOCA, SEGUNDO LOCALIZACCẢO DO TUMOR E IDADE . REG. DE ARACATUBA, 1979-1982 .

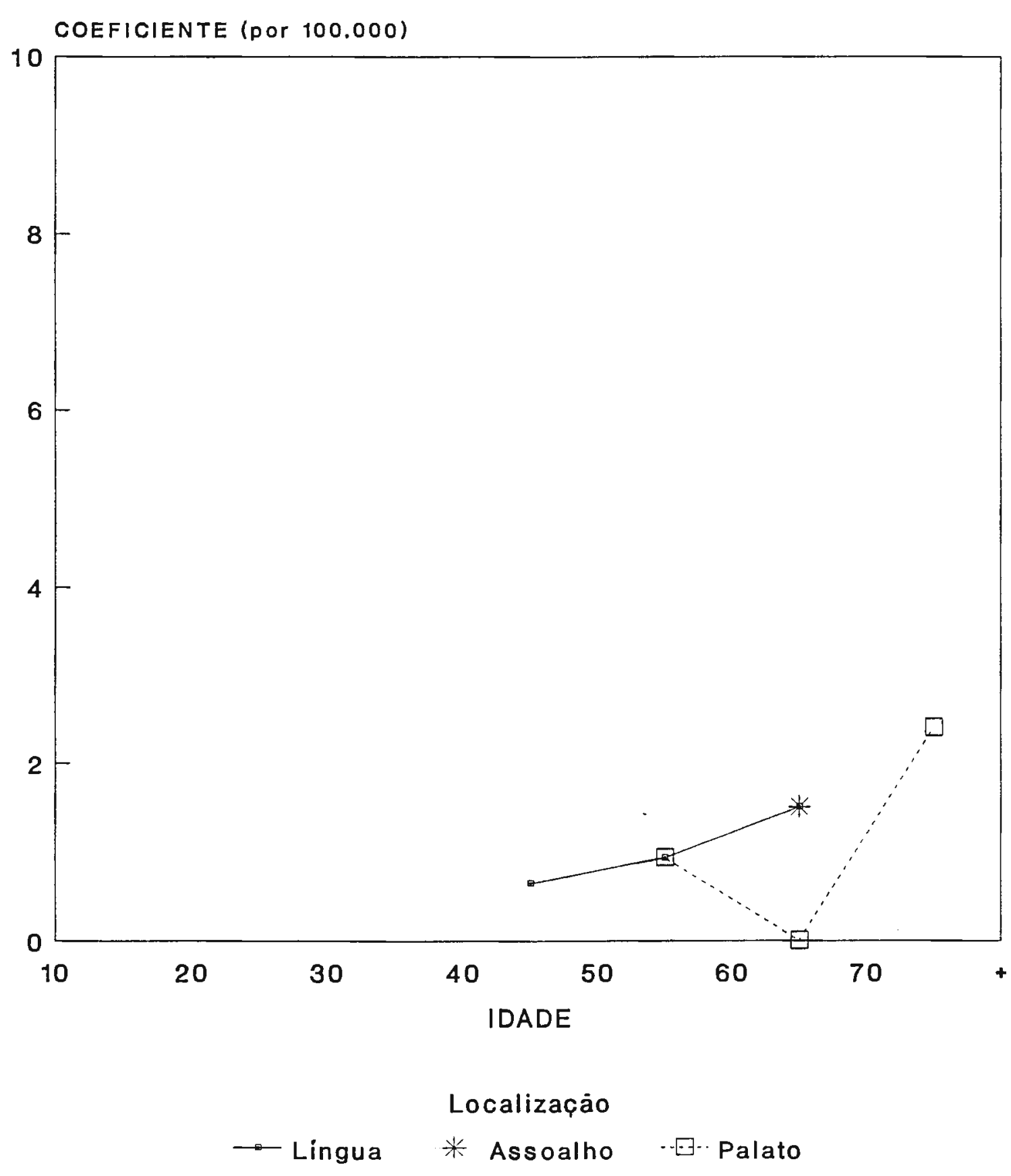


FIG.35-MORTALIDADE POR CÂNCER DE BOCA, SEGUNDO LOCALIZACCẢO DO TUMOR E IDADE . REG. DE PRESIDENTE PRUDENTE, 1979-1982 .

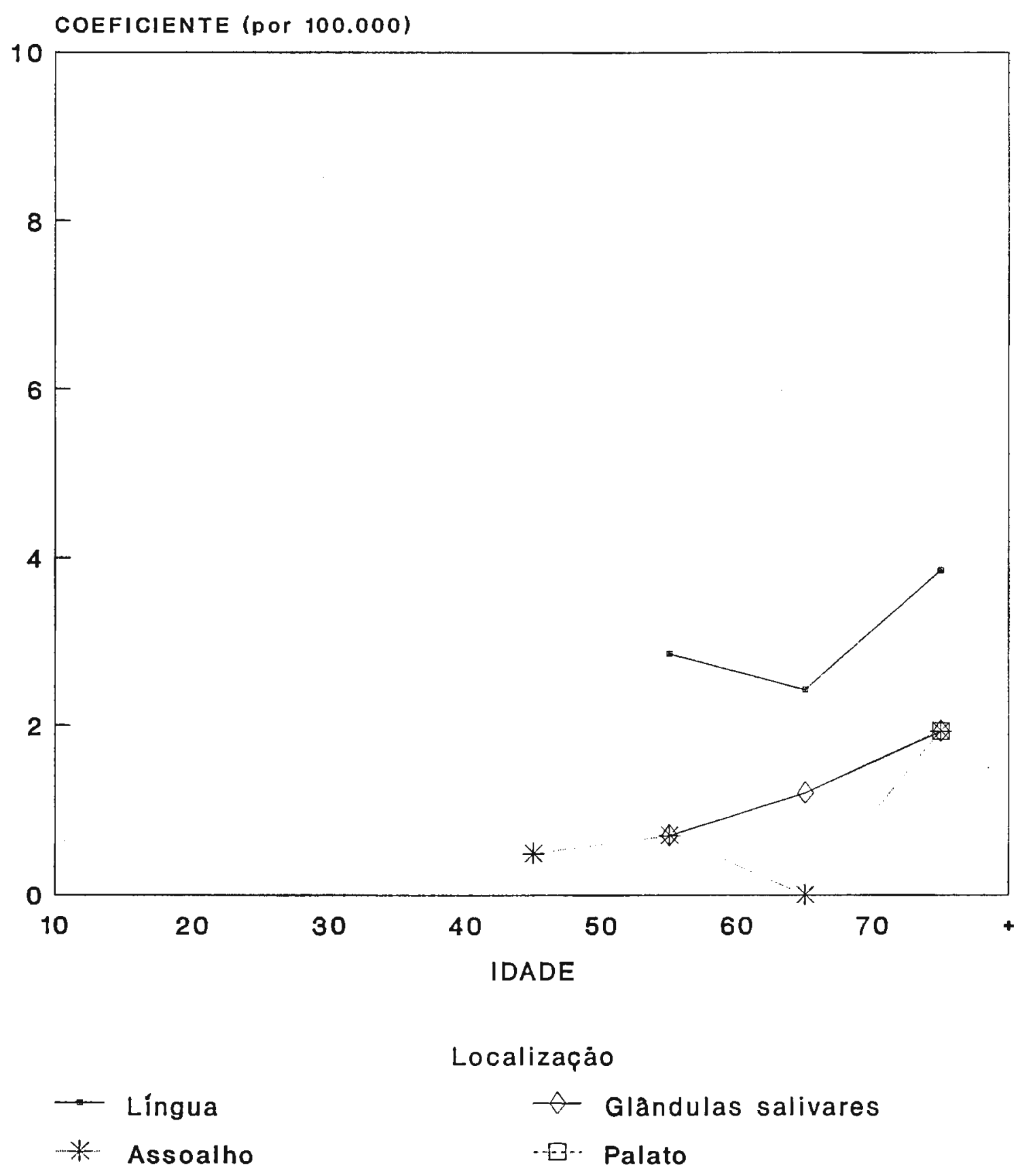


FIG.36-MORTALIDADE POR CÂNCER DE BOCA, SEGUNDO LOCALIZAÇĀO DO TUMOR E IDADE . REG. DE MARÍLIA, 1979-1982 .

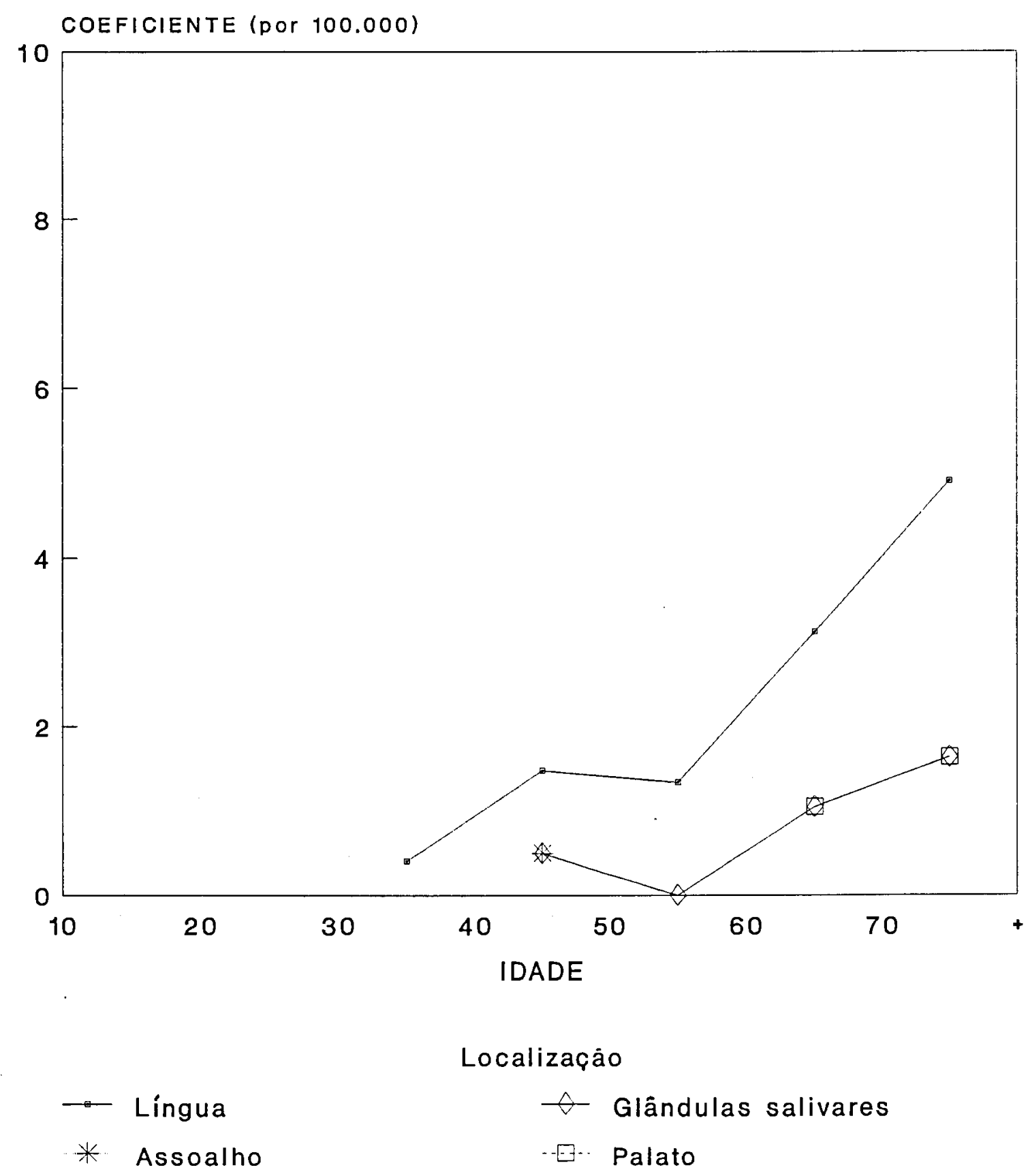


A localização língua apresenta os maiores valores de coeficientes de mortalidade, em todos os grupos etários em que ocorre, em nove das doze Regiōes: Municipio de São Paulo, Grande São Paulo, Sorocaba, Campinas, Ribeirão Preto, Bauru, São José do Rio Preto, Presidente Prudente e Marilia.

A localização lingua perde a primeira posição para a localização palato apenas no grupo acima dos 70 anos, em três Regiões: Litoral, Vale do Paraiba e Araçatuba. No Litoral e no Vale do Paraíba, a língua passa para a segunda posição e na Região de Araçatuba não se registra óbito por câncer de língua nesse grupo etário. Além disso, na Região de Bauru, nesse grupo de 70 anos e mais, a língua iguala-se na primeira posição com o palato e o assoalho da boca.

Quanto à idade mínima em que se registram os óbitos, segundo as localizações, verifica-se que as glândulas salivares são a única localização em que ocorrem óbitos no grupo etário de 10 a 19 anos (Regiões de Ribeirão Preto e Grande São Paulo, com coeficientes muito baixos). Em três localizações registram-se casos a partir do grupo etário de 20 a 29 anos: língua (duas Regiões: Campinas e Ribeirão Preto), glândulas salivares (duas Regiões: Litoral e Sorocaba) e palato (uma Região: Município de São Paulo).

Para a localização língua, é no grupo etário de 40 a 49 anos que, no maior número de Regiões, começam a registrar-se óbitos (cinco Regiões: Litoral, Vale do Paraíba, Bauru, São José do Rio Preto e Araçatuba); segue-se o grupo de 30 a 39 anos (quatro Regiões: Municipio de São Paulo, Grande São Paulo, Sorocaba e Marilia).

Também para a localização palato é no grupo de 40 a 49 anos que, no maior número de Regiões, começam a registrar-se óbitos (seis Regiões: Litoral, Vale do Paraiba, Sorocaba, Campinas, Ribeirão Preto e São José do Rio Preto). Em duas Regiōes (Bauru e Presidente Prudente) só ocorrem óbitos no último grupo etário e, em uma Região (Marilia), é apenas após os 60 anos que se registram óbitos por câncer de palato.

É no grupo etário de 30 a 39 anos que começam a registrar-se óbitos, na maior parte das Regiões, para a localização assoalho da boca (cinco Regiões: 
Litoral, Sorocaba, Campinas, Ribeirão Preto, São José do Rio Preto); segue-se o grupo de 40 a 49 anos (quatro Regiões: Município de São Paulo, Grande São Paulo, Presidente Prudente e Marilia). Para essa localização, em duas Regiões (Bauru e Araçatuba) só aparecem óbitos a partir dos 60 anos.

Em quatro Regiões a curva de mortalidade por câncer de língua é regularmente ascendente (Município de São Paulo, Campinas, São José do Rio Preto e Araçatuba). Em outras quatro Regiões (Grande São Paulo, Litoral, Vale do Paraiba e Bauru), após a curva ascendente, há decréscimo acentuado no grupo de 70 anos e mais, devendo-se observar, entretanto, que a determinação da causa de óbito em idade avançada é problemática, já que, nessa idade, existe freqüentemente concorrência de mais de uma causa de óbito, podendo haver desconsideração da neoplasia, no registro. Em outras três Regiões, a curva também é ascendente, mas há decréscimo em uma das faixas etárias (Sorocaba: 60 a 69 anos; Ribeirão Preto e Marília: 50 a 59 anos). Na Região de Presidente Prudente, em que só há óbitos a partir dos 50 a 59 anos, o coeficiente decresce no grupo etário seguinte, e cresce no de 70 anos e mais.

Para as localizações assoalho da boca e glândulas salivares, só três Regiões mantêm curva regularmente ascendente: no primeiro caso, Sorocaba, Ribeirão Preto e Bauru, e, no segundo caso, Município de São Paulo, São José do Rio Preto e Presidente Prudente. A curva referente ao assoalho da boca tem decréscimo no grupo de 60 a 69 anos em seis Regiões: Município de São Paulo, Litoral, Vale do Paraíba, Campinas, São José do Rio Preto e Presidente Prudente. A curva referente às glândulas salivares tem decréscimo no grupo de 60 a 69 anos em quatro Regiões: Grande São Paulo, Litoral, Vale do Paraíba, e Ribeirão Preto, sendo bem leve nas três últimas. Na Região de Ribeirão Preto se registram dois outros decréscimos leves em grupos anteriores: nos grupos de 20 a 29 anos e 40 a 49 anos. No grupo de 50 a 59 anos a curva referente às glândulas salivares tem decréscimo leve, em Sorocaba, Campinas e Marilia, sendo que, em Sorocaba, o grupo de 30 a 39 anos também apresenta decréscimo, embora leve.

Para a localização palato a curva é regularmente ascendente apenas 
em uma Região (Vale do Paraiba). Há decréscimo na curva, no grupo de 60 a 69 anos em quatro Regiões: Município de São Paulo, Sorocaba, Ribeirão Preto e Araçatuba. Em duas Regiões (Litoral e São José do Rio Preto) há decréscimo no grupo de 50 a 59 anos; em uma Região (Campinas) há decréscimo no grupo de 70 anos e mais; um decréscimo leve no grupo de 40 a 49 anos se verifica em uma Região (Grande São Paulo).

Para todas as localizações, o pico de mortalidade ocorre mais freqüentemente no grupo etário de 70 anos e mais: sete Regiões para a localização lingua (Municipio de São Paulo, Sorocaba, Campinas, Ribeirão Preto, São José do Rio Preto, Presidente Prudente e Marília), dez Regiões para a localização glândulas salivares (Municipio de São Paulo, Grande São Paulo, Litoral, Vale do Paraíba, Sorocaba, Campinas, Ribeirão Preto, São José do Rio Preto, Presidente Prudente e Marília), seis Regiões para a localização assoalho da boca (Município de São Paulo, Litoral, Vale do Paraiba, Bauru, São José do Rio Preto e Presidente Prudente), e onze Regiões para a localização palato (Municipio de São Paulo, Grande São Paulo, Litoral, Vale do Paraiba, Sorocaba, Ribeirão Preto, Bauru, São José do Rio Preto, Araçatuba, Presidente Prudente e Marilia). Deve-se observar que, para a localização glândulas salivares, só esse grupo etário pode ser considerado de pico, já que, nas duas Regiões não citadas, ou não se registram óbitos por essa localização (Araçatuba), ou a ocorrência de óbitos se restringe a apenas um grupo etário (Bauru: 30 a 39 anos).

Outro grupo no qual se registram picos de mortalidade por câncer de boca é o de 60 a 69 anos: cinco Regiões para a localização língua (Grande São Paulo, Litoral, Vale do Paraíba, Bauru e Araçatuba), três Regiões para a localização assoalho da boca (Grande São Paulo, Ribeirão Preto e Araçatuba) e uma Região para a localização palato (Campinas).

Só para a localização assoalho da boca se verifica um pico de mortalidade em grupo etário abaixo dos 60 anos (50 a 59 anos, em Campinas e em Sorocaba, sendo que, nesta última Região, não se registram óbitos acima desse grupo). 


\subsection{Considerações finais}

Apesar do reduzido número de estudos de mortalidade por câncer de boca de que se dispõe, pode-se dizer que os resultados que aqui se apresentam para - Estado de São Paulo como um todo estão de acordo com os achados da literatura em relação aos países do Ocidente, quanto a maiores valores de coeficientes no sexo masculino e nos grupos etários acima dos 60 anos. A ocorrência de óbitos em idades muito baixas, e somente no sexo feminino, refere-se apenas à localização glândulas salivares, e tem de ser avaliada levando-se em conta que, para o câncer dessa localização, indica-se atuação de fatores de risco especificos. Também a baixa mortalidade por câncer de lábio, verificada em região geográfica em que atuam fatores de risco para a incidência nessa localização, deve ser avaliada com vistas a uma especificidade desse câncer, que apresenta prognóstico favorável, possivelmente devido à maior facilidade de detecção.

Ainda na questão da localização do tumor, chama a atenção a alta proporção de casos de óbitos atribuídos a neoplasma de "boca, não especificada", que deixa perder uma determinação mais rigorosa da distribuição das localizações anatômicas. A questão de deficiência no preenchimento das declarações de óbito, ou, mesmo, de possiveis erros e imprecisões de diagnóstico deve ser associada, também, ao fato de que a maioria dos óbitos por câncer de boca ocorre em idade avançada, quando muito freqüentemente atuam várias causas de morte concorrentes. É com vistas a essas possibilidades de distorção que têm de ser avaliados resultados como decréscimos acentuados ou elevações acentuadas dos coeficientes de mortalidade verificados para algumas localizações anatômicas, em algumas Regiões Administrativas, especialmente no grupo de 70 anos e mais.

$\mathrm{Na}$ análise por Regiões Administrativas, verificou-se uma distribuição geográfica muito regular dos coeficientes gerais de mortalidade por câncer de boca, com gradação de acordo com blocos de Regiões geograficamente contíguas. Feita a análise conjunta das variáveis, porém, as Regiōes Administrativas não formaram agrupamentos que sugiram características comuns ligadas, basicamente, à localização geográfica, sendo necessárias investigações que avaliem os diversos indicadores de 
cada Região pertencente a um determinado grupo.

Considera-se que os dados apresentados neste trabalho comportam, em uma outra etapa, uma comparação com a composição sócio-econômica e os indicadores de saúde e de saneamento de cada Região. Comportam, ainda, uma avaliação da exposição das populações aos fatores de risco. Isso vale em especial para uma doença como o câncer de boca, que já foi invocada como exemplo de doença ligada a fatores ambientais, os quais só podem ser pesquisados se se dispõe de dados regionais que suportem a investigação de uma contribuição etiológica, relacionada com os fatores de risco, potencialmente variável segundo uma diferenciação regional. 


\section{CONCLUSÕES}

1. O Estado de São Paulo como um todo apresentou, no periodo de março de 1979 a fevereiro de 1982, 1.158 casos de óbitos por câncer de boca, representando 2,1\% dos óbitos por câncer em geral e correspondendo a um coeficiente de mortalidade por câncer de boca igual a 1,54 por 100.000 habitantes.

2. A distribuição desses óbitos por sexo mostrou um coeficiente de mortalidade do sexo masculino (2,56 por 100.000 homens) bem superior ao do sexo feminino (0,52 por 100.000 mulheres), com uma razão homens/mulheres de 4,92: 1 .

3. Mortalidade mais elevada no sexo masculino também ocorreu em cada um dos grupos etários em estudo, excetuados os grupos de 20 a 29 anos (mortalidade igual nos dois sexos) e de 10 a 19 anos (mortalidade apenas no sexo feminino).

4. Para ambos os sexos, a localização língua constitui a principal causa de mortalidade por câncer de boca (50,4\% dos óbitos masculinos e $36,2 \%$ dos óbitos femininos). Nas demais posições, os dois sexos apresentam resultados diferentes. Na segunda posição está o assoalho $(9,9 \%)$ para os homens e o palato $(14,9 \%)$, para as mulheres. Seguem-se o palato $(7,2 \%)$ e as glândulas salivares $(6,2 \%)$, para os homens, e as glândulas salivares $(13,8 \%)$ e a gengiva $(5,6 \%)$, para as mulheres. Com grande proporção aparece, nos dois sexos, a classificação "boca, não especificada" ( $15,5 \%$ no sexo masculino e $17,9 \%$ no sexo feminino).

5.0 cálculo dos coeficientes de mortalidade para cada uma das localizações do tumor mostrou que, para todas elas, os coeficientes obtidos para o sexo masculino são maiores que os obtidos para o sexo feminino. A maior razão homens/mulheres foi encontrada para a localização assoalho da boca $(12,50: 1)$, seguindo-se a língua $(6,79: 1)$, o lábio $(3,33: 1)$, a gengiva $(3,00: 1)$, as glândulas salivares $(2,29: 1)$ e o palato $(2,25: 1)$. 
6. A análise da mortalidade por câncer de cada uma das localizações do tumor, feita por grupos etários, mostrou que, para o sexo masculino, a localização língua ocupa sempre a primeira posição, destacadamente nos grupos etários situados acima dos 40 anos. No sexo feminino, em que os valores dos coeficientes são muito baixos, para todas as localizações, até o grupo de 50 a 59 anos, a superioridade da língua se destaca apenas a partir desse grupo. No sexo masculino, a segunda posição é ocupada pelo assoalho, nos grupos etários inferiores a 70 anos, e pelas glândulas salivares, a partir dessa idade. No sexo feminino, no grupo de 50 a 59 anos, as glândulas salivares aparecem na segunda posição, e nos grupos etários mais avançados essa posição é ocupada pelo palato.

7. No estudo por Regiões Administrativas verificou-se que as duas Regiões que apresentam os maiores coeficientes de mortalidade - Litoral (2,16 por 100.000 habitantes) e Vale do Paraíba (1,83 por 100.000 habitantes) - ocupam o Sul e o Sudeste do Estado. As três Regiões de menores coeficientes - Araçatuba (0,55 por 100.000 habitantes), Presidente Prudente (0,95 por 100.000 habitantes) e Marília (1,11 por 100.000 habitantes) - se concentram no Oeste do Estado. As demais Regiões apresentam valores de coeficientes intermediários entre esses extremos.

8. Na Região do Litoral ocorreram as maiores taxas de mortalidade tanto para o sexo masculino $(3,40$ por 100.000 homens) como para o sexo feminino $(0,98$ por 100.000 mulheres). As menores taxas ocorreram em duas Regiões vizinhas, no Oeste do Estado, Araçatuba, no sexo masculino (0,72 por 100.000 homens), e Presidente Prudente, no sexo feminino $(0,10$ por 100.000 mulheres $)$.

9. A comparação da mortalidade entre os dois sexos mostrou que, para a maioria das Regiões, a razão homens/mulheres foi cerca de $5: 1$. Valores discrepantes foram obtidos para as Regiões de Presidente Prudente $(18,10: 1)$, São José do Rio Preto $(13,87: 1)$ e Araçatuba $(1,89: 1)$. 
10. Para a maioria das Regiões, a mortalidade cresce com o avanço da idade e atinge seu pico no grupo etário de 70 anos e mais. A idade em que se inicia a ocorrência de óbitos por câncer de boca varia entre as Regiões mas, para a maioria delas, os valores dos coeficientes de mortalidade só têm valor expressivo após os 40 anos, embora já se registrem óbitos antes dessa idade.

11. A análise conjunta das variáveis sexo e idade para cada uma das Regiões resultou na verificação de coeficientes superiores para o sexo masculino, exceto na Região de Araçatuba, na sétima década. Em cinco Regiões se registra, no sexo feminino, mortalidade em grupos de idades mais baixas do que no sexo masculino. Tanto no sexo masculino como no feminino os coeficientes de mortalidade aumentam com a idade, de um modo geral, em todas as Regiöes. O pico de mortalidade situa-se, em todas as Regiões e para ambos os sexos, após os 60 anos; após os 70 anos está o pico em oito Regiões, para o sexo masculino, e em dez, para o sexo feminino.

12. Em todas as Regiões os maiores coeficientes de mortalidade se referem ao câncer de língua. As duas ủltimas posições variam entre o câncer de lábio e o de gengiva em quase todas as Regiões. Os cânceres de assoalho, de glândulas salivares e de palato ficam em posição intermediária na maioria das Regiões, mas o assoalho ocupa a última posição na Região do Vale do Paraíba, o palato, na Região de Bauru, e as glândulas salivares na Região de Araçatuba.

13. Calculados os coeficientes de mortalidade especificos por localização do tumor e sexo, e padronizados por idade, verificaram-se valores maiores no sexo masculino do que no feminino, em todas as localizações, em oito Regiões; o coeficiente feminino só foi maior em uma Região (Grande São Paulo), para palato, em uma Região (Litoral), para gengiva, em uma Região (Bauru), para glândulas salivares, e em duas Regiões (Vale do Paraiba e Araçatuba), para assoalho da boca. 
14. Analisadas conjuntamente as variáveis idade e localização do tumor, verificou-se que, em geral, a língua apresenta os maiores coeficientes nos diversos grupos etários. Em todas as Regiões e em todas as localizações os coeficientes aumentam, de um modo geral, com a idade. O pico de mortalidade, para todas as localizações, e na maior parte das Regiões, se situa no grupo de 70 anos e mais, ou no imediatamente inferior, de modo que em apenas duas Regiões (Campinas e Sorocaba), e apenas para a localização assoalho da boca, se verifica pico de mortalidade abaixo dos 60 anos. 


\section{REFERÊNCIAS BIBLIOGRÁFICAS}

01. ADAIR, S. M. Risks and benefits of fluoride mouthrinsing. Pediatrician, 16: 161-9, 1989.

02. ALTINI, M. et al. The causation of oral precancer and cancer. S.Afr.Med.J. (Suppl. 1): 6-10, 1989.

03. BAKER, S.R. \& SWANSON, N.A. Cancer of the oral cavity and Mohs surgery. Dermatol.Clin., Z: 815-24, 1989.

04 . BANOCZY, J. \& RIGO, O. Prevalence study of oral precancerous lesions within a complex screening system in Hungary. Community Dent.Oral Epidemiol., 19:265-7, 1991.

05 . BARRA, S. et al. Type of alcoholic beverage and cancer of the oral cavity, pharynx and oesophagus in an Italian area with high wine consumption. Int.J.Cancer, 46: 1017-20, 1990.

06 . BARRA, $S$. et al. Cancer and non-cancer controls in studies on the effect of tobacco and alcohol consumption. Int.J.Epidemiol, 20: 845-51, 1991.

07 . BLOT, W.J. et al. Smoking and drinking in relation to oral and pharyngeal cancer. Cancer Res., 48: 3282-7, 1988.

08. BOSCHI-PINTO, C. Mortalidade por câncer do trato digestivo no Estado do Rio de Janeiro: uma apreciação por estratificação. Rio de Janeiro, 1991. [Dissertação de Mestrado-Escola Nacional de Saúde Pública/ FIOCRUZ].

09. BOYLE, P. et al. Epidemiology of mouth cancer in 1989: a review. J.R.Soc.Med., 83: 724-30, 1990.

10. BRYNE, M. et al. Prognostic value of Rhesus blood groups in oral squamous cell carcinomas. Cancer, 68: 2213-6, 1991.

11. CAHN, L.R. The early detection of cancer of the mouth. Br.Dent.J., 111: 285-90, 1961.

12. CALDAROLA, F. Trattamento dei tumori del cavo orale. Minerva Chir.,46: 107798, 1991.

13. CENTERS FOR DISEASE CONTROL. Death from oral cavity and pharyngeal cancer : United States, 1987. MMWR-Morb.Mortal.Wkly.Rep. 39: 457-9, 1990.

14. CHAKRABARTI, R. N. et al. Smokeless tobacco and premalignant lesions of the oral cavity. Indian J.Med.Sci., 45: 273-5, 1991.

15. CHATTOPADHYAY, A. Epidemiologic study of oral cancer in eastern India. Indian J.Dermatol., 34: 59-65, 1989.

16. CHEN, J. K. et al. Epidemiology of oral cancer in Connecticut, 1935 to 1985. Cancer, 65: 2796-802, 1990.

17. CHEN, J.K. et al. Changing trends in oral cancer in the United States, 1935 to 1985: A Connecticut study. J.Oral Maxillofac.Surg., 49:1152-8, 1991. 
18. CHOI, S.Y. \& KAHYO, H. Effect of cigarette smoking and alcohol consumption in the aetiology of cancer of the oral cavity, pharynx and larynx. Int.J.Epidemiol. 20: 878-85, 1991.

19. CIANFRIGLIA, F. \& MANIER, A. Diagnostic delay in neoplasms of the oral cavity. Minerva Stomatol., 40: 717-28, 1991.

20. CIANFRIGLIA, F. et al. Experience in staging malignant tumors of the orofacial area. Minerva Stomatol., 40: 681-7, 1991.

21. CONNOLY, G.N. et al. Snuffing tobbacco out of sport. Am.J.Public Health, $\underline{82}$ 351-3, 1992.

22. CORINO, U. \& SARGIAN, P. Contributo clinico statistico sul $\mathrm{Ca}$ del cavo orale. Dent. Cadmos, 58: 64-70, 1990.

23. COX, M.F et al. Viruses in the aetiology of oral carcinoma: examination of the evidence. Br.J.Maxillofac.Surg., 29: 381-7, 1991.

24. CREATH, C. J. et al. The prevalence of smokeless tobacco use among adolescent male athletes. J.Am.Dent.Assoc., 116: 43-8, 1988.

25. CRIVELLI, M. R. et al. Frequency and distribution of oral lesions in elderly patients. Rev.Assoc. Odontol.Argent., 78: 55-8, 1990.

26. CUMMINGS, K.M. et al. Use of smokeless tobacco in a group of professional baseball players. J.Behav.Med., 12: 559-67, 1989.

27. DE STEFANI, E. et al. Hand-rolled cigarette smoking and risk of cancer of the mouth, pharynx, and larynx. Cancer, 70: 679-682, 1992.

28. DEAN, A.G. et al. Epi Info, Version 5: a word processing database, and statistics program for epidemiology on microcomputers. USD, Incorporated, Stone Mountain, Georgia, 1990.

29. DEEB, Z.E. et al. The association of chronic inflammatory disease in lichen planus with cancer of the oral cavity. Am. J. Otolaringol. ,10:314-6, 1989.

30. DIALLO, P.D. \& MOREAU, J.L. Les cancers buccaux: clinique et épidémiologie au Sénégal. Chir.Dent.Fr., 57: 33-5, 1987.

31. DOHERTY, S.A. Basic issues in screening for oral cancer among male subpopulation. J.Tenn.Dent.Assoc.,69:26-9, 1989.

32 . ELBESHIR, E.I. et al. Snuff dipping and oral cancer in Sudan:a retrospective study. Br.J.Oral Maxillofac.Surg., 27:243-8, 1989.

33. FEDELE, D.J. et al. Oral cancer screening in the elderly. J.Am.Geriatr.Soc., 39: 920-5, 1991.

34. FRANCO, E.L. et al. Risk factors for oral cancer in Brazil: a case-control study. Int. J. Cancer, 43:992-1000, 1989.

35. FRAUMENI Jr, J. The face of cancer in the United States. Hosp. Pract., 18: 81 96, 1983.

36. GAYFORD J.J. \& HASKELL, R. Clinical oral medicine. London, Staples Press, 1971. 
37. GAZIT, D. et al. A study of a sample of oral cancer in Israel. Oral Surg., 57: 118$121,1984$.

38. GERSON, S.J. Oral cancer. Crit. Rev. Oral. Biol. Med, 1: 153-66, 1990.

39. GLOVER E.D. et al. Smokeless tobacco use among American college students. J. Am. Coll. Health, 38: 81-5, 1989.

40. GONZALEZ J.Q. - Carcinoma escamocelular de cavidad oral en la Costa Atlantica colombiana. Unimetro - Organo de Informacion investigacion, (jan. - jun.): 2634, 1985.

41. GOTLIEB, S.L.D. Mortalidade diferencial por causas. São Paulo, 1970: tábua de vida de múltiplo decremento. São Paulo, 1977 [Tese de Doutoramento Faculdade de Saúde Pública da USP].

42. GOUD, M.L. et al. Epidemiological correlates between consumption of Indian chewing tobacco and oral cancer. Eur. J. Epidemiol, 6: 219-22, 1990.

43. GRADDY D. et al. Oral mucosal lesions found in smokeless tobacco users. J. Am. Dent. Assoc, 121: 117-23,1990.

44. GREENBERG, R.S. et al. The relation of socioeconomic status to oral and pharyngeal cancer.Epidemiology,2:194-200, 1991.

45. GRIDLEY, G. et al. Diet and oral and pharyngeal cancer among blacks. Nutr. Cancer, 14: 219-25, 1990.

46. GRIDLEY, G. et al. Vitamin supplement use and reduced risk of oral and pharyngeal cancer. Am. J. Epidemiol., 135: 1083-92, 1992.

47 . GUEDES, J. S. Contribuição para o estudo da evolução do nível de saúde do Estado de São Paulo: análise das regiões administrativas (1950-1970). São Paulo, 1971. [Tese de Doutoramento - Faculdade de Saúde Pública da USP]

48. GUPTA, P.C. Betel quid and oral cancer: prospects for prevention. IARC. Sci. Publ., (105): 406-70, 1991.

49. HAMADA, G.S. et al. Comparative epidemiology of oral cancer in Brazil and India.Tokai J. Ex. Clin. Med.,16:63-72, 1991.

50. HARDT, N. \& SCHLENK, E. Plattenepithel-Karzinom der Mund-Schleimhaut (I). Schweiz Monatsschr. Zahnmed., 101:1453-7, 1991.

51. HINDLE, I.\& NALLY, F. Oral cancer: a comparative study between 1962-67 and 1980-84 in England and Wales. Br. Dent. J., 170: 15-20, 1991.

52. HORN-ROSS, P.L. et al. Recent trends in the incidence of salivary gland cancer. Int. J. Epidemiol., 20:628-33, 1991.

53. ILDSTAD, S.T. et al. A multivariate analysis of determinants of survival for patients with squamous carcinoma of the head and neck. Ann. Surg., 209: 237-41, 1989.

54. JOHNSON, N.W. Orofacial neoplasms: global epidemiology, risk factors and recommendations for research. Int. Dent. J., 41: 365-75, 1991. 
55. KABAT, G.C. \& WYNDER, E.L. Type of alcoholic beverage and oral cancer. Int. J. Cancer, 43: 190-4, 1989.

56. KABAT, G.C. et al. Risk factors for oral cancer in women. Cancer. Res., 49 : 2803-6, 1989.

57. KANDARKAR, S.V. \& READ, P.C. The effect to topical vitamin C on palatal oral mucosal carcinogenesis using 4-nitroquinoline-1- oxide. J. Biol. Buccale, 19: 199-204, 1991.

58. KRUTCHKOFF, D.J. Oral cancer: a survey of 566 cases from the University of Connecticut Oral Pathology Biopsy Service, 1975-1986. Oral Surg. Oral. Med. Oral Pathol., 70:192-8,1990.

59. LANGDON, J.D. et al. Oral cancer: the behaviour and response to treatment of 194 cases. J. Maxillofac. Surg., 5: 221-237, 1977.

60. LANGDON, J.D. \& RAPIDIS, A.D. Oral cancer and sex. Why do females do better ? J. Maxillofac. Surg., 7: 177-81, 1979.

61. LAURENTI, R. Epidemiologia das neoplasias malignas: estudos de mortalidade. São Paulo, Faculdade de Saúde Pública da USP, 1976.

62. LAURENTI, R. Usos das estatísticas de mortalidade. [Apresentado na 2.a Reunião Nacional do Sub-sistema de Informação sobre Mortalidade, Brasilia, 1987].

63. LAURENTI, R. \& JORGE, M.H.P.M. O atestado de óbito. $2^{\circ}$ ed. São Paulo, Centro da OMS para a Classificação de Doenças em Português (Centro Brasileiro de Classificação de Doenças), 1987. (Série Divulgação,1)

64. LA VECCHIA, C. et al. Dietary indicators of oral pharyngeal cancer. Int. J. Epidemiol., 20: 39-44, 1991.

65 . LEBRÃO, M.L. Utilização da classificação internacional de doenças em informações de morbidade. São Paulo, Centro da OMS para a Classificação de Doenças em Português, (Centro Brasileiro de Classificação de Doenças), 1993. (Série Divulgação, 8).

66. LILIENFELD, A.M. et al. Cancer epidemiology: methods of study. Baltimore, The Johns Hopkins Press, 1967.

67. LINDELOV, B et al. Squamous cell carcinoma of the oral cavity. Acta Oncol., 29: 1011-5, 1990.

68. LOWRY, R.J. Prevention of oral carcinoma. Dent.Update, 17: 58-61, 1990.

69. MADEN, $C$. et al. Human papillomaviruses, herpes simplex viruses, and the risk of oral cancer. Am. J. Epidemiol.,135: 1093-102, 1992.

70. MAGEE, W.P. et al. Cancer of the floor of the mouth and bucal cavity. Surg. Clin. North Am. 66: 31-58, 1986.

71. MAIER, $H$. et al. Beruf und Krebs im Bereich von Mundhohle, Pharynx und Larynx; HNO, 38: 271-8, 1990.

72. MAIER, $H$. et al. Risk factors for squamous epithelial carcinoma of the mouth, the oropharynx, and the larynx. Dtsch. Med. Wochenschr., 115: 843-50, 1990. 
73. MAIER, $H$. et al. Tobacco and alcohol and the risk of head and neck cancer. Clin. Investig., 70: 320-7, 1992.

74. MATTSON, M.E \& WINN, D.M. Smokeless tobacco: association with increased cancer risk. NCl Monogr., (8): 13-6, 1989.

75. MCDERMOTT, I. Caring for cancer patients in the general dental office. J. N. Dent. Assoc., 60: 53-6. 1989.

76. McGREGOR, A.D \& RENNIE, J.S. Intra-oral squamous cell carcinoma in patients under 40 years of age. A report of 13 cases and review of the literature. $\mathrm{Br}$. J. Plast. Surg., 40: 270-3, 1987.

77. MECKLENBURG, R. E. et al. Tobacco effects in the mouth. NIH Publication, $\underline{93}$ (3330), 1992.

78. MENDONÇA, G. A. e S. Mortalidade por câncer no Estado do Rio de Janeiro. 1979/1986. Rio de Janeiro, 1991.[Dissertação de Mestrado- Instituto de Medicina Social da UERJ].

79. MERCER, B.L. Oral cancer mortality in the Republic of Ireland 1979 to 1986. J. Ir. Dent. Assoc., 36: 139-42, 1990.

80. MERLETTI, F. et al. Role of tobacco and alcoholic beverages in the etiology of cancer of the oral cavity/ oropharynx in Torino, Italy. Cancer. Res., 49: 491924, 1989.

81. MERLETTI, F. et al. Occupation and cancer of the oral cavity or oropharynx in Turin, Italy. Scand. J. Work Environ. Health, 17: 248-54, 1991.

82. MINISTÉRIO DA SAÚDE. Instituto Nacional de Câncer. Coordenação de

Programas de Controle de Câncer. Registro nacional de patologia tumoral.

Diagnósticos de câncer: Brasil - 1981/85. Rio de Janeiro, 1991.

83. MINISTÉRIO DA SAÚDE. Secretária Nacional de Ações Básicas de Saúde.

Divisão Nacional de Epidemiologia. Estatísticas de mortalidade: Brasil - 1979.

Brasília, Centro de Documentação do Ministério da Saúde, 1982.

84. MINISTÉRIO DA SAÚDE. Secretária Nacional de Ações Básicas de Saúde.

Divisão Nacional de Epidemiologia. Estatísticas de mortalidade: Brasil - 1980.

Brasília, Centro de Documentação do Ministério da Saúde, 1983.

85. MINISTÉRIO DA SAÚDE. Secretária Nacional de Ações Básicas de Saúde.

Divisão Nacional de Epidemiologia. Estatísticas de mortalidade: Brasil - 1981.

Brasília, Centro de Documentação do Ministério da Saúde, 1984.

86. MINISTÉRIO DA SAÚDE. Secretária Nacional de Ações Básicas de Saúde.

Subsistema de informações sobre mortalidade - 1979 a 1986. Brasília, SIM/DNE/SNABS/MS, 1990.

87. MIRRA, A.P. \& FRANCO, E.L. Cancer incidence in São Paulo County Brasil. 1969.1973.1978. São Paulo, Registro de Câncer de São Paulo / Instituto Ludwig de Pesquisa sobre o Câncer, 1985. 
88. MOLLER, $H$. Changing incidence of cancer of the tongue, oral cavity, and pharynx in Denmark. J. Oral. Pathol. Med., 18: 224-9, 1989.

89. MUIR, C.S. et al. Cancer incidence in five continents. Lyon, International Agency for Research on Cancer, 1987. v.5 (IARC Cientific Publication, 88).

90 . NEVES, L.H.M. Cáncer bucal: morbilidad en el Muncipio de Araraquara-SP, Brasil [Apresentado à $24^{\circ}$ Reunión Anual de la División Argentina de la Asociación Internacional de Investigación Odontológica, Córdoba, 1991].

91. NEVES, L.H.M. Câncer de boca: mortalidade no município de Araraquara - SP, no período de 1979 a 1991. Araraquara, 1992.

92. NOCCHETTI, A. et al. Patologia ambientale ed odontoiatria. Nota III. I processi cancerosi dei tessuti mobili della cavità orale. Minerva Stomatol., 39: 619$24,1990$.

93. OREGGIA, F. et al. Occupational exposure in cancer of the mouth, pharynx and larynx. An. Otorrinolaringol. Ibero Am., 16: 365-76, 1989.

94. ORGANIZAÇÃO MUNDIAL DA SAÚDE. Manual de classificação estatística internacional de doenças, lesões e causas de óbito, 9a. revisão, 1975. São Paulo, Centro da OMS para Classificação de Doenças em Português, 1978- v.1.

95 . PASTORELO, E.F. \& GOTLIEB, S.L.D. Mortalidade por câncer no Estado de São Paulo, Brasil - 1970/1972. Rev. Saúde Pública, 12: 1-15, 1978.

96. PETERS, E. \& McGAW, W.T. Oral cancer and precancer. J. Can. Dent. Assoc., 56 : 919-21, 1990.

97 . PILLAI, R. et al. Pathogenesis of oral submucous fibrosis. Relationship with risk factors associated with oral cancer. Cancer, 69: 2011-20, 1992.

98. REICHART, P.A. et al. Oral cancer in northern Thailand. Exp. Pathol, 40: 229-31, 1990.

99. REYCHLER, H. Epidémiologie et étiopathogénie du carcinome buccal: mise au point actualisée. Acta. Stomatol. Belg., 87: 157-65,1990.

100. RINDUM, J. \& PINDBORG, J.J. Intraoral cancer: 100 consecutive cases. Tandlaegebladet, 93: 504-5, 1989.

101. ROSA, M.R.D. Câncer oral: estudo epidemiológico de 670 casos registrados no Hospital "Dr. Napoleão Laureano"- João Pessoa, Pb. $\underline{\text { CCS }}$, 7: 41-5, 1985.

102. ROTHMAN, K.J. Modern Epidemiology. Boston, Brown and Company, 1986.

103. RUIZ MENDEZ, A. et al. Prevalence of malignant oral neoplasms in the Celia Sanchez Clinicosurgical Hospital from 1982 to 1985 . Rev. Cubana Estomatol. 26:235-41, 1989.

104. SAMARA, M. Câncer de boca: incidência e mortalidade em residentes no municipio de São Paulo; periodo 1969-1971. São Paulo, 1987. [Dissertação de Mestrado - Faculdade de Saúde Pública da USP]. 
105. SAMPAIO, M.C. et al. Análise do carcinoma bucal: casuística do hospital Napoleão Laureano - João Pessoa. Rev. Bras. Cancerol., 31: 125-30, 1985.

106. SANKARANARAYANAN, R. Oral cancer in India: an epidemiologic and clinical review. Oral Surg. Oral Med. Oral Pathol., 69: 325-30, 1990.

107. SANKARANARAYANAN, $R$, et al. A case-control investigation of the oral tongue and the floor of the mouth in southern India.Int. J. Cancer, 44: 617-21, 1989.

108. SANKARANARAYANAN, R. et al. Risk factors for cancer of the buccal and labial mucosa in Kerala, southern India. J. Epidemiol. Community Health, 44: 28692, 1990.

109. SANKARANARAYANAN, $R$. et al. Recent results of oral cancer research in Kerala, India. Head Neck, 14: 107-12, 1992.

110. SÃO PAULO (Estado). Secretaria de Economia e Planejamento. Diagnóstico [das Regiōes Administrativas...] São Paulo, 1971. 14v.

111. SÃO PAULO (Estado). Secretaria do Interior. Coordenadoria de Ação Regional. Divisão territorial administrativa do Estado de São Paulo. São Paulo, 1981.

112. SFASCIOTTI, M. et al. Risultati di un questionario sulle neoplasie maligne della cavità orale. Minerva Stomatol., 38: 1035-8, 1989.

113. SILVERMAN Jr.,S. \& GALANTE, M. Oral cancer. $7^{\circ}$ ed. rev. San Francisco, University of California, 1978.

114. SILVERMAN Jr., S. \& GORSKY, M. Epidemiologic and demographic update in oral cancer: California and national data -1973 to 1985 . J.Am. Dent. Assoc., 120: 495-9, 1990.

115. SMITH, C.J. Oral cancer and precancer: epidemiology and aetiology $\mathrm{Br}$. Dent. J., 167: 377-83, 1989.

116. SON, Y.H. \& KAPP, D.S. Oral cavity and oropharyngeal cancer in a younger population: review of literature and experience at Yale. Cancer, 55: 441-4, 1984.

117. SOTELO, O.C. et al. Incidencia de neoplasias bucales en ciudad de la Habana. Rev. Cubana Hiq. Epidemiol., 28: 52-6, 1990.

118. STEELE, C. \& SHILLITOE, E.J. Viruses and oral cancer. Crit. Rev. Oral. Biol. Med., 2: 153-75, 1991.

119. STELL, P.M. Prognosis in mouth cancer: host factors. J. Laryngol. Otol.,106: 399402, 1992.

120. STERLING, T.D. et al. Analysis of the relationship between smokeless tobacco and cancer based on data from the National Mortality Followback Survey. J. Clin. Epidemiol., 45: 223-31, 1992.

121. STOYKEWYCH, A.A. et al. Reverse smoking and its effects on the hard palate: a case report. J. Can. Dent. Assoc., 58: 215-6, 1992.

122. SUMMERLIN, D.J. Oral squamous cell carcinoma in Indiana. J. Indian. Dent. Assoc., 70: 10-3, 1991. 
123. SUNDEFELD, M.L.M.M. et al. O estudo descritivo da ocorrência do câncer de boca, na população da 9a. região administrativa do Estado de São Paulo. Rev. Odontol. UNESP, 22: 135-45, 1993.

124. SWOBODA, $H$. et al. Incidence and age at onset of cancers of the mouth and oropharynx since 1960: the epidemiologic contex in East Austria. HNO (aug.): 338-42, 1989.

125. TALAMINI, R. et al. The role of alcohol in oral and pharyngeal cancer in nonsmokers, and of tobacco in non-drinkers. Int. J. Cancer, 46: 391-3, 1990.

126. THOMAS, J.E. \& FAECHER, R.S. A physician's guide to early detection of oral cancer. Geriatrics, 47: 58-63, 1992.

127. THOMAS, S.J. \& MACLENNAN, R. Slaked lime and betel nut cancer in Papua New Guinea. Lancet, 340(8819): 577-8, 1992.

128. TONIOLO, F.C. \& BORACKS, S. Fatores relacionados ao desenvolvimento do câncer bucal. Rev. Fac. Ondont. FZL, 1: 105-13, 1989.

129. TRAINING in oral and precancer; guidelines from the Comission of European Community. Ned. Tijdschr. Tandheelkd. 96: 159-61, 1989.

130. TUYNS, A.J. Alcohol-related cancers in Mediterraneo countries. Tumori, 76: 315$20,1990$.

131. WALTON, L. et al. Epidemiology and demographic update in oral cancer: California 1973-1990. CDA Journal, 19: 17-22, 1991.

132. WARD-BOOTH, P. Advances in the diagnosis and treatment of oral cancer. Curr. Opin. Dent., 1: 287-95, 1991.

133. WATERHOUSE, J. et al. Cancer incidence in five continents. Lyon, Internacional Agency for Research on Cancer, 1982. v.4 (IARC Cientific Publication,42).

134. WILLIAMS, J.L. Oral cancer and precancer: clinical features. Br. Dent. J., 168:137, 1990.

135. WINN, D.M. et al. Mouthwash use and oral conditions in the risk of oral and pharyngeal cancer. Cancer. Res., 51: 3044-7, 1991.

136. WORLD HEALTH ORGANIZATION. Control of oral cancer in developing countries. Bull. World Health Organ., 62: 817-30, 1984.

137. WYNDER, E.L. et al. Comparative epidemiology of cancer between the United States and Japan. A second look. Cancer, 67(3): 746-51, 1991.

138. ZHENG,T.Z. et al. Dentition, oral hygiene, and risk of oral cancer: a case-control study in Beijing, People's Republic of China . Cancer Causes Control, 1:23541, 1990.

139. ZHENG, T.Z. et al. Tobacco smoking, alcohol consumption, and risk of oral cancer: a case-control study in Beijing, People's Republic of China. $\underline{\text { Cancer }}$ Causes Control, 1: 173-9, 1990. 


\section{ANEXO 1}

Regiões Administrativas do Estado de São Paulo 


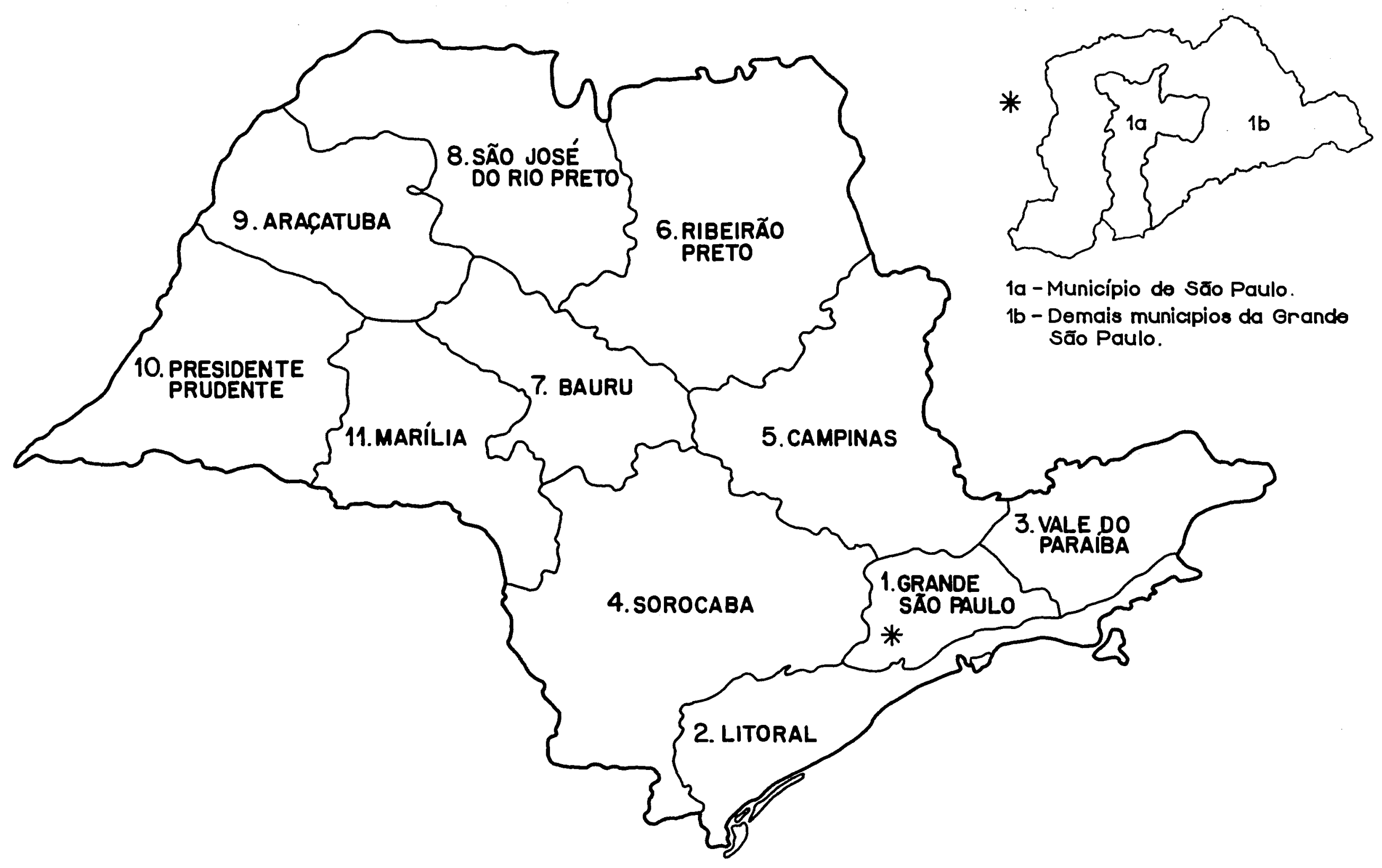

FIG. 1 - REGIÕES ADMINISTRATIVAS do ESTADO de SÃO PAULO 


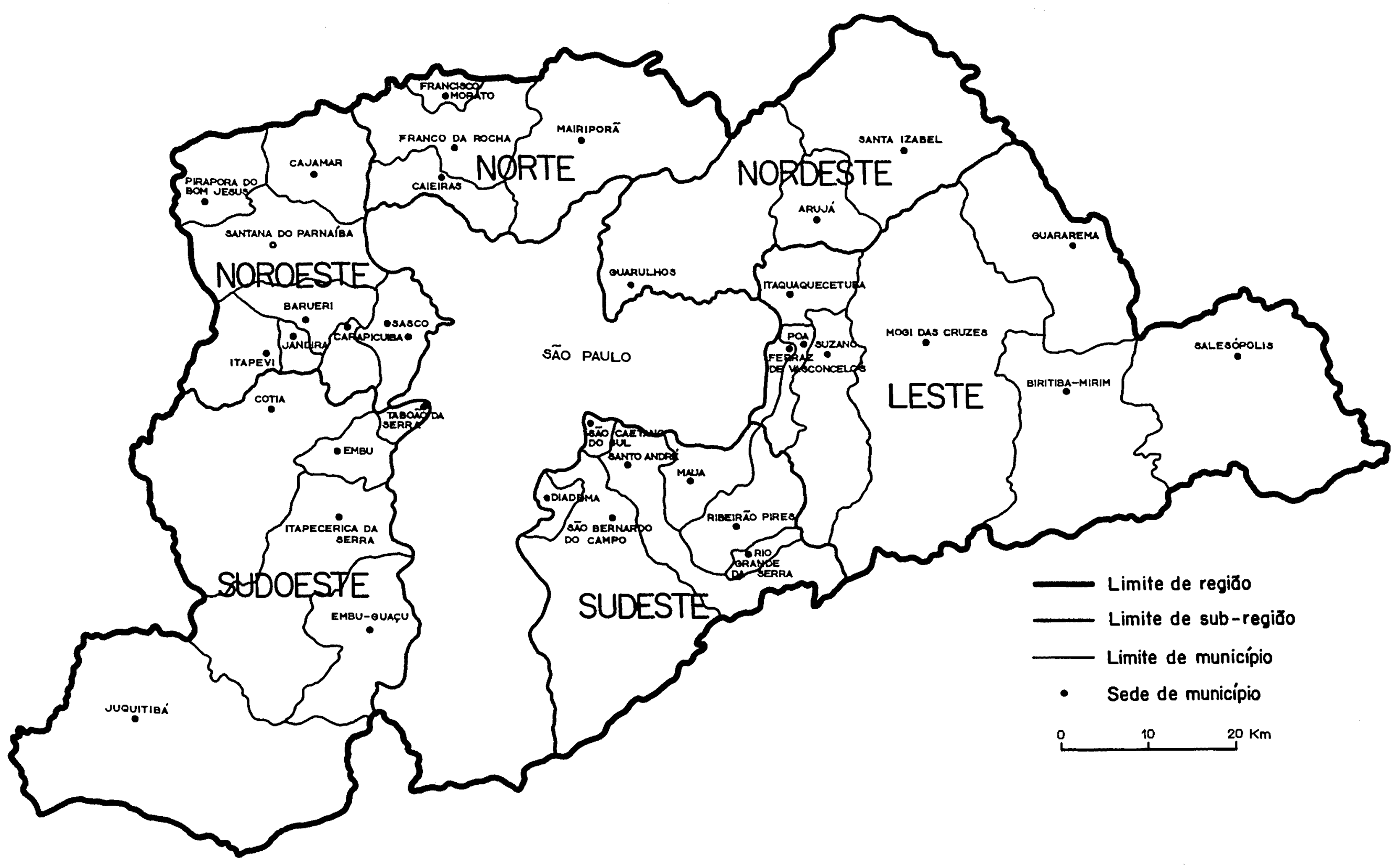

FIG. 2 - 1 9 Região Administrativa - GRANDE SÃO PAULO 


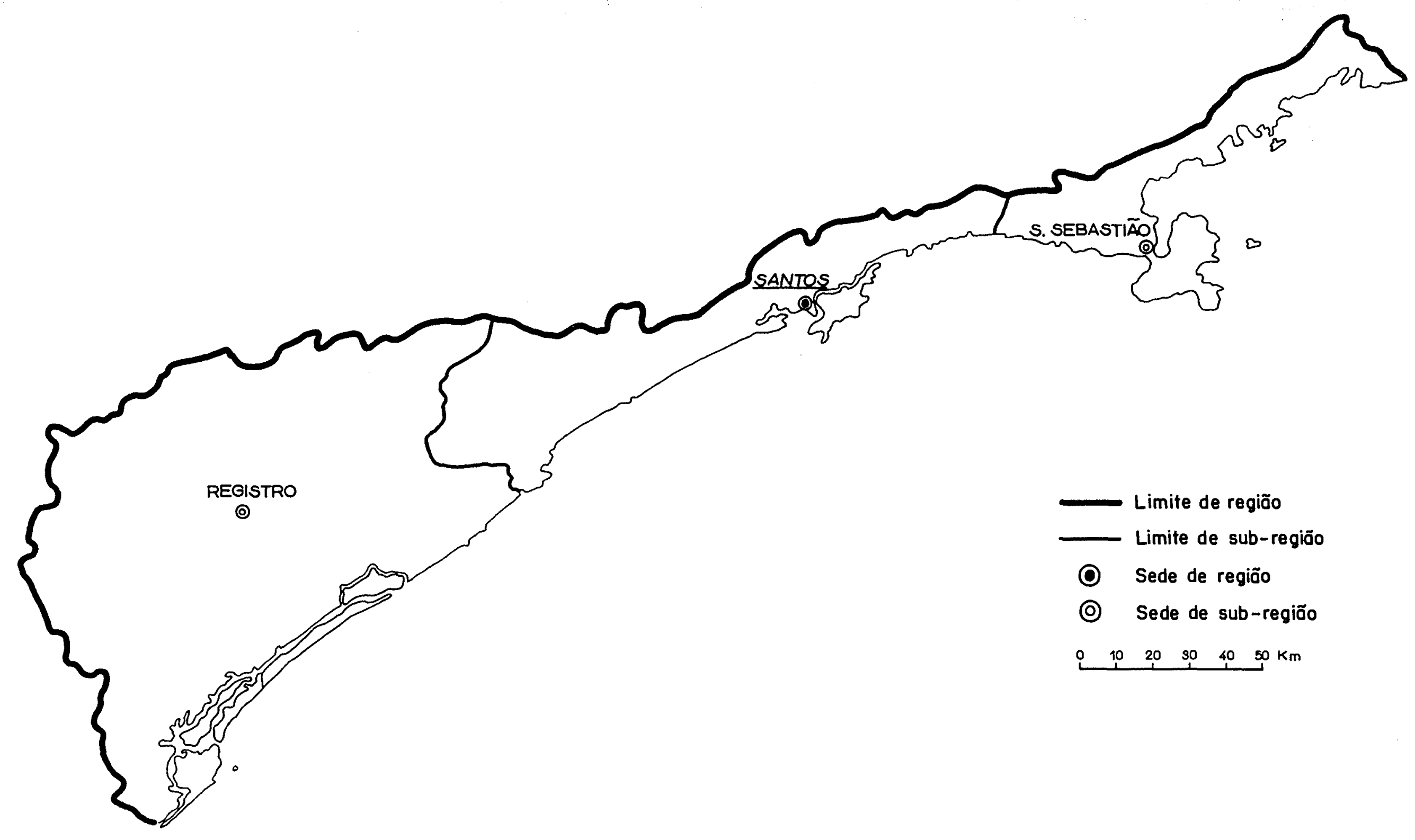

FIG. 3 - 29 Região Administrativa - LITORAL 


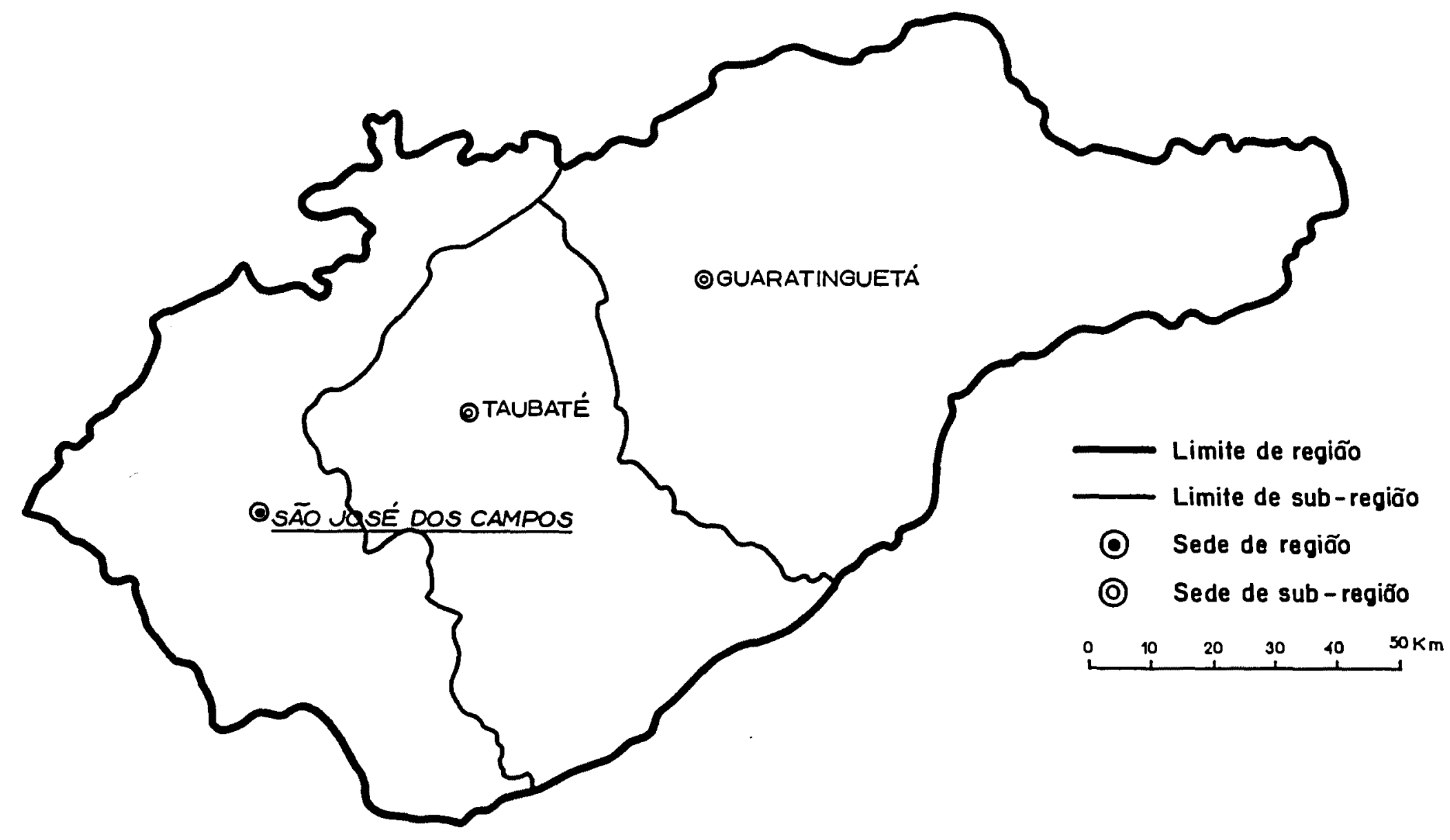

FIG. 4 - 3 Região Administrativa - VALE DO PARAÍBA 


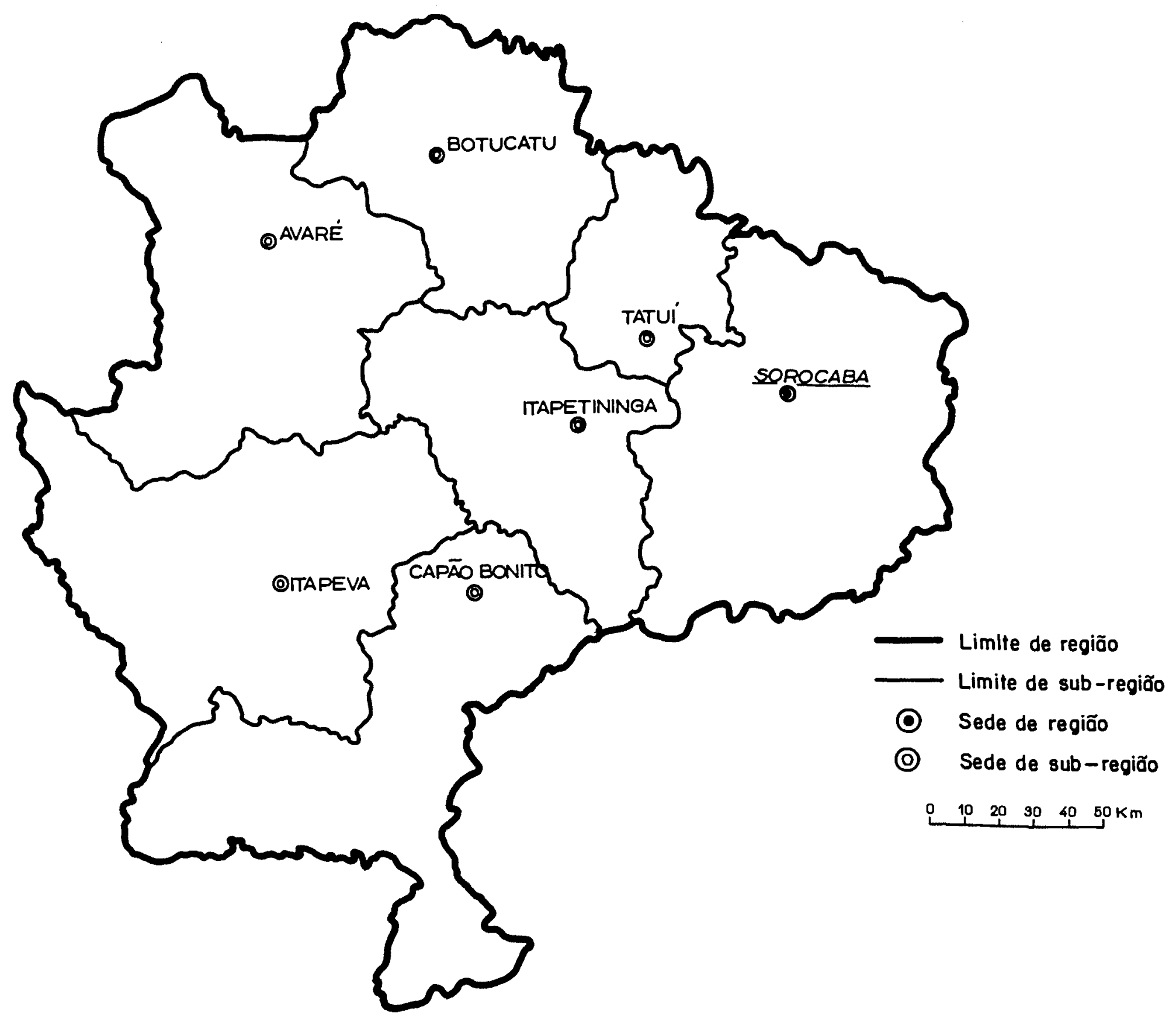

FIG. 5 - 4 9 Região Administrativa - SOROCABA 


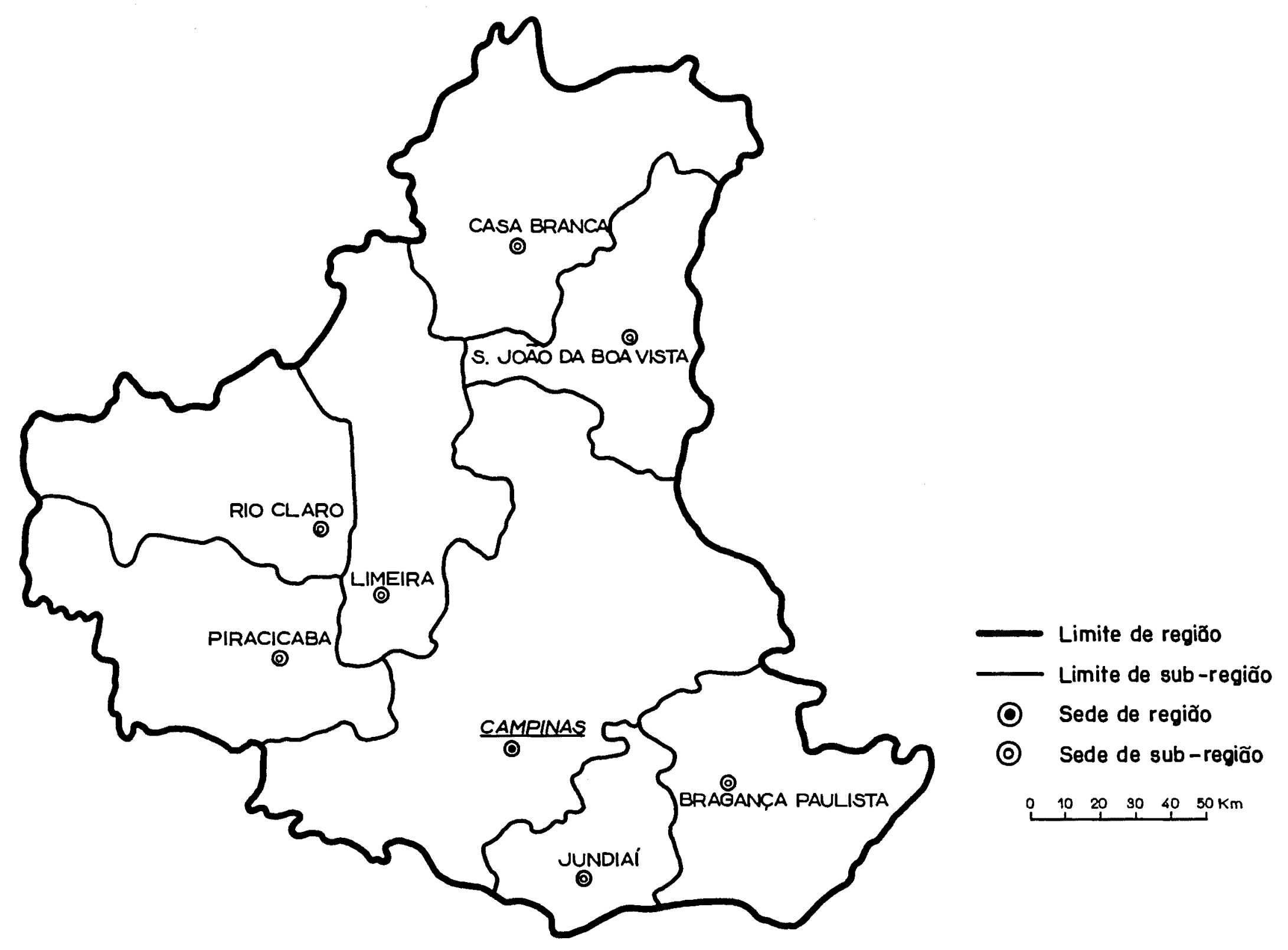

FIG. 6 - 5 Região Administrativa - CAMPINAS 


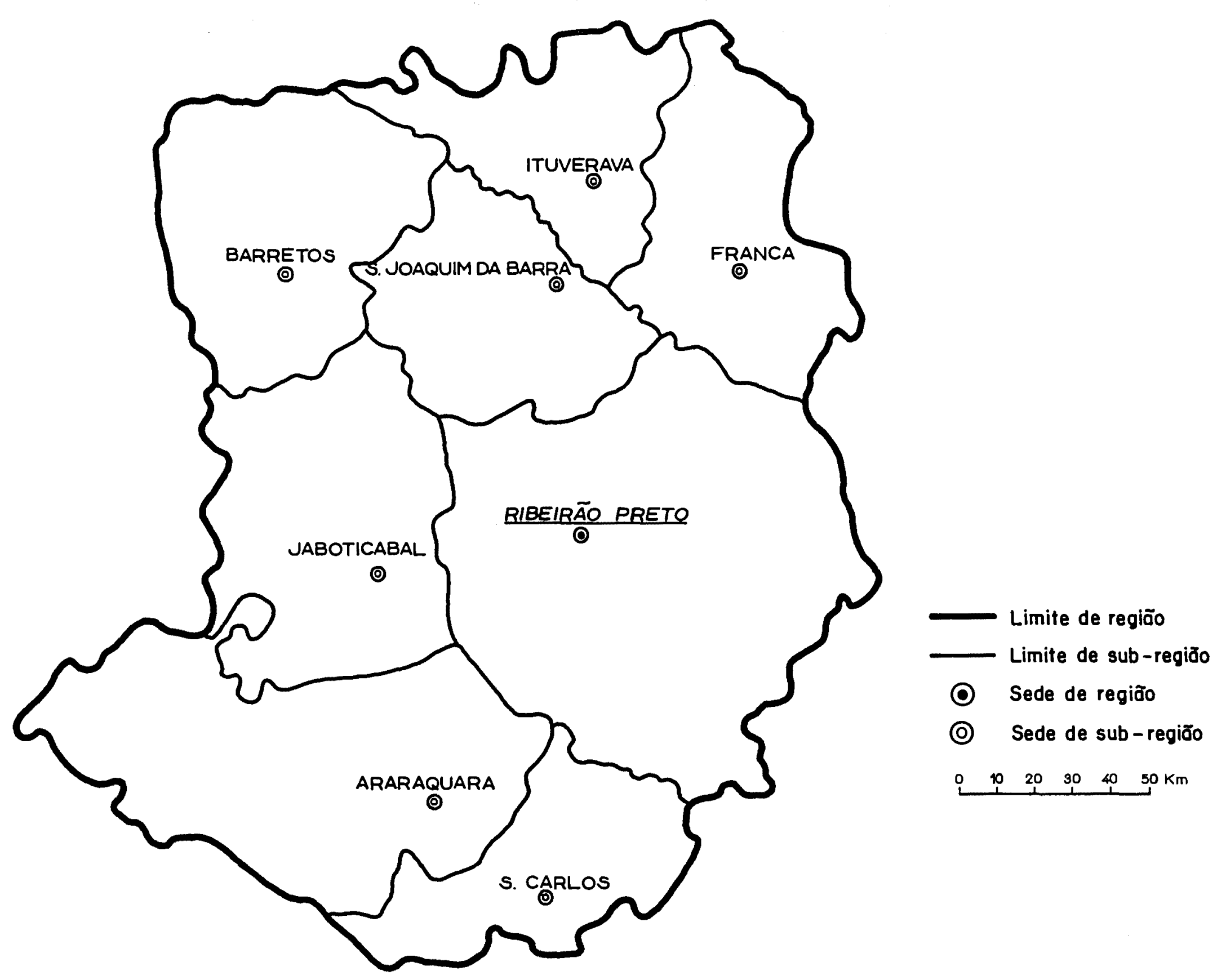

FIG. 7 - 6 @ Região Administrativa - RIBEIRÃO PRETO 


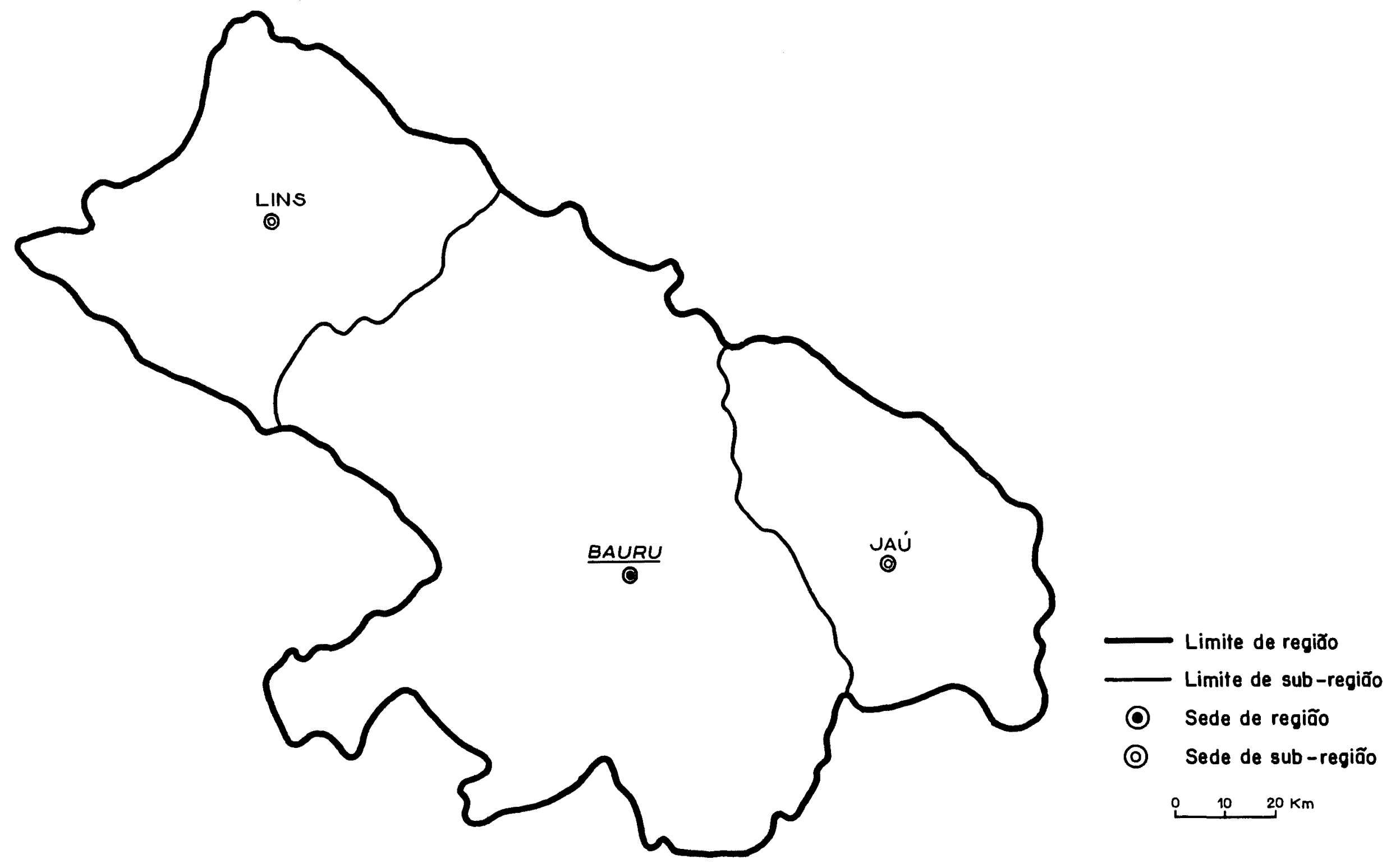

FIG. 8 - 7을 Região Administrativa - BAURU 


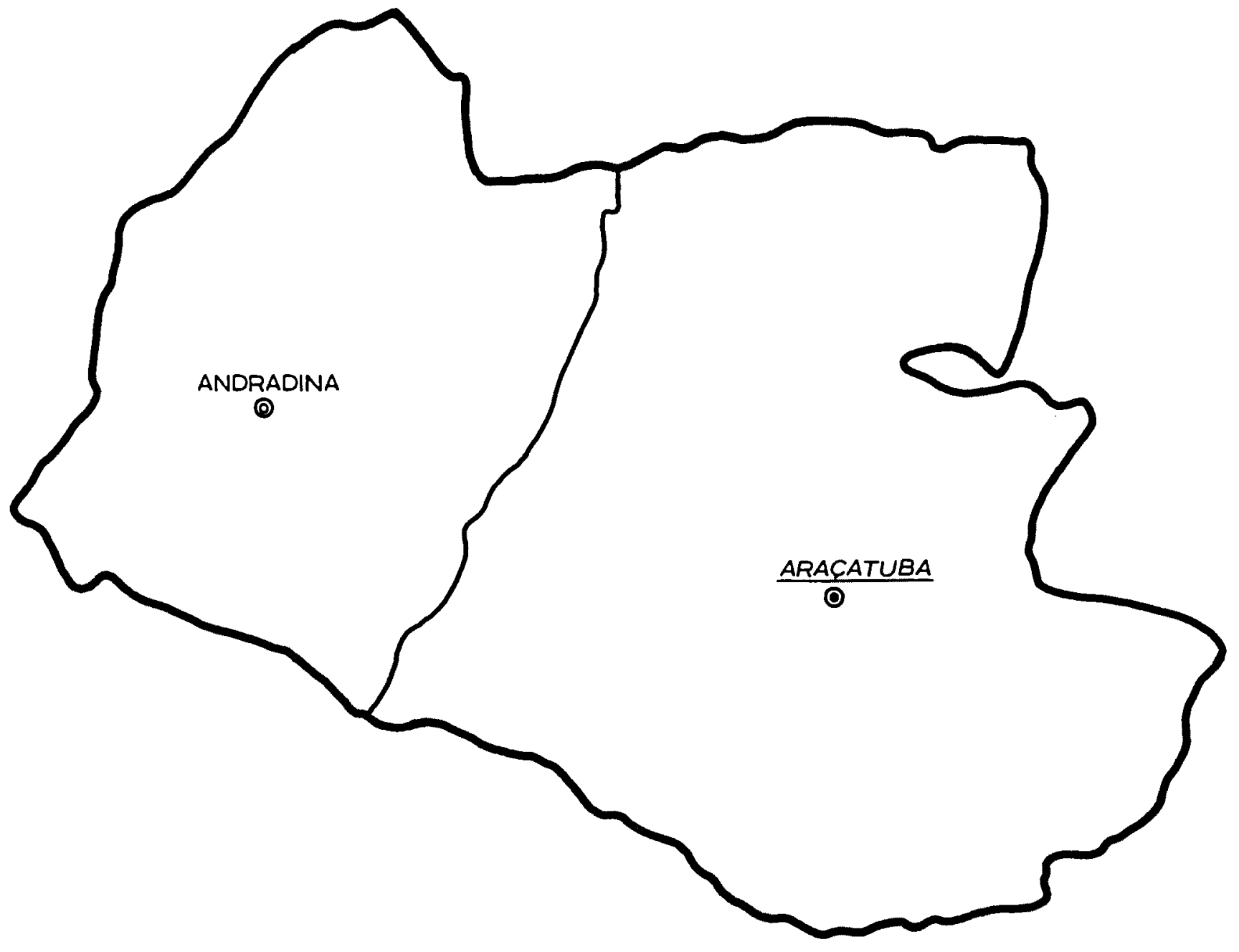

Limite de regiỡo Limite de sub-regiōo

(-) Sede de regiõo

(a) Sede de sub-regiðo

눈 $\quad 20 \mathrm{~km}$

FIG.10 - 9 Região Administrativa - ARAÇATUBA 


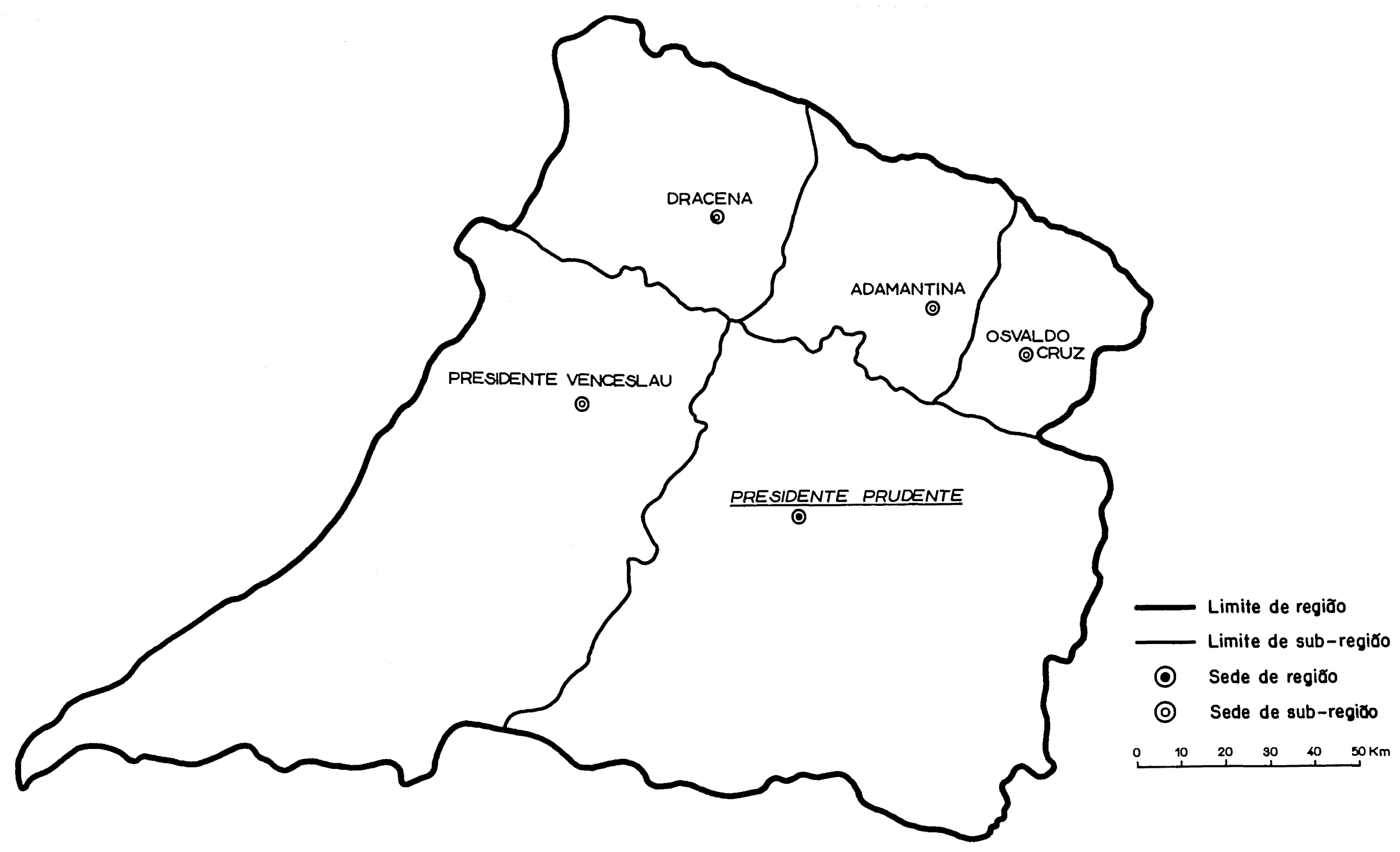

FIG.11 -10 Região Administrativa - PRESIDENTE PRUDENTE 


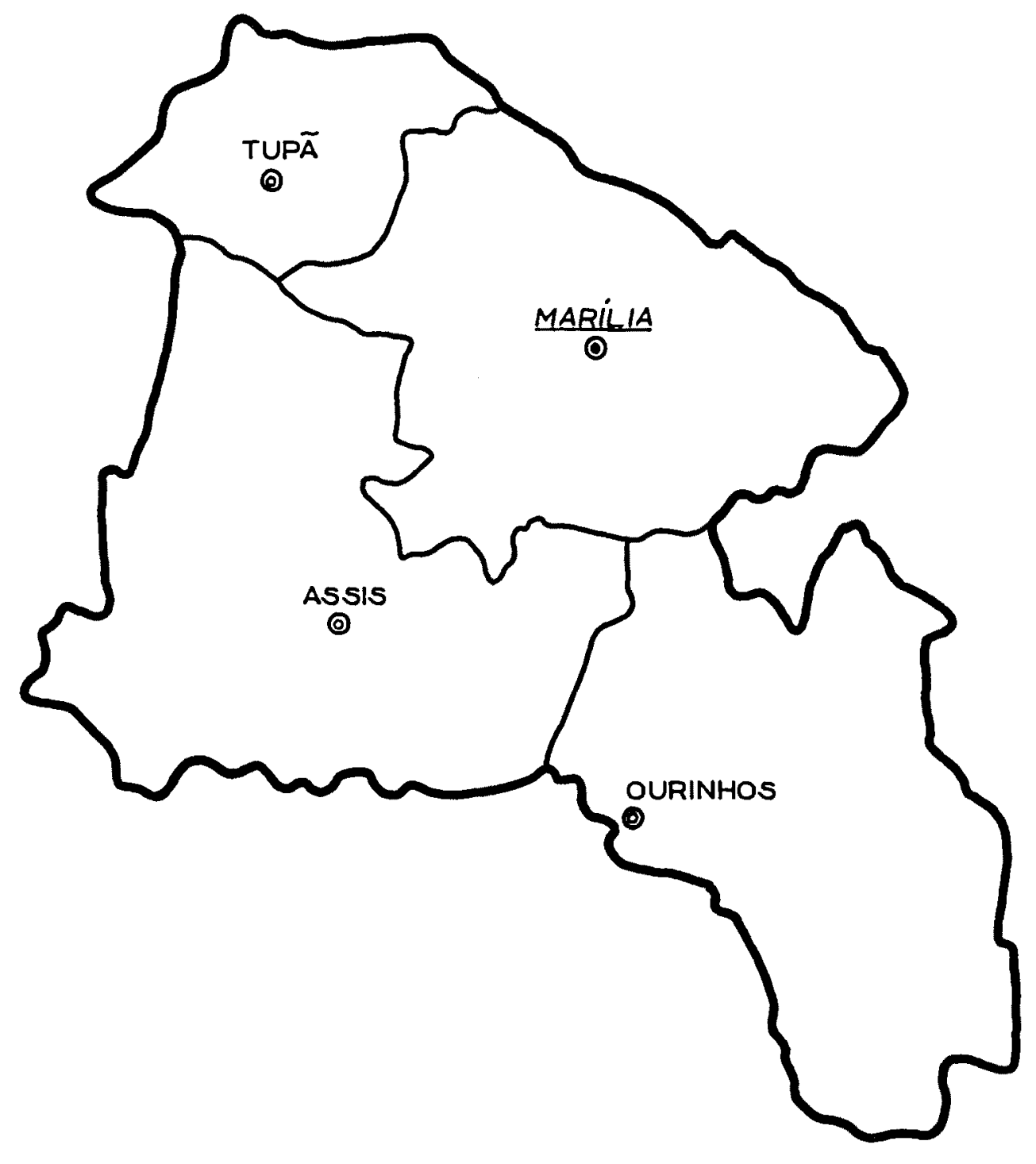

- Limite de regiõo

Limite de sub-regiõo

- Sede de região

(2) Sede de sub-região

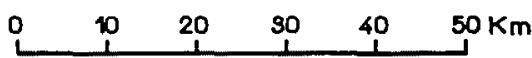

FIG.12 - 119 Região Administrativa - MARÍLIA 


\section{ANEXO 2}

População do Estado de São Paulo (censo de 1980) 


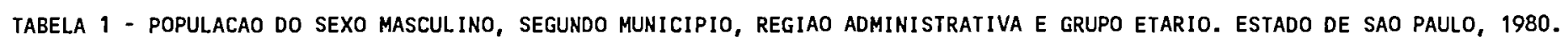

\begin{tabular}{|c|c|c|c|c|c|c|c|c|c|c|c|}
\hline REGIAO & MUNICIPIO & $\begin{array}{l}\text { GRUPO } \\
0 \text { a } 09\end{array}$ & $\begin{array}{l}\text { GRUPO } \\
10 \text { a } 19\end{array}$ & $\begin{array}{c}\text { GRUPO } \\
20 \text { a } 29\end{array}$ & $\begin{array}{l}\text { GRUPO } \\
30 \text { a } 39\end{array}$ & $\begin{array}{l}\text { GRUPO } \\
40 \text { a } 49\end{array}$ & $\begin{array}{c}\text { GRUPO } \\
50 \text { a } 59\end{array}$ & $\begin{array}{l}\text { GRUPO } \\
60 \text { a } 69\end{array}$ & $\begin{array}{l}\text { GRUPO } \\
70 \mathrm{e}+\end{array}$ & I gnorada & TOTAL \\
\hline $\begin{array}{l}01 a \\
01 a\end{array}$ & SAO PAULO & $\begin{array}{l}906.908 \\
906.908\end{array}$ & $\begin{array}{l}785.538 \\
785.538\end{array}$ & $\begin{array}{l}920.188 \\
920.188\end{array}$ & $\begin{array}{l}600.877 \\
600.877\end{array}$ & $\begin{array}{l}413.656 \\
413.656\end{array}$ & $\begin{array}{l}291.398 \\
291.398\end{array}$ & $\begin{array}{l}150.224 \\
150.224\end{array}$ & $\begin{array}{l}79.110 \\
79.110\end{array}$ & $\begin{array}{l}2.656 \\
2.656\end{array}$ & $\begin{array}{l}4.150 .555 \\
4.150 .555\end{array}$ \\
\hline \multirow{36}{*}{$01 \mathrm{~b}$} & ARUJA & 2.334 & 1.974 & 1.626 & 1.156 & 793 & 536 & 324 & 165 & 14 & 8.922 \\
\hline & BARUER I & 10.736 & 8.044 & 8.415 & 5.260 & 3.089 & 1.785 & 845 & 398 & 17 & 38.589 \\
\hline & BIRITIBA MIRIM & 1.847 & 1.609 & 1.118 & 861 & 667 & 441 & 287 & 134 & 12 & 6.976 \\
\hline & CAIEIRAS & 3.260 & 2.790 & 2.358 & 1.758 & 1.157 & 796 & 458 & 218 & 4 & 12.799 \\
\hline & CAJAMAR & 3.156 & 2.493 & 2.321 & 1.476 & 909 & 564 & 317 & 154 & 12 & 11.402 \\
\hline & CARAPI CUIBA & 27.333 & 19.268 & 19.153 & 14.291 & 7.425 & 3.817 & 1.678 & 747 & 42 & 93.754 \\
\hline & COTIA & 8.571 & 6.957 & 6.325 & 4.307 & 2.764 & 1.711 & 907 & 491 & 87 & 32.120 \\
\hline & DIADEMA & 31.705 & 23.924 & 28.016 & 17.362 & 9.070 & 4.658 & 1.870 & 722 & 74 & 117.401 \\
\hline & EMBU & 15.147 & 9.893 & 9.411 & 7.426 & 3.644 & 1.650 & 788 & 329 & 28 & 48.316 \\
\hline & EMBU-GUACU & 3.090 & 2.371 & 1.842 & 1.381 & 903 & 643 & 404 & 201 & 10 & 10.845 \\
\hline & FERRAZ DE VASCONCELOS & 7.784 & 6.323 & 5.130 & 3.769 & 2.364 & 1.324 & 647 & 341 & 29 & 27.711 \\
\hline & FRANCISCO MORATO & 4.298 & 3.130 & 2.757 & 1.949 & 1.138 & 705 & 344 & 179 & 8 & 14.508 \\
\hline & FRANCO DA ROCHA & 6.486 & 4.651 & 4.962 & 3.973 & 2.471 & 1.813 & 1.049 & 402 & 111 & 25.918 \\
\hline & GUARAREMA & 1.993 & 1.682 & 1.294 & 991 & 719 & 545 & 397 & 189 & 8 & 7.818 \\
\hline & GUARULHOS & 70.686 & 55.835 & 55.163 & 39.324 & 24.247 & 13.864 & 6.503 & 2.746 & 160 & 268.528 \\
\hline & ITAPECERICA DA SERRA & 9.113 & 6.370 & 5.758 & 4.293 & 2.511 & 1.528 & 811 & 397 & 46 & 30.827 \\
\hline & ITAPEVI & 7.824 & 6.173 & 5.036 & 3.389 & 2.144 & 1.354 & 803 & 335 & 43 & 27.101 \\
\hline & ITAQUAQUECE TUBA & 10.907 & 8.139 & 7.165 & 5.119 & 2.977 & 1.652 & 794 & 392 & 210 & 37.355 \\
\hline & JANDIRA & 5.490 & 3.839 & 3.910 & 2.549 & 9.404 & 752 & 370 & 147 & 14 & 18.475 \\
\hline & JUQUITIBA & 1.900 & 1.484 & 1.029 & 716 & 600 & 482 & 269 & 123 & 7 & 6.610 \\
\hline & MAIRIPORA & 3.693 & 2.939 & 2.433 & 2.006 & 1.343 & 947 & 536 & 268 & 28 & 14.193 \\
\hline & MAUA & 27.351 & 22.510 & 22.381 & 14.870 & 9.239 & 5.014 & 2.244 & 894 & 37 & 104.540 \\
\hline & MOGI DAS CRUZES & 24.825 & 21.892 & 19.078 & 12.911 & 9.482 & 6.372 & 3.430 & 1.786 & 47 & 99.823 \\
\hline & OSASCO & 59.894 & 49.738 & 53.594 & 33.616 & 21.067 & 12.693 & 5.964 & 2.656 & 181 & 239.403 \\
\hline & PIRAPORA DO BOM JESUS & 676 & 541 & 404 & 315 & 252 & 156 & 98 & 64 & 1 & 2.507 \\
\hline & POA & 6.899 & 6.120 & 5.076 & 3.289 & 2.392 & 1.449 & 764 & 366 & 51 & 26.406 \\
\hline & RIBEIRAO PIRES & 7.409 & 5.833 & 5.458 & 4.182 & 2.590 & 1.647 & 910 & 470 & 24 & 28.523 \\
\hline & RIO GRANDE DA SERRA & 3.088 & 2.236 & 1.990 & 1.315 & 830 & 521 & 247 & 91 & 4 & 10.322 \\
\hline & SALESOPOLIS & 1.363 & 1.360 & 868 & 619 & 500 & 366 & 277 & 156 & 4 & 5.513 \\
\hline & SANTA ISABEL & 3.881 & 3.307 & 2.685 & 1.893 & 1.289 & 860 & 543 & 255 & 7 & 14.720 \\
\hline & SANTANA DO PARNAIBA & 1.524 & 1.097 & 881 & 630 & 428 & 347 & 202 & 104 & 7 & 5.220 \\
\hline & SANTO ANDRE & 58.123 & 54.513 & 59.779 & 40.739 & 29.211 & 19.634 & 9.684 & 4.817 & 169 & 276.669 \\
\hline & SAO BERNARDO DO CAMPO & 51.375 & 41.301 & 50.083 & 33.937 & 20.752 & 11.563 & 5.362 & 2.392 & 124 & 216.889 \\
\hline & SAO CAETANO DO SUL & 14.026 & 14.050 & 18.922 & 11.958 & 9.128 & 7.286 & 3.901 & 1.911 & 28 & 81.210 \\
\hline & $\begin{array}{l}\text { SUZANO } \\
\end{array}$ & 13.576 & 11.508 & 9.712 & 6.924 & 4.512 & 2.859 & 1.545 & 754 & 11 & 51.401 \\
\hline & TABOAO DA SERRA & 13.807 & 10.356 & 9.921 & 7.418 & 4.245 & 2.080 & 875 & 322 & 35 & 49.059 \\
\hline $01 b$ & & 525.170 & 426.250 & 436.054 & 297.972 & 188.256 & 114.414 & 56.447 & 26.116 & 1.694 & 2.072 .373 \\
\hline \multirow[t]{7}{*}{02} & CANANE IA & 1.138 & 805 & 672 & 489 & 374 & 284 & 191 & 114 & 17 & 4.084 \\
\hline & CARAGUATATUBA & 4.917 & 3.657 & 3.206 & 2.329 & 1.505 & 1.037 & 662 & 298 & 12 & 17.623 \\
\hline & $\begin{array}{l}\text { CUBATAO } \\
\text { CUT }\end{array}$ & 9.545 & 8.529 & 11.735 & 6.169 & 3.824 & 1.998 & 813 & 337 & 19 & 42.969 \\
\hline & ELDORADO & 1.722 & 1.406 & 832 & 632 & 542 & 356 & 275 & 123 & 7 & 5.895 \\
\hline & GUARUJA & 20.066 & 17.144 & 15.992 & 10.060 & 6.981 & 4.284 & 1.989 & 919 & 29 & 77.464 \\
\hline & I GUAPE & 3.303 & 2.663 & 1.888 & 1.402 & 1.177 & 840 & 586 & 319 & 6 & 12.184 \\
\hline & ILHABELA & 1.117 & 897 & 669 & 513 & 349 & 256 & 167 & 121 & 2 & 4.091 \\
\hline
\end{tabular}


tabela 1 - populacao do SeXo masculino, SEgundo municipio, regiaO administrativa e Grupo etario. estado de sao paulo, 1980.

\begin{tabular}{|c|c|c|c|c|c|c|c|c|c|c|c|}
\hline REGIAO & MUNICIPIO & $\begin{array}{l}\text { GRUPO } \\
0 \text { a } 09\end{array}$ & $\begin{array}{l}\text { GRUPO } \\
10 \text { a } 19\end{array}$ & $\begin{array}{c}\text { GRUPO } \\
20 \text { a } 29\end{array}$ & $\begin{array}{l}\text { GRUPO } \\
30 \text { a } 39\end{array}$ & $\begin{array}{l}\text { GRUPO } \\
40 \text { a } 49\end{array}$ & $\begin{array}{l}\text { GRUPO } \\
50 \text { a } 59\end{array}$ & $\begin{array}{l}\text { GRUPO } \\
60 \text { a } 69\end{array}$ & $\begin{array}{l}\text { GRUPO } \\
70 \text { e + }\end{array}$ & Ignorada & TOTAL \\
\hline \multirow[t]{16}{*}{02} & I TANHAEM & 3.788 & 2.910 & 2.402 & 1.829 & 1.223 & 939 & 655 & 333 & 5 & 14.084 \\
\hline & ITARIRI & 1.482 & 1.103 & 774 & 583 & 465 & 304 & 199 & 122 & 1 & 5.033 \\
\hline & JACUP I RANGA & 4.419 & 3.306 & 2.420 & 1.735 & 1.335 & 839 & 494 & 260 & 20 & 14.828 \\
\hline & JUQUIA & 2.335 & 1.866 & 1.147 & 877 & 712 & 527 & 321 & 143 & 5 & 7.933 \\
\hline & MIRACATU & 2.682 & 2.177 & 1.382 & 1.026 & 824 & 584 & 299 & 149 & 2 & 9.125 \\
\hline & MONGAGUA & 1.332 & 1.089 & 832 & 633 & 440 & 373 & 263 & 126 & 2 & 5.090 \\
\hline & PARIQUERA-ACU & 1.608 & 1.354 & 894 & 655 & 551 & 362 & 221 & 118 & 4 & 5.767 \\
\hline & PEDRO DE TOLEDO & 838 & 797 & 450 & 311 & 318 & 250 & 169 & 87 & 6 & 3.226 \\
\hline & PERUIBE & 2.481 & 2.036 & 1.470 & 1.103 & 856 & 803 & 501 & 235 & 3 & 9.488 \\
\hline & PRAIA GRANDE & 8.446 & 6.505 & 5.898 & 4.657 & 3.164 & 2.392 & 1.698 & 808 & 47 & 33.615 \\
\hline & REGISTRO & 5.896 & 4.644 & 3.139 & 2.351 & 1.767 & 1.173 & 645 & 343 & 1 & 19.959 \\
\hline & SANTOS & 37.835 & 36.340 & 39.596 & 28.243 & 23.965 & 18.504 & 10.296 & 6.383 & 133 & 201.295 \\
\hline & SAO SEBASTIAO & 2.602 & 2.042 & 1.750 & 1.292 & 898 & 587 & 372 & 214 & 2 & 9.759 \\
\hline & SAO VICENTE & 23.436 & 20.007 & 18.388 & 13.221 & 9.296 & 6.321 & 3.353 & 1.872 & 64 & 95.958 \\
\hline & SETE BARRAS & 1.852 & 1.272 & 946 & 743 & 513 & 354 & 210 & 106 & 2 & 5.998 \\
\hline & UBATUBA & 3.830 & 3.085 & 2.721 & 1.775 & 1.241 & 768 & 509 & 270 & 8 & 14.207 \\
\hline 02 & & 146.670 & 125.634 & 119.203 & 82.628 & 62.320 & 44.135 & 24.888 & 13.800 & 397 & 619.675 \\
\hline \multirow{30}{*}{03} & APARECIDA & 3.356 & 3.470 & 2.888 & 1.856 & 1.349 & 994 & 583 & 275 & 7 & 14.778 \\
\hline & AREIAS & 497 & 513 & 357 & 207 & 154 & 109 & 83 & 64 & 0 & 1.984 \\
\hline & BANANAL & 1.371 & 1.422 & 840 & 603 & 506 & 391 & 294 & 195 & 1 & 5.623 \\
\hline & CACAPAVA & 6.690 & 5.692 & 4.868 & 3.552 & 2.220 & 1.437 & 885 & 502 & 3 & 25.849 \\
\hline & CACHOEIRA PAULISTA & 2.503 & 2.406 & 1.839 & 1.215 & 880 & 738 & 489 & 266 & 1 & 10.337 \\
\hline & CAMPOS DO JORDAO & 3.553 & 3.026 & 2.458 & 1.545 & 1.120 & 805 & 399 & 194 & 0 & 13.100 \\
\hline & CRUZE I RO & 7.035 & 6.788 & 5.481 & 3.398 & 2.591 & 1.714 & 1.098 & 658 & 2 & 28.765 \\
\hline & CUNHA & 2.931 & 2.816 & 1.539 & 1.164 & 984 & 726 & 412 & 239 & 0 & 10.811 \\
\hline & GUARATINGUETA & 10.156 & 9.939 & 7.660 & 5.128 & 3.826 & 2.812 & 1.651 & 905 & 13 & 42.090 \\
\hline & IGARATA & 629 & 546 & 351 & 269 & 188 & 142 & 106 & 38 & 1 & 2.270 \\
\hline & JACARE I & 14.733 & 12.719 & 11.338 & 8.176 & 5.225 & 3.247 & 1.842 & 917 & 21 & 58.218 \\
\hline & JAMBEIRO & 369 & 333 & 271 & 186 & 138 & 99 & 75 & 37 & 0 & 1.508 \\
\hline & LAGOINHA & 593 & 598 & 259 & 249 & 235 & 188 & 140 & 54 & 1 & 2.317 \\
\hline & LAVRINHAS & 547 & 476 & 310 & 188 & 167 & 115 & 68 & 39 & 0 & 1.910 \\
\hline & LORENA & 6.876 & 6.671 & 5.221 & 3.445 & 2.405 & 1.805 & 1.241 & 648 & 12 & 28.324 \\
\hline & MONTEIRO LOBATO & 349 & 367 & 184 & 133 & 146 & 117 & 77 & 54 & 0 & 1.427 \\
\hline & NATIVIDADE DA SERRA & 948 & 950 & 435 & 352 & 324 & 293 & 211 & 107 & 1 & 3.621 \\
\hline & PARAIBUNA & 1.867 & 1.728 & 1.165 & 833 & 678 & 461 & 321 & 192 & 1 & 7.246 \\
\hline & PINDAMONHANGABA & 9.311 & 7.883 & 6.955 & 4.528 & 2.842 & 1.992 & 1.179 & 671 & 47 & 35.408 \\
\hline & PIQUETE & 1.626 & 1.672 & 1.292 & 841 & 642 & 462 & 349 & 175 & 2 & 7.061 \\
\hline & QUELUZ & 906 & 890 & 572 & 378 & 303 & 256 & 158 & 97 & 0 & 3.560 \\
\hline & REDENCAO DA SERRA & 532 & 507 & 324 & 186 & 184 & 185 & 131 & 69 & 1 & 2.119 \\
\hline & ROSEIRA & 649 & 639 & 447 & 302 & 215 & 149 & 86 & 45 & 0 & 2.532 \\
\hline & SANTA BRANCA & 1.065 & 987 & 794 & 522 & 425 & 290 & 194 & 121 & 2 & 4.400 \\
\hline & SANTO ANTONIO DO PINHAL & 769 & 650 & 408 & 307 & 221 & 180 & 107 & 79 & 7 & 2.728 \\
\hline & SAO BENTO DO SAPUCAI & 1.159 & 1.133 & 753 & 495 & 417 & 332 & 248 & 126 & 1 & 4.664 \\
\hline & SAO JOSE DO BARREIRO & 530 & 539 & 287 & 195 & 202 & 166 & 98 & 64 & 0 & 2.081 \\
\hline & SAO JOSE DOS CAMPOS & 37.123 & 30.082 & 32.123 & 20.763 & 11.786 & 7.295 & 3.818 & 1.835 & 67 & 144.892 \\
\hline & SAO LUIZ DO PARAITINGA & 1.225 & 1.316 & 731 & 494 & 472 & 395 & 244 & 131 & 0 & 5.008 \\
\hline & SILVEIRAS & 487 & 455 & 290 & 214 & 209 & 134 & 109 & 82 & 0 & 1.980 \\
\hline
\end{tabular}




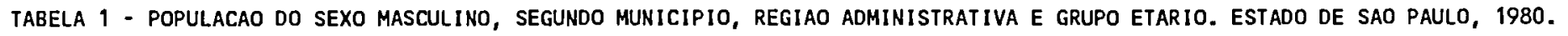

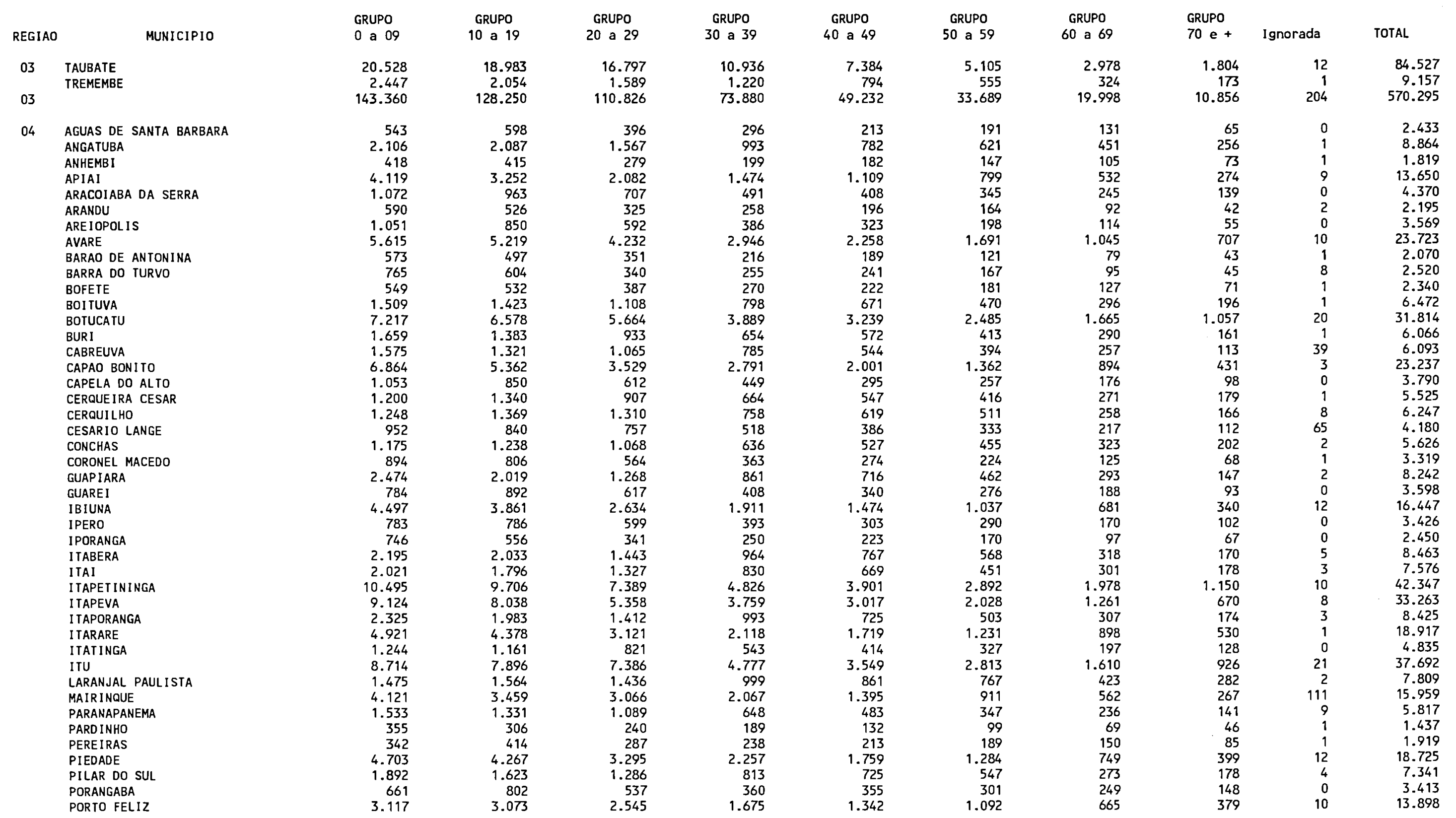


tabela 1 - populacaO do seXo masculino, Segundo municipio, Regiao administrativa e grupo etario. estado de sao paulo, 1980.

\begin{tabular}{|c|c|c|c|c|c|c|c|c|c|c|c|}
\hline REGIAO & MUNICIPIO & $\begin{array}{l}\text { GRUPO } \\
0 \text { a } 09\end{array}$ & $\begin{array}{c}\text { GRUPO } \\
10 \text { a } 19\end{array}$ & $\begin{array}{c}\text { GRUPO } \\
20 \text { a } 29\end{array}$ & $\begin{array}{c}\text { GRUPO } \\
30 \text { a } 39\end{array}$ & $\begin{array}{l}\text { GRUPO } \\
40 \text { a } 49\end{array}$ & $\begin{array}{c}\text { GRUPO } \\
50 \text { a } 59\end{array}$ & $\begin{array}{l}\text { GRUPO } \\
60 \text { a } 69\end{array}$ & $\begin{array}{l}\text { GRUPO } \\
70 \text { e + }\end{array}$ & I gnorada & TOTAL \\
\hline \multirow[t]{15}{*}{04} & RIBEIRA & 1.185 & 982 & 529 & 409 & 323 & 222 & 165 & 92 & 0 & 3.907 \\
\hline & RIBEIRAO BRANCO & 2.223 & 1.727 & 1.164 & 796 & 575 & 422 & 267 & 101 & 0 & 7.275 \\
\hline & RIVERSUL & 1.744 & 1.299 & 957 & 635 & 540 & 367 & 226 & 109 & 0 & 5.877 \\
\hline & SALTO & 5.079 & 4.541 & 4.743 & 2.874 & 2.095 & 1.466 & 746 & 425 & 1 & 21.970 \\
\hline & SALTO DE PIRAPORA & 1.816 & 1.697 & 1.347 & 937 & 721 & 477 & 300 & 176 & 12 & 7.483 \\
\hline & SAO MANUEL & 3.141 & 3.265 & 2.558 & 1.668 & 1.411 & 1.059 & 665 & 427 & 15 & 14.209 \\
\hline & SAO MIGUEL ARCANJO & 2.245 & 2.036 & 1.436 & 1.034 & 807 & 553 & 422 & 245 & 23 & 8.801 \\
\hline & SAO ROQUE & 5.944 & 5.249 & 4.651 & 3.248 & 2.478 & 1.864 & 1.139 & 712 & 11 & 25.296 \\
\hline & SARAPUI & 720 & 659 & 404 & 265 & 234 & 205 & 154 & 97 & 3 & 2.741 \\
\hline & SOROCABA & 30.531 & 28.428 & 26.350 & 17.352 & 12.874 & 9.518 & 5.440 & 3.071 & 165 & 133.729 \\
\hline & TAP IRAI & 744 & 638 & 404 & 304 & 250 & 187 & 113 & 60 & 0 & 2.700 \\
\hline & TAQUARI TUBA & 2.028 & 1.957 & 1.507 & 972 & 768 & 559 & 344 & 207 & 1 & 8.343 \\
\hline & TATUI & 6.664 & 6.189 & 4.862 & 3.352 & 2.636 & 2.045 & 1.363 & 827 & 15 & 27.953 \\
\hline & TIETE & 1.895 & 2.159 & 1.847 & 1.225 & 1.067 & 867 & 519 & 417 & 7 & 10.003 \\
\hline & VOTORANTIM & 7.095 & 6.091 & 5.305 & 3.468 & 2.363 & 1.518 & 856 & 386 & 24 & 27.106 \\
\hline 04 & & 184.323 & 166.914 & 134.336 & 90.507 & 70.022 & 51.859 & 32.182 & 18.505 & 666 & 749.314 \\
\hline \multirow[t]{31}{*}{05} & AGUAI & 1.968 & 1.997 & 1.653 & 1.021 & 828 & 700 & 440 & 193 & 27 & 8.827 \\
\hline & AGUAS DA PRATA & 637 & 608 & 498 & 349 & 280 & 244 & 176 & 104 & 1 & 2.897 \\
\hline & AGUAS DE LINDOIA & 977 & 894 & 787 & 582 & 528 & 400 & 246 & 156 & 7 & 4.577 \\
\hline & AGUAS DE SAO PEDRO & 89 & 94 & 77 & 66 & 48 & 59 & 53 & 44 & 0 & 530 \\
\hline & AMERICANA & 12.782 & 12.963 & 13.534 & 8.059 & 5.971 & 4.395 & 2.275 & 1.261 & 8 & 61.248 \\
\hline & AMPARO & 4.503 & 4.257 & 4.072 & 2.737 & 2.152 & 1.672 & 1.046 & 669 & 0 & 21.108 \\
\hline & ANALANDIA & 246 & 271 & 223 & 138 & 127 & 93 & 60 & 37 & 0 & 1.195 \\
\hline & ARARAS & 7.072 & 7.182 & 6.639 & 4.260 & 3.334 & 2.435 & 1.301 & 748 & 28 & 32.999 \\
\hline & ARTHUR NOGUE IRA & 1.880 & 1.923 & 1.589 & 1.070 & 794 & 571 & 305 & 173 & 3 & 8.308 \\
\hline & ATIBAIA & 6.764 & 6.232 & 5.282 & 3.710 & 2.849 & 2.120 & 1.354 & 851 & 15 & 29.177 \\
\hline & BOM JESUS DOS PERDOES & 957 & 787 & 625 & 461 & 351 & 251 & 174 & 89 & 0 & 3.695 \\
\hline & BRAGANCA PAULISTA & 9.747 & 8.975 & 7.883 & 5.445 & 4.156 & 3.288 & 2.030 & 1.227 & 75 & 42.826 \\
\hline & BROTAS & 1.222 & 1.253 & 938 & 702 & 614 & 459 & 355 & 226 & 2 & 5.771 \\
\hline & CACONDE & 2.083 & 2.007 & 1.371 & 938 & 832 & 594 & 423 & 257 & 11 & 8.516 \\
\hline & CAMPINAS & 74.083 & 67.422 & 68.370 & 45.825 & 32.687 & 22.286 & 12.104 & 6.847 & 143 & 329.767 \\
\hline & CAMPO LIMPO PAULISTA & 2.901 & 2.379 & 2.088 & 1.623 & 1.094 & 643 & 418 & 197 & 3 & 11.346 \\
\hline & CAPIVARI & 3.023 & 2.820 & 2.479 & 1.519 & 1.285 & 907 & 597 & 363 & 6 & 12.999 \\
\hline & CASA BRANCA & 2.337 & 2.454 & 1.928 & 1.447 & 1.406 & 1.126 & 644 & 362 & 3 & 11.707 \\
\hline & CHARQUEADA & 1.086 & 1.007 & 812 & 579 & 454 & 325 & 216 & 113 & 1 & 4.593 \\
\hline & CONCHAL & 1.677 & 1.543 & 1.293 & 839 & 626 & 425 & 230 & 113 & 1 & 6.747 \\
\hline & CORDE IROPOL IS & 971 & 962 & 910 & 645 & 521 & 372 & 235 & 132 & 6 & 4.754 \\
\hline & CORUMBATAI & 321 & 292 & 245 & 182 & 127 & 122 & 111 & 58 & 1 & 1.459 \\
\hline & COSMOPOLIS & 2.910 & 2.493 & 2.287 & 1.668 & 1.173 & 738 & 439 & 249 & 4 & 11.961 \\
\hline & DIVINOLANDIA & 1.105 & 1.207 & 1.024 & 650 & 555 & 413 & 259 & 159 & 5 & 5.377 \\
\hline & ELIAS FAUSTO & 1.128 & 987 & 749 & 488 & 404 & 313 & 188 & 110 & 1 & 4.368 \\
\hline & ESPIRITO SANTO DO PINHAL & 3.712 & 3.765 & 3.084 & 1.986 & 1.690 & 1.365 & 791 & 522 & 2 & 16.917 \\
\hline & INDAIATUBA & 6.567 & 6.149 & 5.705 & 3.995 & 2.729 & 1.965 & 1.134 & 596 & 23 & 28.863 \\
\hline & IPEUNA & 193 & 193 & 152 & 111 & 125 & 90 & 39 & 46 & 0 & 949 \\
\hline & IRACEMAPOLIS & 802 & 986 & 972 & 578 & 434 & 320 & 167 & 91 & 10 & 4.360 \\
\hline & ITAPIRA & 5.163 & 5.183 & 4.664 & 3.283 & 2.529 & 1.907 & 1.246 & 745 & 11 & 24.731 \\
\hline & ITATIBA & 4.659 & 4.399 & 4.112 & 2.778 & 2.223 & 1.608 & 901 & 519 & 1 & 21.200 \\
\hline
\end{tabular}


tabela 1 - populacao do Sexo masculino, Segundo municipio, RegiaO administrativa e grupo etario. estado de sao paulo, 1980.
REGIAO
MUNICIPIO

05 ITIRAPINA

ITOBI
ITUPEVA

JAGUARIUNA

JARINU

JOANOPOLIS

JUNDIAI

LEME

LINDOIA

LOUVEIRA

MOCOCA

MOGI GUACU

MOGI MIRIM

MONTE ALEGRE DO SUL

MONTE ALEGRE

MONTE MOR

NAZARE PAULISTA

NOVA ODESSA

PAULINIA

PEDRA BELA

PEDREIRA

PINHALZINHO
PIRACAIA

PIRACICABA

PIRASSUNUNGA

PORTO FERREIRA

RAFARD

RIO CLARO

RIO DAS PEDRAS

SANTA BARBARA D'OESTE

SANTA CRUZ DA CONCEICAO

SANTA CRUZ DAS PALMEIRAS

SANTA GERTRUDES

SANTA MARIA DA SERRA

SANTO ANTONIO DA POSSE

SAO JOAO DA BOA VISTA

SAO JOSE DO RIO PARDO

SAO PEDRO

SAO SEBASTIAO DA GRAMA

SERRA NEGRA

SOCORRO

SUMARE

TAPIRATIBA

TORR I NHA
GRUPO GRUPO

0 a 09

10 a 19

GRUPO
20 a 29

GRUPO

30 a 39

GRUPO

40 a 49

GRUPO
50 a 59

GRUPO

60 a 69

734
683
1.15
1.65

650

769
1.330
1.935

771
887

28.397

5.515
17.390
379

379
1.237

1.237
5.830

5.830

8.791

3.696
323

524
1.892

1.892
830

.830
2.095

2.615
2.700

2.700
611
2.247

758
1.749

1.749
24.374

4.864
3.075
646

646
11.932

1.733
9.134

9.134
280

280
1.774

866
334

1.220
683

683
5.990

3.901

1.510

1.402
1.894

1.894
2.470

2.470

14.429
1.737

1.214

.214
676
514
359

646
1.033

424

499
7.607

3.122

10.005

190
695

695
3.061

5.023

3.335

156
298

933

450
498

1.442

1.481
304

1.398

438
910

14.256

3.035
1.823

1.823
363

6.907

871
4.863

4.863
166

166
1.127
528

528
169

659
336
3.418

336
3.418
2.216

2.216

858
683

1.143

1.474
7.206

1.019

569
397

390
300
514
716
285
389
13.314
2.208
7.206
178
497
2.294
3.476
2.505
126
236
669
317
475
987
908
233
1.153
322
655
10.417
2.283
1.487
282
5.449
653
3.415
153
859
387
131
551
255
2.911
1.736
585
579
853
1.179
4.106
819
491
370

GRUPO

$70 \mathrm{e}$

I gnorada

TOTAL

3.578

3.027

5.324
7.927

3.264

4.123

130.457

23.698
76.469

1.674

1.674
5.338

24.348
37.799

37.799
25.726

25.726
1.400

1.400
2.519
7.174

7.174
3.369

3.369
4.363

4.363
11.073

10.590

2.452

10.806
3.370

3.370
7.042

107.487

22.745

14.173

3.054
54.805

6.918

39.064

1.401

8.364

4.100

1.494

5.669

2.922

27.961
18.397

6.719

5.870

8.753
12.028

12.028
52.442

52.442
8.053

8.053
5.015

5.015
3.367 
tabela 1 - populacaO do SeXo masculino, segundo municipio, Regiao administrativa e grupo etario. estado de sao paulo, 1980.

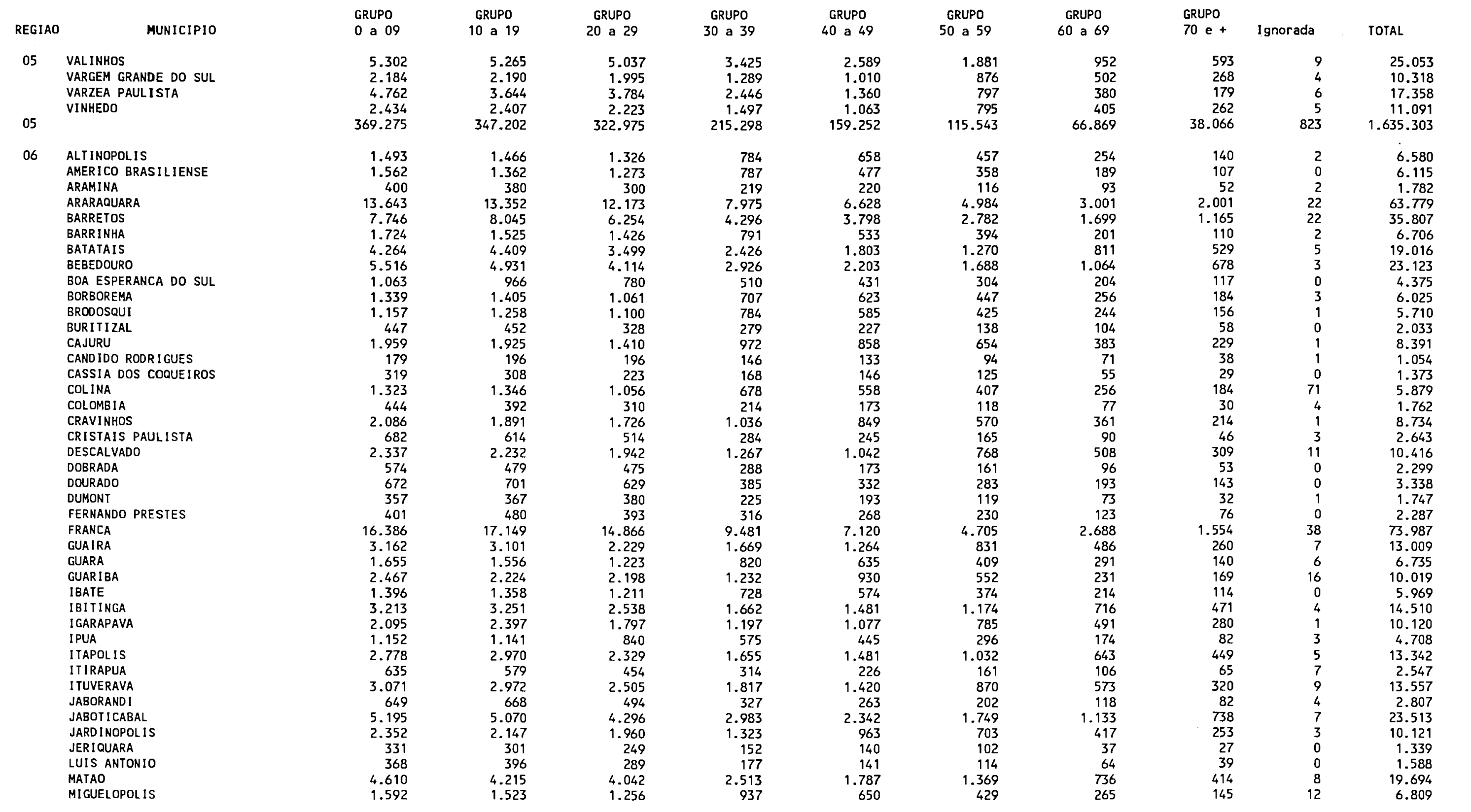




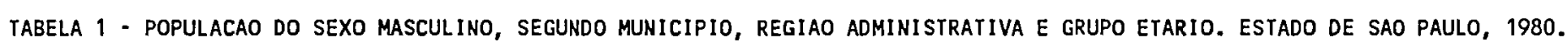

\begin{tabular}{|c|c|c|c|c|c|c|c|c|c|c|c|}
\hline REGIAO & MUNICIPIO & $\begin{array}{l}\text { GRUPO } \\
0 \text { a } 09\end{array}$ & $\begin{array}{c}\text { GRUPO } \\
10 \text { a } 19\end{array}$ & $\begin{array}{c}\text { GRUPO } \\
20 \text { a } 29\end{array}$ & $\begin{array}{c}\text { GRUPO } \\
30 \text { a } 39\end{array}$ & $\begin{array}{c}\text { GRUPO } \\
40 \text { a } 49\end{array}$ & $\begin{array}{c}\text { GRUPO } \\
50 \text { a } 59\end{array}$ & $\begin{array}{l}\text { GRUPO } \\
60 \text { a } 69\end{array}$ & $\begin{array}{l}\text { GRUPO } \\
70 \text { e + }\end{array}$ & I gnorada & TOTAL \\
\hline \multirow[t]{38}{*}{06} & MONTE ALTO & 3.391 & 3.560 & 3.072 & 2.041 & 1.618 & 1.217 & 719 & 419 & 0 & 16.037 \\
\hline & MONTE AZUL PAULISTA & 1.475 & 1.524 & 1.189 & 808 & 657 & 476 & 302 & 205 & 7 & 6.643 \\
\hline & MORRO AGUDO & 2.267 & 2.146 & 1.682 & 1.156 & 795 & 513 & 317 & 189 & 8 & 9.073 \\
\hline & NOVA EUROPA & 542 & 540 & 451 & 266 & 234 & 171 & 98 & 73 & 0 & 2.375 \\
\hline & NUPORANGA & 561 & 606 & 492 & 337 & 267 & 186 & 116 & 63 & 0 & 2.628 \\
\hline & ORLANDIA & 2.886 & 3.023 & 2.635 & 1.710 & 1.246 & 788 & 454 & 225 & 10 & 12.977 \\
\hline & PATROCINIO PAUL ISTA & 1.165 & 1.067 & 834 & 587 & 451 & 287 & 201 & 134 & 8 & 4.734 \\
\hline & PEDREGULHO & 1.742 & 1.565 & 1.097 & 873 & 635 & 400 & 236 & 132 & 5 & 6.685 \\
\hline & $\begin{array}{l}\text { PIRANGI } \\
\text { Plo }\end{array}$ & 794 & 832 & 731 & 519 & 406 & 322 & 194 & 134 & 17 & 3.949 \\
\hline & PITANGUEI RAS & 2.185 & 2.290 & 1.777 & 1.178 & 922 & 712 & 409 & 251 & 1 & 9.725 \\
\hline & $\begin{array}{l}\text { PONTAL } \\
\end{array}$ & 2.170 & 1.920 & 1.711 & 1.038 & 790 & 562 & 312 & 186 & 8 & 8.697 \\
\hline & PRADOPOLIS & 967 & 962 & 840 & 531 & 383 & 214 & 115 & 60 & 0 & 4.072 \\
\hline & RESTINGA & 502 & 459 & 294 & 193 & 196 & 111 & 57 & 26 & 1 & 1.839 \\
\hline & RIBEIRAO BONITO & 1.088 & 970 & 758 & 482 & 434 & 314 & 196 & 121 & 2 & 4.365 \\
\hline & RIBEIRAO CORRENTE & 362 & 346 & 267 & 167 & 135 & 113 & 56 & 20 & 1 & 1.467 \\
\hline & RIBEIRAO PRETO & 34.118 & 32.714 & 30.943 & 20.630 & 15.943 & 11.460 & 6.548 & 3.771 & 67 & 156.194 \\
\hline & RIFAINA & 429 & 424 & 270 & 198 & 159 & 117 & 80 & 43 & 1 & 1.721 \\
\hline & RINCAO & 906 & 809 & 650 & 483 & 351 & 256 & 193 & 112 & 2 & 3.762 \\
\hline & SALES DE OLIVEIRA & 656 & 752 & 629 & 440 & 343 & 264 & 140 & 92 & 5 & 3.321 \\
\hline & SANTA ERNESTINA & 475 & 424 & 311 & 244 & 149 & 125 & 59 & 26 & 1 & 1.814 \\
\hline & SANTA LUCIA & 604 & 607 & 525 & 313 & 228 & 165 & 119 & 58 & 0 & 2.619 \\
\hline & SANTA RITA DO PASSA QUATRO & 2.138 & 2.267 & 1.845 & 1.292 & 1.186 & 989 & 589 & 350 & 6 & 10.662 \\
\hline & SANTA ROSA DO VITERBO & 1.634 & 1.624 & 1.389 & 958 & 763 & 575 & 319 & 165 & 14 & 7.441 \\
\hline & SANTO ANTONIO DA ALEGRIA & 658 & 605 & 502 & 362 & 273 & 201 & 110 & 57 & 2 & 2.770 \\
\hline & SAO CARLOS & 13.125 & 12.451 & 11.646 & 7.617 & 5.893 & 4.505 & 2.763 & 1.880 & 27 & 59.907 \\
\hline & SAO JOAQUIM DA BARRA & 3.380 & 3.333 & 2.759 & 1.794 & 1.432 & 989 & 572 & 385 & 1 & 14.645 \\
\hline & SAO JOSE DA BELA VISTA & 923 & 733 & 571 & 459 & 332 & 242 & 135 & 76 & 0 & 3.471 \\
\hline & SAO SIMAO & 1.100 & 1.296 & 1.107 & 619 & 563 & 407 & 283 & 167 & 2 & 5.544 \\
\hline & SERRA AZUL & 613 & 562 & 478 & 281 & 224 & 169 & 106 & 74 & 1 & 2.508 \\
\hline & SERRANA & 1.763 & 1.734 & 1.689 & 970 & 611 & 461 & 255 & 125 & 6 & 7.614 \\
\hline & SERTAOZ INHO & 6.550 & 5.581 & 5.476 & 3.585 & 2.435 & 1.585 & 852 & 528 & 16 & 26.608 \\
\hline & TABAT I NGA & 951 & 920 & 753 & 483 & 462 & 328 & 209 & 133 & 0 & 4.239 \\
\hline & TAIACU & 382 & 411 & 312 & 234 & 194 & 159 & 80 & 58 & 0 & 1.830 \\
\hline & TAIUVA & 437 & 461 & 432 & 265 & 246 & 222 & 141 & 82 & 0 & 2.286 \\
\hline & TAQUAR I I INGA & 4.202 & 3.875 & 3.205 & 2.327 & 1.769 & 1.367 & 837 & 532 & 20 & 18.134 \\
\hline & TERRA ROXA & 611 & 727 & 615 & 331 & 273 & 239 & 119 & 84 & 4 & 3.003 \\
\hline & VIRADOURO & 1.145 & 1.051 & 1.020 & 674 & 506 & 420 & 261 & 182 & 0 & 5.259 \\
\hline & VISTA ALEGRE DO ALTO & 260 & 324 & 292 & 191 & 159 & 127 & 66 & 33 & 0 & 1.452 \\
\hline 06 & & 203.951 & 198.995 & 172.913 & 114.661 & 89.758 & 64.672 & 38.407 & 23.533 & 528 & 907.418 \\
\hline \multirow[t]{8}{*}{07} & AGUDOS & 3.336 & 2.851 & 2.312 & 1.474 & 1.079 & 788 & 526 & 279 & 10 & 12.655 \\
\hline & AREALVA & 734 & 802 & 570 & 442 & 361 & 315 & 218 & 157 & 4 & 3.603 \\
\hline & AVAI & 687 & 669 & 489 & 326 & 253 & 211 & 133 & 84 & 0 & 2.852 \\
\hline & BALBINOS & 140 & 151 & 116 & 74 & 67 & 48 & 23 & 13 & 0 & 632 \\
\hline & BARI I I & 2.068 & 2.142 & 1.827 & 1.166 & 1.035 & 816 & 579 & 350 & 5 & 9.988 \\
\hline & BARRA BONITA & 2.493 & 2.611 & 2.138 & 1.411 & 1.222 & 850 & 464 & 288 & 2 & 11.479 \\
\hline & BAURU & 20.403 & 19.783 & 16.755 & 11.223 & 9.507 & 7.015 & 4.305 & 2.628 & 123 & 91.742 \\
\hline & BOCAINA & 695 & 765 & 571 & 446 & 325 & 307 & 195 & 115 & 26 & 3.445 \\
\hline
\end{tabular}




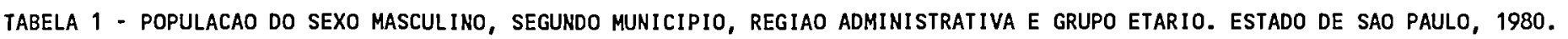

\begin{tabular}{|c|c|c|c|c|c|c|c|c|c|c|c|}
\hline REGIAO & MUNICIPIO & $\begin{array}{l}\text { GRUPO } \\
0 \text { a } 09\end{array}$ & $\begin{array}{c}\text { GRUPO } \\
10 \text { a } 19\end{array}$ & $\begin{array}{c}\text { GRUPO } \\
20 \text { a } 29\end{array}$ & $\begin{array}{l}\text { GRUPO } \\
30 \text { a } 39\end{array}$ & $\begin{array}{l}\text { GRUPO } \\
40 \text { a } 49\end{array}$ & $\begin{array}{c}\text { GRUPO } \\
50 \text { a } 59\end{array}$ & $\begin{array}{l}\text { GRUPO } \\
60 \text { a } 69\end{array}$ & $\begin{array}{l}\text { GRUPO } \\
70 \text { e + }\end{array}$ & I gnorada & TOTAL \\
\hline \multirow[t]{30}{*}{07} & BORACE IA & 421 & 460 & 301 & 238 & 179 & 123 & 71 & 51 & 0 & 1.844 \\
\hline & CABRALIA PAULISTA & 436 & 461 & 354 & 172 & 187 & 124 & 73 & 41 & 0 & 1.848 \\
\hline & CAFELANDIA & 2.253 & 2.036 & 1.449 & 974 & 777 & 675 & 459 & 270 & 6 & 8.899 \\
\hline & DOIS CORREGOS & 1.739 & 1.646 & 1.424 & 912 & 808 & 654 & 443 & 266 & 6 & 7.898 \\
\hline & DUART INA & 1.445 & 1.410 & 996 & 620 & 634 & 510 & 302 & 206 & 1 & 6.124 \\
\hline & GETUL INA & 1.374 & 1.362 & 954 & 564 & 477 & 447 & 285 & 173 & 2 & .5 .638 \\
\hline & GUAI CARA & 675 & 683 & 415 & 300 & 276 & 210 & 114 & 69 & 3 & 2.745 \\
\hline & GUAIMBE & 678 & 682 & 412 & 302 & 247 & 185 & 128 & 67 & 0 & 2.701 \\
\hline & GUARANTA & 772 & 686 & 504 & 310 & 276 & 188 & 118 & 96 & 6 & 2.956 \\
\hline & IACANGA & 754 & 796 & 528 & 389 & 324 & 270 & 191 & 132 & 1 & 3.385 \\
\hline & IGARACU DO TIETE & 1.577 & 1.518 & 1.279 & 785 & 594 & 414 & 201 & 149 & 4 & 6.521 \\
\hline & ITAJU & 281 & 283 & 235 & 167 & 122 & 123 & 90 & 42 & 0 & 1.343 \\
\hline & 1TAPUI & 890 & 833 & 706 & 422 & 342 & 359 & 194 & 130 & 2 & 3.878 \\
\hline & JAU & 8.013 & 7.840 & 7.260 & 4.466 & 3.694 & 2.928 & 1.740 & 1.131 & 21 & 37.093 \\
\hline & JUL1O MESQUI TA & 636 & 619 & 328 & 245 & 201 & 177 & 103 & 47 & 1 & 2.357 \\
\hline & LENCOIS PAUL ISTA & 4.483 & 4.087 & 3.387 & 2.084 & 1.677 & 1.168 & 663 & 384 & 8 & 17.941 \\
\hline & LINS & 5.406 & 5.966 & 4.486 & 2.742 & 2.423 & 2.029 & 1.264 & 840 & 11 & 25.167 \\
\hline & LUCIANOPOLIS & 353 & 306 & 239 & 158 & 114 & 88 & 68 & 31 & 0 & 1.357 \\
\hline & MACATUBA & 1.396 & 1.363 & 1.002 & 616 & 547 & 381 & 170 & 112 & 1 & 5.588 \\
\hline & MINEIROS DO TIETE & 777 & 752 & 652 & 380 & 302 & 289 & 201 & 108 & 1 & 3.462 \\
\hline & PEDERNEIRAS & 3.277 & 2.996 & 2.387 & 1.566 & 1.297 & 987 & 629 & 387 & 9 & 13.535 \\
\hline & PIRAJUI & 2.308 & 2.223 & 1.843 & 1.089 & 993 & 791 & 490 & 293 & 25 & 10.055 \\
\hline & PIRATININGA & 1.193 & 1.133 & 948 & 531 & 464 & 393 & 291 & 171 & 2 & 5.126 \\
\hline & PONGAI & 414 & 421 & 342 & 208 & 187 & 147 & 92 & 44 & 0 & 1.855 \\
\hline & PRESIDENTE ALVES & 668 & 614 & 398 & 249 & 229 & 203 & 106 & 65 & 1 & 2.533 \\
\hline & PROMISSAO & 2.370 & 2.385 & 1.737 & 1.171 & 1.027 & 804 & 476 & 298 & 0 & 10.268 \\
\hline & REGINOPOL IS & 563 & 565 & 421 & 248 & 236 & 194 & 132 & 73 & 7 & 2.439 \\
\hline & SABINO & 598 & 589 & 463 & 277 & 233 & 191 & 127 & 59 & 0 & 2.537 \\
\hline & UBIRA JARA & 563 & 525 & 363 & 273 & 193 & 160 & 85 & 54 & 7 & 2.223 \\
\hline & URU & 196 & 182 & 141 & 87 & 89 & 73 & 36 & 12 & 0 & 816 \\
\hline 07 & & 77.065 & 75.196 & 60.732 & 39.107 & 32.998 & 25.635 & 15.785 & 9.715 & 295 & 336.528 \\
\hline \multirow[t]{16}{*}{08} & ADOLFO & 438 & 456 & 351 & 194 & 195 & 112 & 92 & 44 & 1 & 1.883 \\
\hline & ALTAIR & 269 & 301 & 204 & 146 & 117 & 85 & 58 & 50 & 0 & 1.230 \\
\hline & ALVARES FLORENCE & 775 & 842 & 592 & 429 & 350 & 227 & 131 & 84 & 5 & 3.435 \\
\hline & AMERICO DE CAMPOS & 735 & 816 & 683 & 472 & 354 & 273 & 121 & 87 & 2 & 3.543 \\
\hline & APARECIDA D'OESTE & 640 & 662 & 384 & 308 & 237 & 195 & 133 & 77 & 11 & 2.647 \\
\hline & ARIRANHA & 560 & 634 & 522 & 383 & 300 & 246 & 144 & 85 & 0 & 2.874 \\
\hline & BADY BASSIT & 316 & 324 & 267 & 194 & 159 & 111 & 76 & 50 & 4 & 1.501 \\
\hline & BALSAMO & 590 & 664 & 509 & 368 & 311 & 228 & 132 & 82 & 2 & 2.886 \\
\hline & CAJOBI & 961 & 959 & 794 & 558 & 453 & 331 & 173 & 106 & 1 & 4.336 \\
\hline & CARDOSO & 1.478 & 1.500 & 955 & 731 & 643 & 405 & 274 & 158 & 2 & 6.146 \\
\hline & CATANDUVA & 7.644 & 7.808 & 6.634 & 4.335 & 3.908 & 3.006 & 1.843 & 1.174 & 8 & 36.360 \\
\hline & CATIGUA & 666 & 768 & 567 & 321 & 294 & 214 & 115 & 59 & 3 & 3.007 \\
\hline & CEDRAL & 598 & 698 & 570 & 377 & 354 & 291 & 190 & 113 & 1 & 3.192 \\
\hline & COSMORAMA & 914 & 1.065 & 757 & 578 & 494 & 341 & 189 & 143 & 1 & 4.482 \\
\hline & DOLCINOPOL IS & 289 & 281 & 173 & 129 & 125 & 55 & 64 & 21 & 0 & 1.137 \\
\hline & ESTRELA D'OESTE & 1.139 & 1.101 & 776 & 551 & 467 & 307 & 207 & 126 & 15 & 4.689 \\
\hline
\end{tabular}




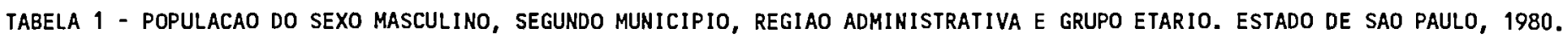

\begin{tabular}{|c|c|c|c|c|c|c|c|c|c|c|c|}
\hline REGIAO & MUNICIPIO & $\begin{array}{l}\text { GRUPO } \\
0 \text { a } 09\end{array}$ & $\begin{array}{l}\text { GRUPO } \\
10 \text { a } 19\end{array}$ & $\begin{array}{c}\text { GRUPO } \\
20 \text { a } 29\end{array}$ & $\begin{array}{c}\text { GRUPO } \\
30 \text { a } 39\end{array}$ & $\begin{array}{l}\text { GRUPO } \\
40 \text { a } 49\end{array}$ & $\begin{array}{c}\text { GRUPO } \\
50 \text { a } 59\end{array}$ & $\begin{array}{l}\text { GRUPO } \\
60 \text { a } 69\end{array}$ & $\begin{array}{l}\text { GRUPO } \\
70 \text { e + }\end{array}$ & Ignorada & TOTAL \\
\hline \multirow[t]{48}{*}{08} & FERNANDOPOLIS & 5.076 & 5.579 & 4.019 & 2.913 & 2.497 & 1.645 & 1.011 & 639 & 15 & 23.394 \\
\hline & GUAPIACU & 775 & 853 & 632 & 441 & 340 & 253 & 149 & 93 & 1 & 3.537 \\
\hline & GUARACI & 756 & 782 & 549 & 377 & 327 & 270 & 159 & 101 & 0 & 3.321 \\
\hline & GUARANI D'OESTE & 1.074 & 1.029 & 654 & 586 & 434 & 271 & 143 & 100 & 0 & 4.291 \\
\hline & IBIRA & 873 & 953 & 739 & 488 & 422 & 355 & 199 & 138 & 3 & 4.170 \\
\hline & ICEM & 615 & 598 & 398 & 354 & 274 & 199 & 126 & 67 & 0 & 2.631 \\
\hline & INDIAPORA & 833 & 846 & 502 & 421 & 376 & 186 & 121 & 49 & 2 & 3.336 \\
\hline & IRAPUA & 912 & 870 & 687 & 434 & 329 & 241 & 166 & 76 & 2 & 3.717 \\
\hline & ITAJOBI & 1.598 & 1.671 & 1.446 & 1.015 & 725 & 619 & 349 & 192 & 3 & 7.618 \\
\hline & JACI & 456 & 499 & 377 & 239 & 189 & 138 & 76 & 38 & 1 & 2.013 \\
\hline & JALES & 4.663 & 4.675 & 3.182 & 2.388 & 1.978 & 1.338 & 804 & 495 & 13 & 19.536 \\
\hline & JOSE BONIFACIO & 2.772 & 2.788 & 2.172 & 1.353 & 1.114 & 854 & 488 & 330 & 0 & 11.871 \\
\hline & MACAUBAL & 679 & 779 & 602 & 420 & 338 & 232 & 149 & 92 & 2 & 3.293 \\
\hline & MACEDON IA & 527 & 521 & 352 & 284 & 201 & 124 & 82 & 45 & 2 & 2.138 \\
\hline & MARINOPOL IS & 295 & 283 & 170 & 104 & 113 & 72 & 46 & 19 & 2 & 1.104 \\
\hline & MENDONCA & 453 & 528 & 368 & 241 & 217 & 146 & 89 & 53 & 0 & 2.095 \\
\hline & MER ID IANO & 446 & 487 & 333 & 245 & 193 & 137 & 91 & 62 & 1 & 1.995 \\
\hline & MIRA ESTRELA & 323 & 300 & 206 & 165 & 134 & 82 & 49 & 23 & 0 & 1.282 \\
\hline & MIRASSOL & 2.945 & 3.206 & 2.646 & 1.766 & 1.480 & 1.061 & 661 & 414 & 19 & 14.198 \\
\hline & MIRASSOLANDIA & 341 & 335 & 252 & 177 & 138 & 95 & 71 & 27 & 5 & 1.441 \\
\hline & MONCOES & 249 & 275 & 245 & 179 & 145 & 91 & 59 & 25 & 2 & 1.270 \\
\hline & MONTE APRAZIVEL & 1.681 & 1.962 & 1.380 & 1.060 & 894 & 604 & 415 & 285 & 3 & 8.284 \\
\hline & NEVES PAUL ISTA & 876 & 945 & 655 & 495 & 428 & 319 & 179 & 151 & 0 & 4.048 \\
\hline & NHANDEARA & 1.097 & 1.154 & 963 & 693 & 531 & 348 & 252 & 154 & 0 & 5.192 \\
\hline & NIPOA & 357 & 354 & 240 & 161 & 148 & 100 & 73 & 46 & 0 & 1.479 \\
\hline & NOVA ALIANCA & 470 & 466 & 392 & 254 & 252 & 181 & 105 & 80 & 2 & 2.202 \\
\hline & NOVA GRANADA & 1.288 & 1.295 & 954 & 726 & 621 & 419 & 311 & 212 & 2 & 5.828 \\
\hline & NOVA LUZITAHIA & 245 & 245 & 159 & 140 & 92 & 62 & 42 & 21 & 1 & 1.007 \\
\hline & NOVO HORI ZOWTE & 3.062 & 3.173 & 2.563 & 1.552 & 1.357 & 1.007 & 593 & 408 & 13 & 13.728 \\
\hline & OLIMPIA & 3.347 & 3.390 & 2.770 & 2.116 & 1.617 & 1.295 & 886 & 567 & 1 & 15.989 \\
\hline & ONDA VERDE & 255 & 263 & 154 & 119 & 117 & 70 & 39 & 25 & 0 & 1.042 \\
\hline & OR INDIUVA & 267 & 272 & 187 & 130 & 127 & 62 & 40 & 23 & 1 & 1.109 \\
\hline & PALESTINA & 979 & 1.066 & 698 & 600 & 505 & 369 & 264 & 171 & 0 & 4.652 \\
\hline & PALMARES PALLISTA & 527 & 504 & 489 & 245 & 229 & 115 & 86 & 38 & 38 & 2.271 \\
\hline & PALMEIRA D'OESTE & 1.515 & 1.690 & 1.025 & 745 & 677 & 432 & 230 & 150 & 7 & 6.471 \\
\hline & PARAISO & 412 & 402 & 357 & 238 & 190 & 145 & 89 & 51 & 1 & 1.885 \\
\hline & PARANAPUA & 771 & 749 & 447 & 317 & 296 & 208 & 112 & 68 & 0 & 2.968 \\
\hline & PAULOO DE FARIA & 699 & 830 & 556 & 408 & 376 & 244 & 167 & 87 & 4 & 3.371 \\
\hline & PEDRANOPOLIS & 449 & 435 & 343 & 233 & 172 & 145 & 59 & 39 & 1 & 1.876 \\
\hline & PINDORAMA & 1.156 & 1.104 & 912 & 644 & 553 & 430 & 275 & 173 & 7 & 5.254 \\
\hline & PLANALTO & 764 & 782 & 591 & 355 & 295 & 196 & 116 & 61 & 1 & 3.161 \\
\hline & POLONI & 472 & 526 & 420 & 294 & 271 & 168 & 139 & 109 & 3 & 2.402 \\
\hline & PONTES GESTAL & 345 & 326 & 237 & 170 & 138 & 108 & 45 & 36 & 7 & 1.412 \\
\hline & POPULINA & 615 & 610 & 369 & 280 & 272 & 183 & 107 & 64 & 0 & 2.500 \\
\hline & POTIRENDABA & 1.101 & 1.224 & 971 & 703 & 600 & 436 & 268 & 196 & 1 & 5.500 \\
\hline & RIOLANDIA & 784 & 838 & 564 & 449 & 346 & 244 & 134 & 82 & 46 & 3.487 \\
\hline & RUBINEIA & 303 & 287 & 184 & 136 & 122 & 85 & 65 & 33 & 0 & 1.215 \\
\hline & SALES & 587 & 626 & 433 & 287 & 230 & 159 & 109 & 52 & 0 & 2.483 \\
\hline
\end{tabular}




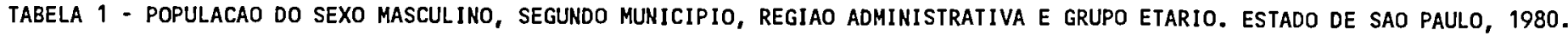

REGIAO MUNICIPIO

08 SANTA ADELIA

SANTA ALBERTINA

SANTA CLARA D'OESTE

SANTA FE DO SUL

SANTANA DA PONTE PENSA

SANTANA DA PONTE

SAO JOAO DAS DUAS PONTES

SAO JOSE DO RIO PRETO

SEBASTIANOPOLIS DO SUL

SEVERINIA

TANABI

TRES FRONTEIRAS

TURMAL INA

UCHOA

UNIAO PAULISTA

URANIA

VALENTIM GENTIL

08

VOTUPORANGA

09 ALTO ALEGRE

ANDRADINA

ARACATUBA

AURI FLAMA

AVANHANDAVA

BARBOSA

BENTO DE ABREU

BILAC

BRAUNA

BUR I TAMA

CASTILHO

CLEMENTINA

COROADOS

FLOREAL

GABRIEL MONTEIRO

GASTAO VIDIGAL

GENERAL SALGADO

GLICERIO

GUARARAPES

GUZOLANDIA

ITAPURA

LUIZIANIA $\begin{array}{lll}\text { GRUPO } & \text { GRUPO } \\ 0 & 10 \text { GRUPO }\end{array}$

0 a 09

GRUPO

GRUPO

1.159

1.159

682
316
2.317

2.317
476

476
365
590

368
8.842

18.842
264

991

1.364

2.267

1.027

360
838

138

138
1.638

1.315
597

597
5.581

110.592

784
323
2.379

2.379

338

619
411

19.666

276

959
1.472

2.386

1.173

392
909

909
140

1.671

1.456
693

693
5.995

116.051

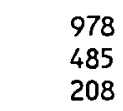

1.620

369
228

295
245

17.612

237
801

1.180

1.937

702
264
670

670
128

1.103

499

4.724
89.676

778
5.710

$\begin{array}{r}736 \\ 5.594 \\ \hline\end{array}$

5.594
14.966

1.383

790
760
247

247
553

$\begin{array}{r}553 \\ 5.703 \\ \hline\end{array}$

503
1.507

1.507
1.635

499

757
418

418
318

485

1.423

650
961

961
2.640

578
478

703
503

14.991
1.594

824
703

703
276

638
5.998

5.998
566

1.342

1.537

562
679

679
432

419
421

1.441

660

1.096
2.873

580

406
794
529

89.676

535

11.169

1.045

578
443

138
481

4.814

401
1.063

952

403
486

486
321

304

338
1.018

423
694

1.784

1.784
372
248

493
302
GRUPO

50 a 59

60 a 69

514
328
151

1.109

242
135
241

241
158

10.032

117
349

678
1.037

1.037
448

160
397

63
688

688
652
253
2.701

52.634

309
2.305

2.305

6.207

306

$\begin{array}{r}271 \\ 98 \\ \hline\end{array}$

285
2.460

268

569
549
208

208
264

194
167

167
190

610

270
429

429
1.143

207

120
306
177

476
261
92
729
131
94
163
112
7.215
93
267
498
722
353
109
325
43
466
469
223
1.837
37.648

237
13
47
464
7
56
103
49
3.996

3.996
47

161
270

466
191

55
200

27

256
274
121

121
1.16

1.162
22.615

249
1.667

4.447

443
225
175

225
175
72

190
1.813
159
360

159
360

374
197

197
193

147

96
119

379
165

296
766

766
134
95

95
227

132

1.089

2.677

136
128

44
123

1.058

106

221
281

95
113

78

74
70

246
105

217

512
79
82

82
158
73

73
GRUPO

70 e + I gnorada

TOTAL

$\begin{array}{rr}158 & 2 \\ 111 & 2 \\ 44 & 0 \\ 319 & 2 \\ 55 & 1 \\ 36 & 0 \\ 63 & 6 \\ 34 & 0 \\ 2.444 & 70 \\ 34 & 0 \\ 90 & 0 \\ 163 & 6 \\ 287 & 4 \\ 141 & 0 \\ 27 & 1 \\ 147 & 1 \\ 11 & 0 \\ 189 & 22 \\ 172 & 8 \\ 81 & 0 \\ 712 & 104 \\ 14.237 & 497\end{array}$

5.345

10.166

2.205

1.435

2.372

1.551

1.229

4.106

6.381

10.335

4.525

1.557
3.974
642

642

6.799

6.158 2.795 26.160 506.768

72
666

1.606

13

87

29
79
602
67

602
67

16

158

57
5
56

5
56
41

14

, 133

33

53
105
45

3.190
23.710

63.948

63.948

3.313

2.844

1.033

2.687

25.660
2.350

5.995

6.214

2.263

1.878

1.614

1.918

5.979

2.614

4.339

2.256

1.672

3.133
1.975 


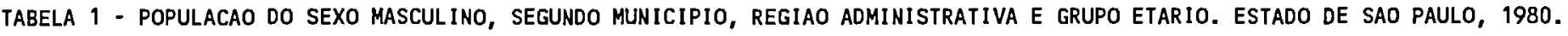

\begin{tabular}{|c|c|c|c|c|c|c|c|c|c|c|c|}
\hline REGIAO & MUNICIPIO & $\begin{array}{l}\text { GRUPO } \\
0 \text { a } 09\end{array}$ & $\begin{array}{l}\text { GRUPO } \\
10 \text { a } 19\end{array}$ & $\begin{array}{c}\text { GRUPO } \\
20 \text { a } 29\end{array}$ & $\begin{array}{l}\text { GRUPO } \\
30 \text { a } 39\end{array}$ & $\begin{array}{l}\text { GRUPO } \\
40 \text { a } 49\end{array}$ & $\begin{array}{c}\text { GRUPO } \\
50 \text { a } 59\end{array}$ & $\begin{array}{c}\text { GRUPO } \\
60 \text { a } 69\end{array}$ & $\begin{array}{l}\text { GRUPO } \\
70 \text { e + }\end{array}$ & I gnorada & TOTAL \\
\hline \multirow[t]{12}{*}{09} & MAGDA & 456 & 453 & 336 & 224 & 183 & 108 & 73 & 60 & 0 & 1.893 \\
\hline & MIRANDOPOLIS & 2.464 & 2.708 & 1.763 & 1.299 & 1.063 & 765 & 497 & 350 & 6 & 10.915 \\
\hline & MURUT INGA DO SUL & 439 & 609 & 447 & 278 & 209 & 206 & 109 & 67 & 0 & 2.364 \\
\hline & NOVA I NDEPENDENCIA & 258 & 229 & 159 & 118 & 74 & 70 & 44 & 19 & 0 & 971 \\
\hline & PENAPOLIS & 4.474 & 4.614 & 3.647 & 2.406 & 1.980 & 1.465 & 999 & 617 & 35 & 20.237 \\
\hline & PEREIRA BARRETO & 6.163 & 5.474 & 3.701 & 3.102 & 2.216 & 1.363 & 718 & 419 & 16 & 23.172 \\
\hline & PIACATU & 573 & 690 & 445 & 287 & 232 & 163 & 119 & 60 & 2 & 2.571 \\
\hline & RUBIACEA & 261 & 281 & 185 & 105 & 104 & 87 & 41 & 40 & 0 & 1.104 \\
\hline & SANTOPOLIS DO AGUAPEI & 465 & 463 & 274 & 153 & 162 & 127 & 66 & 59 & 4 & 1.773 \\
\hline & SUD MENUCCI & 767 & 685 & 446 & 348 & 211 & 168 & 112 & 52 & 0 & 2.789 \\
\hline & TURIUBA & 476 & 480 & 365 & 282 & 193 & 133 & 77 & 66 & 4 & 2.076 \\
\hline & VALPARAISO & 1.599 & 1.634 & 1.134 & 741 & 608 & 474 & 305 & 216 & 0 & 6.711 \\
\hline 09 & & 63.185 & 64.169 & 45.612 & 32.166 & 25.773 & 18.249 & 11.269 & 6.955 & 212 & 267.590 \\
\hline \multirow[t]{34}{*}{10} & ADAMANTINA & 3.533 & 3.951 & 2.685 & 1.834 & 1.670 & 1.227 & 756 & 486 & 2 & 16.144 \\
\hline & ALFREDO MARCONDES & 461 & 563 & 323 & 277 & 197 & 172 & 126 & 92 & 3 & 2.214 \\
\hline & ALVARES MACHADO & 1.720 & 1.909 & 1.191 & 916 & 673 & 530 & 312 & 226 & 3 & 7.480 \\
\hline & ANHUMAS & 458 & 448 & 263 & 175 & 184 & 116 & 67 & 61 & 0 & 1.772 \\
\hline & CAIABU & 462 & 595 & 246 & 200 & 173 & 130 & 75 & 41 & 1 & 1.923 \\
\hline & CAIUA & .438 & 408 & 191 & 158 & 162 & 105 & 55 & 31 & 1 & 1.549 \\
\hline & DRACENA & 3.789 & 4.354 & 3.018 & 2.045 & 1.879 & 1.420 & 836 & 604 & 10 & 17.955 \\
\hline & ESTRELA DO NORTE & 418 & 575 & 273 & 152 & 155 & 107 & 52 & 25 & 0 & 1.757 \\
\hline & FLORA RICA & 372 & 414 & 199 & 136 & 137 & 105 & 51 & 38 & 2 & 1.454 \\
\hline & FLORIDA PAULISTA & 1.825 & 2.074 & 1.291 & 797 & 754 & 569 & 339 & 205 & 1 & 7.855 \\
\hline & IEPE & 1.150 & 1.211 & 652 & 487 & 494 & 361 & 228 & 130 & 0 & 4.713 \\
\hline & INDIANA & 525 & 601 & 363 & 234 & 210 & 162 & 120 & 62 & 0 & 2.277 \\
\hline & INUB IA PAUL ISTA & 577 & 550 & 341 & 225 & 193 & 162 & 107 & 51 & 6 & 2.212 \\
\hline & $\begin{array}{l}\text { IRAPURU } \\
\text { I In }\end{array}$ & 1.169 & 1.328 & 724 & 547 & 539 & 378 & 238 & 125 & 2 & 5.050 \\
\hline & JOAO RAMALHO & 351 & 344 & 264 & 189 & 150 & 125 & 50 & 27 & 0 & 1.500 \\
\hline & JUNQUE I ROPOL IS & 2.460 & 2.828 & 1.956 & 1.215 & 1.029 & 790 & 444 & 291 & 6 & 11.019 \\
\hline & LUCELIA & 2.229 & 2.333 & 1.557 & 1.112 & 878 & 691 & 473 & 275 & 10 & 9.558 \\
\hline & MARABA PAULISTA & 503 & 564 & 313 & 213 & 179 & 130 & 73 & 34 & 0 & 2.009 \\
\hline & $\begin{array}{l}\text { MARIAPOL IS } \\
\text { M }\end{array}$ & 652 & 767 & 410 & 262 & 259 & 198 & 115 & 85 & 2 & 2.750 \\
\hline & MARTINOPOLIS & 2.370 & 2.700 & 1.480 & 1.106 & 919 & 650 & 468 & 267 & 0 & 9.960 \\
\hline & MIRANTE DO PARANAPANEMA & 2.057 & 2.104 & 1.158 & 836 & 724 & 547 & 324 & 158 & 0 & 7.908 \\
\hline & MONIE CASTELO & 734 & 828 & 574 & 335 & 293 & 229 & 127 & 70 & 0 & 3.190 \\
\hline & $\begin{array}{l}\text { NARANDIBA } \\
\text { IB }\end{array}$ & 458 & 517 & 292 & 165 & 181 & 122 & 69 & 27 & 0 & 1.831 \\
\hline & NOVA GUATAPORANGA & 346 & 347 & 259 & 139 & 137 & 101 & 53 & 27 & 1 & 1.410 \\
\hline & OSVALDO CRUZ & 2.913 & 3.116 & 2.256 & 1.570 & 1.303 & 1.057 & 617 & 413 & 3 & 13.248 \\
\hline & OURO VERDE & 764 & 752 & 437 & 330 & 290 & 209 & 116 & 81 & 1 & 2.980 \\
\hline & $\begin{array}{l}\text { PACAEMBU } \\
\text { PAC }\end{array}$ & 1.900 & 2.132 & 1.272 & 891 & 792 & 593 & 300 & 196 & 4 & 8.080 \\
\hline & PANORAMA & 1.221 & 1.064 & 546 & 440 & 364 & 268 & 155 & 98 & 2 & 4.158 \\
\hline & $\begin{array}{l}\text { PARAPUA } \\
\text { PAP }\end{array}$ & 1.492 & 1.607 & 1.068 & 663 & 640 & 467 & 280 & 171 & 1 & 6.389 \\
\hline & PAULICEIA & 386 & 306 & 156 & 116 & 129 & 66 & 53 & 32 & 1 & 1.245 \\
\hline & PIQUEROBI & 435 & 496 & 266 & 228 & 178 & 115 & 75 & 40 & 0 & 1.833 \\
\hline & PIRAPOZINHO & 2.185 & 2.422 & 1.446 & 972 & 843 & 610 & 313 & 198 & 4 & 8.993 \\
\hline & PRESIDENTE BERNARDES & 1.863 & 2.156 & 1.205 & 872 & 785 & 609 & 356 & 256 & 1 & 8.103 \\
\hline & PRESIDENTE EPITACIO & 3.947 & 3.852 & 2.203 & 1.574 & 1.476 & 1.052 & 568 & 290 & 14 & 14.976 \\
\hline
\end{tabular}




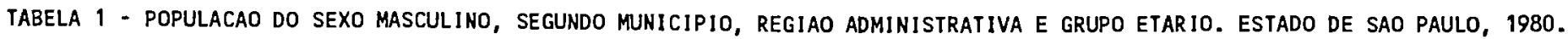

\begin{tabular}{|c|c|c|c|c|c|c|c|c|c|c|c|}
\hline REGIAO & MUNICIPIO & $\begin{array}{l}\text { GRUPO } \\
0 \text { a } 09\end{array}$ & $\begin{array}{l}\text { GRUPO } \\
10 \text { a } 19\end{array}$ & $\begin{array}{c}\text { GRUPO } \\
20 \text { a } 29\end{array}$ & $\begin{array}{l}\text { GRUPO } \\
30 \text { a } 39\end{array}$ & $\begin{array}{l}\text { GRUPO } \\
40 \text { a } 49\end{array}$ & $\begin{array}{c}\text { GRUPO } \\
50 \text { a } 59\end{array}$ & $\begin{array}{l}\text { GRUPO } \\
60 \text { a } 69\end{array}$ & $\begin{array}{l}\text { GRUPO } \\
70 \text { e + }\end{array}$ & I gnorada & TOTAL \\
\hline 10 & & $\begin{array}{r}15.736 \\
3.506\end{array}$ & 15.933 & 11.897 & 8.242 & 6.708 & 4.676 & 2.597 & 1.566 & 19 & 67.374 \\
\hline & $\begin{array}{l}\text { RRESIDENTE VENCESLAU } \\
\text { RANCHARIA }\end{array}$ & $\begin{array}{l}3.596 \\
2.824\end{array}$ & $\begin{array}{l}3.564 \\
2.882\end{array}$ & $\begin{array}{l}2.642 \\
1.839\end{array}$ & 1.837 & 1.514 & 988 & 584 & 363 & 2 & 15.090 \\
\hline & REGENTE FE IJO & 1.303 & 1.331 & $\begin{array}{r}1.0058 \\
901\end{array}$ & $\begin{array}{r}1.261 \\
622\end{array}$ & $\begin{array}{r}1.123 \\
586\end{array}$ & $\begin{array}{l}889 \\
390\end{array}$ & 536 & 321 & 0 & $\begin{array}{r}11.675 \\
5.556\end{array}$ \\
\hline & RINOPOLIS & 1.830 & 1.929 & 1.346 & $\begin{array}{l}0<2 \\
846\end{array}$ & & 602 & $\begin{array}{l}246 \\
313\end{array}$ & $\begin{array}{l}175 \\
163\end{array}$ & $\begin{array}{l}2 \\
5\end{array}$ & $\begin{array}{l}5.556 \\
7.843\end{array}$ \\
\hline & SAGRES & 397 & 415 & 245 & 146 & 148 & 105 & 77 & 30 & 1 & .1 .564 \\
\hline & SALMORAO & 625 & 632 & 397 & 270 & 241 & 165 & 100 & 47 & 3 & 2.480 \\
\hline & SANDOVAL INA & 432 & 345 & 201 & 154 & 118 & 77 & 42 & 36 & 1 & 1.406 \\
\hline & SANTA MERCEDES & 607 & 558 & 365 & 190 & 200 & 129 & 89 & 44 & 0 & 2.182 \\
\hline & SANTO ANASTACIO & 2.494 & 2.725 & 1.657 & 1.184 & 1.098 & 841 & 495 & 316 & 21 & 10.831 \\
\hline & SANTO EXPEDI TO & 301 & 334 & 150 & 113 & 113 & 81 & 44 & 31 & 1 & 1.168 \\
\hline & SAO JOAO DO PAU D'ALHO & 456 & 475 & 314 & 203 & 184 & 130 & 60 & 30 & 2 & 1.854 \\
\hline & TACIBA & 593 & 617 & 351 & 266 & 241 & 137 & 90 & 62 & 0 & 2.357 \\
\hline & TARABAI & 452 & 508 & 325 & 183 & 163 & 121 & 64 & 33 & 0 & 1.849 \\
\hline & TEODORO SAMPAIO & 3.995 & 3.192 & 2.432 & 1.887 & 1.418 & 779 & 447 & 198 & 5 & 14.353 \\
\hline & TUPI PAULISTA & 1.850 & 2.062 & 1.402 & 937 & 825 & 672 & 343 & 235 & 1 & 8.327 \\
\hline 10 & & 83.654 & 87.718 & 57.342 & 39.752 & 34.458 & 24.955 & 14.518 & 8.863 & 144 & 351.404 \\
\hline 11 & ALVARO DE CARVALHO & 548 & 503 & 285 & 212 & 169 & 156 & 80 & 45 & 0 & 1.998 \\
\hline & ALVINLANDIA & 466 & 415 & 314 & 232 & 143 & 124 & 59 & 33 & 1 & 1.787 \\
\hline & ASSIS & 7.647 & 7.774 & 5.538 & 3.987 & 3.304 & 2.520 & 1.522 & 1.011 & 10 & 33.313 \\
\hline & BASTOS & 1.903 & 2.002 & 1.385 & 869 & 692 & 504 & 299 & 146 & 4 & 7.804 \\
\hline & BERNARDINO DE CAMPOS & 991 & 1.013 & 616 & 498 & 468 & 361 & 290 & 209 & 0 & 4.446 \\
\hline & BORA & 124 & 120 & 74 & 39 & 38 & 32 & 20 & 8 & 0 & 455 \\
\hline & CAMPOS NOVOS PAULISTA & 509 & 454 & 307 & 233 & 173 & 136 & 118 & 66 & 1 & 1.997 \\
\hline & CANDIDO MOTA & 2.194 & 2.474 & 1.690 & 1.197 & 1.018 & 746 & 473 & 317 & 4 & 10.113 \\
\hline & CHAVANTES & 1.695 & 1.611 & 1.064 & 788 & 646 & 402 & 271 & 175 & 3 & 6.655 \\
\hline & CRUZAL IA & 632 & 586 & 400 & 301 & 238 & 133 & 96 & 57 & 0 & 2.443 \\
\hline & ECHAPORA & 713 & 718 & 456 & 308 & 293 & 182 & 142 & 78 & 0 & 2.890 \\
\hline & FARTURA & 1.600 & 1.601 & 1.028 & 764 & 598 & 430 & 279 & 180 & 3 & 6.483 \\
\hline & FLOR INEA & 324 & 324 & 227 & 190 & 120 & 103 & 70 & 35 & 0 & 1.393 \\
\hline & GALIA & 1.479 & 1.351 & 992 & 655 & 597 & 461 & 286 & 197 & 1 & 6.019 \\
\hline & GARCA & 5.034 & 4.514 & 3.472 & 2.258 & 1.874 & 1.570 & 943 & 546 & 2 & 20.213 \\
\hline & HERCULANDIA & 942 & 881 & 571 & 400 & 328 & 272 & 162 & 106 & 2 & 3.664 \\
\hline & IACR I & 1.164 & 1.199 & 839 & 498 & 437 & 327 & 173 & 111 & 1 & 4.749 \\
\hline & IBIRAREMA & 546 & 574 & 338 & 334 & 242 & 179 & 144 & 95 & 1 & 2.453 \\
\hline & IPAUCU & 1.192 & 1.274 & 840 & 613 & 508 & 381 & 245 & 173 & 0 & 5.226 \\
\hline & LUPERCIO & 469 & 454 & 285 & 198 & 180 & 118 & 61 & 32 & 1 & 1.798 \\
\hline & LUTECIA & 372 & 390 & 252 & 181 & 149 & 120 & 87 & 44 & 1 & 1.596 \\
\hline & MANDUR I & 556 & 655 & 450 & 333 & 282 & 197 & 142 & 92 & 12 & 2.719 \\
\hline & MARACAI & 1.308 & 1.214 & 910 & 626 & 457 & 331 & 196 & 116 & 1 & 5.159 \\
\hline & MARILIA & 14.047 & 13.677 & 11.014 & 7.174 & 5.768 & 4.475 & 2.688 & 1.576 & 53 & 60.472 \\
\hline & OCAUCU & 661 & 659 & 408 & 276 & 261 & 194 & 120 & 58 & 3 & 2.640 \\
\hline & OLEO & 325 & 362 & 256 & 157 & 177 & 148 & 87 & 75 & 0 & 1.587 \\
\hline & ORIENTE & 744 & 873 & 584 & 326 & 327 & 273 & 151 & 75 & 0 & 3.353 \\
\hline & OSCAR BRESSANE & 404 & 388 & 212 & 199 & 183 & 95 & 67 & 46 & 0 & 1.594 \\
\hline & OUR INHOS & 7.024 & 6.896 & 5.125 & 3.738 & 2.902 & 2.106 & 1.269 & 745 & 13 & 29.818 \\
\hline & PALMITAL & 1.876 & 1.878 & 1.350 & 1.075 & 899 & 724 & 466 & 347 & 2 & 8.617 \\
\hline
\end{tabular}


tABELA 1 - POPULACAO dO SEXO MASCULINO, SEGUNDO MUNICIPIO, REgIAO ADMINISTRATIVA E GRUPO ETARIO. ESTAdO DE SAO PAULO, 1980.

\begin{abstract}
REGIAO MUNICIPIO
\end{abstract}
11 PARAGUACU PAULISTA PIRAJU PLATINA

POMPEIA

QUATA

QUETRO2

RIBEIRAO DO SUL

SALTO GRANDE

SANTA CRUZ DO RIO PARDO

SAO PEDRO DO TURVO

SARUTAIA

TEJUPA
TIMBUR I

TUPA

11

VERA CRUZ

\begin{tabular}{|c|c|c|c|c|c|}
\hline $\begin{array}{l}\text { GRUPO } \\
0 \text { a } 09\end{array}$ & $\begin{array}{c}\text { GRUPO } \\
10 \text { a } 19\end{array}$ & $\begin{array}{c}\text { GRUPO } \\
20 \text { a } 29\end{array}$ & $\begin{array}{c}\text { GRUPO } \\
30 \text { a } 39\end{array}$ & $\begin{array}{c}\text { GRUPO } \\
40 \text { a } 49\end{array}$ & $\begin{array}{c}\text { GRUPO } \\
50 \text { a } 59\end{array}$ \\
\hline 2.821 & 2.919 & 1.766 & 1.371 & 1.126 & 905 \\
\hline 2.418 & 2.419 & 1.754 & 1.265 & 1.150 & 790 \\
\hline 291 & 282 & 192 & 126 & 127 & 102 \\
\hline 2.068 & 1.884 & 1.399 & 967 & 715 & 588 \\
\hline 1.088 & 1.097 & 643 & 476 & 436 & 369 \\
\hline 345 & 310 & 134 & 119 & 103 & 77 \\
\hline 630 & 622 & 416 & 267 & 236 & 195 \\
\hline 409 & 414 & 244 & 187 & 161 & 129 \\
\hline 886 & 810 & 501 & 397 & 351 & 287 \\
\hline 3.783 & 4.046 & 3.003 & 2.097 & 1.693 & 1.190 \\
\hline 1.035 & 907 & 609 & 464 & 362 & 273 \\
\hline 384 & 359 & 224 & 178 & 144 & 92 \\
\hline 767 & 690 & 534 & 358 & 273 & 162 \\
\hline 660 & 620 & 406 & 325 & 215 & 158 \\
\hline 417 & 407 & 271 & 186 & 178 & 127 \\
\hline 6.365 & 6.420 & 4.613 & 3.258 & 2.851 & 2.192 \\
\hline 1.413 & 1.490 & 887 & 625 & 551 & 440 \\
\hline 83.269 & 82.530 & 58.878 & 41.325 & 34.143 & 25.876 \\
\hline 397.422 & 2.604 .447 & 2.528 .735 & 1.690 .991 & 1.212 .502 & 848.073 \\
\hline
\end{tabular}

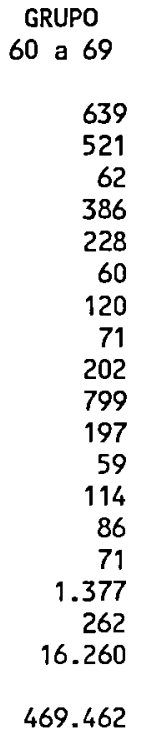

GRUPO

$70 \mathrm{e}+$

I gnorada

TOTAL

389
324
43
243
135
24
84
42
136
573
114
47
58
49
49
911
195
10.210
259.966

259.966

11.939

10.643

1.225

4.475

$1: 172$

2.578

1.657

3.572

17.189

3.961

1.487

2.956

2.520

1.706

28.014

28.014
5.868
352.667

352.667

12.519 .890 


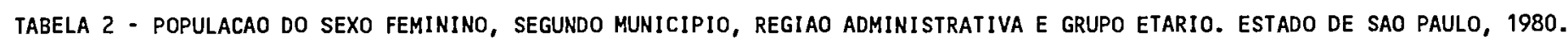

\begin{tabular}{|c|c|c|c|c|c|c|c|c|c|c|c|}
\hline REGIAO & MUNICIPIO & $\begin{array}{l}\text { GRUPO } \\
0 \text { a } 09\end{array}$ & $\begin{array}{l}\text { GRUPO } \\
10 \text { a } 19\end{array}$ & $\begin{array}{c}\text { GRUPO } \\
20 \text { a } 29\end{array}$ & $\begin{array}{c}\text { GRUPO } \\
30 \text { a } 39\end{array}$ & $\begin{array}{l}\text { GRUPO } \\
40 \text { a } 49\end{array}$ & $\begin{array}{c}\text { GRUPO } \\
50 \text { a } 59\end{array}$ & $\begin{array}{l}\text { GRUPO } \\
60 \text { a } 69\end{array}$ & $\begin{array}{l}\text { GRUPO } \\
70 \text { e + }\end{array}$ & Ignorada & TOTAL \\
\hline $\begin{array}{l}01 a \\
01 a\end{array}$ & SAO PAULO & $\begin{array}{l}886.648 \\
886.648\end{array}$ & $\begin{array}{l}819.602 \\
819.602\end{array}$ & $\begin{array}{l}934.523 \\
934.523\end{array}$ & $\begin{array}{l}623.756 \\
623.756\end{array}$ & $\begin{array}{l}439.204 \\
439.204\end{array}$ & $\begin{array}{l}326.924 \\
326.924\end{array}$ & $\begin{array}{l}188.258 \\
188.258\end{array}$ & $\begin{array}{l}121.225 \\
121.225\end{array}$ & $\begin{array}{l}2.531 \\
2.531\end{array}$ & $\begin{array}{l}4.342 .671 \\
4.342 .671\end{array}$ \\
\hline \multirow[t]{36}{*}{$01 b$} & ARUJA & 2.383 & 1.975 & 1.559 & 1.038 & 702 & 468 & 267 & 163 & 7 & 8.562 \\
\hline & BARUER I & 10.619 & 8.183 & 7.468 & 4.611 & 2.731 & 1.766 & 913 & 440 & 16 & 36.747 \\
\hline & BIRITIBA MIRIM & 1.743 & 1.581 & 1.038 & 745 & 539 & 369 & 256 & 125 & 5 & .6 .401 \\
\hline & CAIEIRAS & 3.102 & 2.709 & 2.344 & 1.680 & 1.097 & 740 & 448 & 232 & 1 & 12.353 \\
\hline & CAJAMAR & 3.056 & 2.440 & 2.073 & 1.264 & 773 & 505 & 293 & 127 & 8 & 10.539 \\
\hline & CARAPICUIBA & 27.033 & 19.757 & 19.128 & 12.579 & 6.654 & 3.929 & 2.026 & 909 & 47 & 92.062 \\
\hline & COTIA & 8.396 & 6.798 & 6.036 & 4.029 & 2.449 & 1.601 & 874 & 588 & 61 & 30.832 \\
\hline & DIADEMA & 30.909 & 24.000 & 25.422 & 14.640 & 8.274 & 4.615 & 2.275 & 1.048 & 76 & 111.259 \\
\hline & EMBU & 14.870 & 9.923 & 9.820 & 6.475 & 3.239 & 1.756 & 942 & 426 & 33 & 47.484 \\
\hline & EMBU-GUACU & 3.018 & 2.386 & 1.664 & 1.221 & 823 & 546 & 357 & 175 & 8 & 10.198 \\
\hline & FERRAZ DE VASCONCELOS & 7.687 & 6.210 & 5.303 & 3.466 & 2.228 & 1.323 & 723 & 383 & 21 & 27.344 \\
\hline & FRANCISCO MORATO & 4.312 & 3.110 & 2.717 & 1.681 & 1.039 & 629 & 352 & 181 & 8 & 14.029 \\
\hline & FRANCO DA ROCHA & 6.472 & 4.536 & 4.793 & 3.337 & 2.258 & 1.739 & 1.089 & 562 & 97 & 24.883 \\
\hline & GUARAREMA & 1.883 & 1.653 & 1.216 & 848 & 621 & 522 & 323 & 205 & 14 & 7.285 \\
\hline & GUARULHOS & 68.579 & 56.208 & 54.888 & 36.807 & 22.511 & 13.978 & 7.262 & 3.837 & 128 & 264.198 \\
\hline & ITAPECERICA DA SERRA & 8.961 & 6.443 & 5.693 & 3.758 & 2.132 & 1.408 & 787 & 430 & 37 & 29.649 \\
\hline & ITAPEVI & 7.576 & 6.042 & 4.964 & 3.218 & 2.071 & 1.334 & 724 & 370 & 41 & 26.340 \\
\hline & ITAQUAQUECETUBA & 10.610 & 8.072 & 6.867 & 4.451 & 2.733 & 1.659 & 815 & 428 & 74 & 35.709 \\
\hline & JANDIRA & 5.132 & 3.950 & 3.611 & 2.280 & 1.267 & 765 & 406 & 146 & 11 & 17.568 \\
\hline & JUQUITIBA & 1.759 & 1.381 & 938 & 657 & 515 & 349 & 190 & 90 & 3 & 5.882 \\
\hline & MAIRIPORA & 3.614 & 2.986 & 2.376 & 1.782 & 1.088 & 764 & 442 & 269 & 27 & 13.348 \\
\hline & MAUA & 26.890 & 22.751 & 21.360 & 13.548 & 8.088 & 4.807 & 2.504 & 1.225 & 27 & 101.200 \\
\hline & MOGI DAS CRUZES & 24.094 & 21.910 & 18.539 & 12.526 & 9.078 & 6.138 & 3.577 & 2.211 & 50 & 98.123 \\
\hline & OSASCO & 57.933 & 50.705 & 50.867 & 31.949 & 20.395 & 12.900 & 6.692 & 3.500 & 199 & 235.140 \\
\hline & PIRAPORA DO BOM JESUS & 641 & 511 & 384 & 264 & 179 & 141 & 105 & 69 & 3 & 2.297 \\
\hline & POA & 6.768 & 5.961 & 5.030 & 3.332 & 2.360 & 1.492 & 887 & 490 & 57 & 26.377 \\
\hline & RIBEIRAO PIRES & 7.267 & 5.840 & 5.516 & 3.854 & 2.440 & 1.637 & 892 & 531 & 32 & 28.009 \\
\hline & RIO GRANDE DA SERRA & 2.976 & 2.271 & 1.825 & 1.196 & 704 & 429 & 245 & 123 & 2 & 9.771 \\
\hline & SALESOPOLIS & 1.362 & 1.261 & 791 & 557 & 462 & 336 & 219 & 149 & 3 & 5.140 \\
\hline & SANTA ISABEL & 3.797 & 3.373 & 2.670 & 1.690 & 1.113 & 819 & 494 & 339 & 2 & 14.297 \\
\hline & SANTANA DO PARNAIBA & 1.437 & 1.067 & 847 & 598 & 380 & 282 & 141 & 105 & 4 & 4.861 \\
\hline & SANTO ANDRE & 56.396 & 54.945 & 58.020 & 40.131 & 28.877 & 20.391 & 11.028 & 6.461 & 154 & 276.403 \\
\hline & SAO BERNARDO DO CAMPO & 49.596 & 41.714 & 46.226 & 31.601 & 18.575 & 11.414 & 6.161 & 3.338 & 88 & 208.713 \\
\hline & SAO CAETANO DO SUL & 13.377 & 14.422 & 17.415 & 11.950 & 9.469 & 7.923 & 4.448 & 2.833 & 35 & 81.872 \\
\hline & SUZANO & 13.328 & 11.197 & 9.432 & 6.432 & 4.103 & 2.773 & 1.542 & 841 & 7 & 49.655 \\
\hline & TABOAO DA SERRA & 13.225 & 10.609 & 10.019 & 6.830 & 3.987 & 2.256 & 1.097 & 539 & 34 & 48.596 \\
\hline $01 b$ & & 510.801 & 428.880 & 418.859 & 277.025 & 175.954 & 114.503 & 61.796 & 33.888 & 1.420 & 2.023 .126 \\
\hline \multirow[t]{7}{*}{02} & CANANEIA & 1.068 & 746 & 583 & 400 & 312 & 254 & 141 & 127 & 11 & 3.642 \\
\hline & CARAGUATATUBA & 4.711 & 3.641 & 2.812 & 1.935 & 1.204 & 945 & 619 & 304 & 5 & 16.176 \\
\hline & CUBATAO & 9.379 & 8.255 & 7.578 & 4.739 & 2.828 & 1.602 & 818 & 456 & 6 & 35.661 \\
\hline & ELDORADO & 1.708 & 1.278 & 709 & 562 & 452 & 307 & 226 & 158 & 5 & 5.405 \\
\hline & GUARUJA & 19.574 & 16.716 & 14.267 & 9.219 & 6.524 & 4.108 & 2.135 & 1.088 & 32 & 73.663 \\
\hline & IGUAPE & 3.245 & 2.504 & 1.636 & 1.271 & 1.022 & 678 & 497 & 330 & 6 & 11.189 \\
\hline & ILHABELA & 1.062 & 859 & 599 & 430 & 311 & 197 & 149 & 109 & 3 & 3.719 \\
\hline
\end{tabular}


tABela 2 - Populacao do SeXo feminino, SEgundo municipio, Regiao administrativa e grupo etario. estado de sao paulo, 1980.

\begin{tabular}{|c|c|c|c|c|c|c|c|c|c|c|c|}
\hline REGIAO & MUNICIPIO & $\begin{array}{l}\text { GRUPO } \\
0 \text { a } 09\end{array}$ & $\begin{array}{l}\text { GRUPO } \\
10 \text { a } 19\end{array}$ & $\begin{array}{c}\text { GRUPO } \\
20 \text { a } 29\end{array}$ & $\begin{array}{l}\text { GRUPO } \\
30 \text { a } 39\end{array}$ & $\begin{array}{l}\text { GRUPO } \\
40 \text { a } 49\end{array}$ & $\begin{array}{l}\text { GRUPO } \\
50 \text { a } 59\end{array}$ & $\begin{array}{c}\text { GRUPO } \\
60 \text { a } 69\end{array}$ & $\begin{array}{l}\text { GRUPO } \\
70 \mathrm{e}+\end{array}$ & I gnorada & TOTAL \\
\hline \multirow[t]{16}{*}{02} & I TANHAEM & 3.700 & 2.845 & 2.305 & 1.656 & 1.066 & 897 & 580 & 329 & 2 & 13.380 \\
\hline & ITARIRI & 1.424 & 1.025 & 634 & 477 & 369 & 235 & 146 & 106 & 1 & 4.417 \\
\hline & JACUPIRANGA & 4.339 & 3.270 & 2.169 & 1.478 & 1.064 & 714 & 438 & 249 & 10 & 13.731 \\
\hline & JUQUIA & 2.292 & 1.739 & 1.079 & 773 & 587 & 402 & 229 & 121 & 6 & 7.228 \\
\hline & MIRACATU & 2.624 & 2.064 & 1.279 & 918 & 615 & 395 & 226 & 113 & 1 & 8.235 \\
\hline & MONGAGUA & 1.364 & 1.064 & 739 & 569 & 393 & 368 & 235 & 99 & 6 & .4 .837 \\
\hline & PARIQUERA-ACU & 1.626 & 1.327 & 826 & 624 & 452 & 337 & 200 & 146 & 4 & 5.542 \\
\hline & PEDRO DE TOLEDO & 803 & 677 & 407 & 304 & 250 & 199 & 119 & 67 & 4 & 2.830 \\
\hline & PERUIBE & 2.512 & 2.009 & 1.373 & 1.036 & 739 & 616 & 396 & 232 & 6 & 8.919 \\
\hline & PRAIA GRANDE & 8.263 & 6.624 & 5.620 & 4.277 & 2.848 & 2.350 & 1.653 & 709 & 52 & 32.396 \\
\hline & REGISTRO & 5.707 & 4.560 & 3.034 & 2.235 & 1.531 & 1.070 & 625 & 379 & 6 & 19.147 \\
\hline & SANTOS & 36.572 & 37.329 & 41.038 & 30.893 & 26.070 & 20.603 & 13.104 & 9.616 & 161 & 215.386 \\
\hline & SAO SEBASTIAO & 2.509 & 1.999 & 1.714 & 1.167 & 716 & 544 & 342 & 256 & 1 & 9.248 \\
\hline & SAO VICENTE & 22.643 & 19.877 & 18.771 & 13.171 & 9.179 & 6.774 & 4.051 & 2.499 & 79 & 97.044 \\
\hline & SETE BARRAS & 1.797 & 1.186 & 827 & 557 & 399 & 254 & 167 & 91 & 1 & 5.279 \\
\hline & UBATUBA & 3.682 & 2.937 & 2.333 & 1.543 & 995 & 677 & 474 & 301 & 12 & 12.954 \\
\hline 02 & & 142.604 & 124.531 & 112.332 & 80.234 & 59.926 & 44.526 & 27.570 & 17.885 & 420 & 610.028 \\
\hline \multirow[t]{30}{*}{03} & APARECIDA & 3.168 & 3.481 & 2.778 & 1.756 & 1.311 & 1.035 & 590 & 433 & 7 & 14.559 \\
\hline & AREIAS & 473 & 465 & 262 & 176 & 130 & 108 & 64 & 35 & 0 & 1.713 \\
\hline & BANANAL & 1.341 & 1.323 & 823 & 549 & 467 & 395 & 258 & 183 & 0 & 5.339 \\
\hline & CACAPAVA & 6.592 & 5.690 & 4.627 & 3.259 & 2.100 & 1.482 & 1.010 & 729 & 9 & 25.498 \\
\hline & CACHOEIRA PAULISTA & 2.392 & 2.404 & 1.728 & 1.237 & 950 & 738 & 461 & 306 & 0 & 10.216 \\
\hline & CAMPOS DO JORDAO & 3.351 & 3.135 & 2.476 & 1.549 & 1.092 & 776 & 418 & 208 & 2 & 13.007 \\
\hline & CRUZE IRO & 6.954 & 6.655 & 5.438 & 3.572 & 2.608 & 1.860 & 1.335 & 811 & 1 & 29.234 \\
\hline & CUNHA & 2.864 & 2.609 & 1.530 & 1.120 & 825 & 552 & 347 & 207 & 1 & 10.055 \\
\hline & GUARA I I NGUE TA & 9.772 & 9.860 & 7.883 & 5.409 & 3.909 & 2.933 & 1.849 & 1.158 & 16 & 42.789 \\
\hline & IGARATA & 607 & 535 & 331 & 237 & 169 & 98 & 71 & 53 & 0 & 2.101 \\
\hline & JACARE I & 14.284 & 12.696 & 11.420 & 7.656 & 4.887 & 3.283 & 2.024 & 1.240 & 24 & 57.514 \\
\hline & JAMBEIRO & 397 & 335 & 215 & 152 & 99 & 77 & 54 & 37 & 0 & 1.366 \\
\hline & LAGOINHA & 597 & 546 & 247 & 227 & 191 & 167 & 98 & 53 & 0 & 2.126 \\
\hline & LAVRINHAS & 530 & 451 & 272 & 175 & 128 & 112 & 55 & 37 & 0 & 1.760 \\
\hline & LORENA & 6.636 & 6.503 & 5.262 & 3.759 & 2.617 & 1.983 & 1.369 & 907 & 13 & 29.049 \\
\hline & MONTEIRO LOBATO & 369 & 300 & 158 & 137 & 108 & 101 & 53 & 38 & 1 & 1.265 \\
\hline & NATIVIDADE DA SERRA & 888 & 828 & 414 & 337 & 300 & 224 & 173 & 104 & 0 & 3.268 \\
\hline & PARAIBUNA & 2.016 & 1.702 & 996 & 765 & 535 & 408 & 261 & 195 & 3 & 6.881 \\
\hline & PINDAMONHANGABA & 8.914 & 7.781 & 6.498 & 4.050 & 2.722 & 2.009 & 1.238 & 906 & 36 & 34.154 \\
\hline & PIQUETE & 1.600 & 1.813 & 1.309 & 901 & 616 & 559 & 327 & 176 & 0 & 7.301 \\
\hline & QUELUZ & 855 & 817 & 568 & 398 & 311 & 245 & 159 & 86 & 0 & 3.439 \\
\hline & REDENCAO DA SERRA & 485 & 484 & 252 & 168 & 188 & 140 & 99 & 51 & 0 & 1.867 \\
\hline & ROSEIRA & 657 & 549 & 400 & 244 & 191 & 145 & 73 & 52 & 0 & 2.311 \\
\hline & SANTA BRANCA & 1.049 & 960 & 710 & 461 & 368 & 272 & 161 & 119 & 0 & 4.100 \\
\hline & SANTO ANTONIO DO PINHAL & 777 & 655 & 353 & 279 & 233 & 145 & 101 & 62 & 2 & 2.607 \\
\hline & SAO BENTO DO SAPUCAI & 1.175 & 1.212 & 709 & 509 & 413 & 314 & 209 & 111 & 3 & 4.655 \\
\hline & SAO JOSE DO BARREIRO & 509 & 539 & 264 & 188 & 189 & 138 & 78 & 53 & 0 & 1.958 \\
\hline & SAO JOSE DOS CAMPOS & 36.133 & 31.104 & 31.239 & 19.198 & 10.938 & 7.470 & 4.167 & 2.316 & 56 & 142.621 \\
\hline & SAO LUIZ DO PARAITINGA & 1.199 & 1.296 & 657 & 515 & 414 & 308 & 220 & 128 & 2 & 4.739 \\
\hline & SILVEIRAS & 518 & 466 & 271 & 221 & 182 & 125 & 86 & 55 & 1 & 1.925 \\
\hline
\end{tabular}


tabela 2 - populacao do sexo feminino, Segundo municipio, Regiao administrativa e grupo etario. estado de sao paulo, 1980.

\begin{tabular}{|c|c|c|c|c|c|c|c|c|c|c|c|}
\hline REGIAO & MUNICIPIO & $\begin{array}{l}\text { GRUPO } \\
0 \text { a } 09\end{array}$ & $\begin{array}{l}\text { GRUPO } \\
10 \text { a } 19\end{array}$ & $\begin{array}{c}\text { GRUPO } \\
20 \text { a } 29\end{array}$ & $\begin{array}{c}\text { GRUPO } \\
30 \text { a } 39\end{array}$ & $\begin{array}{l}\text { GRUPO } \\
40 \text { a } 49\end{array}$ & $\begin{array}{l}\text { GRUPO } \\
50 \text { a } 59\end{array}$ & $\begin{array}{l}\text { GRUPO } \\
60 \text { a } 69\end{array}$ & $\begin{array}{l}\text { GRUPO } \\
70 \text { e + }\end{array}$ & Ignorada & TOTAL \\
\hline $\begin{array}{l}03 \\
03\end{array}$ & $\begin{array}{l}\text { TAUBATE } \\
\text { TREMEMBE }\end{array}$ & $\begin{array}{r}19.995 \\
2.343 \\
139.440\end{array}$ & $\begin{array}{r}19.025 \\
2.095 \\
128.314\end{array}$ & $\begin{array}{r}16.205 \\
1.567 \\
107.862\end{array}$ & $\begin{array}{r}10.545 \\
1.106 \\
70.855\end{array}$ & $\begin{array}{r}7.385 \\
723 \\
47.299\end{array}$ & $\begin{array}{r}5.530 \\
551 \\
34.283\end{array}$ & $\begin{array}{r}3.629 \\
316 \\
21.353\end{array}$ & $\begin{array}{r}2.409 \\
233 \\
13.491\end{array}$ & $\begin{array}{r}15 \\
3 \\
195\end{array}$ & $\begin{array}{r}84.738 \\
8.937 \\
563.092\end{array}$ \\
\hline \multirow{44}{*}{04} & AGUAS DE SANTA BARBARA & 510 & 539 & 357 & 243 & 214 & 162 & 108 & 58 & 0 & 2.191 \\
\hline & ANGATUBA & 2.058 & 1.993 & 1.377 & 948 & 714 & 538 & 356 & 201 & 0 & 8.185 \\
\hline & ANHEMB I & 439 & 367 & 228 & 180 & 156 & 123 & 82 & 51 & 0 & 1.626 \\
\hline & APIAI & 3.994 & 3.363 & 2.037 & 1.404 & 1.015 & 768 & 466 & 234 & 5 & 13.286 \\
\hline & ARACOIABA DA SERRA & 1.094 & 948 & 692 & 464 & 363 & 301 & 188 & 119 & 1 & 4.170 \\
\hline & ARANDU & 593 & 436 & 300 & 227 & 162 & 117 & 82 & 33 & 3 & 1.953 \\
\hline & AREIOPOLIS & 938 & 784 & 548 & 316 & 269 & 163 & 105 & 57 & 0 & 3.180 \\
\hline & AVARE & 5.399 & 4.943 & 4.094 & 2.753 & 2.353 & 1.725 & 1.164 & 753 & 11 & 23.195 \\
\hline & BARAO DE ANTONINA & 549 & 454 & 299 & 208 & 147 & 126 & 58 & 41 & 0 & 1.882 \\
\hline & BARRA DO TURVO & 800 & 561 & 337 & 226 & 202 & 131 & 71 & 34 & 3 & 2.365 \\
\hline & BOFETE & 570 & 467 & 305 & 240 & 199 & 145 & 92 & 51 & 1 & 2.070 \\
\hline & BOITUVA & 1.407 & 1.324 & 1.034 & 786 & 630 & 450 & 296 & 174 & 4 & 6.105 \\
\hline & BOTUCATU & 7.023 & 6.468 & 5.763 & 4.069 & 3.419 & 2.795 & 1.859 & 1.310 & 19 & 32.725 \\
\hline & BURI & 1.559 & 1.375 & 896 & 584 & 479 & 319 & 218 & 116 & 2 & 5.548 \\
\hline & CABREUVA & 1.516 & 1.330 & 953 & 669 & 443 & 329 & 218 & 125 & 33 & 5.616 \\
\hline & CAPAO BONITO & 6.672 & 5.083 & 3.598 & 2.685 & 1.872 & 1.207 & 801 & 368 & 3 & 22.289 \\
\hline & CAPELA DO ALTO & 1.054 & 871 & 578 & 363 & 315 & 202 & 148 & 67 & 1 & 3.599 \\
\hline & CERQUEIRA CESAR & 1.188 & 1.177 & 814 & 653 & 521 & 363 & 290 & 191 & 1 & 5.198 \\
\hline & CERQUILHO & 1.186 & 1.372 & 1.236 & 762 & 651 & 469 & 267 & 148 & 7 & 6.098 \\
\hline & CESARIO LANGE & 909 & 729 & 626 & 453 & 349 & 283 & 180 & 95 & 55 & 3.679 \\
\hline & CONCHAS & 1.079 & 1.266 & 966 & 595 & 535 & 478 & 305 & 189 & 0 & 5.413 \\
\hline & CORONEL MACEDO & 876 & 758 & 487 & 336 & 266 & 156 & 88 & 56 & 3 & 3.026 \\
\hline & GUAPIARA & 2.388 & 1.940 & 1.207 & 823 & 648 & 422 & 233 & 114 & 3 & 7.778 \\
\hline & GUAREI & 821 & 823 & 527 & 347 & 325 & 219 & 171 & 87 & 0 & 3.320 \\
\hline & IBIUNA & 4.364 & 3.685 & 2.487 & 1.759 & 1.316 & 902 & 593 & 265 & 11 & 15.382 \\
\hline & IPERO & 773 & 711 & 526 & 371 & 309 & 257 & 158 & 75 & 0 & 3.180 \\
\hline & IPORANGA & 718 & 517 & 335 & 206 & 209 & 134 & 84 & 64 & 1 & 2.268 \\
\hline & ITABERA & 2.199 & 1.984 & 1.284 & 934 & 649 & 478 & 256 & 145 & 2 & 7.931 \\
\hline & ITAI & 1.956 & 1.654 & 1.220 & 705 & 617 & 399 & 278 & 141 & 1 & 6.971 \\
\hline & ITAPETININGA & 10.038 & 9.227 & 7.548 & 4.979 & 4.001 & 3.057 & 1.960 & 1.216 & 11 & 42.037 \\
\hline & ITAPEVA & 9.017 & 7.890 & 5.345 & 3.657 & 2.753 & 1.891 & 1.145 & 576 & 7 & 32.281 \\
\hline & ITAPORANGA & 2.263 & 1.971 & 1.381 & 854 & 693 & 439 & 265 & 155 & 2 & 8.023 \\
\hline & ITARARE & 4.869 & 4.452 & 3.042 & 2.137 & 1.653 & 1.297 & 862 & 536 & 0 & 18.848 \\
\hline & ITATINGA & 1.194 & 1.029 & 724 & 476 & 375 & 291 & 167 & 120 & 0 & 4.376 \\
\hline & ITU & 8.551 & 7.802 & 6.704 & 4.396 & 3.435 & 2.713 & 1.672 & 1.219 & 20 & 36.512 \\
\hline & LARANJAL PAULISTA & 1.447 & 1.513 & 1.305 & 910 & 803 & 681 & 417 & 285 & 1 & 7.362 \\
\hline & MAIR I NQUE & 3.892 & 3.468 & 2.773 & 1.800 & 1.179 & 886 & 507 & 270 & 97 & 14.872 \\
\hline & PARANAPANEMA & 1.484 & 1.233 & 923 & 593 & 449 & 277 & 193 & 90 & 6 & 5.248 \\
\hline & PARD INHO & 344 & 287 & 242 & 152 & 108 & 79 & 58 & 38 & 0 & 1.308 \\
\hline & PEREIRAS & 316 & 407 & 273 & 201 & 206 & 207 & 145 & 88 & 0 & 1.843 \\
\hline & PIEDADE & 4.486 & 4.202 & 2.743 & 2.029 & 1.540 & 1.122 & 654 & 392 & 5 & 17.173 \\
\hline & PILAR DO SUL & 1.834 & 1.612 & 1.018 & 705 & 587 & 383 & 232 & 132 & 0 & 6.503 \\
\hline & PORANGABA & 639 & 668 & 431 & 348 & 307 & 263 & 210 & 112 & 1 & 2.979 \\
\hline & PORTO FELIZ & 2.950 & 2.949 & 2.280 & 1.565 & 1.331 & 1.057 & 664 & 417 & 12 & 13.225 \\
\hline
\end{tabular}




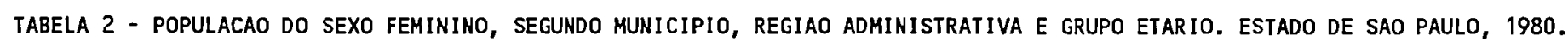

\begin{tabular}{|c|c|c|c|c|c|c|c|c|c|c|c|}
\hline REGIAO & MUNICIPIO & $\begin{array}{l}\text { GRUPO } \\
0 \text { a } 09\end{array}$ & $\begin{array}{c}\text { GRUPO } \\
10 \text { a } 19\end{array}$ & $\begin{array}{c}\text { GRUPO } \\
20 \text { a } 29\end{array}$ & $\begin{array}{c}\text { GRUPO } \\
30 \text { a } 39\end{array}$ & $\begin{array}{l}\text { GRUPO } \\
40 \text { a } 49\end{array}$ & $\begin{array}{c}\text { GRUPO } \\
50 \text { a } 59\end{array}$ & $\begin{array}{l}\text { GRUPO } \\
60 \text { a } 69\end{array}$ & $\begin{array}{l}\text { GRUPO } \\
70 \text { e + }\end{array}$ & Ignorada & TOTAL \\
\hline \multirow[t]{15}{*}{04} & RIBEIRA & 1.140 & 820 & 499 & 369 & 321 & 205 & 134 & 60 & 0 & 3.548 \\
\hline & RIBEIRAO BRANCO & 2.186 & 1.658 & 956 & 712 & 488 & 362 & 177 & 89 & 1 & 6.629 \\
\hline & RIVERSUL & 1.667 & 1.331 & 881 & 564 & 457 & 277 & 175 & 95 & 0 & 5.447 \\
\hline & SALTO & 4.800 & 4.478 & 3.856 & 2.490 & 1.989 & 1.420 & 821 & 550 & 2 & 20.406 \\
\hline & SALTO DE PIRAPORA & 1.893 & 1.587 & 1.323 & 879 & 686 & 434 & 241 & 159 & $\overline{1}$ & 7.203 \\
\hline & SAO MANUEL & 3.105 & 2.997 & 2.219 & 1.460 & 1.360 & 1.019 & 697 & 471 & 9 & 13.337 \\
\hline & SAO MIGUEL ARCANJO & 2.274 & 1.946 & 1.365 & 905 & 750 & 567 & 370 & 161 & 11 & 8.349 \\
\hline & SAO ROQUE & 5.735 & 5.142 & 4.427 & 2.920 & 2.327 & 1.749 & 1.171 & 756 & 16 & 24.243 \\
\hline & SARAPUI & 697 & 543 & 363 & 260 & 230 & 167 & 107 & 65 & 2 & 2.434 \\
\hline & SOROCABA & 29.938 & 28.427 & 26.110 & 17.101 & 13.607 & 10.533 & 6.247 & 3.999 & 139 & 136.101 \\
\hline & TAPIRAI & 759 & 568 & 342 & 276 & 190 & 125 & 99 & 45 & 0 & 2.404 \\
\hline & TAQUARI TUBA & 1.978 & 1.831 & 1.367 & 928 & 744 & 506 & 328 & 139 & 2 & 7.823 \\
\hline & TATUI & 6.234 & 6.042 & 4.678 & 3.433 & 2.693 & 2.123 & 1.438 & 878 & 17 & 27.536 \\
\hline & TIETE & 1.860 & 2.116 & 1.712 & 1.267 & 1.074 & 889 & 633 & 474 & 5 & 10.030 \\
\hline & VOTORANTIM & 6.775 & 5.939 & 4.985 & 3.223 & 2.168 & 1.551 & 938 & 442 & 20 & 26.041 \\
\hline 04 & & 178.997 & 162.057 & 126.926 & 85.898 & 67.851 & 50.731 & 31.942 & 19.391 & 557 & 724.350 \\
\hline \multirow[t]{31}{*}{05} & AGUAI & 1.829 & 1.844 & 1.486 & 969 & 845 & 642 & 376 & 229 & 15 & 8.235 \\
\hline & AGUAS DA PRATA & 620 & 619 & 456 & 331 & 273 & 236 & 163 & 127 & 1 & 2.826 \\
\hline & AGUAS DE LINDOIA & 933 & 966 & 799 & 590 & 485 & 385 & 257 & 163 & 4 & 4.582 \\
\hline & AGUAS DE SAO PEDRO & 87 & 99 & 90 & 77 & 59 & 70 & 52 & 29 & 0 & 563 \\
\hline & AMER I CANA & 12.293 & 13.014 & 12.791 & 7.838 & 6.411 & 4.538 & 2.417 & 1.439 & 15 & 60.756 \\
\hline & AMPARO & 4.332 & 4.125 & 3.805 & 2.516 & 2.023 & 1.649 & 1.153 & 885 & 2 & 20.490 \\
\hline & ANALANDIA & 264 & 269 & 177 & 113 & 112 & 61 & 68 & 39 & 3 & 1.106 \\
\hline & ARARAS & 6.872 & 6.923 & 6.217 & 4.108 & 3.198 & 2.313 & 1.434 & 937 & 16 & 32.018 \\
\hline & ARTHUR NOGUEIRA & 1.812 & 1.761 & 1.485 & 915 & 706 & 495 & 271 & 186 & 2 & 7.633 \\
\hline & ATIBAIA & 6.579 & 6.250 & 5.127 & 3.563 & 2.677 & 2.078 & 1.439 & 892 & 25 & 28.630 \\
\hline & BOM JESUS DOS PERDOES & 891 & 807 & 562 & 399 & 300 & 197 & 160 & 79 & 0 & 3.395 \\
\hline & BRAGANCA PAULISTA & 9.369 & 8.515 & 7.371 & 5.124 & 3.999 & 3.167 & 2.109 & 1.511 & 57 & 41.222 \\
\hline & BROTAS & 1.195 & 1.201 & 871 & 653 & 565 & 421 & 336 & 243 & 4 & 5.489 \\
\hline & CACONDE & 1.966 & 1.869 & 1.205 & 900 & 728 & 558 & 412 & 250 & 4 & 7.892 \\
\hline & CAMPINAS & 71.619 & 68.131 & 69.614 & 45.406 & 32.516 & 23.813 & 14.427 & 9.125 & 141 & 334.792 \\
\hline & CAMPO LIMPO PAULISTA & 2.815 & 2.273 & 1.949 & 1.433 & 860 & 643 & 366 & 195 & 1 & 10.535 \\
\hline & CAPIVARI & 2.821 & 2.605 & 2.211 & 1.428 & 1.156 & 923 & 617 & 409 & 4 & 12.174 \\
\hline & CASA BRANCA & 2.234 & 2.284 & 1.669 & 1.122 & 938 & 802 & 590 & 405 & 0 & 10.044 \\
\hline & CHARQUEADA & 1.029 & 996 & 755 & 508 & 411 & 291 & 205 & 111 & 0 & 4.306 \\
\hline & CONCHAL & 1.605 & 1.515 & 1.082 & 789 & 563 & 365 & 232 & 125 & 2 & 6.278 \\
\hline & CORDEIROPOLIS & 936 & 919 & 908 & 600 & 489 & 392 & 231 & 156 & 1 & 4.632 \\
\hline & CORUMBATAI & 331 & 268 & 226 & 157 & 109 & 102 & 84 & 61 & 0 & 1.338 \\
\hline & COSMOPOLIS & 2.644 & 2.511 & 2.201 & 1.443 & 988 & 729 & 474 & 277 & 4 & 11.271 \\
\hline & DIVINOLANDIA & 1.114 & 1.136 & 853 & 604 & 468 & 376 & 217 & 125 & 1 & 4.894 \\
\hline & ELIAS FAUSTO & 1.001 & 919 & 698 & 406 & 366 & 281 & 156 & 93 & 0 & 3.920 \\
\hline & ESPIRITO SANTO DO PINHAL & 3.519 & 3.655 & 2.916 & 1.857 & 1.729 & 1.258 & 890 & 610 & 4 & 16.438 \\
\hline & INDAIATUBA & 6.334 & 5.991 & 5.292 & 3.553 & 2.596 & 1.792 & 1.132 & 660 & 24 & 27.374 \\
\hline & IPEUNA & 174 & 210 & 143 & 117 & 95 & 88 & 42 & 31 & 0 & 900 \\
\hline & IRACEMAPOL IS & 806 & 925 & 764 & 505 & 396 & 269 & 151 & 95 & 7 & 3.918 \\
\hline & ITAPIRA & 4.991 & 4.896 & 4.189 & 2.853 & 2.295 & 1.816 & 1.271 & 874 & 13 & 23.198 \\
\hline & ITATIBA & 4.478 & 4.413 & 3.828 & 2.576 & 2.038 & 1.566 & 932 & 599 & 1 & 20.431 \\
\hline
\end{tabular}




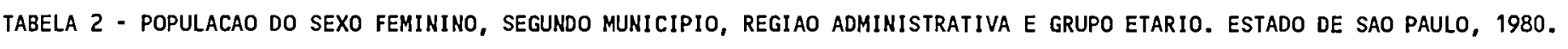

\begin{tabular}{|c|c|c|c|c|c|c|c|c|c|c|c|}
\hline REGIAO & MUNICIPIO & $\begin{array}{l}\text { GRUPO } \\
0 \text { a } 09\end{array}$ & $\begin{array}{c}\text { GRUPO } \\
10 \text { a } 19\end{array}$ & $\begin{array}{c}\text { GRUPO } \\
20 \text { a } 29\end{array}$ & $\begin{array}{c}\text { GRUPO } \\
30 \text { a } 39\end{array}$ & $\begin{array}{c}\text { GRUPO } \\
40 \text { a } 49\end{array}$ & $\begin{array}{c}\text { GRUPO } \\
50 \text { a } 59\end{array}$ & $\begin{array}{l}\text { GRUPO } \\
60 \text { a } 69\end{array}$ & $\begin{array}{l}\text { GRUPO } \\
70 \text { e + }\end{array}$ & I gnorada & TOTAL \\
\hline \multirow[t]{48}{*}{05} & IT I RAP INA & 718 & 705 & 547 & 400 & 373 & 289 & 193 & 124 & 1 & 3.350 \\
\hline & I TOBI & 691 & 609 & 459 & 306 & 228 & 187 & 144 & 89 & 0 & 2.713 \\
\hline & I TUPEVA & 1.318 & 1.125 & 857 & 577 & 414 & 280 & 201 & 104 & 0 & 4.876 \\
\hline & JAGUAR IUNA & 1.731 & 1.651 & 1.344 & 891 & 672 & 487 & 324 & 172 & 11 & 7.283 \\
\hline & JARI INU & 801 & 627 & 519 & 337 & 270 & 190 & 135 & 64 & 2 & 2.945 \\
\hline & JOANOPOL IS & 869 & 822 & 572 & 427 & 345 & 276 & 200 & 118 & 0 & 3.629 \\
\hline & JUND IAI & 27.731 & 26.358 & 25.236 & 16.990 & 12.845 & 9.501 & 5.906 & 3.753 & 31 & 128.351 \\
\hline & LEME & 5.339 & 5.086 & 4.216 & 2.817 & 2.001 & 1.616 & 910 & 540 & 34 & 22.559 \\
\hline & LIMEIRA & 17.031 & 16.278 & 14.517 & 9.280 & 6.870 & 5.178 & 3.016 & 1.874 & 45 & 74.089 \\
\hline & LINDOIA & 303 & 318 & 274 & 184 & 162 & 131 & 85 & 74 & 0 & 1.531 \\
\hline & LOUVEI RA & 1.175 & 1.088 & 988 & 599 & 473 & 340 & 198 & 128 & 0 & 4.989 \\
\hline & MOCOCA & 5.548 & 5.154 & 4.166 & 2.796 & 2.064 & 1.526 & 1.008 & 696 & 4 & 22.962 \\
\hline & MOGI GUACU & 8.387 & 8.472 & 7.102 & 4.543 & 3.175 & 2.116 & 1.253 & 701 & 1 & 35.750 \\
\hline & MOGI MIRIM & 5.259 & 5.418 & 4.787 & 3.102 & 2.414 & 1.909 & 1.188 & 830 & 1 & 24.908 \\
\hline & MOMBUCA & 326 & 289 & 204 & 152 & 121 & 77 & 52 & 31 & 5 & 1.257 \\
\hline & MONTE ALEGRE DO SUL & 493 & 490 & 383 & 271 & 267 & 190 & 152 & 94 & 1 & 2.341 \\
\hline & MONTE MOR & 1.867 & 1.512 & 1.222 & 843 & 554 & 432 & 273 & 133 & 10 & 6.846 \\
\hline & MORUNGABA & 803 & 745 & 539 & 384 & 272 & 204 & 127 & 80 & 2 & 3.156 \\
\hline & NAZARE PAULISTA & 1.084 & 871 & 543 & 461 & 392 & 332 & 227 & 141 & 0 & 4.051 \\
\hline & NOVA ODESSA & 2.685 & 2.385 & 2.142 & 1.347 & 975 & 639 & 400 & 247 & 0 & 10.820 \\
\hline & PAULIINIA & 2.839 & 2.211 & 2.036 & 1.318 & 817 & 468 & 308 & 160 & 8 & 10.165 \\
\hline & PEDRA BELA & 588 & 455 & 336 & 270 & 236 & 162 & 119 & 72 & 0 & 2.238 \\
\hline & PEDREIRA & 2.246 & 2.364 & 1.921 & 1.284 & 1.105 & 821 & 504 & 331 & 1 & 10.577 \\
\hline & PINHALZINHO & 714 & 625 & 510 & 351 & 287 & 291 & 166 & 81 & 1 & 3.026 \\
\hline & PIRACAIA & 1.653 & 1.504 & 1.139 & 787 & 608 & 473 & 320 & 218 & 4 & 6.706 \\
\hline & PIRACICABA & 23.442 & 22.088 & 20.630 & 13.983 & 10.476 & 7.948 & 4.933 & 3.224 & 84 & 106.808 \\
\hline & PIRASSUNUNGA & 4.744 & 4.657 & 3.868 & 3.017 & 2.140 & 1.840 & 1.152 & 806 & 9 & 22.233 \\
\hline & PORTO FERREIRA & 2.980 & 3.085 & 2.502 & 1.728 & 1.492 & 1.021 & 583 & 402 & 23 & 13.816 \\
\hline & RAFARD & 638 & 653 & 449 & 335 & 315 & 256 & 133 & 96 & 0 & 2.875 \\
\hline & RIO CLARO & 11.710 & 11.106 & 9.644 & 7.025 & 5.655 & 4.835 & 3.239 & 2.184 & 9 & 55.407 \\
\hline & RIO DAS PEDRAS & 1.659 & 1.544 & 1.170 & 789 & 579 & 406 & 256 & 144 & 3 & 6.550 \\
\hline & SANTA BARBARA D'OESTE & 9.101 & 8.546 & 7.757 & 4.451 & 3.504 & 2.209 & 1.288 & 680 & 21 & 37.557 \\
\hline & SANTA CRUZ DA CONCEICAO & 268 & 291 & 247 & 149 & 119 & 111 & 57 & 40 & 0 & 1.282 \\
\hline & SANTA CRUZ DAS PALMEIRAS & 1.674 & 1.775 & 1.498 & 1.002 & 711 & 556 & 295 & 208 & 2 & 7.721 \\
\hline & SANTA GERTRUDES & 934 & 891 & 690 & 476 & 353 & 275 & 173 & 89 & 1 & 3.882 \\
\hline & SANTA MARIA DA SERRA & 348 & 318 & 202 & 161 & 114 & 99 & 51 & 37 & 0 & 1.330 \\
\hline & SANTO ANTONIO DA POSSE & 1.228 & 1.229 & 906 & 610 & 485 & 363 & 236 & 142 & 4 & 5.203 \\
\hline & SANTO ANTONIO DO JARDIM & 643 & 578 & 418 & 276 & 260 & 199 & 136 & 68 & 2 & 2.580 \\
\hline & SAO JOAO DA BOA VISTA & 5.911 & 5.967 & 4.978 & 3.305 & 2.936 & 2.322 & 1.501 & 1.041 & 13 & 27.974 \\
\hline & SAO JOSE DO RIO PARDO & 3.803 & 3.930 & 3.300 & 2.041 & 1.730 & 1.404 & 929 & 620 & 2 & 17.759 \\
\hline & SAO PEDRO & 1.438 & 1.292 & 1.062 & 800 & 585 & 599 & 419 & 258 & 3 & 6.456 \\
\hline & SAO SEBASTIAO DA GRAMA & 1.329 & 1.307 & 976 & 611 & 470 & 368 & 253 & 138 & 8 & 5.460 \\
\hline & SERRA NEGRA & 1.816 & 1.749 & 1.412 & 1.039 & 846 & 791 & 540 & 367 & 1 & 8.561 \\
\hline & SOCORRO & 2.489 & 2.293 & 2.005 & 1.442 & 1.190 & 1.014 & 715 & 479 & 11 & 11.638 \\
\hline & SUMARE & 13.944 & 10.995 & 10.216 & 6.049 & 3.729 & 2.407 & 1.372 & 638 & 42 & 49.392 \\
\hline & TAMBAU & 1.652 & 1.659 & 1.302 & 909 & 720 & 547 & 364 & 240 & 0 & 7.393 \\
\hline & TAPIRATIBA & 1.202 & 1.244 & 832 & 518 & 423 & 317 & 208 & 111 & 4 & 4.859 \\
\hline & TORRINHA & 653 & 648 & 524 & 430 & 307 & 264 & 206 & 136 & 1 & 3.169 \\
\hline
\end{tabular}




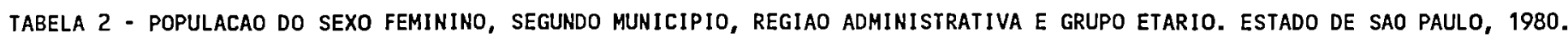

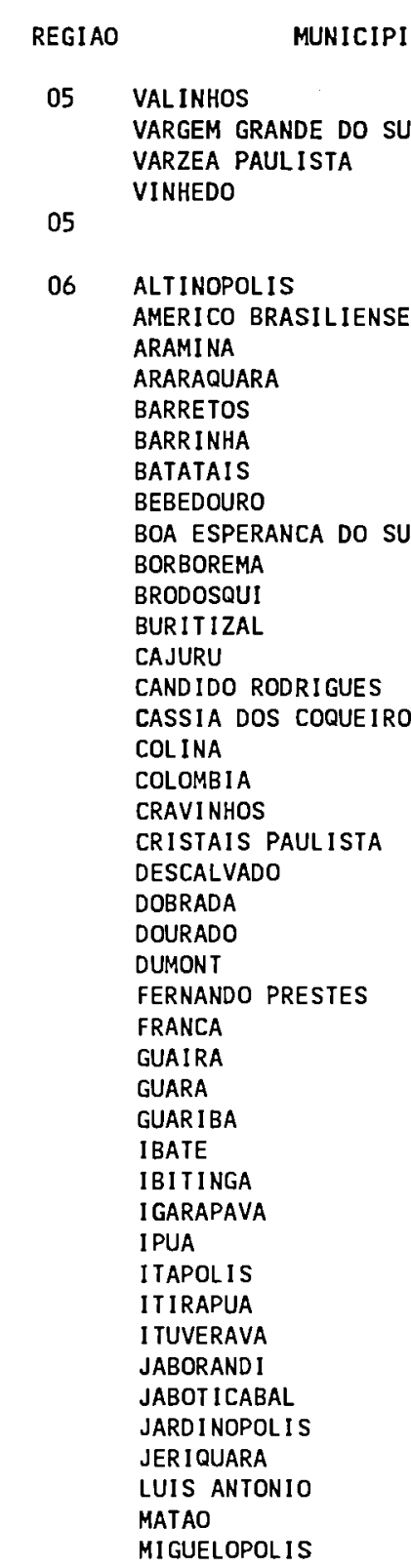

\begin{tabular}{rrr}
\multicolumn{1}{c}{ GRUPO } & \multicolumn{1}{c}{ GRUPO } & \multicolumn{1}{c}{ GRUPO } \\
0 a 09 & 10 a 19 & $20 \mathrm{a} 29$ \\
& & \\
5.194 & 5.190 & 4.737 \\
2.131 & 2.335 & 1.783 \\
4.696 & 3.702 & 3.494 \\
2.400 & 2.420 & 1.978 \\
357.719 & 340.563 & 306.879 \\
& & \\
1.422 & 1.426 & 1.171 \\
1.521 & 1.359 & 1.139 \\
333 & 421 & 303 \\
13.008 & 13.155 & 12.116 \\
7.623 & 8.130 & 6.492 \\
1.628 & 1.395 & 1.085 \\
3.902 & 3.800 & 3.525 \\
5.180 & 4.903 & 4.094 \\
1.053 & 960 & 655 \\
1.351 & 1.307 & 945 \\
1.225 & 1.211 & 1.000 \\
429 & 442 & 297 \\
1.913 & 1.761 & 1.301 \\
163 & 191 & 150 \\
298 & 297 & 171 \\
1.331 & 1.347 & 997 \\
453 & 362 & 269 \\
1.956 & 1.808 & 1.483 \\
627 & 538 & 394 \\
2.273 & 2.144 & 1.803 \\
565 & 469 & 395 \\
702 & 680 & 568 \\
335 & 338 & 342 \\
392 & 439 & 324 \\
15.883 & 16.875 & 14.945 \\
3.021 & 3.026 & 2.255 \\
1.614 & 1.487 & 1.147 \\
2.407 & 2.065 & 1.665 \\
1.393 & 1.350 & 948 \\
3.216 & 3.316 & 2.536 \\
2.029 & 2.310 & 1.779 \\
1.118 & 1.071 & 778 \\
2.665 & 2.695 & 2.196 \\
640 & 556 & 432 \\
3.138 & 3.041 & 2.558 \\
648 & 645 & 452 \\
4.965 & 4.859 & 4.340 \\
2.149 & 2.106 & 1.778 \\
339 & 290 & 218 \\
336 & 362 & 191 \\
4.430 & 4.129 & 3.660 \\
1.672 & 1.536 & 1.183
\end{tabular}

GRUPO
30 a 39

3.120
1.184
2.038
1.316
202.974

727
682
210
8.234
4.745
624
2.303
2.774
448
697
713
248
906
128
124
628
197
953
260
1.166
223
335
187
303
9.788
1.670
815
1.031
620
1.781
1.252
534
1.594
231
1.862
300
3.032
1.243
143
171
2.161
890

GRUPO
40 a 49

\subsection{6}

2.346
1.007
1.207
988
153.021

GRUPO
50 a 59

1.649
830
711
724
114.496

$\begin{array}{r}602 \\ 417 \\ 171 \\ \hline\end{array}$

6.731

3.941
508

1.855
2.174

358
552

552
546

183

745
121
122

121
122
562
134

134
774
220
936

114.496

412
331
104

104
5.290

2.850

317
1.359

1.791
234
360

360
379

117
577

577
92
66

GRUPO

70 e

I gnorada

TOTAL

23.869

10.045

16.473

1.593 .240

280
45.350

6.164

5.756

1.665
64.330

64.330
36.962

64.962
5.857

5.857
18.270

18.270

22.906

3.979

5.615

5.491

1.836

7.846
940

1.148

5.727

1.582

8.208

2.272

9.922
2.086

3.224

\begin{tabular}{l}
1.559 \\
\hline
\end{tabular}

2.125

75.010

12.658

6.583

6.583
8.874

5.484

14.630
10.137

10.137
4.424

4.424
12.627

12.627
2.379

2.379
13.939

2.650

23.472
9.556

9.556

1.229

1.345

18.431
6.731 


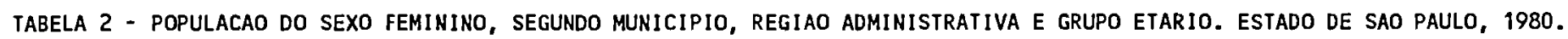

\begin{tabular}{|c|c|c|c|c|c|c|c|c|c|c|c|}
\hline REGIAO & MUNICIPIO & $\begin{array}{l}\text { GRUPO } \\
0 \text { a } 09\end{array}$ & $\begin{array}{l}\text { GRUPO } \\
10 \text { a } 19\end{array}$ & $\begin{array}{c}\text { GRUPO } \\
20 \text { a } 29\end{array}$ & $\begin{array}{c}\text { GRUPO } \\
30 \text { a } 39\end{array}$ & $\begin{array}{l}\text { GRUPO } \\
40 \text { a } 49\end{array}$ & $\begin{array}{c}\text { GRUPO } \\
50 \text { a } 59\end{array}$ & $\begin{array}{l}\text { GRUPO } \\
60 \text { a } 69\end{array}$ & $\begin{array}{l}\text { GRUPO } \\
70 \text { e + }\end{array}$ & Ignorada & TOTAL \\
\hline \multirow[t]{31}{*}{07} & BORACEIA & 435 & 402 & 273 & 227 & 154 & 97 & 80 & 41 & 1 & 1.710 \\
\hline & CABRALIA PAULISTA & 395 & 398 & 257 & 174 & 166 & 107 & 60 & 47 & $i$ & 1.605 \\
\hline & $\begin{array}{l}\text { CAFELANDIA } \\
\text { SIA }\end{array}$ & 2.142 & 2.020 & 1.340 & 938 & 835 & 590 & 414 & 294 & 12 & 8.585 \\
\hline & DOIS CORREGOS & 1.576 & 1.524 & 1.288 & 878 & 809 & 662 & 507 & 317 & 4 & 7.565 \\
\hline & DUARTINA & 1.466 & 1.416 & 922 & 643 & 624 & 508 & 270 & 213 & 3 & 6.065 \\
\hline & GETULINA & 1.349 & 1.295 & 878 & 600 & 539 & 339 & 270 & 152 & 0 & .5 .422 \\
\hline & GUAICARA & 666 & 614 & 403 & 299 & 250 & 171 & 102 & 71 & 1 & 2.577 \\
\hline & GUAIMBE & 617 & 609 & 375 & 281 & 259 & 130 & 104 & 69 & 0 & 2.444 \\
\hline & GUARANTA & 744 & 664 & 453 & 299 & 247 & 164 & 115 & 71 & 3 & 2.760 \\
\hline & IACANGA & 751 & 678 & 543 & 366 & 304 & 257 & 195 & 114 & 3 & 3.211 \\
\hline & IGARACU DO TIETE & 1.659 & 1.417 & 1.141 & 687 & 551 & 375 & 233 & 151 & 5 & 6.219 \\
\hline & $\begin{array}{l}\text { ITAJU } \\
\text { ITSTL }\end{array}$ & 232 & 258 & 186 & 157 & 118 & 105 & 62 & 37 & 0 & 1.155 \\
\hline & ITAPUI & 856 & 827 & 630 & 393 & 369 & 298 & 198 & 173 & 0 & 3.744 \\
\hline & JAU & 7.619 & 7.872 & 6.925 & 4.335 & 3.818 & 2.959 & 1.985 & 1.378 & 27 & 36.918 \\
\hline & JULIO MESOUITA & 639 & 606 & 313 & 235 & 177 & 131 & 83 & 43 & 0 & 2.227 \\
\hline & LENCOIS PAULISTA & 4.342 & 3.888 & 3.083 & 2.006 & 1.556 & 1.108 & 686 & 391 & 6 & 17.066 \\
\hline & LINS & 5.109 & 5.723 & 4.687 & 3.049 & 2.787 & 2.235 & 1.364 & 890 & 16 & 25.860 \\
\hline & LUCIANOPOLIS & 348 & 288 & 235 & 149 & 99 & 81 & 50 & 25 & 0 & 1.275 \\
\hline & MACATUBA & 1.364 & 1.329 & 889 & 597 & 479 & 305 & 184 & 125 & 1 & 5.273 \\
\hline & MINEIROS DO TIETE & 714 & 712 & 572 & 350 & 315 & 284 & 163 & 128 & 1 & 3.239 \\
\hline & PEDERNEIRAS & 3.102 & 2.732 & 2.199 & 1.382 & 1.268 & 908 & 598 & 374 & 7 & 12.570 \\
\hline & PIRAJUI & 2.174 & 2.065 & 1.584 & 1.036 & 968 & 725 & 488 & 305 & 22 & 9.367 \\
\hline & PIRATININGA & 1.181 & 1.093 & 837 & 515 & 475 & 383 & 273 & 169 & 2 & 4.928 \\
\hline & $\begin{array}{l}\text { PONGAI } \\
\text { PONA }\end{array}$ & 408 & 403 & 281 & 187 & 168 & 115 & 72 & 50 & 0 & 1.684 \\
\hline & PRESIDENTE ALVES & 688 & 546 & 357 & 246 & 189 & 156 & 85 & 57 & 1 & 2.325 \\
\hline & $\begin{array}{l}\text { PROMISSAO } \\
\text { PLS }\end{array}$ & 2.239 & 2.326 & 1.729 & 1.127 & 1.033 & 696 & 477 & 320 & 3 & 9.950 \\
\hline & REGINOPOLIS & 514 & 482 & 391 & 227 & 217 & 171 & 96 & 77 & 5 & 2.180 \\
\hline & SABINO & 588 & 531 & 385 & 266 & 225 & 151 & 86 & 62 & 1 & 2.295 \\
\hline & UBIRA JARA & 545 & 472 & 321 & 226 & 204 & 113 & 72 & 45 & 5 & 2.003 \\
\hline & URU & 213 & 197 & 115 & 82 & 68 & 61 & 18 & 16 & 0 & 770 \\
\hline & & 74.230 & 72.736 & 58.958 & 38.840 & 33.384 & 25.162 & 16.251 & 10.482 & 258 & 330.301 \\
\hline \multirow[t]{16}{*}{08} & ADOLFO & 376 & 466 & 304 & 205 & 162 & 108 & 66 & 40 & 1 & 1.728 \\
\hline & ALTAIR & 241 & 263 & 160 & 147 & 99 & 77 & 56 & 45 & 0 & 1.088 \\
\hline & ALVARES FLORENCE & 739 & 809 & 517 & 411 & 292 & 202 & 107 & 74 & 3 & 3.154 \\
\hline & AMERICO DE CAMPOS & 717 & 816 & 577 & 469 & 333 & 241 & 112 & 68 & 0 & 3.333 \\
\hline & APARECIDA D'OESTE & 611 & 638 & 374 & 317 & 233 & 158 & 110 & 59 & 7 & 2.507 \\
\hline & ARIRANHA & 588 & 537 & 497 & 314 & 274 & 219 & 136 & 102 & 1 & 2.668 \\
\hline & BADY BASSIT & 277 & 287 & 242 & 186 & 146 & 91 & 61 & 45 & 1 & 1.336 \\
\hline & BALSAMO & 598 & 692 & 447 & 367 & 297 & 205 & 149 & 69 & 1 & 2.825 \\
\hline & CAJOBI & 870 & 929 & 685 & 495 & 410 & 285 & 169 & 109 & 0 & 3.952 \\
\hline & CARDOSO & 1.374 & 1.469 & 957 & 794 & 543 & 339 & 233 & 161 & 0 & 5.870 \\
\hline & CATANDUVA & 7.130 & 7.566 & 6.550 & 4.635 & 4.016 & 3.085 & 2.118 & 1.392 & 14 & 36.506 \\
\hline & CATIGUA & 656 & 647 & 463 & 287 & 266 & 166 & 119 & 63 & 1 & 2.668 \\
\hline & CEDRAL & 570 & 684 & 505 & 342 & 362 & 243 & 166 & 132 & 0 & 3.004 \\
\hline & COSMORAMA & 936 & 1.005 & 663 & 540 & 434 & 283 & 170 & 118 & 0 & 4.149 \\
\hline & DOLCINOPOL IS & 285 & 284 & 159 & 137 & 94 & 42 & 42 & 31 & 0 & 1.074 \\
\hline & ESTRELA D'OESTE & 1.058 & 1.050 & 723 & 521 & 404 & 240 & 214 & 92 & 16 & 4.318 \\
\hline
\end{tabular}




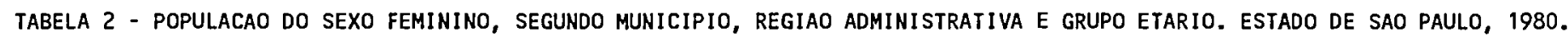

\begin{tabular}{|c|c|c|c|c|c|c|c|c|c|c|c|}
\hline REGIAO & MUNICIPIO & $\begin{array}{l}\text { GRUPO } \\
\begin{array}{lll}0 & \text { a } & 09\end{array}\end{array}$ & $\begin{array}{l}\text { GRUPO } \\
10 \text { a } 19\end{array}$ & $\begin{array}{c}\text { GRUPO } \\
20 \text { a } 29\end{array}$ & $\begin{array}{l}\text { GRUPO } \\
30 \text { a } 39\end{array}$ & $\begin{array}{l}\text { GRUPO } \\
40 \text { a } 49\end{array}$ & $\begin{array}{c}\text { GRUPO } \\
50 \text { a } 59\end{array}$ & $\begin{array}{l}\text { GRUPO } \\
60 \text { a } 69\end{array}$ & $\begin{array}{l}\text { GRUPO } \\
70 \text { e + }\end{array}$ & Ignorada & TOTAL \\
\hline \multirow[t]{48}{*}{08} & FERNANDOPOLIS & 5.239 & 5.496 & 4.187 & 3.023 & 2.432 & 1.562 & 993 & 649 & 14 & 23.595 \\
\hline & GUAP I ACU & 724 & 754 & 579 & 427 & 303 & 215 & 132 & 87 & 0 & 3.221 \\
\hline & GUARACI & 742 & 768 & 503 & 368 & 305 & 210 & 158 & 89 & 0 & 3.143 \\
\hline & GUARANI D'OESTE & 1.099 & 984 & 645 & 525 & 342 & 203 & 124 & 78 & 0 & 4.000 \\
\hline & IBIRA & 880 & 947 & 688 & 493 & 407 & 329 & 198 & 147 & 2 & 4.091 \\
\hline & ICEM & 618 & 632 & 428 & 336 & 241 & 149 & 89 & 64 & 0 & .2 .557 \\
\hline & INDI APORA & 827 & 826 & 543 & 439 & 262 & 168 & 91 & 61 & 0 & 3.217 \\
\hline & IRAPUA & 901 & 868 & 613 & 385 & 323 & 223 & 103 & 68 & 1 & 3.485 \\
\hline & ITAJOBI & 1.455 & 1.543 & 1.314 & 842 & 681 & 555 & 311 & 190 & 0 & 6.891 \\
\hline & JACI & 451 & 433 & 319 & 204 & 179 & 98 & 58 & 47 & 0 & 1.789 \\
\hline & JALES & 4.466 & 4.449 & 3.325 & 2.458 & 1.883 & 1.196 & 772 & 490 & 15 & 19.054 \\
\hline & JOSE BONIFACIO & 2.519 & 2.742 & 1.970 & 1.278 & 1.110 & 740 & 451 & 289 & 0 & 11.099 \\
\hline & MACAUBAL & 661 & 722 & 563 & 409 & 320 & 202 & 141 & 76 & 1 & 3.095 \\
\hline & MACEDONIA & 547 & 524 & 349 & 257 & 165 & 93 & 77 & 45 & 0 & 2.057 \\
\hline & MAR INOPOL IS & 245 & 241 & 167 & 115 & 92 & 51 & 28 & 19 & 3 & 961 \\
\hline & MENDONCA & 448 & 462 & 333 & 232 & 179 & 129 & 73 & 52 & 0 & 1.908 \\
\hline & MER ID I ANO & 410 & 414 & 300 & 222 & 167 & 119 & 88 & 47 & 0 & 1.767 \\
\hline & MIRA ESTRELA & 314 & 260 & 222 & 140 & 97 & 71 & 35 & 20 & 0 & 1.159 \\
\hline & MIRASSOL & 2.881 & 3.119 & 2.529 & 1.817 & 1.484 & 1.152 & 665 & 452 & 16 & 14.115 \\
\hline & MIRASSOLANDIA & 302 & 294 & 209 & 175 & 113 & 81 & 55 & 31 & 0 & 1.260 \\
\hline & MONCOES & 254 & 248 & 201 & 156 & 134 & 67 & 41 & 24 & 3 & 1.128 \\
\hline & MONTE APRAZIVEL & 1.639 & 1.911 & 1.387 & 1.056 & 892 & 565 & 417 & 281 & 11 & 8.159 \\
\hline & NEVES PAULISTA & 792 & 854 & 604 & 471 & 418 & 280 & 207 & 139 & 0 & 3.765 \\
\hline & NHANDEARA & 1.062 & 1.170 & 933 & 664 & 498 & 351 & 196 & 146 & 1 & 5.021 \\
\hline & NIPOA & 339 & 271 & 195 & 152 & 117 & 82 & 56 & 33 & 0 & 1.245 \\
\hline & NOVA ALIANCA & 441 & 474 & 338 & 243 & 225 & 170 & 96 & 87 & 3 & 2.077 \\
\hline & NOVA GRANADA & 1.247 & 1.292 & 919 & 718 & 568 & 413 & 264 & 193 & 1 & 5.615 \\
\hline & NOVA LUZITANIA & 255 & 237 & 146 & 124 & 86 & 51 & 35 & 28 & 0 & 962 \\
\hline & NOVO HORIZONTE & 2.958 & 3.083 & 2.253 & 1.584 & 1.320 & 966 & 579 & 346 & 1 & 13.090 \\
\hline & OLIMPIA & 3.277 & 3.358 & 2.752 & 1.967 & 1.626 & 1.315 & 888 & 619 & 0 & 15.802 \\
\hline & ONDA VERDE & 261 & 245 & 148 & 123 & 91 & 60 & 30 & 21 & 0 & 979 \\
\hline & ORINDIUVA & 246 & 248 & 175 & 136 & 96 & 51 & 36 & 20 & 0 & 1.008 \\
\hline & PALESTINA & 911 & 1.010 & 692 & 560 & 501 & 322 & 202 & 174 & 1 & 4.373 \\
\hline & PALMARES PAULISTA & 483 & 487 & 388 & 231 & 163 & 108 & 65 & 36 & 32 & 1.993 \\
\hline & PALMEIRA D'OESTE & 1.464 & 1.624 & 1.061 & 766 & 572 & 354 & 214 & 133 & 10 & 6.198 \\
\hline & PARAISO & 342 & 414 & 303 & 222 & $18 \overline{3}$ & 131 & 72 & 44 & 4 & 1.715 \\
\hline & PARANAPUA & 765 & 706 & 442 & 330 & 260 & 158 & 102 & 64 & 0 & 2.827 \\
\hline & PAULO DE FARIA & 716 & 814 & 541 & 420 & 307 & 224 & 151 & 91 & 5 & 3.269 \\
\hline & PEDRANOPOLIS & 418 & 431 & 290 & 208 & 138 & 102 & 63 & 37 & 0 & 1.687 \\
\hline & PINDORAMA & 1.055 & 995 & 822 & 629 & 528 & 392 & 310 & 191 & 5 & 4.927 \\
\hline & PLANALTO & 796 & 706 & 482 & 329 & 261 & 163 & 78 & 65 & 2 & 2.882 \\
\hline & POLONI & 453 & 556 & 383 & 296 & 284 & 181 & 136 & 83 & 2 & 2.374 \\
\hline & PONTES GESTAL & 354 & 362 & 236 & 179 & 128 & 91 & 60 & 30 & 6 & 1.446 \\
\hline & POPUL INA & 547 & 505 & 373 & 279 & 232 & 132 & 91 & 54 & 0 & 2.213 \\
\hline & POTIRENDABA & 1.024 & 1.239 & 840 & 648 & 579 & 411 & 255 & 211 & 0 & 5.207 \\
\hline & RIOLANDIA & 769 & 868 & 503 & 445 & 318 & 205 & 138 & 74 & 37 & 3.357 \\
\hline & RUBINEIA & 300 & 336 & 181 & 144 & 103 & 62 & 54 & 23 & 1 & 1.204 \\
\hline & SALES & 622 & 584 & 406 & 262 & 185 & 137 & 72 & 44 & 0 & 2.312 \\
\hline
\end{tabular}




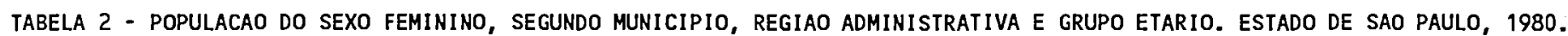

\begin{tabular}{|c|c|c|c|c|c|c|c|c|c|c|c|}
\hline REGIAO & MUNICIPIO & $\begin{array}{l}\text { GRUPO } \\
0 \text { a } 09\end{array}$ & $\begin{array}{c}\text { GRUPO } \\
10 \text { a } 19\end{array}$ & $\begin{array}{c}\text { GRUPO } \\
20 \text { a } 29\end{array}$ & $\begin{array}{c}\text { GRUPO } \\
30 \text { a } 39\end{array}$ & $\begin{array}{c}\text { GRUPO } \\
40 \text { a } 49\end{array}$ & $\begin{array}{c}\text { GRUPO } \\
50 \text { a } 59\end{array}$ & $\begin{array}{c}\text { GRUPO } \\
60 \text { a } 69\end{array}$ & $\begin{array}{l}\text { GRUPO } \\
70 \text { e + }\end{array}$ & Ignorada & TOTAL \\
\hline \multirow[t]{21}{*}{08} & SANTA ADEL IA & 1.007 & 1.078 & 866 & 579 & 565 & 422 & 244 & 172 & 3 & 4.936 \\
\hline & SANTA ALBERTINA & 670 & 740 & 503 & 376 & 302 & 216 & 140 & 83 & 1 & 3.031 \\
\hline & SANTA CLARA D'OESTE & 312 & 361 & 205 & 164 & 125 & 65 & 44 & 29 & 0 & 1.305 \\
\hline & SANTA FE DO SUL & 2.209 & 2.308 & 1.816 & 1.383 & 1.060 & 688 & 462 & 271 & 8 & 10.205 \\
\hline & SANTA RITA D'OESTE & 496 & 519 & 322 & 269 & 186 & 117 & 70 & 47 & 0 & 2.026 \\
\hline & SANTANA DA PONTE PENSA & 349 & 329 & 224 & 165 & 127 & 83 & 51 & 42 & 0 & 1.370 \\
\hline & SAO FRANCISCO & 630 & 572 & 322 & 279 & 220 & 111 & 70 & 39 & 2 & 2.245 \\
\hline & SAO JOAO DAS DUAS PONTES & 349 & 373 & 211 & 168 & 141 & 77 & 46 & 51 & 0 & 1.416 \\
\hline & SAO JOSE DO RIO PRETO & 18.197 & 20.148 & 19.083 & 13.268 & 10.709 & 7.465 & 4.599 & 2.925 & 82 & 96.476 \\
\hline & SEBAST IANOPOL IS DO SUL & 241 & 298 & 186 & 149 & 117 & 70 & 41 & 26 & 2 & 1.130 \\
\hline & SEVERINIA & 1.011 & 882 & 642 & 431 & 325 & 252 & 151 & 80 & 0 & 3.774 \\
\hline & TABAPUA & 1.392 & 1.402 & 972 & 722 & 593 & 412 & 264 & 170 & 3 & 5.930 \\
\hline & TANABI & 2.139 & 2.426 & 1.725 & 1.214 & 1.012 & 714 & 445 & 283 & 4 & 9.962 \\
\hline & TRES FRONTEIRAS & 1.006 & 1.075 & 675 & 487 & 419 & 262 & 156 & 111 & 1 & 4.192 \\
\hline & TURMAL INA & 379 & 384 & 237 & 176 & 139 & 64 & 50 & 22 & 1 & 1.452 \\
\hline & UCHOA & 855 & 859 & 618 & 454 & 408 & 314 & 196 & 136 & $i$ & 3.841 \\
\hline & UNIAO PAULISTA & 146 & 141 & 113 & 72 & 54 & 33 & 26 & 10 & $i$ & 596 \\
\hline & URANIA & 1.610 & 1.739 & 1.033 & 830 & 628 & 394 & 272 & 173 & 13 & 6.692 \\
\hline & URUPES & 1.256 & 1.438 & 959 & 697 & 619 & 444 & 248 & 176 & 6 & 5.843 \\
\hline & VALENTIM GENTIL & 592 & 603 & 426 & 309 & 284 & 168 & 123 & 85 & 1 & 2.591 \\
\hline & VOTUPORANGA & 5.444 & 5.805 & 4.940 & 3.420 & 2.685 & 1.827 & 1.191 & 719 & 90 & 26.121 \\
\hline 08 & & 106.835 & 113.128 & 87.681 & 63.266 & 50.981 & 35.272 & 22.467 & 14.542 & 441 & 494.613 \\
\hline 09 & ALTO ALEGRE & 711 & 707 & 486 & 352 & 274 & 198 & 103 & 65 & 2 & 2.898 \\
\hline & ANDRADINA & 5.342 & 5.585 & 4.266 & 3.011 & 2.362 & 1.657 & 1.082 & 634 & 9 & 23.948 \\
\hline & ARACATUBA & 14.482 & 14.905 & 11.900 & 8.365 & 6.554 & 4.499 & 2.834 & 1.774 & 43 & 65.356 \\
\hline & AUR I FLAMA & 1.425 & 1.480 & 970 & 706 & 582 & 366 & 196 & 129 & 4 & 5.858 \\
\hline & AVANHANDAVA & 805 & 753 & 491 & 340 & 308 & 187 & 131 & 76 & 3 & 3.094 \\
\hline & BARBOSA & 750 & 694 & 431 & 317 & 238 & 160 & 88 & 61 & 1 & 2.740 \\
\hline & BENTO DE ABREU & 265 & 255 & 144 & 120 & 98 & 61 & 39 & 26 & 0 & 1.008 \\
\hline & BILAC & 559 & 627 & 503 & 306 & 283 & 176 & 108 & 77 & 7 & 2.646 \\
\hline & BIRIGUI & 5.385 & 5.799 & 4.914 & 3.104 & 2.424 & 1.839 & 1.055 & 700 & 9 & 25.229 \\
\hline & BRAUNA & 492 & 566 & 340 & 274 & 209 & 168 & 84 & 65 & 4 & 2.202 \\
\hline & BURI TAMA & 1.407 & 1.305 & 995 & 730 & 508 & 295 & 215 & 128 & 4 & 5.587 \\
\hline & CASTILHO & 1.633 & 1.515 & 929 & 715 & 510 & 340 & 258 & 126 & 6 & 6.032 \\
\hline & CLEMENTINA & 421 & 524 & 381 & 219 & 220 & 142 & 79 & 45 & 0 & 2.031 \\
\hline & COROADOS & 725 & 648 & 427 & 327 & 228 & 167 & 102 & 74 & 3 & 2.701 \\
\hline & FLOREAL & 352 & 418 & 307 & 212 & 183 & 120 & 77 & 51 & 0 & 1.720 \\
\hline & GABRIEL MONTEIRO & 290 & 367 & 232 & 182 & 139 & 78 & 62 & 39 & 0 & 1.389 \\
\hline & GASTAO VIDIGAL & 441 & 467 & 313 & 233 & 171 & 108 & 62 & 43 & 0 & 1.838 \\
\hline & GENERAL SALGADO & 1.376 & 1.359 & 940 & 680 & 515 & 310 & 200 & 135 & 3 & 5.518 \\
\hline & GL ICER IO & 600 & 594 & 344 & 271 & 214 & 139 & 80 & 62 & 2 & 2.306 \\
\hline & GUARACAI & 912 & 1.043 & 659 & 485 & 402 & 240 & 192 & 125 & 0 & 4.058 \\
\hline & GUARARAPES & 2.587 & 2.760 & 1.815 & 1.380 & 1.106 & 729 & 498 & 324 & 0 & 11.199 \\
\hline & GUZOLANDIA & 548 & 579 & 319 & 223 & 167 & 105 & 72 & 41 & 1 & 2.055 \\
\hline & ITAPURA & 437 & 386 & 243 & 169 & 97 & 86 & 64 & 27 & 3 & 1.512 \\
\hline & LAVINIA & 668 & 738 & 483 & 348 & 285 & 211 & 145 & 105 & 1 & 2.984 \\
\hline & LUIZIANIA & 461 & 521 & 292 & 204 & 190 & 113 & 50 & 41 & 0 & 1.872 \\
\hline
\end{tabular}




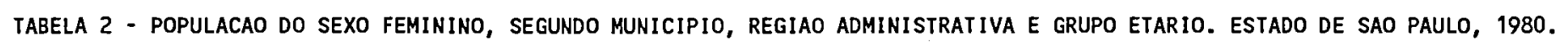

\begin{tabular}{|c|c|c|c|c|c|c|c|c|c|c|c|}
\hline REGIAO & MUNICIPIO & $\begin{array}{l}\text { GRUPO } \\
\begin{array}{lll}0 \text { a } & 09\end{array}\end{array}$ & $\begin{array}{l}\text { GRUPO } \\
10 \text { a } 19\end{array}$ & $\begin{array}{c}\text { GRUPO } \\
20 \text { a } 29\end{array}$ & $\begin{array}{l}\text { GRUPO } \\
30 \text { a } 39\end{array}$ & $\begin{array}{l}\text { GRUPO } \\
40 \text { a } 49\end{array}$ & $\begin{array}{c}\text { GRUPO } \\
50 \text { a } 59\end{array}$ & $\begin{array}{l}\text { GRUPO } \\
60 \text { a } 69\end{array}$ & $\begin{array}{l}\text { GRUPO } \\
70 \text { e + }\end{array}$ & I gnorada & TOTAL \\
\hline \multirow[t]{12}{*}{09} & MAGDA & 415 & 421 & 275 & 208 & 167 & 86 & 68 & 34 & 1 & 1.675 \\
\hline & MIRANDOPOLIS & 2.360 & 2.650 & 1.704 & 1.327 & 1.074 & 655 & 509 & 326 & 10 & 10.615 \\
\hline & MURUT INGA DO SUL & 483 & 502 & 396 & 252 & 247 & 150 & 90 & 71 & 0 & 2.191 \\
\hline & NOVA INDEPENDENCIA & 264 & 212 & 146 & 102 & 69 & 54 & 36 & 13 & 0 & 896 \\
\hline & PENAPOLIS & 4.415 & 4.630 & 3.473 & 2.425 & 2.024 & 1.529 & 935 & 622 & 32 & 20.085 \\
\hline & PEREIRA BARRETO & 5.951 & 5.775 & 4.229 & 3.141 & 1.903 & 1.141 & 629 & 413 & 12 & 23.194 \\
\hline & PIACATU & 478 & 564 & 349 & 275 & 223 & 127 & 92 & 50 & 0 & 2.158 \\
\hline & RUBIACEA & 291 & 297 & 163 & 112 & 98 & 63 & 41 & 34 & 0 & 1.099 \\
\hline & SANTOPOLIS DO AGUAPEI & 455 & 431 & 259 & 191 & 146 & 102 & 63 & 42 & 6 & 1.695 \\
\hline & SUD MENUCCI & 752 & 626 & 415 & 311 & 201 & 156 & 71 & 36 & 0 & 2.568 \\
\hline & TUR IUBA & 465 & 495 & 303 & 252 & 175 & 106 & 74 & 52 & 1 & 1.923 \\
\hline & VALPARAISO & 1.611 & 1.554 & 1.058 & 787 & 591 & 439 & 335 & 211 & 1 & 6.587 \\
\hline 09 & & 61.014 & 62.752 & 45.894 & 32.656 & 25.185 & 17.102 & 10.819 & 6.877 & 168 & 262.467 \\
\hline \multirow[t]{34}{*}{10} & ADAMANTINA & 3.337 & 3.861 & 2.682 & 1.983 & 1.750 & 1.119 & 717 & 450 & 1 & 15.900 \\
\hline & ALFREDO MARCONDES & 424 & 492 & 346 & 257 & 222 & 146 & 119 & 84 & 1 & 2.091 \\
\hline & ALVARES MACHADO & 1.662 & 1.760 & 1.220 & 846 & 672 & 471 & 301 & 240 & 1 & 7.173 \\
\hline & ANHUMAS & 422 & 439 & 253 & 174 & 150 & 103 & 51 & 49 & 0 & 1.641 \\
\hline & CAIABU & 446 & 494 & 257 & 190 & 170 & 107 & 60 & 45 & 0 & 1.769 \\
\hline & CAIUA & 402 & 375 & 200 & 154 & 129 & 76 & 57 & 22 & 0 & 1.415 \\
\hline & DRACENA & 3.804 & 4.273 & 3.110 & 2.247 & 1.987 & 1.289 & 790 & 509 & 7 & 18.016 \\
\hline & ESTRELA DO NORTE & 421 & 451 & 236 & 167 & 125 & 76 & 41 & 16 & 0 & 1.533 \\
\hline & FLORA RICA & 341 & 339 & 200 & 133 & 129 & 69 & 45 & 27 & 0 & 1.283 \\
\hline & FLORIDA PAULISTA & 1.745 & 1.970 & 1.114 & 873 & 713 & 433 & 272 & 179 & 2 & 7.301 \\
\hline & IEPE & 1.188 & 1.228 & 673 & 517 & 435 & 305 & 182 & 114 & 2 & 4.644 \\
\hline & INDIANA & 532 & 478 & 336 & 257 & 175 & 159 & 84 & 63 & 0 & 2.084 \\
\hline & INUBIA PAULISTA & 564 & 543 & 309 & 223 & 182 & 142 & 65 & 51 & 3 & 2.082 \\
\hline & IRAPURU & 1.075 & 1.197 & 723 & 588 & 486 & 328 & 163 & 140 & 0 & 4.700 \\
\hline & JOAO RAMALHO & 304 & 365 & 258 & 156 & 129 & 82 & 33 & 27 & 0 & 1.354 \\
\hline & JUNQUEIROPOL IS & 2.395 & 2.635 & 1.726 & 1.287 & 1.021 & 653 & 351 & 278 & 3 & 10.349 \\
\hline & LUCELIA & 2.199 & 2.160 & 1.505 & 1.056 & 937 & 612 & 438 & 234 & 11 & 9.152 \\
\hline & MARABA PAULISTA & 551 & 509 & 290 & 207 & 156 & 83 & 46 & 20 & 1 & 1.863 \\
\hline & MARIAPOLIS & 650 & 733 & 364 & 288 & 223 & 164 & 93 & 63 & 0 & 2.578 \\
\hline & MARTINOPOLIS & 2.256 & 2.537 & 1.551 & 1.175 & 884 & 656 & 395 & 246 & 0 & 9.700 \\
\hline & MIRANTE DO PARANAPANEMA & 1.989 & 2.048 & 1.196 & 852 & 645 & 449 & 235 & 134 & 2 & 7.550 \\
\hline & MONTE CASTELO & 710 & 769 & 495 & 328 & 265 & 194 & 96 & 64 & 0 & 2.921 \\
\hline & NARANDIBA & 486 & 475 & 239 & 176 & 148 & 79 & 57 & 21 & 1 & 1.682 \\
\hline & NOVA GUATAPORANGA & 344 & 345 & 221 & 124 & 137 & 81 & 39 & 18 & 1 & 1.310 \\
\hline & OSVALDO CRUZ & 2.730 & 2.997 & 2.249 & 1.604 & 1.336 & 948 & 615 & 388 & 9 & 12.868 \\
\hline & OURO VERDE & 820 & 685 & 474 & 325 & 255 & 147 & 97 & 73 & 1 & 2.877 \\
\hline & PACAEMBU & 1.829 & 1.966 & 1.182 & 957 & 776 & 453 & 276 & 202 & 0 & 7.641 \\
\hline & PANORAMA & 1.139 & 1.003 & 574 & 440 & 343 & 208 & 125 & 79 & 4 & 3.915 \\
\hline & PARAPUA & 1.443 & 1.486 & 932 & 697 & 590 & 374 & 243 & 123 & 1 & 5.889 \\
\hline & PAUL I CE IA & 361 & 293 & 166 & 117 & 88 & 52 & 27 & 24 & 0 & 1.128 \\
\hline & PIQUEROBI & 455 & 416 & 280 & 208 & 163 & 89 & 57 & 44 & 0 & 1.712 \\
\hline & PIRAPOZINHO & 2.100 & 2.338 & 1.510 & 1.065 & 847 & 520 & 336 & 211 & 1 & 8.928 \\
\hline & PRESIDENTE BERNARDES & 1.764 & 1.987 & 1.152 & 942 & 755 & 499 & 330 & 241 & 4 & 7.674 \\
\hline & PRESIDENTE EPITACIO & 3.833 & 3.728 & 2.379 & 1.689 & 1.429 & 840 & 477 & 250 & 7 & 14.632 \\
\hline
\end{tabular}


TABELA 2 - POPULACAO dO SEXO fEMININO, SEgundo MUNICIPIO, REgIAO ADMINISTRATIVA E GRUPO ETARIO. ESTADO DE SAO PAULO, 1980.

\begin{tabular}{|c|c|c|c|c|c|c|c|c|c|c|c|}
\hline REGIAO & MUNICIPIO & $\begin{array}{l}\text { GRUPO } \\
0 \text { a } 09\end{array}$ & $\begin{array}{c}\text { GRUPO } \\
10 \text { a } 19\end{array}$ & $\begin{array}{c}\text { GRUPO } \\
20 \text { a } 29\end{array}$ & $\begin{array}{c}\text { GRUPO } \\
30 \text { a } 39\end{array}$ & $\begin{array}{l}\text { GRUPO } \\
40 \text { a } 49\end{array}$ & $\begin{array}{c}\text { GRUPO } \\
50 \text { a } 59\end{array}$ & $\begin{array}{l}\text { GRUPO } \\
60 \text { a } 69\end{array}$ & $\begin{array}{l}\text { GRUPO } \\
70 \text { e + }\end{array}$ & I gnorada & TOTAL \\
\hline \multirow[t]{16}{*}{10} & PRESIDENTE PRUDENTE & 15.122 & 16.239 & 13.229 & 8.872 & 6.901 & 4.644 & 2.711 & 1.731 & 23 & 69.472 \\
\hline & PRESIDENTE VENCESLAU & 3.481 & 3.796 & 2.634 & 1.807 & 1.481 & 963 & 544 & 361 & 3 & 15.070 \\
\hline & $\begin{array}{l}\text { RANCHARIA } \\
\end{array}$ & 2.743 & 2.926 & 1.861 & 1.343 & 1.146 & 802 & 495 & 347 & 1 & 11.664 \\
\hline & REGENTE FEI JO & 1.272 & 1.381 & 889 & 681 & 523 & 370 & 242 & 174 & $i$ & 5.533 \\
\hline & RINOPOLIS & 1.729 & 1.856 & 1.246 & 826 & 753 & 466 & 257 & 179 & 4 & 7.316 \\
\hline & SAGRES & 409 & 356 & 224 & 159 & 122 & 82 & 58 & 27 & 2 & 1.439 \\
\hline & SALMORAO & 573 & 602 & 366 & 290 & 195 & 143 & 81 & 41 & 0 & 2.291 \\
\hline & SANDOVALINA & 463 & 320 & 213 & 127 & 103 & 51 & 42 & 16 & 2 & 1.337 \\
\hline & SANTA MERCEDES & 513 & 556 & 297 & 228 & 175 & 81 & 49 & 37 & 0 & 1.936 \\
\hline & SANTO ANASTACIO & 2.414 & 2.818 & 1.664 & 1.344 & 1.066 & 739 & 452 & 308 & 20 & 10.825 \\
\hline & SANTO EXPEDITO & 272 & 307 & 155 & 130 & 98 & 65 & 42 & 23 & 0 & 1.092 \\
\hline & SAO JOAO DO PAU D'ALHO & 421 & 454 & 291 & 217 & 166 & 102 & 53 & 31 & 3 & 1.738 \\
\hline & TACIBA & 596 & 605 & 316 & 264 & 184 & 117 & 79 & 26 & 0 & 2.187 \\
\hline & TARABAI & 443 & 465 & 297 & 172 & 158 & 85 & 61 & 44 & 0 & 1.725 \\
\hline & TEODORO SAMPAIO & 3.812 & 3.009 & 1.952 & 1.392 & 909 & 494 & 256 & 155 & 2 & 11.981 \\
\hline & TUPI PAULISTA & 1.715 & 1.983 & 1.431 & 961 & 842 & 538 & 325 & 224 & 5 & 8.024 \\
\hline 10 & & 80.699 & 85.048 & 57.467 & 41.115 & 33.274 & 21.748 & 13.060 & 8.453 & 121 & 340.985 \\
\hline \multirow[t]{30}{*}{11} & ALVARO DE CARVALKO & 612 & 470 & 282 & 194 & 152 & 102 & 68 & 40 & 1 & 1.921 \\
\hline & ALVINLANDIA & 460 & 403 & 294 & 195 & 149 & 89 & 65 & 21 & 1 & 1.677 \\
\hline & ASSIS & 7.534 & 7.614 & 5.944 & 4.182 & 3.567 & 2.547 & 1.600 & 1.045 & 11 & 34.044 \\
\hline & BASTOS & 1.802 & 1.886 & 1.429 & 846 & 689 & 484 & 258 & 151 & 4 & 7.549 \\
\hline & BERNARDINO DE CAMPOS & 985 & 1.013 & 648 & 571 & 472 & 366 & 287 & 203 & 0 & 4.545 \\
\hline & BORA & 112 & 121 & 50 & 45 & 32 & 20 & 13 & 10 & 0 & 403 \\
\hline & CAMPOS NOVOS PAULISTA & 481 & 414 & 259 & 207 & 157 & 107 & 82 & 36 & 1 & 1.744 \\
\hline & CANDIDO MOTA & 2.178 & 2.289 & 1.595 & 1.170 & 1.004 & 688 & 481 & 266 & 2 & 9.673 \\
\hline & $\begin{array}{l}\text { CHAVANTES } \\
\text { la }\end{array}$ & 1.695 & 1.451 & 1.022 & 739 & 576 & 394 & 298 & 148 & 3 & 6.326 \\
\hline & CRUZALIA & 574 & 545 & 400 & 296 & 195 & 141 & 67 & 64 & 0 & 2.282 \\
\hline & ECHAPORA & 731 & 722 & 420 & 314 & 240 & 168 & 118 & 77 & 4 & 2.794 \\
\hline & FARTURA & 1.499 & 1.565 & 997 & 754 & 612 & 412 & 280 & 205 & 6 & 6.330 \\
\hline & FLORINEA & 375 & 311 & 219 & 168 & 101 & 79 & 66 & 30 & 0 & 1.349 \\
\hline & GALIA & 1.558 & 1.361 & 933 & 583 & 544 & 380 & 246 & 168 & 1 & 5.774 \\
\hline & GARCA & 4.735 & 4.456 & 3.299 & 2.255 & 1.948 & 1.529 & 908 & 593 & 3 & 19.726 \\
\hline & HERCULAND IA & 855 & 867 & 565 & 391 & 302 & 207 & 157 & 84 & 2 & 3.430 \\
\hline & IACR I & 1.173 & 1.203 & 724 & 471 & 408 & 236 & 135 & 89 & 5 & 4.444 \\
\hline & IBIRAREMA & 514 & 588 & 349 & 321 & 231 & 178 & 133 & 77 & 0 & 2.391 \\
\hline & IPAUCU & 1.183 & 1.190 & 744 & 560 & 511 & 395 & 252 & 164 & 0 & 4.999 \\
\hline & LUPERCIO & 484 & 427 & 265 & 183 & 154 & 89 & 67 & 30 & 0 & 1.699 \\
\hline & LUTECIA & 352 & 359 & 208 & 176 & 121 & 98 & 55 & 33 & 1 & 1.403 \\
\hline & MANDURI & 624 & 634 & 415 & 322 & 248 & 185 & 131 & 79 & 8 & 2.646 \\
\hline & MARACAI & 1.314 & 1.168 & 850 & 570 & 397 & 293 & 185 & 118 & 1 & 4.896 \\
\hline & MARILIA & 13.366 & 13.663 & 11.554 & 7.594 & 6.049 & 4.408 & 2.780 & 1.850 & 38 & 61.302 \\
\hline & OCAUCU & 572 & 548 & 348 & 243 & 245 & 121 & 66 & 46 & 2 & 2.191 \\
\hline & OLEO & 318 & 340 & 190 & 158 & 155 & 103 & 81 & 72 & 0 & 1.417 \\
\hline & ORIENTE & 780 & 808 & 495 & 341 & 304 & 205 & 120 & 63 & 0 & 3.116 \\
\hline & OSCAR BRESSANE & 357 & 403 & 231 & 184 & 123 & 82 & 52 & 41 & 1 & 1.474 \\
\hline & OUR INHOS & 6.850 & 6.846 & 5.204 & 3.819 & 2.926 & 2.187 & 1.299 & 782 & 8 & 29.921 \\
\hline & PALMI TAL & 1.802 & 1.892 & 1.346 & 1.135 & 906 & 676 & 442 & 307 & 2 & 8.508 \\
\hline
\end{tabular}




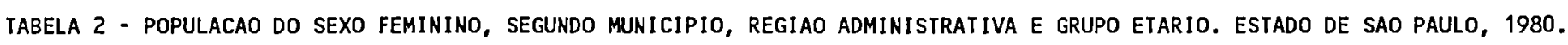

\begin{tabular}{cl} 
REGIAO & \multicolumn{1}{c}{ MUNICIPIO } \\
11 & PARAGUACU PAULISTA \\
& PIRAJU \\
& PLATINA \\
& POMPEIA \\
& QUATA \\
& QUEIROZ \\
& QUINTANA \\
& RIBEIRAO DO SUL \\
& SALTO GRANDE \\
& SANTA CRUZ DO RIO PARDO \\
& SAO PEDRO DO TURVO \\
& SARUTAIA \\
& TAGUAI \\
& IEJUPA \\
& TIMBURI \\
& TUPA \\
& VERA CRUZ \\
11 &
\end{tabular}

\begin{tabular}{|c|c|c|c|c|c|c|}
\hline $\begin{array}{l}\text { GRUPO } \\
0 \text { a } 09\end{array}$ & $\begin{array}{c}\text { GRUPO } \\
10 \text { a } 19\end{array}$ & $\begin{array}{c}\text { GRUPO } \\
20 \text { a } 29\end{array}$ & $\begin{array}{l}\text { GRUPO } \\
30 \text { a } 39\end{array}$ & $\begin{array}{c}\text { GRUPO } \\
40 \text { a } 49\end{array}$ & $\begin{array}{c}\text { GRUPO } \\
50 \text { a } 59\end{array}$ & $\begin{array}{c}\text { GRUPO } \\
60 \text { a } 69\end{array}$ \\
\hline 2.736 & 2.736 & 1.871 & 1.439 & 1.141 & 858 & 527 \\
\hline 2.455 & 2.385 & 1.804 & 1.271 & 1.147 & 818 & 525 \\
\hline 281 & 250 & 157 & 117 & 107 & 75 & 47 \\
\hline 1.924 & 1.927 & 1.380 & 934 & 707 & 534 & 374 \\
\hline 1.094 & 1.062 & 614 & 491 & 396 & 320 & 187 \\
\hline 364 & 278 & 157 & 120 & 94 & 53 & 38 \\
\hline 589 & 573 & 365 & 268 & 214 & 145 & 100 \\
\hline 363 & 344 & 239 & 181 & 144 & 110 & 62 \\
\hline 884 & 797 & 502 & 406 & 305 & 251 & 194 \\
\hline 3.698 & 3.731 & 2.859 & 1.999 & 1.584 & 1.154 & 776 \\
\hline 969 & 910 & 552 & 438 & 304 & 229 & 133 \\
\hline 384 & 373 & 207 & 167 & 138 & 87 & 73 \\
\hline 758 & 668 & 470 & 342 & 244 & 154 & 90 \\
\hline 675 & 547 & 354 & 281 & 227 & 132 & 74 \\
\hline 437 & 421 & 229 & 167 & 169 & 101 & 69 \\
\hline 6.177 & 6.533 & 4.866 & 3.651 & 2.919 & 2.053 & 1.346 \\
\hline 1.426 & 1.220 & 863 & 640 & 549 & 395 & 260 \\
\hline 81.089 & 80.312 & 58.768 & 41.899 & 33.899 & 24.438 & 15.667 \\
\hline .815 .831 & 2.611 .191 & 2.482 .431 & 1.671 .285 & 1.208 .070 & 873.614 & 522.098 \\
\hline
\end{tabular}

\begin{tabular}{rr}
\multicolumn{1}{l}{ GRUPO } \\
70 e + & I gnorada \\
346 & 5 \\
337 & 1 \\
19 & 1 \\
226 & 0 \\
112 & 1 \\
20 & 1 \\
69 & 6 \\
31 & 1 \\
102 & 2 \\
613 & 8 \\
71 & 1 \\
39 & 0 \\
51 & 0 \\
42 & 2 \\
28 & 1 \\
1.001 & 28 \\
206 & 2 \\
10.205 & 165 \\
328.767 & 7.535
\end{tabular}

TOTAL

11.659

10.743

1.054

8.006
4.277

$\cdot 1.125$

2.329

1.475

3.443
16.422

3.607
1.468

3.607
1.468

1.468
2.777

2.777
2.334

1.614
28.574

28.574
5.561

346.442

2.482 .431

7.535

12.520 .822 


\section{ANEXO 3}

Distribuição dos óbitos por câncer de boca dos residentes no Estado de São Paulo 
Tabela 1. Distribuição de óbitos por câncer de boca, segundo grupo etário e localização do tumor - residentes do sexo masculino - Município de São Paulo, 1979 -1982

\begin{tabular}{|c|c|c|c|c|c|c|c|c|c|c|c|c|c|c|}
\hline \multirow[b]{2}{*}{ Grupo Etário } & \multicolumn{13}{|c|}{ LOCALIZAÇÃO * } & \multirow[b]{2}{*}{ TOTAL } \\
\hline & 140 & 141 & 142 & 143 & 144 & 145.0 & 145.1 & 145.2 & 145.3 & 145.4 & 145.5 & 145.6 & 145.9 & \\
\hline $10+20$ & - & - & - & - & - & - & - & - & - & - & - & - & - & - \\
\hline $20+30$ & - & - & - & - & - & - & - & - & - & - & - & - & - & - \\
\hline $30+40$ & - & 06 & 01 & 02 & - & - & - & - & - & - & 03 & - & - & 12 \\
\hline $40+50$ & 01 & 41 & 07 & 02 & 13 & - & - & - & 02 & 01 & 05 & - & 06 & 78 \\
\hline $50+60$ & 05 & 77 & 02 & 05 & 14 & 02 & - & - & 06 & - & 08 & 06 & 16 & 141 \\
\hline $60+70$ & 03 & 40 & 03 & 02 & 07 & - & - & - & - & - & 04 & 03 & 09 & 71 \\
\hline $70 \mathrm{e}+$ & 05 & 31 & 07 & 01 & 06 & 01 & - & - & - & - & 04 & 01 & 05 & 61 \\
\hline TOTAL & 14 & 195 & 20 & 12 & 40 & 03 & - & - & 08 & 01 & 24 & 10 & 36 & 363 \\
\hline
\end{tabular}

* CID - ga Revisão

Tabela 2. Distribuição de óbitos por câncer de boca, segundo grupo etário e localização do tumor - residentes do sexo feminino - Município de São Paulo, 1979 - 1982

\begin{tabular}{|c|c|c|c|c|c|c|c|c|c|c|c|c|c|c|}
\hline \multirow[b]{2}{*}{ Grupo Etário } & \multicolumn{13}{|c|}{ LOCALIZAÇÃO * } & \multirow[b]{2}{*}{ TOTAL } \\
\hline & 140 & 141 & 142 & 143 & 144 & 145.0 & 145.1 & 145.2 & 145.3 & 145.4 & 145.5 & 145.6 & 145.9 & \\
\hline $10+20$ & - & - & - & - & - & - & - & - & - & - & - & - & - & - \\
\hline $20+30$ & - & - & - & - & - & - & - & 01 & - & - & - & - & 01 & 02 \\
\hline $30+40$ & - & - & - & - & - & $\cdot$ & - & - & - & - & - & - & - & - \\
\hline $40+50$ & - & - & - & - & - & - & - & - & - & - & 01 & 01 & 03 & 04 \\
\hline $50+60$ & 01 & 12 & 04 & 01 & - & - & - & - & 01 & - & - & - & - & 20 \\
\hline $60+70$ & 01 & 10 & 05 & 05 & - & - & - & 01 & - & - & 01 & - & 01 & 24 \\
\hline $70 e+$ & 03 & 08 & 03 & - & 01 & - & - & 01 & 01 & - & 02 & 01 & 03 & 23 \\
\hline TOTAL & 05 & 30 & 12 & 06 & 01 & - & - & 03 & 02 & - & 04 & 02 & 08 & 73 \\
\hline
\end{tabular}

* CID - 9a Revisão 
Tabela 3. Distribuição de óbitos por câncer de boca, segundo grupo etário e localização do tumor - residentes do sexo masculino - Região da Grande São Paulo, 1979 -1982

\begin{tabular}{|c|c|c|c|c|c|c|c|c|c|c|c|c|c|c|}
\hline \multirow[b]{2}{*}{ Grupo Etário } & \multicolumn{13}{|c|}{ LOCALIZAÇÃO * } & \multirow[b]{2}{*}{ TOTAL } \\
\hline & 140 & 141 & 142 & 143 & 144 & 145.0 & 145.1 & 145.2 & 145.3 & 145.4 & 145.5 & 145.6 & 145.9 & \\
\hline $10+20$ & - & - & - & - & - & - & - & - & - & - & - & - & - & - \\
\hline $20+30$ & - & - & 01 & - & - & - & - & - & - & - & - & - & - & 01 \\
\hline $30+40$ & 01 & 02 & - & - & - & - & - & - & - & - & - & - & 01 & 04 \\
\hline $40+50$ & 01 & 17 & 02 & 01 & 03 & - & - & - & - & - & - & 01 & 01 & 26 \\
\hline $50+60$ & 01 & 19 & 04 & - & 02 & - & - & - & - & 01 & - & - & 07 & 34 \\
\hline $60+70$ & - & 23 & 01 & 01 & 03 & - & 01 & - & - & 01 & 01 & 02 & 05 & 38 \\
\hline $70 e+01$ & 01 & 07 & 01 & - & - & 01 & - & - & - & - & 01 & - & 05 & 16 \\
\hline TOTAL & 04 & 68 & 09 & 02 & 08 & 01 & 01 & - & - & 02 & 02 & 03 & 19 & 119 \\
\hline
\end{tabular}

* CID - 9 Revisáo

Tabela 4. Distribuição de óbitos por câncer de boca, segundo grupo etário e localização do tumor - residentes do sexo feminino - Região da Grande São Paulo, 1979 - 1982

\begin{tabular}{|c|c|c|c|c|c|c|c|c|c|c|c|c|c|c|}
\hline \multirow[b]{2}{*}{ Grupo Etário } & \multicolumn{13}{|c|}{ LOCALIZAÇÃO * } & \multirow[b]{2}{*}{ TOTAL } \\
\hline & 140 & 141 & 142 & 143 & 144 & 145.0 & 145.1 & 145.2 & 145.3 & 145.4 & 145.5 & 145.6 & 145.9 & \\
\hline $10+20$ & - & - & 01 & - & - & - & - & - & - & - & - & - & - & 01 \\
\hline $20+30$ & - & - & - & - & - & - & - & - & - & - & - & - & - & - \\
\hline $30+40$ & - & - & - & - & - & - & - & 01 & - & - & - & - & - & 01 \\
\hline $40+50$ & - & 01 & - & - & - & - & - & - & - & - & - & - & 01 & 02 \\
\hline $50+60$ & - & 02 & - & 01 & - & - & - & - & - & - & 01 & - & $\cdot$ & 04 \\
\hline $60+70$ & - & 05 & 01 & - & - & - & $=$ & - & 02 & - & - & - & 01 & 09 \\
\hline $70 \mathrm{e}+$ & 01 & 02 & 01 & - & - & - & - & 01 & - & - & - & - & 01 & 06 \\
\hline TOTAL & 01 & 10 & 03 & 01 & - & - & - & 02 & 02 & - & 01 & - & 03 & 23 \\
\hline
\end{tabular}

* CID - 9a Revisáo 
Tabela 5. Distribuição de óbitos por câncer de boca, segundo grupo etário e localização do tumor - residentes do sexo masculino - Região do Litoral, 1979 -1982

\begin{tabular}{|c|c|c|c|c|c|c|c|c|c|c|c|c|c|c|}
\hline \multirow[b]{2}{*}{ Grupo Etário } & \multicolumn{13}{|c|}{ LOCALIZAÇĀO * } & \multirow[b]{2}{*}{ TOTAL } \\
\hline & 140 & 141 & 142 & 143 & 144 & 145.0 & 145.1 & 145.2 & 145,3 & 145.4 & 145.5 & 145.6 & 145.9 & \\
\hline $10+20$ & - & - & - & - & - & - & - & - & . & - & - & - & - & - \\
\hline $20+30$ & - & - & - & - & - & - & - & - & - & - & - & - & - & - \\
\hline $30+40$ & - & - & - & - & 02 & - & - & - & - & - & - & - & 02 & 04 \\
\hline $40+50$ & 01 & 06 & 02 & - & 01 & 01 & - & - & - & - & 01 & - & 04 & 16 \\
\hline $50+60$ & - & 08 & 01 & - & 04 & - & - & - & - & - & - & - & 02 & 15 \\
\hline $60+70$ & - & 09 & 01 & 01 & 01 & - & - & 01 & - & - & 01 & - & 05 & 19 \\
\hline $70 \mathrm{e}+$ & - & 03 & 01 & - & 02 & - & - & - & - & - & 04 & - & - & 10 \\
\hline TOTAL & 01 & 26 & 05 & 01 & 10 & 01 & - & 01 & - & - & 06 & - & 13 & 64 \\
\hline
\end{tabular}

- CID - ga Revisão

Tabela 6. Distribuição de óbitos por câncer de boca, segundo grupo etário e localização do tumor - residentes do sexo feminino - Região do Litoral, 1979 - 1982

\begin{tabular}{|c|c|c|c|c|c|c|c|c|c|c|c|c|c|c|}
\hline \multirow[b]{2}{*}{ Grupo Etário } & \multicolumn{13}{|c|}{ LOCALIZAÇÃO * } & \multirow[b]{2}{*}{ TOTAL } \\
\hline & 140 & 141 & 142 & 143 & 144 & 145.0 & 145.1 & 145.2 & 145.3 & 145.4 & 145.5 & 145.6 & 145.9 & \\
\hline $10+20$ & - & - & - & - & - & - & - & - & - & - & - & - & - & - \\
\hline $20+30$ & - & - & 01 & - & - & - & - & - & - & - & - & - & - & 01 \\
\hline $30+40$ & - & - & - & - & - & - & - & - & - & - & - & - & - & - \\
\hline $40+50$ & - & 02 & - & - & - & - & - & - & - & - & - & - & 01 & 03 \\
\hline $50+60$ & - & 02 & 01 & - & 01 & - & - & - & . & - & - & - & - & 04 \\
\hline $60+70$ & - & 03 & - & - & - & - & - & 02 & - & - & - & - & 01 & 06 \\
\hline $70 \mathrm{e}+$ & - & - & - & 02 & - & - & - & - & - & - & 03 & - & 01 & 06 \\
\hline TOTAL & - & 07 & 02 & 02 & - & - & - & 02 & - & - & 03 & - & 03 & 20 \\
\hline
\end{tabular}

" CID - ga Revisão 
Tabela 7. Distribuição de óbitos por câncer de boca, segundo grupo etário e localização do tumor - residentes do sexo masculino - Região do Vale do Paraíba, 1979 -1982

\begin{tabular}{|c|c|c|c|c|c|c|c|c|c|c|c|c|c|c|}
\hline \multirow[b]{2}{*}{ Grupo Etário } & \multicolumn{13}{|c|}{ LOCALIZAÇĀO * } & \multirow[b]{2}{*}{ TOTAL } \\
\hline & 140 & 141 & 142 & 143 & 144 & 145.0 & 145.1 & 145.2 & 145.3 & 145.4 & 145.5 & 145.6 & 145.9 & \\
\hline $10 \vdash 20$ & - & - & - & - & - & - & - & - & - & - & - & - & - & - \\
\hline $20+30$ & - & - & - & - & - & - & - & - & - & - & - & - & - & - \\
\hline $30+40$ & - & - & - & 01 & - & - & - & - & - & - & - & - & - & 01 \\
\hline $40+50$ & - & 03 & - & - & - & - & - & - & - & - & 01 & - & 03 & 07 \\
\hline $50 \vdash 60$ & - & 07 & 02 & 01 & - & - & - & - & - & - & 01 & 01 & 03 & 15 \\
\hline $60+70$ & 02 & 11 & - & 02 & - & - & - & - & - & - & 01 & - & - & 16 \\
\hline $70 e+$ & 03 & 02 & - & - & - & - & - & 01 & - & - & 01 & - & 01 & 08 \\
\hline TOTAL & 05 & 23 & 02 & 04 & - & - & - & 01 & - & - & 04 & 01 & 07 & 47 \\
\hline
\end{tabular}

* CID - $9^{2}$ Revisão

Tabela 8. Distribuição de óbitos por câncer de boca, segundo grupo etário e localização do tumor - residentes do sexo feminino - Região do Vale do Paraíba, 1979 - 1982

\begin{tabular}{|c|c|c|c|c|c|c|c|c|c|c|c|c|c|c|}
\hline \multirow[b]{2}{*}{ Grupo Etário } & \multicolumn{13}{|c|}{ LOCALIZAÇÃO * } & \multirow[b]{2}{*}{ TOTAL } \\
\hline & 140 & 141 & 142 & 143 & 144 & 145.0 & 145.1 & 145.2 & 145.3 & 145.4 & 145.5 & 145.6 & 145.9 & \\
\hline $10+20$ & - & - & - & - & - & - & - & - & - & - & - & - & - & - \\
\hline $20+30$ & - & - & - & - & - & - & - & - & - & - & - & - & - & - \\
\hline $30+40$ & - & - & - & - & - & - & - & - & - & - & - & - & - & - \\
\hline $40+50$ & - & - & - & . & - & - & - & - & - & - & - & - & - & - \\
\hline $50 \vdash 60$ & - & 01 & - & - & 01 & - & - & - & - & - & - & - & - & 02 \\
\hline $60+70$ & - & - & - & - & - & - & - & - & - & - & - & - & - & - \\
\hline $70 e+$ & - & - & 01 & - & 01 & - & - & - & 01 & - & - & - & 04 & 07 \\
\hline TOTAL & - & 01 & 01 & - & 02 & - & - & - & 01 & - & - & - & 04 & 09 \\
\hline
\end{tabular}

${ }^{*}$ CID - 9a Revisåo 
Tabela 9. Distribuição de óbitos por câncer de boca, segundo grupo etário e lodlização do tumor - rcresidentes do sexo masculino - Região de Sorocaba, 1979 -1982

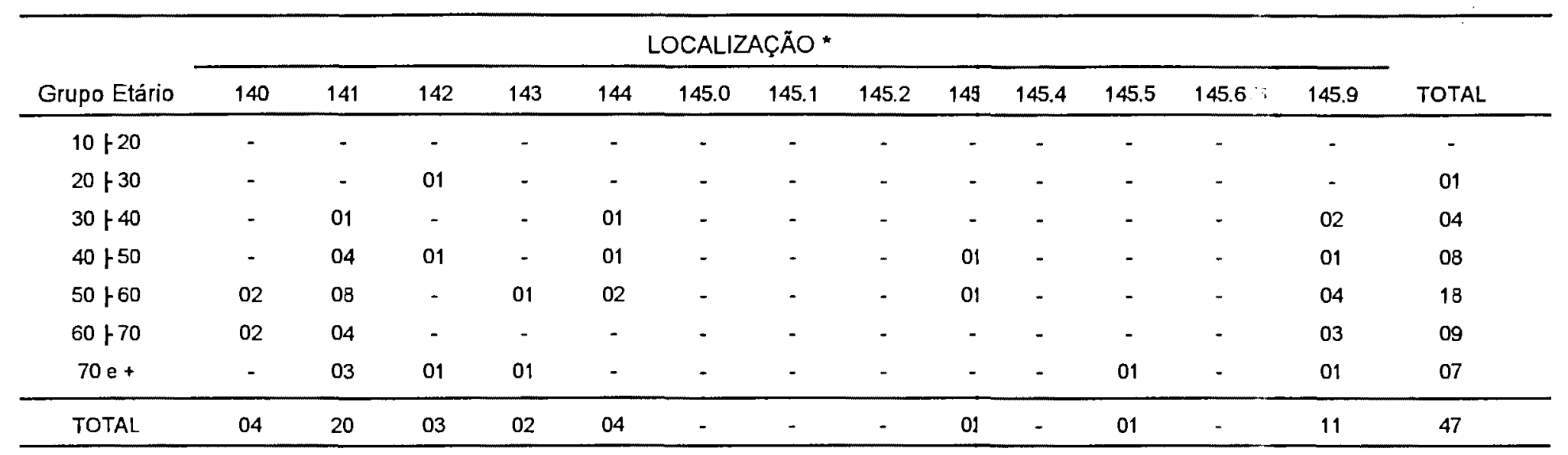

- CID - 9 Revisão

Tabela 10. Distribuição de óbitos por câncer de boca, segundo grupo etário e lodlização do tumor - re:esidentes do sexo feminino - Região de Sorocaba, $1979-1982$

\begin{tabular}{|c|c|c|c|c|c|c|c|c|c|c|c|c|c|c|}
\hline \multirow[b]{2}{*}{ Grupo Etário } & \multicolumn{13}{|c|}{ LOCALIZAÇÄO * } & \multirow[b]{2}{*}{ TOTAL } \\
\hline & 140 & 141 & 142 & 143 & 144 & 145.0 & 145.1 & 145.2 & 149 & 145.4 & 145.5 & 145.6 & 145.9 & \\
\hline $10+20$ & - & - & - & - & - & - & - & - & - & - & - & - & - & . \\
\hline $20+30$ & - & - & - & - & - & - & - & - & - & - & - & - & - & - \\
\hline $30+40$ & - & - & - & - & - & - & - & - & - & - & - & - & 01 & 01 \\
\hline $40+50$ & - & - & - & - & - & - & - & - & - & - & - & - & - & - \\
\hline $50+60$ & - & - & - & - & - & - & - & - & - & - & - & - & 01 & 01 \\
\hline $60+70$ & - & - & 01 & - & - & 01 & - & - & - & - & - & - & 01 & 03 \\
\hline $70 \mathrm{e}+$ & 01 & 01 & 01 & - & - & - & - & - & - & - & - & - & - & 03 \\
\hline TOTAL & 01 & 01 & 02 & - & - & 01 & - & - & - & - & - & - & 03 & 08 \\
\hline
\end{tabular}

* CID - ga Revisåo 
Tabela 11. Distribuição de óbitos por câncer de boca, segundo grupo etário e localização do tumor - residentes do sexo masculino - Região de Campinas, 1979 -1982

\begin{tabular}{|c|c|c|c|c|c|c|c|c|c|c|c|c|c|c|}
\hline \multirow[b]{2}{*}{ Grupo Etário } & \multicolumn{13}{|c|}{ LOCALIZAÇÄO * } & \multirow[b]{2}{*}{ TOTAL } \\
\hline & 140 & 141 & 142 & 143 & 144 & 145.0 & 145.1 & 145.2 & 145.3 & 145.4 & 145.5 & 145.6 & 145.9 & \\
\hline $10+20$ & - & - & - & - & - & - & - & - & - & - & - & - & - & - \\
\hline $20+30$ & - & - & - & 01 & - & - & - & - & - & - & - & - & - & 01 \\
\hline $30+40$ & - & 05 & - & - & 02 & - & - & - & - & - & - & - & 01 & 08 \\
\hline $40+50$ & - & 09 & - & 01 & 03 & - & - & - & - & - & 01 & - & 06 & 20 \\
\hline $50+60$ & 01 & 19 & - & - & 05 & 01 & - & - & 01 & - & 01 & 01 & 08 & 37 \\
\hline $60+70$ & 01 & 12 & 02 & - & 01 & - & - & - & 01 & - & 02 & - & 05 & 24 \\
\hline $70 \mathrm{e}+$ & 01 & 13 & 06 & - & 01 & 01 & - & - & - & - & - & - & 09 & 31 \\
\hline TOTAL & 03 & 58 & 08 & 02 & 12 & 02 & - & - & 02 & - & 04 & 01 & 29 & 121 \\
\hline
\end{tabular}

* CID - ga Revisão

Tabela 12. Distribuição de óbitos por câncer de boca, segundo grupo etário e localização do tumor - residentes do sexo feminino - Região de Campinas, 1979 - 1982

\begin{tabular}{|c|c|c|c|c|c|c|c|c|c|c|c|c|c|c|}
\hline \multirow[b]{2}{*}{ Grupo Etário } & \multicolumn{13}{|c|}{ LOCALIZAÇÃO * } & \multirow[b]{2}{*}{ TOTAL } \\
\hline & 140 & 141 & 142 & 143 & 144 & 145.0 & 145.1 & 145.2 & 145.3 & 145.4 & 145.5 & 145.6 & 145.9 & \\
\hline $10+20$ & - & - & - & - & - & - & - & - & - & - & - & - & - & - \\
\hline $20+30$ & - & 01 & - & - & - & - & - & - & - & - & - & - & - & 01 \\
\hline $30+40$ & - & - & - & - & - & - & - & - & - & - & - & - & - & - \\
\hline $40+50$ & - & - & 01 & - & - & - & - & - & - & - & - & - & - & 01 \\
\hline $50+60$ & 01 & - & - & - & 01 & - & - & - & - & - & 01 & - & - & 03 \\
\hline $60+70$ & - & 01 & 01 & 01 & - & - & - & - & - & - & 01 & - & 03 & 07 \\
\hline $70 \mathrm{e}+$ & 01 & 06 & 02 & - & 01 & - & - & - & - & - & 01 & - & 04 & 15 \\
\hline TOTAL & 02 & 08 & 04 & 01 & 02 & - & - & - & - & - & 03 & - & 07 & 27 \\
\hline
\end{tabular}


Tabela 13. Distribuição de óbitos por câncer de boca, segundo grupo etário e localização do tumor - residentes do sexo masculino - Região de Ribeirão Preto, 1979 -1982

\begin{tabular}{|c|c|c|c|c|c|c|c|c|c|c|c|c|c|c|}
\hline \multirow[b]{2}{*}{ Grupo Etário } & \multicolumn{13}{|c|}{ LOCALIZAÇĀO * } & \multirow[b]{2}{*}{ TOTAL. } \\
\hline & 140 & 141 & 142 & 143 & 144 & 145.0 & 145.1 & 145.2 & 145.3 & 145.4 & 145.5 & 145.6 & 145.9 & \\
\hline $10+20$ & - & - & - & - & - & - & - & - & - & - & - & - & - & - \\
\hline $20+30$ & - & 01 & - & - & - & - & - & - & - & - & - & - & 01 & 02 \\
\hline $30+40$ & - & 01 & 01 & - & 01 & - & - & - & - & - & - & - & 01 & 04 \\
\hline $40+50$ & - & 09 & - & 01 & - & - & - & - & - & - & 02 & 01 & - & 13 \\
\hline $50+60$ & - & 03 & 01 & - & 02 & - & - & 01 & 02 & - & 01 & 01 & 01 & 12 \\
\hline $60+70$ & 01 & 12 & - & 02 & 03 & - & - & - & - & - & - & - & 04 & 22 \\
\hline $70 \mathrm{e}+$ & 02 & 05 & 02 & 02 & - & - & - & - & - & - & 02 & - & 05 & 18 \\
\hline TOTAL & 03 & 31 & 04 & 05 & 06 & - & - & 01 & 02 & - & 05 & 02 & 12 & 71 \\
\hline
\end{tabular}

* CID - 9a Revisão

Tabela 14. Distribuição de óbitos por câncer de boca, segundo grupo etário e localização do tumor - residentes do sexo feminino - Região de Ribeirão Preto, 1979 - 1982

\begin{tabular}{|c|c|c|c|c|c|c|c|c|c|c|c|c|c|c|}
\hline \multirow[b]{2}{*}{ Grupo Etário } & \multicolumn{13}{|c|}{ LOCALIZAÇÄO * } & \multirow[b]{2}{*}{ TOTAL } \\
\hline & 140 & 141 & 142 & 143 & 144 & 145.0 & 145.1 & 145.2 & 145.3 & 145.4 & 145.5 & 145.6 & 145.9 & \\
\hline $10+20$ & - & - & 01 & - & - & - & - & - & - & - & - & - & - & 01 \\
\hline $20+30$ & - & - & - & - & - & - & - & - & - & - & - & - & - & 01 \\
\hline $30+40$ & - & 01 & - & - & - & - & - & - & - & - & - & - & - & - \\
\hline $40+50$ & - & - & - & - & 01 & - & - & - & - & - & - & - & - & 01 \\
\hline $50+60$ & - & 02 & - & - & - & - & - & - & - & - & - & - & 02 & 04 \\
\hline $60+70$ & - & - & - & - & - & - & - & - & - & - & - & - & - & - \\
\hline $70 \mathrm{e}+$ & - & 04 & 01 & 01 & - & - & - & - & - & - & 01 & - & 01 & 08 \\
\hline TOTAL & - & 07 & 02 & 01 & 01 & - & - & - & - & - & 01 & - & 03 & 15 \\
\hline
\end{tabular}

* CID - 9a Revisão 
Tabela 15. Distribuição de óbitos por câncer de boca, segundo grupo etário e localização do tumor - residentes do sexo masculino - Região de Bauru, 1979 -1982

\begin{tabular}{|c|c|c|c|c|c|c|c|c|c|c|c|c|c|c|}
\hline \multirow[b]{2}{*}{ Grupo Etário } & \multicolumn{13}{|c|}{ LOCALIZAÇÃO * } & \multirow[b]{2}{*}{ TOTAL } \\
\hline & 140 & 141 & 142 & 143 & 144 & 145.0 & 145.1 & 145.2 & 145.3 & 145.4 & 145.5 & 145.6 & 145.9 & \\
\hline $10+20$ & - & - & - & - & - & - & - & - & - & - & - & - & - & - \\
\hline $20+30$ & - & - & - & - & - & - & - & - & - & - & - & - & - & - \\
\hline $30+40$ & - & - & - & - & - & - & - & - & - & - & - & - & - & - \\
\hline $40 \vdash 50$ & - & 01 & - & 01 & - & 01 & - & - & - & - & - & - & - & 03 \\
\hline $50 \vdash 60$ & 01 & 07 & - & - & - & - & - & - & - & - & - & 02 & 01 & 11 \\
\hline $60+70$ & - & 06 & - & 01 & 01 & 01 & - & - & - & - & - & - & 03 & 12 \\
\hline $70 \mathrm{e}+$ & 01 & - & - & - & 01 & - & - & - & - & - & - & 01 & 01 & 04 \\
\hline TOTAL & 02 & 14 & - & 02 & 02 & 02 & - & - & - & - & - & 03 & 05 & 30 \\
\hline
\end{tabular}

"CID - 9a Revisão

Tabela 16. Distribuição de óbitos por câncer de boca, segundo grupo etário e localização do tumor - residentes do sexo feminino - Região de Bauru, 1979 - 1982

\begin{tabular}{|c|c|c|c|c|c|c|c|c|c|c|c|c|c|c|}
\hline \multirow[b]{2}{*}{ Grupo Etário } & \multicolumn{13}{|c|}{ LOCALIZAÇÃO * } & \multirow[b]{2}{*}{ TOTAL } \\
\hline & 140 & 141 & 142 & 143 & 144 & 145.0 & 145.1 & 145.2 & 145.3 & 145.4 & 145.5 & 145.6 & 145.9 & \\
\hline $10+20$ & - & - & - & - & - & - & - & - & - & - & - & - & - & - \\
\hline $20+30$ & - & - & - & - & - & - & - & - & - & - & - & - & - & - \\
\hline $30+40$ & - & - & 01 & - & - & - & - & - & - & - & - & - & - & 01 \\
\hline $40+50$ & 01 & - & - & - & - & - & - & - & - & - & - & - & - & 01 \\
\hline $50+60$ & - & 01 & - & - & - & - & - & - & - & - & - & - & - & 01 \\
\hline $60+70$ & - & - & - & - & - & - & - & - & - & - & - & - & - & - \\
\hline $70 \mathrm{e}+$ & . & 01 & - & - & - & - & - & - & - & - & 01 & - & 02 & 04 \\
\hline TOTAL & 01 & 02 & 01 & - & . & - & - & - & - & . & 01 & - & 02 & 07 \\
\hline
\end{tabular}

* CID - 9a Revisåo 
Tabela 17. Distribuição de óbitos por câncer de boca, segundo grupo etário e localização do tumor - residentes do sexo masculino - Região de São José do Rio Preto, 1979 -1982

\begin{tabular}{|c|c|c|c|c|c|c|c|c|c|c|c|c|c|c|}
\hline \multirow[b]{2}{*}{ Grupo Etário } & \multicolumn{13}{|c|}{ LOCALIZAÇÃO * } & \multirow[b]{2}{*}{ TOTAL } \\
\hline & 140 & 141 & 142 & 143 & 144 & 145.0 & 145.1 & 145.2 & 145.3 & 145.4 & 145.5 & 145.6 & 145.9 & \\
\hline $10+20$ & - & - & - & - & - & - & - & - & - & - & - & - & - & - \\
\hline $20+30$ & - & - & - & - & - & - & - & - & - & - & - & - & - & - \\
\hline $30 \vdash 40$ & - & - & - & - & 01 & - & - & - & - & - & - & - & - & 01 \\
\hline $40+50$ & - & 09 & - & - & 02 & - & - & - & 01 & - & - & - & 01 & 13 \\
\hline $50+60$ & - & 08 & 01 & - & 04 & - & - & - & - & - & - & 01 & 01 & 15 \\
\hline $60+70$ & - & 08 & 01 & - & 01 & - & - & - & - & - & - & - & 01 & 11 \\
\hline $70 e+$ & 01 & 07 & 01 & - & 01 & - & - & - & - & - & 02 & - & 02 & 14 \\
\hline TOTAL & 01 & 32 & 03 & - & 09 & - & - & - & 01 & - & 02 & 01 & 05 & 54 \\
\hline
\end{tabular}

* CID - ga Revisão

Tabela 18. Distribuição de óbitos por câncer de boca, segundo grupo etário e localização do tumor - residentes do sexo feminino - Região de São José do Rio Preto, 1979 - 1982

\begin{tabular}{|c|c|c|c|c|c|c|c|c|c|c|c|c|c|c|}
\hline \multirow[b]{2}{*}{ Grupo Etário } & \multicolumn{13}{|c|}{ LOCALIZAÇÃO * } & \multirow[b]{2}{*}{ TOTAL } \\
\hline & 140 & 141 & 142 & 143 & 144 & 145.0 & 145.1 & 145.2 & 145.3 & 145.4 & 145.5 & 145.6 & 145.9 & \\
\hline $10+20$ & - & - & - & - & - & - & - & - & - & - & - & - & - & - \\
\hline $20+30$ & - & - & - & - & - & - & - & - & - & - & - & - & - & - \\
\hline $30+40$ & - & - & - & - & - & - & - & - & - & - & - & - & - & - \\
\hline $40+50$ & - & - & - & - & - & - & - & - & - & - & - & - & - & - \\
\hline $50+60$ & - & - & - & - & 01 & - & - & - & - & - & - & - & - & 01 \\
\hline $60+70$ & - & - & - & - & - & - & - & - & - & - & 01 & - & . & 01 \\
\hline $70 \mathrm{e}+$ & - & - & - & - & - & - & - & - & - & - & 01 & - & 01 & 02 \\
\hline TOTAL & - & - & - & - & 01 & - & - & - & - & . & 02 & - & 01 & 04 \\
\hline
\end{tabular}

* CID - $9^{a}$ Revisăo 
Tabela 19. Distribuição de óbitos por câncer de boca, segundo grupo etário e localização do tumor - residentes do sexo masculino - Região de Araçatuba, $1979-1982$

\begin{tabular}{|c|c|c|c|c|c|c|c|c|c|c|c|c|c|c|}
\hline \multirow[b]{2}{*}{ Grupo Etário } & \multicolumn{13}{|c|}{ LOCALIZAÇÃO * } & \multirow[b]{2}{*}{ TOTAL } \\
\hline & 140 & 141 & 142 & 143 & 144 & 145.0 & 145.1 & 145.2 & 145.3 & 145.4 & 145.5 & 145.6 & 145.9 & \\
\hline $10+20$ & - & - & - & - & - & - & - & - & - & - & - & - & - & - \\
\hline $20+30$ & - & - & - & - & - & - & - & - & - & - & - & - & - & - \\
\hline $30+40$ & - & - & - & - & - & - & - & - & - & - & - & - & - & - \\
\hline $40+50$ & - & 01 & - & - & - & - & - & - & - & - & - & - & - & 01 \\
\hline $50+60$ & - & - & - & - & - & - & - & - & - & - & 01 & - & 01 & 02 \\
\hline $60+70$ & - & 01 & - & - & - & - & - & - & - & - & - & - & - & 01 \\
\hline $70 \mathrm{e}+$ & - & - & - & 01 & - & - & - & - & - & - & 01 & - & - & 02 \\
\hline TOTAL & . & 02 & - & 01 & - & - & - & - & - & - & 02 & . & 01 & 06 \\
\hline
\end{tabular}

* CID - $9^{\mathrm{a}}$ Revisão

Tabela 20. Distribuição de óbitos por câncer de boca, segundo grupo etário e localização do tumor - residentes do sexo feminino - Região de Araçatuba, 1979 - 1982

\begin{tabular}{|c|c|c|c|c|c|c|c|c|c|c|c|c|c|c|}
\hline \multirow[b]{2}{*}{ Grupo Etário } & \multicolumn{13}{|c|}{ LOCALIZAÇÃO * } & \multirow[b]{2}{*}{ TOTAL } \\
\hline & 140 & 141 & 142 & 143 & 144 & 145.0 & 145.1 & 145.2 & 145.3 & 145.4 & 145.5 & 145.6 & 145.9 & \\
\hline $10+20$ & - & - & - & - & - & - & - & - & - & - & - & - & - & - \\
\hline $20+30$ & - & - & - & - & - & - & - & - & - & - & - & - & - & - \\
\hline $30+40$ & - & - & - & - & - & - & - & - & - & - & - & - & - & - \\
\hline $40+50$ & - & - & - & - & - & - & - & - & - & - & - & - & - & - \\
\hline $50+60$ & - & 01 & - & - & - & - & - & - & - & - & - & - & - & 01 \\
\hline $60+70$ & - & - & - & - & 01 & - & - & - & - & - & - & - & 01 & 02 \\
\hline $70 \mathrm{e}+$ & - & - & - & - & - & - & - & - & - & - & - & - & - & - \\
\hline TOTAL & - & 01 & - & - & 01 & - & - & - & - & - & - & - & 01 & 03 \\
\hline
\end{tabular}


Tabela 21. Distribuição de óbitos por câncer de boca, segundo grupo etário e localização do tumor - residentes do sexo masculino - Região de Presidente Prudente, 1979 -1982

\begin{tabular}{|c|c|c|c|c|c|c|c|c|c|c|c|c|c|c|}
\hline \multirow[b]{2}{*}{ Grupo Etário } & \multicolumn{13}{|c|}{ LOCALIZAÇÄO * } & \multirow[b]{2}{*}{ TOTAL } \\
\hline & 140 & 141 & 142 & 143 & 144 & 145.0 & 145.1 & 145.2 & 145.3 & 145.4 & 145.5 & 145.6 & 145.9 & \\
\hline $10+20$ & - & - & - & - & - & - & - & - & - & - & - & - & - & - \\
\hline $20+30$ & - & - & - & - & - & - & - & - & - & - & - & - & - & - \\
\hline $30+40$ & - & - & - & - & - & - & - & - & - & - & - & - & - & - \\
\hline $40+50$ & - & - & - & - & 01 & - & - & - & - & - & - & - & - & 01 \\
\hline $50+60$ & - & 04 & 01 & - & 01 & - & - & - & - & - & - & - & 03 & 09 \\
\hline $60+70$ & - & 01 & 01 & - & - & - & - & - & . & - & - & - & - & 02 \\
\hline $70 \mathrm{e}+$ & - & 02 & 01 & - & 01 & - & - & - & - & - & 01 & - & 03 & 08 \\
\hline TOTAL & - & 07 & 03 & - & 03 & - & - & - & - & - & 01 & - & 06 & 20 \\
\hline
\end{tabular}

* CID - $9^{\mathrm{a}}$ Revisåo

Tabela 22. Distribuição de óbitos por câncer de boca, segundo grupo etário e localização do tumor - residentes do sexo feminino - Região de Presidente Prudente, 1979 - 1982

\begin{tabular}{ccccccccccccccc}
\hline & \multicolumn{10}{c}{ LOCALIZAÇÃO* } & \\
\cline { 2 - 10 } Grupo Etário & 140 & 141 & 142 & 143 & 144 & 145.0 & 145.1 & 145.2 & 145.3 & 145.4 & 145.5 & 145.6 & 145.9 & TOTAL \\
\hline $10+20$ & - & - & - & - & - & - & - & - & - & - & - & - & - & - \\
$20+30$ & - & - & - & - & - & - & - & - & - & - & - & - & - & - \\
$30+40$ & - & - & - & - & - & - & - & - & - & - & - & - & - & - \\
$40+50$ & - & - & - & - & - & - & - & - & - & - & - & - & - & - \\
$50+60$ & - & - & - & - & - & - & - & - & - & - & - & - & - & - \\
$60+70$ & - & 01 & - & - & - & - & - & - & - & - & - & - & - & 01 \\
$70 \mathrm{e}+$ & - & - & - & - & - & - & - & - & - & - & - & - & - & - \\
\hline TOTAL & - & 01 & - & - & - & - & - & - & - & - & - & - & - & 01 \\
\hline
\end{tabular}

- CID - ga Revisão 
Tabela 23. Distribuição de óbitos por câncer de boca, segundo grupo etário e localização do tumor - residentes do sexo masculino - Região de Marília, 1979 -1982

\begin{tabular}{|c|c|c|c|c|c|c|c|c|c|c|c|c|c|c|}
\hline \multirow[b]{2}{*}{ Grupo Etário } & \multicolumn{13}{|c|}{ LOCALIZAÇÃO * } & \multirow[b]{2}{*}{ TOTAL } \\
\hline & 140 & 141 & 142 & 143 & 144 & 145.0 & 145.1 & 145.2 & 145.3 & 145.4 & 145.5 & 145.6 & 145.9 & \\
\hline $10+20$ & - & - & - & - & - & - & - & - & - & - & - & - & - & - \\
\hline $20+30$ & $\cdot$ & - & - & - & - & - & - & - & - & - & - & - & - & - \\
\hline $30+40$ & - & 01 & - & - & - & - & - & - & - & - & - & - & - & 01 \\
\hline $40+50$ & - & 02 & 01 & - & 01 & - & - & - & - & - & - & - & 01 & 05 \\
\hline $50+60$ & - & 02 & - & - & - & - & - & - & - & - & - & - & - & 02 \\
\hline $60+70$ & - & 01 & 01 & - & - & - & - & - & - & - & - & 01 & 01 & 04 \\
\hline $70 e+$ & - & 03 & 01 & 01 & - & - & - & - & - & - & - & - & 03 & 08 \\
\hline TOTAL & - & 09 & 03 & 01 & 01 & - & - & - & - & - & - & 01 & 05 & 20 \\
\hline
\end{tabular}

Tabela 24. Distribuição de óbitos por câncer de boca, segundo grupo etário e localização do tumor - residentes do sexo feminino - Região de Marília, 1979 - 1982

\begin{tabular}{|c|c|c|c|c|c|c|c|c|c|c|c|c|c|c|}
\hline Grupo Etário & \multicolumn{13}{|c|}{ LOCALIZAÇÃO * } & TOTAL \\
\hline $10+20$ & - & - & - & - & - & - & - & - & - & - & - & - & - & - \\
\hline $20+30$ & - & - & - & - & - & - & - & - & - & - & - & - & - & - \\
\hline $30+40$ & - & - & - & - & - & - & - & - & - & - & - & - & - & - \\
\hline $40+50$ & - & 01 & - & - & - & - & - & - & - & - & - & - & - & 01 \\
\hline $70 \mathrm{e}+$ & - & - & - & - & - & 01 & - & 01 & - & - & - & - & - & 02 \\
\hline TOTAL & - & 03 & - & - & - & 01 & - & 01 & - & - & 01 & - & - & 06 \\
\hline
\end{tabular}

CID - 9a Revisåo 
ANEXO 4

Populações-padrão 
Tabela 1 - Populações-padrão utilizadas para os cálculos dos coeficientes de mortalidade padronizados por idade.

\begin{tabular}{ccc}
\hline $\begin{array}{c}\text { GRUPO } \\
\text { ETÁRIO }\end{array}$ & $\begin{array}{c}\text { POPULAÇÃO DO * } \\
\text { ESTADO DE SÃO PAULO }\end{array}$ & $\begin{array}{c}\text { POPULAÇÃO ** } \\
\text { MUNDIAL }\end{array}$ \\
\hline $0 \vdash 10$ & 22.829 & 22.000 \\
$10+20$ & 20.842 & 18.000 \\
$20+30$ & 20.025 & 16.000 \\
$30+40$ & 13.436 & 12.000 \\
$40+50$ & 9.673 & 12.000 \\
$50+60$ & 6.880 & 9.000 \\
$60+70$ & 3.962 & 7.000 \\
70 e + & 2.353 & 4.000 \\
\hline TOTAL & 100.000 & 100.000 \\
\hline
\end{tabular}

* obtida a partir do censo de 1980

** Waterhouse, 1982

Tabela 2 - Coeficientes de mortalidade por câncer de boca (por 100.000), brutos e padronizados considerando a população-padrão mundial.

\begin{tabular}{llcc}
\hline & REGIÃO & COEF. BRUTO & COEF. PADRON. \\
\hline $01 \mathrm{a}$ & Município de São Paulo & 1,71 & 2,43 \\
$01 \mathrm{~b}$ & Grande São Paulo & 1,16 & 2,28 \\
02 & Litoral & 2,28 & 3,17 \\
03 & Vale do Paraíba & 1,65 & 2,79 \\
04 & Sorocaba & 1,24 & 1,71 \\
05 & Campinas & 1,53 & 2,14 \\
06 & Ribeirão Preto & 1,60 & 2,15 \\
07 & Bauru & 1,85 & 2,40 \\
08 & São José do Rio Preto & 1,93 & 2,55 \\
09 & Araçatuba & 0,57 & 0,59 \\
10 & Presidente Prudente & 1,01 & 1,43 \\
11 & Marília & 1,24 & 1,69 \\
\hline
\end{tabular}

